\title{
Vibration Based Structural Health Monitoring of Composite Skin-Stiffener Structures
}

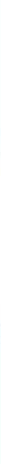

Ted Ooijevaar 



\section{VIBRATION BASED STRUCTURAL HEALTH MONITORING OF COMPOSITE SKIN-STIFFENER STRUCTURES}

Ted Ooijevaar 
De promotiecommissie is als volgt samengesteld:

Voorzitter en secretaris:

prof.dr. G.P.M.R. Dewulf

Universiteit Twente

Promotor:

prof.dr.ir. R. Akkerman

Universiteit Twente

prof.dr.ir. T. Tinga

Universiteit Twente

Leden (in alfabetische volgorde):

prof.dr.-ing. C. Boller

Universität des Saarlandes

prof.dr.ir. F.J.A.M. van Houten

Universiteit Twente

prof.dr.ir. P.M. Lugt

prof.dr. V. Michaud

Universiteit Twente

Ecole Polytechnique Fédérale de Lausanne

This research project was financially supported by the Eco-Design ITD within the Clean Sky framework (grant agreement number CSJU-GAM-ED-2008-001).

Vibration based structural health monitoring of composite skin-stiffener structures Ooijevaar, Theodorus Hendricus

$\mathrm{PhD}$ thesis, University of Twente, Enschede, The Netherlands

March 2014

ISBN 978-90-365-3624-0

DOI 10.3990/1.9789036536240

Copyright ( 2014 by T.H. Ooijevaar, Enschede, The Netherlands

Printed by Ipskamp Drukkers B.V., Enschede, The Netherlands

Cover: photograph of the composite skin-stiffener structures used in the present research. The curved lines represent the steady state velocity responses measured at the damaged area of a pristine (upper curve) and impact damaged (lower curve) skin-stiffener structure. 


\title{
VIBRATION BASED STRUCTURAL HEALTH MONITORING OF COMPOSITE SKIN-STIFFENER STRUCTURES
}

\section{PROEFSCHRIFT}

\author{
ter verkrijging van \\ de graad van doctor aan de Universiteit Twente, \\ op gezag van de rector magnificus, \\ prof.dr. H. Brinksma, \\ volgens besluit van het College voor Promoties \\ in het openbaar te verdedigen \\ op vrijdag 7 maart 2014 om 14:45 uur
}

door

Theodorus Hendricus Ooijevaar

geboren op 20 januari 1983

te Wognum 
Dit proefschrift is goedgekeurd door de promotoren:

prof.dr.ir. R. Akkerman

prof.dr.ir. T. Tinga 


\section{Summary}

Composite materials combine a high strength and stiffness with a relatively low density. These materials can, however, exhibit complex types of damage, like transverse cracks and delaminations. These damage scenarios can severely influence the structural performance of a component. Periodic inspections are required to ensure the integrity of a component during its life. The current inspection methods are often time-consuming, costly and require the components to be readily accessible. Vibration based structural health monitoring (SHM) technologies propose a promising alternative and involve the continuous monitoring of a structure by employing an integrated sensor system. These methods are based on the concept that the dynamic behavior of a structure can change if damage occurs.

Although many damage identification methods have been proposed in the literature, there are still numerous difficulties in the practical application of these approaches, especially to complex structures. The performance of a vibration based damage identification approach is highly dependent on the actual design of the structure and the damage scenario that is considered. This thesis focuses on the identification of damage in advanced composite skin-stiffener structures. The principle objective is to develop guidelines for the detection, localization and characterization of damage in composite skin-stiffener structures based on changes in the dynamic behavior.

A literature study supported by an analytical model showed that mode shape curvatures combined with the modal strain energy damage index (MSE-DI) algorithm are a potentially powerful damage feature and classifier for the identification of damage in several advanced composite skin-stiffener structures. A experimental set-up, including a shaker and laser-vibrometer, was used to measure the dynamic responses. A linear dynamic system description is obtained by applying experimental modal analysis. The vibration experiments demonstrated the feasibility of the MSE-DI algorithm to detect, localize and roughly estimate the size of barely visible impact damage (BVID) in advanced composite skin-stiffener structures. It is concluded that the method is particularly effective for health monitoring of skin-stiffener connections. The method remained inconclusive in the case of pure skin related damage.

Experiments showed that damage at the skin-stiffener interface can introduce clear nonlinear effects in the dynamic behavior of the structure. These nonlinear effects 
are attributed to the interaction between the skin and stiffener that occurs during opening and closing motion of the damage. It is shown that linear damage identification methods (e.g. modal domain methods) are feasible for low excitation amplitudes, but the presence of nonlinear dynamic effects cannot remain silent for higher amplitudes. The nonlinear dynamic effects can act as strong indicator of damage, but can also be useful for characterization purposes.

The nonlinear dynamic effects introduced by the skin-stiffener damage urges the development of nonlinear damage identification methods. A study on the understanding and feasibility of using nonlinear vibro-acoustic modulations for the detection, localization and characterization of impact damage in a composite Tbeam is presented. A time domain analysis at multiple spatial locations is used to detect and localize impact damage in a skin-stiffener connection, based on locally increased amplitude modulation effects. Analysis of the characteristics of the nonlinear modulations opens the ability to characterize the nonlinear dynamic behavior introduced by the damage at the skin-stiffener interface.

The work presented in this thesis showed that the relations between the characteristics of the structure, the potential damage scenarios and the damage identification method together define the performance of the vibration based damage identification strategy. Therefore, it is concluded that the design of a vibration based damage identification strategy is made-to-measure work and requires a thorough physical understanding of the potential failure mechanisms, the critical damage locations and their effect on the dynamic behavior. To aid in this process, a scenario based procedure for the design of a damage identification strategy is proposed. All findings presented in this thesis contribute to the development of a design tool for research engineers, to assist the implementation of structural health monitoring technology in safety-critical composite structures. 


\section{Samenvatting}

Composiet materialen combineren een hoge sterkte en stijfheid met een relatief lage dichtheid. Deze materialen kunnen echter complexe schadevormen vertonen, zoals transversale scheuren en delaminaties. Deze schades kunnen de structurele eigenschappen van een component aanzienlijk beïnvloeden. Periodieke inspecties zijn noodzakelijk om de integriteit van een component gedurende zijn levensduur te kunnen garanderen. De huidige inspectietechnieken zijn vaak tijdrovend, kostbaar en vereisen dat de componenten gemakkelijk toegankelijk zijn. Het monitoren van de structurele integriteit op basis van trillingen is een veelbelovend alternatief en omvat het continue monitoren van een component middels een geïntegreerd sensorsysteem. Deze technieken zijn gebaseerd op het concept dat het dynamische gedrag van een component kan veranderen indien schade optreedt.

Hoewel er veel schade-identificatiemethodes zijn beschreven in de literatuur, zijn er nog tal van moeilijkheden bij de praktische toepassing van deze methodes, vooral voor complexe structuren. De prestaties van een schade-identificatiemethode gebaseerd op trillingen zijn sterk afhankelijk van het ontwerp van een structuur en de schade die wordt beschouwd. Dit proefschrift richt zich op de identificatie van de schade in verstijfde composiet structuren. Het hoofddoel is om ontwerprichtlijnen te ontwikkelen voor de detectie, lokalisatie en karakterisatie van schade in verstijfde composiet structuren gebaseerd op veranderingen in het dynamische gedrag.

Een literatuurstudie ondersteund door een analytisch model toonde aan dat de kromming van trilvormen in combinatie met een modale schadeindex (MSE-DI) algoritme een potentieel krachtige parameter en methode zijn voor de identificatie van schade in verschillende verstijfde composiet structuren. Een experimentele opstelling, inclusief een shaker en laser-vibrometer, is gebruikt om het dynamisch gedrag te meten. Een lineair dynamische systeembeschrijving is verkregen door het toepassen van een experimentele modaal analyse. De dynamische metingen toonden aan dat het MSE-DI-algoritme in staat is om nauwelijks zichtbare impactschade (BVID) in verstijfde composiet structuren te detecteren, te lokaliseren en een schatting van de omvang te geven. Geconcludeerd is dat de methode bijzonder effectief is voor het monitoren van de integriteit van de verbinding tussen de huid en de verstijver. De methode bleef onbeslist in het geval dat de schade zich puur in de huid van de structuur bevindt.

Experimenten toonden aan dat schade in de verbinding tussen de huid en 
de verstijver duidelijke niet-lineaire effecten in het dynamische gedrag van een component kan introduceren. Deze niet-lineaire effecten worden toegeschreven aan de interactie tussen de huid en verstijver die optreedt tijdens de openen sluitbeweging van de schade. $\mathrm{Er}$ is aangetoond dat lineaire schadeidentificatiemethodes (bijvoorbeeld de modale domein methodes) geschikt zijn voor lage excitatie amplitudes, maar dat de aanwezigheid van niet-lineaire dynamische effecten niet verzwegen kan worden voor hogere amplitudes. De niet-lineaire dynamische effecten kunnen fungeren als sterke aanwijzing voor schade, maar kunnen ook nuttig zijn voor karakterisatie doeleinden.

De niet-lineaire dynamische effecten veroorzaakt door de schade in de verstijver, spoort aan tot de ontwikkeling van niet-lineaire schade-identificatiemethodes. Een studie gericht op het begrip en de toepasbaarheid van niet-lineaire vibroakoestische modulaties voor de detectie, lokalisatie en karakterisatie van impactschade in een composieten T-balk is uitgevoerd. Een analyse in het tijddomein op verschillende locaties is gebruikt om schade in de verbinding tussen de huid en de verstijver te detecteren en te lokaliseren op basis van lokaal verhoogde amplitudemodulatie effecten. Analyse van de modulatie-eigenschappen geeft mogelijkheden tot het karakteriseren van het niet-lineaire dynamische gedrag dat is veroorzaakt door de schade in de verbinding tussen de verstijver en de huid van de structuur.

Dit proefschrift laat zien dat de relatie tussen de eigenschappen van de structuur, de potentiële schades en de schade-identificatiemethode samen de prestaties van de op trillingen gebaseerde schade-identificatiestrategie bepalen. Daarom is geconcludeerd dat het ontwerp van een strategie maatwerk is en dat het vereist is dat er een grondig fysisch begrip is van de potentiële faalmechanismes, de kritische schadelocaties en hun effect op het dynamische gedrag. Om te helpen bij dit proces is er een procedure ontwikkeld voor het ontwerpen van een schadeidentificatiestrategie. Alle bevindingen gepresenteerd in dit proefschrift dragen bij aan de ontwikkeling van een ontwerpgereedschap voor ingenieurs om de implementatie van de schade-identificatietechnieken in composiet structuren te bevorderen. 


\section{Contents}

Summary

Samenvatting

Nomenclature $\quad$ ix

1 Introduction 1

1.1 Background and motivation . . . . . . . . . . . . . . . . 1

1.2 Composite structures . . . . . . . . . . . . . . . 3

1.2.1 Fiber reinforced plastics ............... 3

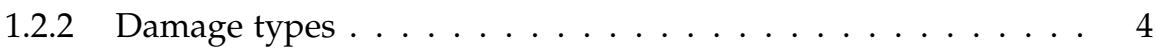

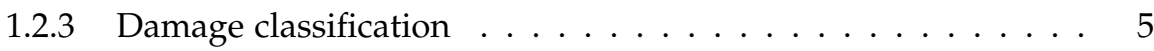

1.3 Structural health monitoring ............... 6

1.3.1 General ................... 6

1.3.2 Classifications . . . . . . . . . . . . 7

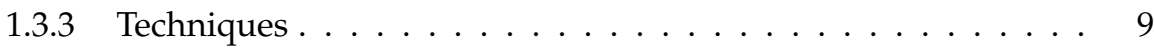

1.3.4 Major technology gaps . . . . . . . . . . . . . . . . 11

1.4 Objective and scope . . . . . . . . . . . . . . . 12

1.5 Outline ......................... 14

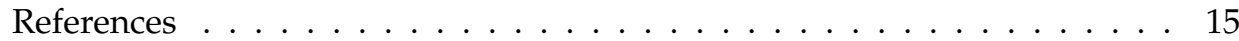

2 Overview of vibration based damage identification methods 19

2.1 Introduction . . . . . . . . . . . . . . . . . 20

2.2 Generalized description damaged system . . . . . . . . . . . . . 20

2.3 Literature overview vibration based methods . . . . . . . . . . . . . . 22

2.4 Damage feature selection . . . . . . . . . . . . . . 24

2.4.1 Effect of damage on dynamic properties . . . . . . . . . . 25

2.4 .2 Information condensation . . . . . . . . . . . . . 30

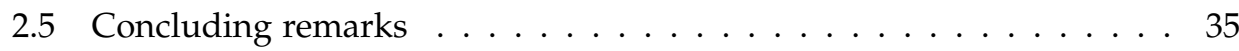

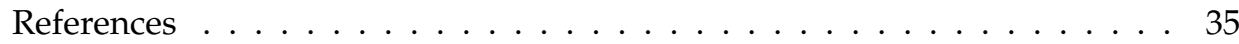


3 Vibration based structural health monitoring of a composite T-beam 39

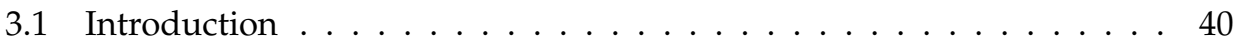

3.2 The modal strain energy damage index algorithm . . . . . . . . . 41

3.3 Composite T-beam structure . . . . . . . . . . . . . . . . . 43

3.4 Experimental analysis of a sub-structure $\ldots \ldots \ldots \ldots \ldots \ldots 4$

3.4.1 Experimental outline . . . . . . . . . . . . . . . 44

3.4 .2 Set-up and vibration measurements . . . . . . . . . 45

3.4 .3 Results . . . . . . . . . . . . . . . . . . 46

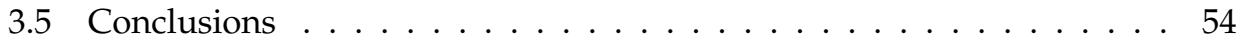

References ........................ . . 56

4 Damage identification in skin-stiffener structures based on curvatures $\quad 59$

4.1 Introduction . . . . . . . . . . . . . . . . . . . . . 60

4.2 Composite skin-stiffener structures . . . . . . . . . . . . . . . . 61

4.3 Damage identification procedure . . . . . . . . . . . . 65

4.4 Experimental set-up and signal processing . . . . . . . . . . . . 69

4.5 Experimental results . . . . . . . . . . . . . . . 71

4.5.1 Two stiffener structure with damage scenario I and II . . . . . 71

4.5.2 Three stiffener structure with damage scenario III . . . . . . . 74

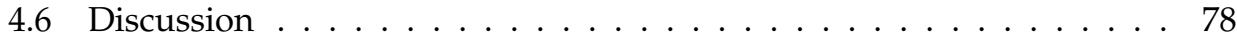

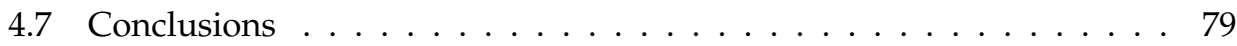

References . . . . . . . . . . . . . . . . . . . 81

5 Nonlinear dynamic behavior of an impact damaged skin-stiffener structure 85

5.1 Introduction . . . . . . . . . . . . . . . . 86

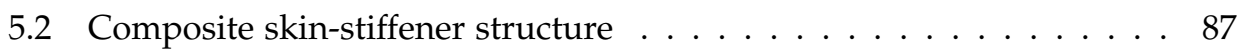

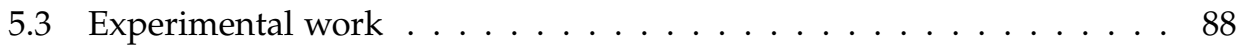

5.3.1 Set-up and signal processing . . . . . . . . . . . . . . . . 89

5.3.2 Initial global dynamic characterization . . . . . . . . . . . 89

5.3.3 Harmonic waveform distortion . . . . . . . . . . . . . . 92

5.3.4 Damage induced dynamic mechanisms . . . . . . . . . . . 94

5.3 .5 Spatial effects . . . . . . . . . . . . . . . . . . . 98

5.3.6 Influence of excitation frequency . . . . . . . . . . . . . . 101

5.4 Discussion . . . . . . . . . . . . . . . . . . . . . . 102

5.4.1 Underlying physical phenomena . . . . . . . . . . . . 102

5.4 .2 Higher harmonics . . . . . . . . . . . . . . . . . . . 104

5.5 Conclusions \& future prospects . . . . . . . . . . . . . 106

References . . . . . . . . . . . . . . . . . . . . . . . . . . 107 
6 Vibro-acoustic modulation based damage identification 109

6.1 Introduction . . . . . . . . . . . . . . . . . 110

6.1 Background and motivation . . . . . . . . . . . . 110

6.1.2 Vibro-acoustic modulation concept . . . . . . . . . . . . 110

6.1 .3 Objective and outline . . . . . . . . . . . . . . 112

6.2 Theoretical description . . . . . . . . . . . . . . . . 113

6.2.1 Two-tone forced vibration of a nonlinear system . . . . . . . 113

6.2.2 Signal decomposition approach . . . . . . . . . . . . 115

6.2.3 Nonlinear response characteristics . . . . . . . . . . . . . . 116

6.3 Experimental work . . . . . . . . . . . . . . . . 118

6.3.1 Composite skin-stiffener structure . . . . . . . . . . . . . . 118

6.3 .2 Experimental set-up . . . . . . . . . . . . . . . 118

6.3.3 Experimental procedure . . . . . . . . . . . . . 120

6.4 Experimental results and discussion . . . . . . . . . . . . . . 122

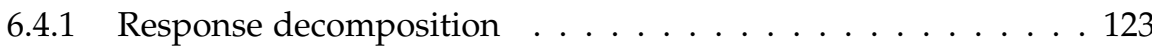

6.4 .2 Spatial results . . . . . . . . . . . . . . . . . . 125

6.4.3 Underlying dynamic behavior . . . . . . . . . . . . . . . 130

6.5 Conclusions \& future prospects . . . . . . . . . . . . . . . . . 131

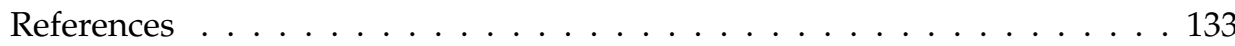

7 Discussion $\quad 135$

7.1 Design of an SHM strategy . . . . . . . . . . . . . . 135

7.1.1 Scenario based design procedure . . . . . . . . . . . . 136

7.1.2 Combination of approaches . . . . . . . . . . . . . . . 140

7.2 Application of vibration based SHM . . . . . . . . . . . . . . . . . . . . . . . . . . . . . . . . . . . .

7.2.1 Integrated sensing . . . . . . . . . . . . . 142

7.2.2 Operational and environmental effects . . . . . . . . . . . 145

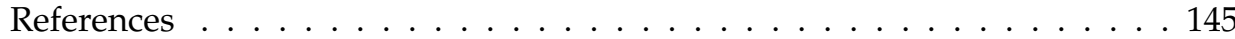

8 Conclusions and recommendations $\quad 149$

8.1 Conclusions . . . . . . . . . . . . . . . . . . . . . . 149

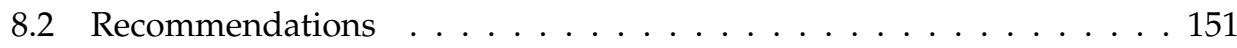

A Dynamics based nondestructive testing techniques 153

B Damage features and classifiers $\quad 157$

$\begin{array}{ll}\text { C Hilbert transform } & 163\end{array}$

$\begin{array}{ll}\text { Dankwoord } & 165\end{array}$

$\begin{array}{ll}\text { Publications } & 169\end{array}$ 



\section{Nomenclature}

The symbols used in this thesis are classified into a Greek or a Roman symbol group. Although some symbols can represent multiple quantities, its intended meaning follows from the textual context. An overview of the most important abbreviations, symbols and terminology used in the present thesis:

\section{Greek symbols}

\begin{tabular}{|c|c|c|}
\hline$\alpha$ & Extent of bilinearity & {[} \\
\hline$\beta_{i}$ & Damage index of beam element $i$ & [ \\
\hline$\beta_{i j}$ & Damage index of plate element $i j$ & \\
\hline$\gamma_{i}^{(n)}$ & Geometrical function of beam element $i$ and mode $n$ & {$\left[1 / \mathrm{m}^{3}\right.$} \\
\hline$\gamma_{i j}^{(n)}$ & Geometrical function of plate element $i j$ and mode $n$ & {$\left[1 / \mathrm{m}^{2}\right.$} \\
\hline$\epsilon$ & Control factor of the nonlinear function & \\
\hline$\zeta^{(n)}, \zeta_{n}$ & Viscous damping of mode $n$ & \\
\hline$\theta$ & Rotation angle & [rac \\
\hline$\lambda_{n}, \lambda_{n}^{*}$ & Poles (complex conjugate pair) of mode $n$ & {$[\mathrm{rad} /$} \\
\hline$\mu$ & Mean value of the damage index $\beta_{i j}$ & \\
\hline$v$ & Poisson's ratio & \\
\hline$\rho$ & Density & {$[\mathrm{kg} / \mathrm{m}$} \\
\hline$\sigma_{n}$ & Damping factor of mode $n$ & {$[\mathrm{rad} /$} \\
\hline$\sigma$ & Standard deviation of the damage index $\beta_{i j}$ & \\
\hline$\tau$ & Shear stress & {$[\mathrm{MP}$} \\
\hline$\phi$ & Instantaneous phase & {$[\mathrm{rac}$} \\
\hline$\phi_{\mathrm{p}}$ & Phase of the pump excitation signal & {$[\mathrm{rac}$} \\
\hline$\phi_{\mathrm{c}}$ & Phase of the carrier excitation signal & {$[\mathrm{ra}$} \\
\hline$\chi_{\mathrm{d}}$ & Damage parameter (e.g. crack length, loss of stiffness) & \\
\hline$\chi_{\mathrm{e}}$ & $\begin{array}{l}\text { Influence of the environmental and the operational } \\
\text { conditions (e.g. temperature, humidity) }\end{array}$ & \\
\hline$\psi_{n}$ & Mode shape vector of mode $n$ & \\
\hline$\psi_{m}^{\mathrm{A}}, \psi_{n}^{\mathrm{B}}$ & Mode shape vector of case A and mode $m$, case B and mode $n$ & \\
\hline$\omega$ & Frequency & {$[\mathrm{rad} /$} \\
\hline$\omega_{\mathrm{d} n}$ & Damped natural frequency of mode $n$ & {$[\mathrm{rad} /$} \\
\hline$\omega_{n}$ & Undamped natural frequency of mode $n$ & {$[\mathrm{rad} /$} \\
\hline
\end{tabular}




$\begin{array}{llr}\omega_{\mathrm{p}} & \text { Pump excitation frequency } & {[\mathrm{rad} / \mathrm{s}]} \\ \omega_{\mathrm{c}} & \text { Carrier excitation frequency } & {[\mathrm{rad} / \mathrm{s}]} \\ \omega_{\text {inst }} & \text { Instantaneous frequency } & {[\mathrm{rad} / \mathrm{s}]}\end{array}$

\section{Roman symbols}

$A_{\mathrm{c}} \quad$ Carrier amplitude [m]

$A_{\mathrm{sb} 1} \quad$ Left sideband amplitude [m]

$A_{\mathrm{sb} 2} \quad$ right sideband amplitude $\quad[\mathrm{m}]$

$A_{\text {inst }} \quad$ Instantaneous amplitude (signal envelope) [m/s]

a Length of intact beam segment 1 [m]

$a_{\mathrm{c}} \quad$ Spanwise delamination location [m]

$\bar{a} \quad$ Dimensionless length intact beam segment 1

$\bar{a}_{\mathrm{c}} \quad$ Dimensionless spanwise delamination location [-]

$b \quad$ Length of delaminated beam segment [m]

$\bar{b} \quad$ Dimensionless delamination length [-]

c Viscous damping coefficient [Ns/m]

c Length of intact beam segment $4 \quad$ [m]

$\bar{c} \quad$ Dimensionless length intact beam segment 4 [-]

$D \quad$ Flexural rigidity of a plate-like structure [Nm]

$D_{i j} \quad$ Weighted average flexural rigidity of element $i j$ of a plate-like $\quad$ [Nm]

E Young's modulus $\quad\left[\mathrm{N} / \mathrm{m}^{2}\right]$

$F_{\text {op }} \quad$ Operational load vector $\quad$ [N]

$\boldsymbol{F}_{\text {test }} \quad$ Test load vector $\quad$ [N]

$F_{\mathrm{a}} \quad$ Excitation force $\quad$ [N]

$F_{\mathrm{p}} \quad$ Pump excitation amplitude [N]

$F_{\mathrm{c}} \quad$ Carrier excitation amplitude [N]

$F_{\mathrm{B}, i}^{(n)} \quad$ Local fractional modal strain energy of mode $n$ and element $i$

$F_{i j}^{(n)} \quad$ Local fractional modal strain energy of mode $n$ and element $i j$

$F_{\text {spring }} \quad$ Spring force [N]

$f \quad$ Frequency [Hz]

$f_{\mathrm{p}} \quad$ Pump excitation frequency $\quad[\mathrm{Hz}]$

$f_{\mathrm{c}} \quad$ Carrier excitation frequency [Hz]

$f_{\mathrm{a}} \quad$ Harmonic excitation frequency $\quad[\mathrm{Hz}]$

$f^{(n)}, f_{n} \quad$ Natural frequency of the $n^{\text {th }}$ mode $\quad[\mathrm{Hz}]$

$f_{\mathrm{B}}^{(n)}, f_{\mathrm{T}}^{(n)} \quad$ Natural frequency of the $n^{\text {th }}$ bending and torsion mode [Hz]

$f_{\text {inst }} \quad$ Instantaneous frequency [Hz]

G Shear modulus $\quad\left[\mathrm{N} / \mathrm{m}^{2}\right]$

$G_{\mathrm{p}}, G_{\mathrm{C}} \quad$ Constants [-]

$g \quad$ Force vector of elastic forces, damping forces, etc. [N] 


\begin{tabular}{|c|c|c|}
\hline$H$ & Frequency response function matrix & \\
\hline$H_{F v}$ & $\begin{array}{l}\text { Frequency response function (mobility = } \\
\text { velocity/force) }\end{array}$ & $[(\mathrm{m} / \mathrm{s}) / \mathrm{N})]$ \\
\hline$H_{F x}$ & $\begin{array}{l}\text { Frequency response function (admittance }= \\
\text { displacement } / \text { force) }\end{array}$ & {$[\mathrm{m} / \mathrm{N}]$} \\
\hline$h_{\text {in }}$ & $\begin{array}{l}\text { Transfer function between input signal } \boldsymbol{u}(t) \text { and test loads } \\
\boldsymbol{F}_{\text {test }}(t)\end{array}$ & \\
\hline$h_{\text {out }}$ & $\begin{array}{l}\text { Transfer function between system response } \boldsymbol{q}(t) \text { and } \\
\text { measured signal } \boldsymbol{y}(t)\end{array}$ & \\
\hline$h_{s}$ & Height of beam segment $s=1,2,3$ and 4 & {$[\mathrm{~m}]$} \\
\hline$h$ & Beam height & {$[\mathrm{m}]$} \\
\hline $\bar{h}_{2}$ & Dimensionless transversal delamination location, $h_{2} / h$ & {$[-]$} \\
\hline$I$ & Second moment of area & {$\left[\mathrm{m}^{4}\right]$} \\
\hline$i$ & Beam element number & {$[-]$} \\
\hline$i j$ & Plate element number & {$[-]$} \\
\hline$J$ & Torsion constant & {$\left[\mathrm{m}^{4}\right]$} \\
\hline$k$ & Stiffness & {$[\mathrm{N} / \mathrm{m}]$} \\
\hline$l$ & Length of the beam & {$[\mathrm{m}]$} \\
\hline$l_{x}, l_{y}$ & Dimensions of the plate structure & {$[\mathrm{m}]$} \\
\hline$M$ & Mass matrix & [kg] \\
\hline$M$ & Bending moment & {$[\mathrm{Nm}]$} \\
\hline$M_{S}$ & Bending moment in beam segment $s=1,2,3$ and 4 & {$[\mathrm{Nm}]$} \\
\hline$M_{\mathrm{a}}$ & Amplitude modulation & {$[\mathrm{m} / \mathrm{s}]$} \\
\hline$M_{\mathrm{f}}$ & Frequency modulation & {$[\mathrm{Hz}]$} \\
\hline$M A C$ & Modal assurance criterion & {$[-]$} \\
\hline$m$ & Mass & [kg] \\
\hline$N_{s}$ & Normal force in beam segment $s=1,2,3$ and 4 & {$[\mathrm{~N}]$} \\
\hline$N_{\text {modes }}$ & Number of modes & {$[-]$} \\
\hline$N_{x}, N_{y}$ & Number of elements in $x$-and $y$-direction & {$[-]$} \\
\hline$n$ & Mode number & {$[-]$} \\
\hline$P$ & Damage evolution function & \\
\hline$Q_{n}$ & Modal scaling constant of mode $n$ & {$[-]$} \\
\hline$q$ & Displacement vector & {$[\mathrm{m}]$} \\
\hline$q_{\mathrm{bp}}$ & Bandpass filtered response & [m] \\
\hline $\boldsymbol{R}_{n}$ & Residue matrix of mode $n$ & \\
\hline$S_{F v}$ & Cross-power spectral density (force - velocity) & {$[(\mathrm{Nm} / \mathrm{s}) / \mathrm{Hz}]$} \\
\hline$S_{F x}$ & Cross-power spectral density (force - displacement) & {$[\mathrm{Nm} / \mathrm{Hz}]$} \\
\hline$S_{F F}$ & Auto-power spectral density (force - force) & {$\left[\mathrm{N}^{2} / \mathrm{Hz}\right]$} \\
\hline$T$ & Torque & {$[\mathrm{Nm}]$} \\
\hline$t$ & Time & [s] \\
\hline$t$ & Thickness & {$[\mathrm{m}]$} \\
\hline
\end{tabular}




$\begin{array}{llr}U_{\mathrm{T}} & \text { Elastic strain energy torsional deformations } & {[\mathrm{Nm}]} \\ U_{\mathrm{B}} & \text { Elastic strain energy bending deformations } & {[\mathrm{Nm}]} \\ U_{\mathrm{B}}^{(n)} & \text { Total modal strain energy of mode } n & {[\mathrm{~N} / \mathrm{m}]} \\ U_{\mathrm{B}, i}^{(n)} & \text { Local modal strain energy of element } i \text { and mode } n & {[\mathrm{~N} / \mathrm{m}]} \\ U^{(n)} & \text { Total modal strain energy of mode } n & {[\mathrm{~N} / \mathrm{m}]} \\ U_{i j}^{(n)} & \text { Local modal strain energy of element } i j \text { and mode } n & {[\mathrm{~N} / \mathrm{m}]} \\ u & \text { Input signal of the actuator } & \\ u & \text { Displacement } & {[\mathrm{m}]} \\ u^{(n)} & \text { Normalized mode shape of mode } n & {[-]} \\ V & \text { Voltage } & {[\mathrm{V}]} \\ V_{s} & \text { Shear force in beam segment } s=1,2,3 \text { and } 4 & {[\mathrm{~N}]} \\ v_{\mathrm{bp}} & \text { Bandpass filtered velocity response } & {[\mathrm{m} / \mathrm{s}]} \\ v & \text { Velocity response } & {[\mathrm{m} / \mathrm{s}]} \\ X & \text { Fourier spectra of the displacement signal, } \mathcal{F}(x) & {[\mathrm{m}]} \\ x & \text { Displacement signal } & {[\mathrm{m}]} \\ x_{i-1}, x_{i} & \text { Boundaries of element } i \text { in } x \text {-direction } & {[\mathrm{m}]} \\ x, y, z & \text { Cartesian coordinates } & {[\mathrm{m}]} \\ y & \text { Measured system response vector } & {[\mathrm{m}]} \\ y_{0} & \text { Baseline system response vector } & {[\mathrm{m}]} \\ \Delta y & \text { Deviation in the time domain system response } & {[-]} \\ \Delta Y & \text { Deviation in the frequency or modal domain system response } & {[\mathrm{ms} / \mathrm{m}]} \\ y_{j-1}, y_{j} & \text { Boundaries of element } j \text { in } y \text {-direction } & \\ Z_{i j} & \text { Normalized damage index of element } i j & \\ Z_{\mathrm{st}} & \text { Mechanical impedance of the structure } & \\ z_{i-1}, z_{i} & \text { Boundaries of element } i \text { in } z \text {-direction } & \\ 1,2,3 & \text { Material coordinate system } & \end{array}$

\section{Operators}

$\begin{array}{cl}* & \text { Complex conjugate } \\ \mathrm{T} & \text { Damaged case } \\ & \text { Transpose }\end{array}$

\section{Abbreviations}

$\begin{array}{ll}\text { ADL } & \text { Allowable damage limit } \\ \text { AE } & \text { Acoustic emission } \\ \text { AU } & \text { Acousto-ultrasonics } \\ \text { BVID } & \text { Barely visible impact damage } \\ \text { CBM } & \text { Condition based maintenance } \\ \text { CMIF } & \text { Complex mode indicator function } \\ \text { EMA } & \text { Experimental modal analysis }\end{array}$




$\begin{array}{ll}\text { EMI } & \text { Electro-mechanical impedance } \\ \text { FIR } & \text { Finite impulse response } \\ \text { FRF } & \text { Frequency response function } \\ \text { ITD } & \text { Integrated technology demonstrators } \\ \text { MAC } & \text { Modal assurance criterion } \\ \text { MSE-DI } & \text { Modal strain energy damage index algorithm } \\ \text { NDT } & \text { Nondestructive testing } \\ \text { NLR } & \text { National aerospace laboratories } \\ \text { ODS } & \text { Operational deflection shape } \\ \text { PEKK } & \text { Poly(ether-ketone-ketone) } \\ \text { RFP } & \text { Rational fraction polynomial } \\ \text { SHM } & \text { Structural health monitoring } \\ \text { SV } & \text { Structural vibration } \\ \text { UL } & \text { Ultimate load } \\ \text { UT } & \text { Ultrasonic testing } \\ \text { VAM } & \text { Vibro-acoustic modulation } \\ \text { VID } & \text { Visible impact damage }\end{array}$





\section{CHAPTER 1}

\section{Introduction}

\subsection{Background and motivation}

Composite materials combine a high strength and stiffness with a relatively low density. This makes them extremely useful in applications where weight plays an important role such as aircraft and wind turbines. These materials can, however, exhibit unconventional and complex types of damage, like transverse cracks and delaminations. These damage scenarios are often invisible, but can severely influence the structural performance of a component, and hence tremendously decrease its service life. Periodic inspections are required to ensure the integrity of a component during its life. The current scheduled visual inspections are often timeconsuming, costly and require the components to be readily accessible, as shown in Figure 1.1. Structural health monitoring (SHM) technologies propose a promising alternative and involve the continuous monitoring of a structure by employing a nondestructive testing (NDT) approach based on an integrated sensor system. The output of this process is information regarding the ability of the structure to perform its intended function in consideration of the applied loadings, aging and degradation resulting from the operational environments.

Another motivation for the development of SHM technologies is that they potentially can reduce the maintenance costs and increase the operational availability of a system. Firstly, by making maintenance routines shorter and more effective, given the actual physical condition of the component. Secondly, by optimizing the maintenance intervals utilizing condition based maintenance (CBM) routines rather than relying on the conventional time-based inspection intervals [1]. The use of structural health monitoring technologies will not only provide safety benefits or enable new possibilities for maintenance concepts, but can also have a significant influence on the design concepts. The change in design of lightweight structures from a safe life to a damage tolerant design supported by a monitoring system is, although far from reality, also considered as a potential weight-saving benefit. 


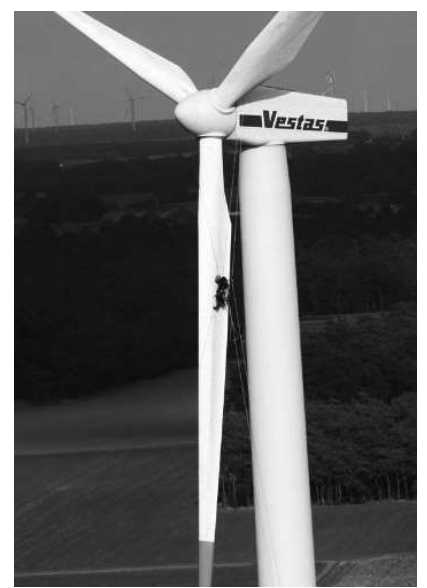

(a) Wind turbine inspection (photo courtesy of Spiegel Online).

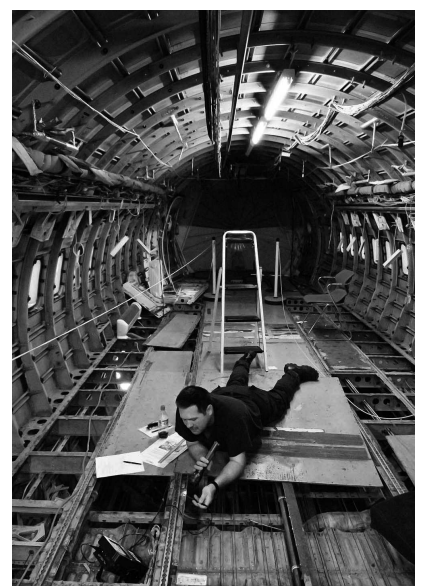

(b) Aircraft fuselage inspection (c) (photo courtesy of Sandia National Laboratories, USA).

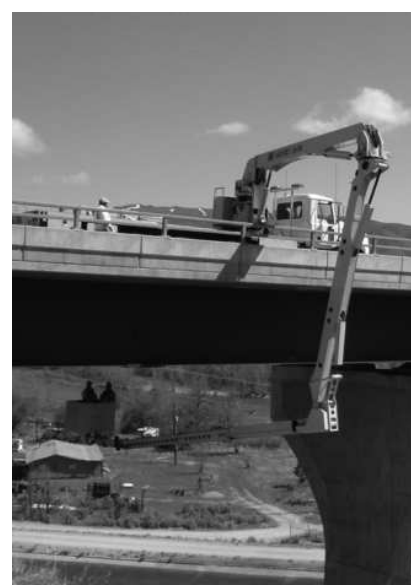

Bridge inspection (photo courtesy of Aspen Aerials, USA).

Figure 1.1 An overview of potential application fields for structural health monitoring techniques.

The research presented in this thesis was performed within the European research program Clean Sky [2], which focuses on the development of breakthrough technologies to significantly improve the environmental performances of airplanes and air transport. Clean Sky comprises six Integrated Technology Demonstrators (ITDs). The work presented here was part of the Eco-Design ITD, which concentrates on green design and production, withdrawal and recycling of aircraft by optimal use of raw materials and energy. The development of structural health monitoring technologies is one of the objectives of this research program. Structural components are usually replaced prior to their end of life, which is costly and resource inefficient. A monitoring system can allow for an increase in the service life of aircraft components and hence reduces the costs and long-term ecological impact of these components.

To summarize, the development of structural health monitoring technologies for composite structures is aiming to provide safety, cost saving (maintenance and weight) as well as environmental benefits. However, the number of successful practical applications of structural health monitoring technologies is still limited. This is mainly due to the complexity of the composite components, the variety of potential damage scenarios and the high performance demands of the damage identification method. The work described in this thesis primarily concerns the relation between those three aspects in order to achieve a higher level of maturity of the structural health monitoring technologies. Background information about composite structures and the typical damage scenarios is presented in the next section, followed by a general introduction to structural health monitoring. The 
knowledge contained in these sections is required to fully understand the theme of this thesis.

\subsection{Composite structures}

\subsubsection{Fiber reinforced plastics}

A composite material is one in which two or more materials are combined to obtain material properties that could not be obtained with the separate constituents. Speaking about composite materials today often refers to combinations of a polymer matrix and fiber reinforcement materials such as carbon or glass. This type of composite is known as fiber reinforced plastic and is generally used in laminate form. The fibers in these composites are used for their high strength and stiffness, while the matrix transfers loads, binds the fibers together and protects them from harsh environmental influences. Given the nature of the composites there are numerous ways of combining matrix and fibers. Composite laminates also provide the ability to stack the individual layers according to a desired lay-up. In this way, every composite laminate can be tailored specifically for a certain application. The scale of the fibers and the matrix or the scale of an individual layer are of a lower level than the scale of the resulting laminate and structure as illustrated in Figure 1.2. Composite materials are therefore multi-scale by nature [3]. The mechanical properties at the structure or laminate level are the result of the material characteristics at the lower levels.

Fiber reinforced plastics have some great advantages over more conventional materials. They combine a high strength and stiffness with a low density. Fiber reinforced plastics can also be formed into complex shapes, which allows for the manufacturing of structures with complex geometries such as curved panels and skin-stiffener structures. Other advantages include the high durability due to a high resistance against corrosion, the possibility to tailor the material properties

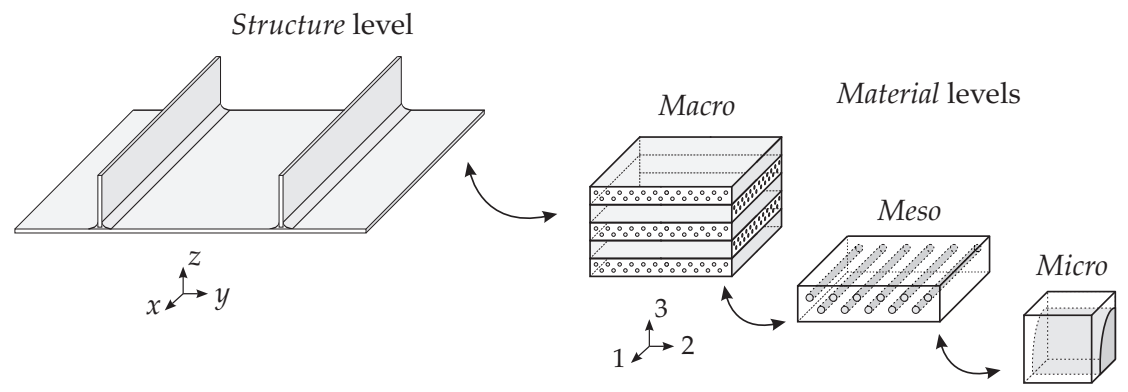

Figure 1.2 The multi-scale levels related to fiber reinforced plastics. 
and the ability to reduce manufacturing costs by lowering the number of individual components in an assembly. These strengths are why research in composites has flourished over the past decades and why composites are more and more employed over a variety of applications in, for example, the aerospace, automotive and marine industry.

\subsubsection{Damage types}

Due to their complex nature, fiber reinforced plastics suffer from various damage types unknown to homogeneous materials. These damage types can be examined at different scales, according to the levels presented in Figure 1.2. Although they originate at the material levels, they can be of profound importance for the integrity of the structure.

One of the first damage mechanisms to occur is known as transverse (matrix) cracking. This type of crack grows parallel to the fiber and in the thickness direction of the laminate. Figure 1.3 illustrates a cracked laminate. In this case the crack initiates at the free surface of the $0^{\circ}$ layer, and grows in the thickness direction until it meets the fibers of the $90^{\circ}$ layer. Transverse cracks can be caused during production by, for example, the difference in thermal expansion coefficient between fiber and matrix or by in-service loading (e.g. impact). The small size makes them generally hard to detect during inspections. The formation of transverse cracks rarely means the total fracture of a laminate, as it does not affect the load carrying capacity of the fibers. However, transverse cracks can influence the mechanical and thermal properties of the laminate. Most importantly, this type of cracking forms a trigger for further damage mechanisms.

Delamination is a damage type that generally is preceded by transverse cracking. This damage type is a debonding between individual plies of a laminate. The crack runs again in a plane parallel to the fibers, but at the interface between two layers. Chronologically, it is recognized that a delamination mostly initiates from the tip of a transverse crack. Figure 1.3 also shows a delamination at the interface between the $0^{\circ}$ and the $90^{\circ}$ layer. Delaminations are hardly visible on the surface, since they

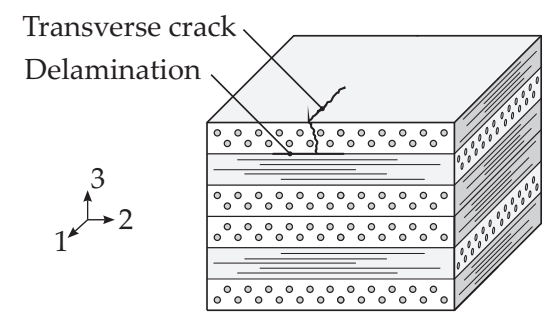

Figure 1.3 Schematic representation of transverse crack and delamination in a $[0 / 90 / 0]_{s}$ laminate. 


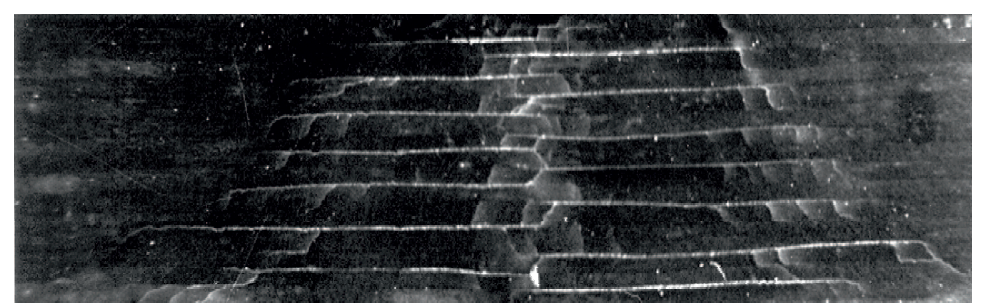

Figure 1.4 Cross section of a glass-reinforced epoxy laminate with transverse cracks and delaminations caused by an impact test.

are embedded within the composite structure. This makes them barely detectable during, for example, visual inspections. Figure 1.4 shows a micrograph of a cross section of a laminate with both transverse cracks and delaminations originating from an impact test. Although delaminations do not lead to complete fracture, they can seriously affect the thermal and mechanical properties of the laminate.

The type of damage that significantly decreases the load carrying capacity of a laminate is fiber failure. Fiber related failure in a laminate is mostly accompanied by matrix related damage like transverse cracks and delaminations. Typical failure modes can involve local buckling of fibers, fiber breakage and fiber pull-out.

\subsubsection{Damage classification}

Structural components used in aircraft are usually designed according to the damage tolerance principle. This principle implies that the structure needs to function safely despite the presence of (minor) flaws. The severity of damage in aircraft structures is classified into five categories according to [4]. This classification is linked to the required residual strength and ranges from allowable damage, category 1 , up to very severe damage, category 5 . The assessment of damage in aircraft structures has historically relied on visual inspection methods to identify damage. Category 1 is classified as barely visible impact damage (BVID) and may remain undetected, while repair scenarios are required for the visible impact damage (VID) of category 2 to 5. Structures containing BVID must sustain ultimate load (UL) for the life of the aircraft structure. The dent depth is often used as the damage metric to define BVID [5]. This criterion sets the lower bounds to the identification capabilities of a structural health monitoring approach. 


\subsection{Structural health monitoring}

\subsubsection{General}

Structural health monitoring is the multidisciplinary process of implementing a strategy for damage identification in a way that nondestructive testing becomes an integral part of the structure. This process involves the definition of potential damage scenarios for a structure, the observation of the structure over a period of time using periodically spaced measurements, the extraction of damage sensitive parameters (features) from these measurements and the analysis of these features to determine the current state of health of the structure (classification). The output of this process is periodically updated information regarding the ability of the structure to perform its intended function in consideration of the applied loadings, aging and degradation resulting from the operational environments.

In contrast to conventional nondestructive testing techniques that are operated offline during maintenance, structural health monitoring techniques can be operated off-line as well as on-line. On-line refers, in this case, to the monitoring during operation of the system or structure. The structural health monitoring technique is part of the on-board systems. Sensors are permanently attached (surface sensors) or embedded (integrated sensors) in the structure. As a result, information on the structural state is available at arbitrary times.

As stated by Farrar and Doebling [6], the process of structural health monitoring is fundamentally one of statistical pattern recognition. A statistical pattern recognition process aims to classify data (patterns) based on either a priori knowledge or on information extracted from the patterns. The patterns to be classified are usually groups of measurements or observations. A pattern recognition process covers all stages of an investigation from problem formulation up to the interpretation of the results. Figure 1.5 shows a simplified process, which consists of a diagnostic and a prognostic part. The diagnostic analyses are used to estimate the current state of the structure. The prognostic analysis evaluates the damage evolution and estimates the residual service life [7]. The present thesis focuses on the diagnostic part of the structural health monitoring process, which can be divided into a four-step process:

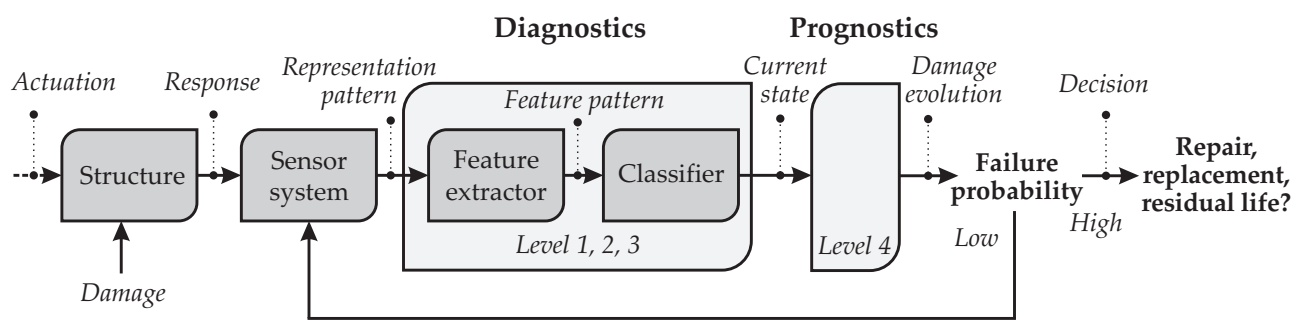

Figure 1.5 The multidisciplinary structural health monitoring process. 


\section{Operational evaluation}

Operational evaluation answers questions regarding the implementation of the structural health monitoring system, such as possible failure modes, operational and environmental conditions and data acquisition related limitations.

\section{Data acquisition}

This step defines the data acquisition in terms of the quantities to be measured, the type and quantity of sensors to be used, the locations where these sensors are to be placed and the hardware to be used. Moreover, it defines the data fusion and cleansing, which is the determination of which data is necessary and useful in the feature extraction process.

\section{Feature extraction}

This step in the structural health monitoring process receives the most attention in the literature. Feature extraction is the process of identifying damage sensitive parameters from measured data. These damage features are defined in the time, frequency or modal domain. Information reduction and condensation is also of concern for a large quantity of data, particularly if comparisons of many measurements over the service life of the structure are required.

\section{Classification}

The last step is concerned with the implementation of algorithms (e.g. neural networks) that operate on the extracted features to distinguish between the damaged and the undamaged structural state and to quantify the damage state of the structure. Statistical methods are used to establish the feature's sensitivity to damage and to prevent false damage identification.

According to Doebling et al. [8], an ideal robust damage identification scheme should be able to: detect damage at a very early stage, locate the damage within the sensor resolution being used, provide some estimate of the extent or severity of the damage and predict the remaining useful life of the structural component in which damage has been identified, all independent from changes in the operational and environmental conditions. The method should also be well suited to automation, and should be independent of human judgement and ability.

\subsubsection{Classifications}

Damage identification methods can be classified in different ways. This section summarizes the most important classifications used in this thesis.

Performance levels A performance based classification of the damage identification methods was introduced by Rytter [9]. Rytter defined four levels of damage 
identification:

- Level 1: Verification of the presence of damage in a structure.

- Level 2: Determination of the location of the damage.

- Level 3: Estimation of the extent / severity of the damage.

- Level 4: Prediction of the remaining service life of the structure.

Some researchers [10-12] included the determination of the type of damage (characterization) as an additional step between level 2 and 3 . Levels 1 to 3 are related to the damage diagnosis, while level 4 is concerned with the damage prognosis. Higher levels generally represent an increasing degree of complexity and a greater need for mathematical models. Generally, a level 4 prediction requires a fracture mechanics and fatigue life analysis based on structural and damage models to predict the evolution of the damage [7].

Model and non-model based approach The second classification distinguishes two approaches, namely model and non-model based damage identification methods. In a non-model based method the results are compared with the results of a reference measurement performed prior to setting the structure in service. Deviances in the damage sensitive parameters are used to identify damage. In a model based technique the response is compared with some form of model. This can either be an analytical or a numerical (e.g. finite element) model. Advantages of model based techniques are that these could well be extended to provide information about the severity of the detected damage and can be used to account for environmental or operational variations (e.g. temperature, boundary conditions). On the contrary, it is rather difficult to obtain an accurate model representation of complex (composite) structures. Moreover, the computational costs can limit the applicability for in situ monitoring.

Local and global methods Damage identification techniques are usually classified as local or global [13]. This classification is based on the relative size of the area that can be inspected at once by the method with respect to the overall dimensions of the structure. The local methods concentrate on a part of the structure and are usually considered to be more sensitive than the global methods. They are capable of detecting small damages such as cracks, but their application requires a prior knowledge of the location of the damaged area. The global methods can analyze a relatively large area at once, but the resolution is, however, rather limited. As a consequence, only relatively severe damage cases can be identified.

Baseline and non-baseline One of the fundamental axioms of Structural Health Monitoring proposed by Worden, et al. [11] reads that the assessment of damage requires a comparison between two system states. The response of a structure 
Table 1.1 An overview of the most commonly used nondestructive testing (NDT) techniques.

\begin{tabular}{|c|c|c|c|c|}
\hline Technique & Ref. & $\begin{array}{l}\text { Inspection } \\
\text { area }\end{array}$ & $\begin{array}{l}\text { Inspection } \\
\text { mode }\end{array}$ & $\begin{array}{c}\text { Structure } \\
\text { accessibility }\end{array}$ \\
\hline \multicolumn{5}{|l|}{$\begin{array}{l}\text { Electric, magnetic and } \\
\text { electromagnetic }\end{array}$} \\
\hline $\begin{array}{l}\text { Electrical conductivity } \\
\text { testing }\end{array}$ & {$[16,17]$} & Local/global & Off-/on-line & Not required \\
\hline Magnetic particle testing & {$[18,19]$} & Local & Off-line & Required \\
\hline Eddy current testing & {$[18,20]$} & Local & Off-line & Required \\
\hline Radiography (X-ray) & {$[18,21]$} & Local & Off-line & Required \\
\hline Infrared thermography & {$[18,22]$} & Local/global & Off-line & Required \\
\hline \multicolumn{5}{|l|}{ Mechanic, dynamic } \\
\hline (Quasi-) static & [23] & Local & Off-/on-line & Not required \\
\hline $\begin{array}{l}\text { Structural vibrations } \\
\text { and acoustics }\end{array}$ & {$[24,25]$} & Local/global & Off-/on-line & Not required \\
\hline $\begin{array}{l}\text { Electro-mechanical } \\
\text { impedance }\end{array}$ & {$[26,27]$} & Local/global & Off-/on-line & Not required \\
\hline Acoustic emission & {$[18,28]$} & Local/global & On-line & Not required \\
\hline Acousto-ultrasonics & {$[29,30]$} & Local/global & Off-/on-line & Not required \\
\hline Ultrasonic testing & {$[18]$} & Local & Off-line & Required \\
\hline \multicolumn{5}{|l|}{ Optical } \\
\hline Shearography & {$[31,32]$} & Local & Off-line & Required \\
\hline Visual inspection & {$[5,18]$} & Local/global & Off-line & Required \\
\hline
\end{tabular}

measured at an earlier stage is usually utilized as a baseline to distinguish between the damaged and undamaged state. For model based methods, this baseline can also be obtained from a model (e.g. finite element model). Other researchers [14, 15] also propose methods that do not require a baseline to classify the structure as damaged or undamaged. This might be interpreted as not requiring a comparison of system states. It can be argued that this discrepancy is a matter of terminology. Non-baseline methods still compare two states, but instead of utilizing a baseline measurement they rely on an assumed normal behavior (e.g. a smooth pattern or a linear-elastic response) of the structure. The system is in this case classified as damaged when the response deviates from the norm.

\subsubsection{Techniques}

A wide range of nondestructive testing techniques can be employed for damage identification purposes. An overview of the most commonly used nondestructive testing techniques and their characteristics is presented in Table 1.1. The majority of these techniques can only be applied when the structure is not in operation ('off-line') and readily accessible. Consequently, only a few of these techniques are suitable to be applied in a health monitoring environment. As part of this 
Table 1.2 An overview of the dynamics based nondestructive testing (NDT) technologies.

\begin{tabular}{|c|c|c|c|c|c|}
\hline Technology & $\begin{array}{c}\text { Frequency } \\
\text { range }[\mathrm{Hz}]^{1}\end{array}$ & $\begin{array}{c}\text { Actuation } \\
\text { approach }\end{array}$ & $\begin{array}{l}\text { Sensitivity } \\
\text { to damage }\end{array}$ & $\begin{array}{l}\text { Ease of data } \\
\text { interpretation }\end{array}$ & $\begin{array}{l}\text { Applicability } \\
\text { for SHM }\end{array}$ \\
\hline $\begin{array}{l}\text { Structural vibration } \\
\text { and acoustics }\end{array}$ & $10^{0}-10^{4}$ & $\begin{array}{l}\text { active/ } \\
\text { passive }\end{array}$ & $\mathbf{D} \square \square \square$ & $\square \square \square \square$ & $\square$ \\
\hline $\begin{array}{l}\text { Electro-mechanical } \\
\text { impedance }\end{array}$ & $10^{3}-10^{5}$ & active & $\square$ & 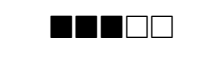 & \\
\hline Acoustic emission & $10^{4}-10^{6}$ & passive & $\square$ & $\mathbf{\square} \square \square \square$ & $\square \square$ \\
\hline Acousto-ultrasonics & $10^{4}-10^{6}$ & active & & $\square \square \square \square \square$ & $\square$ \\
\hline Ultrasonic testing & $10^{5}-10^{7}$ & active & 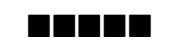 & $\mathbf{\square} \square \square \square$ & $\square \square \square \square \square$ \\
\hline
\end{tabular}

1 Typical frequency range at which the technology is operating.

selection, the technologies based on electrical conductivity are generally limited to conductive materials. The (quasi-) static techniques are of lower interest because of a rather low sensitivity to damage compared to the dynamics based techniques. The dynamics based techniques are applicable to a wide range of structures and are therefore considered to be a promising group of technologies for structural health monitoring.

The basic principles of the dynamics based techniques are described in Appendix A. Each technique comprises a large amount of literature and is usually treated as a different field of research. Table 1.2 provides a more detailed comparison of their performances. The low frequency structural vibration (SV) and electromechanical impedance (EMI) techniques primarily rely on standing wave patterns, while the higher frequency acoustic emission (AE), acousto-ultrasonics (AU) and ultrasonic testing (UT) utilize traveling wave characteristics. The former group of methods provide data that is relatively easy to interpret. More complex structures can be analyzed with these methods and a relatively large area can be explored at once. The frequency range, and hence the resolution, is however limited [13]. As a consequence, only relatively severe damage such as delaminations can be identified. The latter group of methods are usually considered to be more sensitive. They are capable of detecting small damage such as cracks [29]. For that reason, these wave propagation based technologies are increasingly being explored for aircraft applications [33,34]. The downside is the more complex interpretation of the data, in particular in case of non-flat or complex (composite) structures [35]. The rating for the sensitivity is linked to the operational frequency range [11], while the other aspects are ranked according to the available literature. It should be noted that these ratings are rather subjective. The intention here is, however, to give an impression of the relative strengths and weaknesses rather than to condemn techniques. 


\subsubsection{Major technology gaps}

Although many structural health monitoring techniques have been proposed in the literature, there are still numerous difficulties in the practical application of these approaches. The most important technical issues that need to be resolved before structural health monitoring technologies can make the transition from a research topic to actual practice are summarized below.

\section{- Complex composite structures}

The structural health monitoring technologies are extensively tested on concrete and metallic structures. The applications to composite structures are to a large extent limited to relatively simple composite beams and plates with mainly well-defined or artificial damage scenarios. The complexity of the components and the wide variety of potential damage scenarios hampers the application of structural health monitoring to more complex composite structures. Therefore, research should be focused on the application to composite structures such as stiffened panels and torsion boxes, as well as realistic damage scenarios.

\section{- Selection damage feature and classifier}

Damage identification aims to uniquely identify damage at an early stage with a minimum of false positive results. For this purpose, an enormous amount of damage features and (statistical) classifiers are addressed in the literature with a varying level of success. None of the methods solves all problems in all structures. The development and selection of damage sensitive features and classifiers that provide a high detection probability without getting false alarms is therefore one of the key challenges for structural health monitoring.

\section{- High performance level}

Current health monitoring approaches are often capable to detect (level 1) and localize (level 2) damage, but are limited in their ability to estimate the type or extent/severity (level 3) of the damage accurately. Damage severity assessment is an important requirement for the analysis of the damage evolution and the prediction of the remaining lifetime (level 4). The evolution towards a high performance level is considered as an important step forward in the development of autonomous monitoring of the integrity of structures.

\section{- Integrated sensors and network}

A structural health monitoring system requires an integrated sensor system. The design and implementation of these systems involve numerous challenges. These challenges range from the selection of the optimal position and number of sensors and the monitoring of failure or debonding of a sensor to the data transmission and the supply or harvesting of power. Consequently, a large part of the research in the field of structural health monitoring is dedicated to the development of sensor systems. 


\section{- Operational and environmental variability}

A large obstacle for the practical application of structural health monitoring technologies is the dependency of damage parameters on the operational and environmental conditions, such as temperature, humidity, loads and boundary conditions. Changes in these conditions can mask or magnify the effects that are resulting from the damage. Methods should have the ability to separate the damage related effects from those that are coming from changes in environmental conditions. A wide variety of methods, comprising statistical techniques and model based methods, are presented in the literature to compensate for these variations, but confidence in these methods is lacking.

In addition to the technical issues described above, there are other nontechnical issues that must be addressed before structural health monitoring technologies can make the transition to actual application. These issues include, for example, convincing operators, engineers and authorities of the potentials of the technology as well as the certification of the technologies. More detailed discussions on this topic are provided by Boller [36] and Farrar et al. [37].

\subsection{Objective and scope}

The development of a structural health monitoring strategy involves multidisciplinary research challenges, as was shown in the previous section. Figure 1.6 schematically illustrates the associated multidisciplinary framework. This framework comprises four components (i.e. structure, damage identification method, damage scenario, actuation and sensing technology). The characteristics of these components are closely interconnected and together they define the performance of the structural health monitoring strategy. Ideally, a strategy combines a high probability of detection and a high performance level with a low number of false positives. The success of a damage identification strategy is, however, dependent on the actual structure and the damage scenario that is considered. The selection of the most suitable approach is, therefore, far from straightforward and is finally a matter of compromise. This gives rise to the development of a dedicated tool that can be used to design a damage identification strategy depending on the type of structure and the potential threats. Design recommendations and guidelines are required for each scenario to assist in the development of such a tool.

This thesis is dedicated to the identification of damage in composite skin-stiffener structures. Stiffened composite skins are a widely used engineering structure. Besides the application in wind turbine blades, skin-stiffener structures are used in nearly all aircraft wing and fuselage designs. Stiffeners are used to increase the bending stiffness of the component without a severe weight penalty. A primary failure mode for these structures is delamination damage at the connection between 


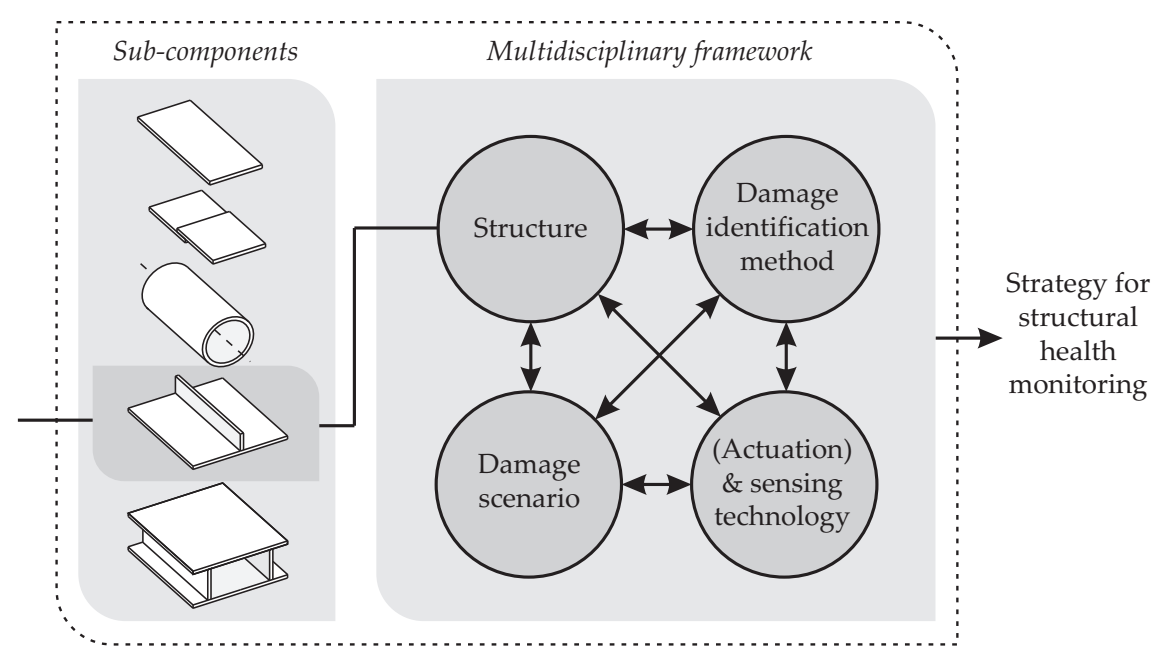

Figure 1.6 The multidisciplinary framework for the design of a structural health monitoring system.

skin and stiffener. Impacts near these connections can lead to local skin-stringer separation. This is a safety-critical failure mode, because it can significantly affect the structural performance of the component while remaining invisible from the outer surface. Skin-stiffener structures are therefore considered as a good candidate for health monitoring.

The structural vibration based health monitoring approaches are considered in the present work. These methods are based on the concept that the dynamic behavior of a structure can change if damage occurs. The motivation is twofold: firstly, because they do not require the structure to be readily accessible. Secondly, because these low frequency methods provide data that is relatively easy to interpret. This provides opportunities to analyze more complex structures, such as the skinstiffener structures. A drawback of the vibration based methods is the limited sensitivity. The identification of barely visible impact damage, as discussed in Section 1.2.3, sets the lower bound for the capabilities of the approach.

In summary, the objective of the research presented in this thesis is:

To develop guidelines for the detection, localization and characterization of damage in composite skin-stiffener structures based on changes in the dynamic behavior.

This work will contribute to the development of a design tool for research engineers, to assist the implementation of structural health monitoring technology in safetycritical composite structures. 


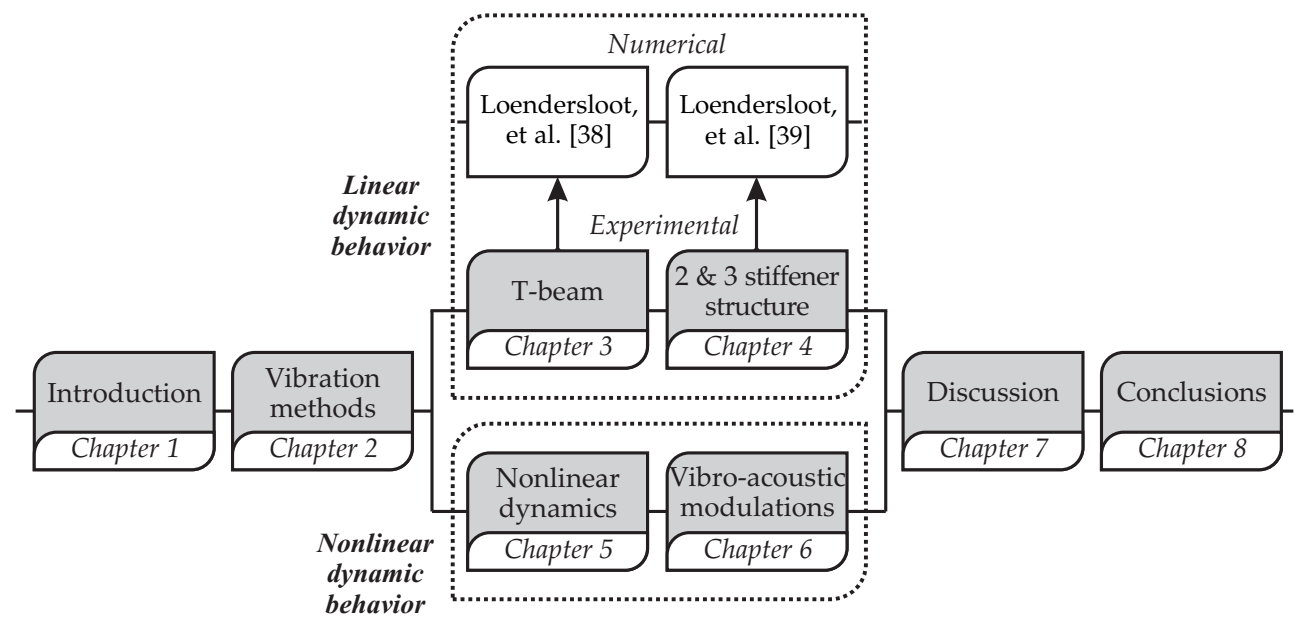

Figure 1.7 Schematic overview of the thesis outline.

\subsection{Outline}

The outline of the thesis is schematically illustrated in Figure 1.7. The core comprises five chapters. Chapters 3 to 6 are reproduced from research papers. As a consequence, some of the essential details are repeated in the different chapters. The author apologizes for any inconvenience caused by the chosen presentation. From a more positive point of view, however, the reader is able to study any individual chapter without having to miss out on any essential details.

Chapter 2 provides an overview of the vibration based damage identification methods. The basic concept of these methods is explained based on a generalized description of a damaged system. A literature study supported by an analytical beam model are used to select a potentially powerful approach for the detection, localization and characterization of damage in the skin-stiffener structure. Two approaches are considered. The first approach utilizes mode shape curvatures and assumes a linear dynamic behavior, while the second approach is focused on the nonlinear dynamic effects that are introduced by the damage.

Chapter 3 is focused on the experimental feasibility of a vibration based damage identification method to identify an artificial delamination at the skin-stiffener connection of a composite T-beam. A force-vibration set-up, including a laservibrometer system, is used to measure the dynamic behavior of the T-beam experimentally. Both bending and torsion modes are considered in the analysis. Special attention is paid to the effect of the number of measurement points.

Chapter 4 extends the work described in Chapter 3 to larger and more complex skin-stiffener structures (i.e. a 2 stiffener structure and a 3 stiffener structure with non-uniform skin thickness). Impact induced damage scenarios are considered. 
The relation between the damage location, the structural design and the dynamic behavior is investigated in order to extract recommendations for the effective application of the methodology. Readers are referred to the book chapters of Loendersloot et al. [38, 39] for numerical studies utilizing finite element models of the structures that were used in Chapters 3 and 4 .

The vibration based method used in Chapters 3 and 4 assumes a linear dynamic behavior. The observation of potential nonlinear dynamic effects caused by damage can also be a strong indicator of the damage. Chapter 5 describes a study on the interaction of a low frequency vibration with skin-stiffener damage. This interaction can yield dynamic phenomena that exhibit complicated nonlinear behavior. Different phenomena are linked to measured waveforms with the help of phase portraits.

The nonlinear effects introduced by skin-stiffener damage urges the development of nonlinear damage identification methods. Chapter 6 concerns a study on the understanding and feasibility of using nonlinear vibro-acoustic modulations for the detection, localization and characterization of impact damage in a composite T-beam. A time domain analysis of the vibro-acoustic modulation phenomena is presented at multiple spatial locations. From a broader perspective, this work intends to contribute to the development of enhanced methods for the identification and characterization of damage in advanced composite structures.

The complete work is put into a broader perspective in Chapter 7. Additional design recommendations and guidelines are extracted based on the work presented in this thesis. The practical application of the methods is discussed. Finally, Chapter 8 presents the important conclusions and provides the recommendations for further research.

\section{References}

[1] T. Tinga. Application of physical failure models to enable usage and load based maintenance. Reliability Engineering \& System Safety, 95(10):1061-1075, 2010.

[2] Clean Sky website: http://www.cleansky.eu, visited on June $28^{\text {th }}, 2013$.

[3] R.L. Foye. Finite element analysis of the stiffness of fabric reinforced composites. Technical report, NASA Contractor Report, 1992.

[4] Volume 3. Polymer matrix composites: material usage, design and analysis. In Composite materials handbook CMH-17-3G, Chapter 12, page 952. SAE International, 2012.

[5] J. Baaran. Visual inspection of composite structures. Technical report, Institute of Composite Structures and Adaptive Systems, DLR Braunschweig, 2009.

[6] C.R. Farrar, S.W. Doebling, and D.A. Nix. Vibration-based structural damage identification. Philosophical Transactions of the Royal Society A: Mathematical, Physical and Engineering Sciences, 359(1778):131-149, 2001.

[7] C.R. Farrar, H. Sohn, F.M. Hemez, M.C. Anderson, M.T. Bement, P.J. Cornwell, S.W. Doebling, J.F. Schultze, N. Lieven, and A.N. Robertson. Damage prognosis: current 
status and future needs. Technical report, Los Alamos National Laboratory, Los Alamos, NM, 2001.

[8] S.W. Doebling, C.R. Farrar, M.B. Prime, and D.W. Shevitz. Damage identification and health monitoring of structural and mechanical systems from changes in their vibration characteristics: a literature review. Technical report, Los Alamos National Laboratory, NM, USA, 1996.

[9] A. Rytter. Vibration based inspection of civil engineering structures. Ph.D. thesis, Aalborg University, 1993.

[10] H. Sohn, C.R. Farrar, F.M. Hemez, D.D. Shunk, D. Stinemans, and B.R. Nadler. A review of structural health monitoring literature: 1996-2001. Technical report, Los Alamos National Laboratory, Los Alamos, NM, 2003.

[11] K. Worden, C.R. Farrar, G. Manson, and G. Park. The fundamental axioms of structural health monitoring. Proceedings of the Royal Society A: Mathematical, Physical and Engineering Sciences, 463(2082):1639-1664, 2007.

[12] K. Worden and J.M. Dulieu-Barton. An overview of intelligent fault detection in systems and structures. Structural Health Monitoring, 3(1):85, 2004.

[13] C.-P. Fritzen and P. Kraemer. Self-diagnosis of smart structures based on dynamical properties. Mechanical Systems and Signal Processing, 23(6):1830-1845, 2009.

[14] E.S. Sazonov, P. Klinkhachorn, U.B. Halabe, and H. V.S. GangaRao. Non-baseline detection of small damages from changes in strain energy mode shapes. Nondestructive Testing And Evaluation, 18(3-4):91-107, 2003.

[15] S. Park, C. Lee, and H. Sohn. Reference-free crack detection using transfer impedances. Journal of Sound and Vibration, 329(12):2337-2348, 2010.

[16] J.C. Abry, S. Bochard, and A. Chateauminois. In situ detection of damage in CFRP laminates by electrical resistance measurements. Composites Science and Technology, 59:925-935, 1999.

[17] R. Schueler, S.P. Joshi, and K. Schulte. Damage detection in CFRP by electrical conductivity mapping. Composites Science and Technology, 61(6):921-930, 2001.

[18] C. Hellier. Handbook of nondestructive evaluation. McGraw-Hill, 2003.

[19] ISO 9934-1 Non-destructive testing - Magnetic particle testing - Part 1: general principles.

[20] B.A. Auld and J.C. Moulder. Review of advances in quantitative eddy current nondestructive evaluation. Journal of Nondestructive Evaluation, 18(1), 1999.

[21] P.J. Schilling, B.R. Karedla, A.K. Tatiparthi, M.A. Verges, and P.D. Herrington. X-ray computed microtomography of internal damage in fiber reinforced polymer matrix composites. Composites Science and Technology, 65(14):2071-2078, 2005.

[22] X.P.V. Maldague. Introduction to NDT by active infrared thermography. Materials Evaluation, 60(9):1060-1073, 2002.

[23] A. Kesavan, S. John, and I. Herszberg. Strain-based structural health monitoring of complex composite structures. Structural Health Monitoring, 7(3):203-213, 2008.

[24] E.P. Carden and P. Fanning. Vibration based condition monitoring: a review. Structural Health Monitoring, 3(4):355-377, 2004.

[25] D. Montalvão, N.M.M. Maia, and A.M.R. Ribeiro. A review of vibration-based structural health monitoring with special emphasis on composite materials. Shock and Vibration Digest, 38(4):295-326, 2006.

[26] G. Park, H. Sohn, C.R. Farrar, and D.J. Inman. Overview of piezoelectric impedance-based health monitoring and path forward. The Shock and Vibration Digest, 
35(6):451-463, 2003.

[27] V. Gopal, M. Annamdas, and C.K. Soh. Application of electromechanical impedance technique for engineering structures: review and future issues. Journal of Intelligent Material Systems and Structures, 21(1):41-59, 2009.

[28] T. Kundu, S. Das, and K.V. Jata. Detection of the point of impact on a stiffened plate by the acoustic emission technique. Smart Materials and Structures, 18(3):035006, 2009.

[29] A. Raghavan and C.E.S. Cesnik. Review of guided-wave structural health monitoring. The Shock and Vibration Digest, 39(2):91-114, 2007.

[30] Z. Su, L. Ye, and Y. Lu. Guided lamb waves for identification of damage in composite structures: a review. Journal of Sound and Vibration, 295(3-5):753-780, 2006.

[31] Y.Y. Hung and H.P. Ho. Shearography: an optical measurement technique and applications. Materials Science and Engineering: R: Reports, 49(3):61-87, 2005.

[32] Y.Y. Hung. Applications of digital shearography for testing of composite structures. Composites Part B: Engineering, 30(7):765-773, 1999.

[33] W.J. Staszewski, S. Mahzan, and R. Traynor. Health monitoring of aerospace composite structures - Active and passive approach. Composites Science and Technology, 69(11-12):1678-1685, 2009.

[34] K. Diamanti and C. Soutis. Structural health monitoring techniques for aircraft composite structures. Progress in Aerospace Sciences, 46(8):342-352, 2010.

[35] R.P. Dalton, P. Cawley, and M.J.S. Lowe. The potential of guided waves for monitoring large areas of metallic aircraft fuselage structure. Journal of Nondestructive Evaluation, 20(1), 2001.

[36] C. Boller. Structural health monitoring - Its association and use. In W. Ostachowicz and J.A. Güemes, editors, New Trends in Structural Health Monitoring, volume 542 of CISM International Centre for Mechanical Sciences, Chapter 1, pages 1-79. Springer Vienna, 2013.

[37] C.R. Farrar and K. Worden. An introduction to structural health monitoring. Philosophical Transactions of the Royal Society A: Mathematical, Physical and Engineering Sciences, 365(1851):303-15, 2007.

[38] R. Loendersloot, T.H. Ooijevaar, L.L. Warnet, A. de Boer, and R. Akkerman. Vibration based structural health monitoring and the modal strain energy damage index algorithm applied to a composite T-beam. In C.M.A. Vasques and J.D. Rodrigues, editors, Vibration and Structural Acoustics Analysis: Current Research and Related Technologies, Chapter 6, pages 121-150. Springer, 2011.

[39] R. Loendersloot, T.H. Ooijevaar, A. de Boer, and R. Akkerman. Development of a damage quantification model for composite skin-stiffener structures. In C. Boller and H. Janocha, editors, New Trends in Smart Technologies, pages 99-108. Fraunhofer Verlag, 2013. 



\title{
CHAPTER 2
}

\section{Overview of vibration based damage identification methods}

\begin{abstract}
An overview of the vibration based damage identification methods is presented in this chapter. The basic concept of these methods is explained based on a generalized description of a damaged system. One of the challenges in the development of a successful approach is the selection of a damage identification method. A literature study supported by an analytical model showed that mode shape curvatures combined with the modal strain energy damage index (MSE-DI) algorithm are a potentially powerful damage feature and classifier. However, when severe nonlinear dynamic effects are introduced by the damage, the modal domain based methods are suffering under their linear system assumption. Alternative methods in, for example, the time or frequency domain are in that case required to obtain an adequate description of the nonlinear behavior introduced by the damage.
\end{abstract}




\subsection{Introduction}

The basic concept of the vibration based damage identification methods is that the dynamic behavior of a structure can change if damage occurs [1]. Damage in a structure can alter the structural integrity and therefore the physical properties like stiffness, mass and/or damping. The dynamic behavior of a structure is a function of these physical properties and will therefore directly be affected by the damage. The dynamic behavior can be described by time, frequency and modal domain parameters. The changes in these parameters or properties derived from these parameters are used as indicators of damage.

The structural vibration based approaches generally allow for a relatively easy interpretation of the measured responses, have the ability to analyze complex structures and do not require the structure to be readily accessible in order to be able to identify damage [2]. Drawbacks are, however, the limited sensitivity compared to higher frequency approaches and the number of required sensors in case the standing wave patterns need to be described [3]. As a consequence, the application of structural vibration based methods has to be tailored to the structure and the expected damage cases to fully utilize the potential of this technology.

This chapter has two objectives. The first objective is to provide an overview of the structural vibration based damage identification methods. For this purpose, a fundamental description of the structural vibration based damage identification problem is given, followed by a short literature overview of the damage features and (statistical) classifiers that are commonly addressed. The second objective is to select a promising damage identification method for the detection, localization and characterization of skin-stiffener damage. The selection of an appropriate method is often all but straightforward and finally a matter of compromise. To aid in this process, two basic principles are discussed, namely the effect of the potential damage case on the dynamic behavior and the consequences involved with the information reduction in the signal processing. The former determines whether the parameter is sensitive to the damage and is analyzed by considering an analytical model of a delaminated composite beam. This model is a simplified representation of the damage that is expected in skin-stiffener connections. The latter is explained and demonstrated based on a mass-spring-damper system with a bilinear stiffness, representing the potential opening and closing behavior of defects in a skin-stiffener connection.

\subsection{Generalized description damaged system}

The dynamics of a general time-varying damaged structure can be described by the coupled system of the nonlinear equation of motion and the nonlinear evolution of 
the damage according to Fritzen et al. [3]:

$$
\begin{aligned}
& \boldsymbol{M}\left(\chi_{\mathrm{d}}, \chi_{\mathrm{e}}, t\right) \ddot{\boldsymbol{q}}+\boldsymbol{g}\left(\chi_{\mathrm{d}}, \chi_{\mathrm{e}}, \boldsymbol{q}, \dot{\boldsymbol{q}}, t\right)=\boldsymbol{F}_{\mathrm{op}}(t)+\boldsymbol{F}_{\mathrm{test}}(t), \\
& \dot{\chi}_{\mathrm{d}}=\boldsymbol{P}\left(\chi_{\mathrm{d}}, \chi_{\mathrm{e}}, \boldsymbol{q}, \dot{\boldsymbol{q}}, t\right)
\end{aligned}
$$

where $M$ is the mass matrix, $g$ the force vector of elastic forces, damping forces, etc. depending on the displacements $\boldsymbol{q}$, the velocities $\dot{\boldsymbol{q}}$, the time $t$, a damage parameter $\chi_{\mathrm{d}}$ and a parameter $\chi_{\mathrm{e}}$ that indicates the influence of the environmental and operational conditions (e.g. temperature, humidity). The damage parameter $\chi_{\mathrm{d}}$ characterizes the damage scenario in terms of e.g. the crack length or the loss of stiffness. Equation (2.1) describes the fundamentals of the damage diagnosis process, whereas Equation (2.2) provides a starting point for a prognostic analysis (e.g. damage evolution and residual service life estimation) [4]. The damage evolution is usually considered as a rather slow process compared to the dynamic behavior of the structure. The damage parameter $\chi_{\mathrm{d}}$ is, therefore, assumed constant during the short time span of a dynamic measurement. The forced excitation of the system consists of the operational loads $\boldsymbol{F}_{\mathrm{op}}(t)$ and the test loads $\boldsymbol{F}_{\text {test }}(t)$. The latter is absent in the case of a passive method. For the active approach, the test loads are generated by an actuator (e.g. piezoelectric element, shaker). The transformation of the input signal $\boldsymbol{u}(t)$ of the actuator to the forces and moments applied to the structure can be described by:

$$
\boldsymbol{F}_{\text {test }}(t)=\boldsymbol{h}_{\mathrm{in}}\left(\chi_{\mathrm{d}}, \chi_{\mathrm{e}}, \boldsymbol{u}(t)\right) \text {. }
$$

A similar transfer function can be defined for the response side of the system:

$$
\boldsymbol{y}(t)=\boldsymbol{h}_{\mathrm{out}}\left(\chi_{\mathrm{d}}, \chi_{\mathrm{e}}, \boldsymbol{q}, \dot{\boldsymbol{q}}, t\right) .
$$

The transfer function $\boldsymbol{h}_{\text {out }}$ relates the state variables to the actually measured system response $\boldsymbol{y}(t)$ (e.g. strains or voltage). The damage parameter $\chi_{\mathrm{d}}$ in Equations (2.3) and (2.4) can also account for any failure or debonding of the actuator or sensor.

Although the damage parameter $\chi_{\mathrm{d}}$ provides the most direct description of the damage, this parameter can usually not be measured directly. Alternatively, the changes in the dynamic response related to this damage parameter is considered in the damage identification process. For this purpose, the system response $y(t)$ is usually compared with an earlier obtained baseline response $\boldsymbol{y}_{0}$. The associated forward problem relates the deviations in the response $\Delta y(t)$ with the damage characteristics $\chi_{\mathrm{d}}$ and the environmental and operational conditions $\chi_{\mathrm{e}}$ :

$$
\Delta y=y-y_{0}=f\left(\chi_{\mathrm{d}}, \chi_{\mathrm{e}}\right)
$$

The key challenge for damage diagnosis is, however, to solve the inverse problem, 


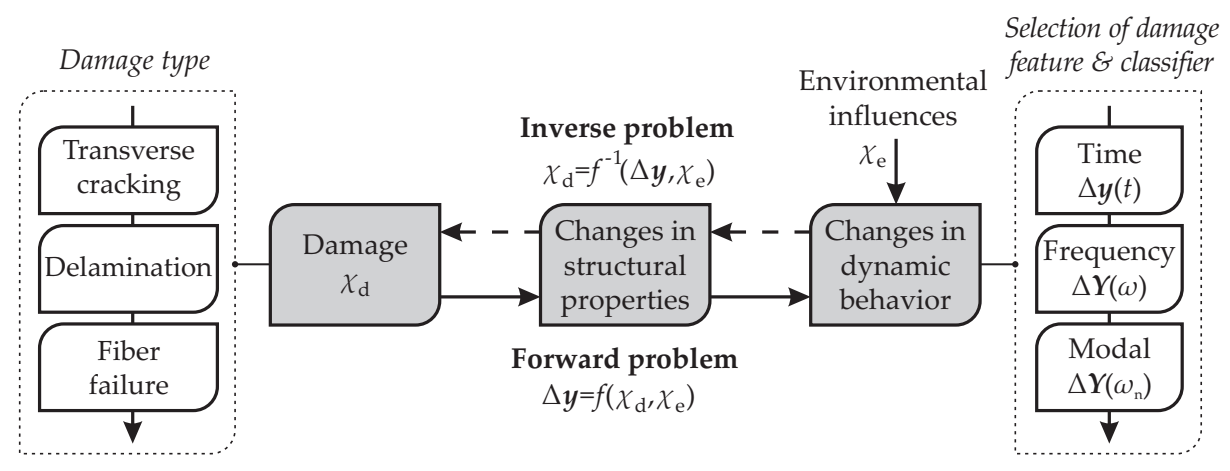

Figure 2.1 Schematic illustration of the forward and inverse problem involved with vibration based damage identification of composite structures.

which is defined as:

$$
\chi_{\mathrm{d}}=f^{-1}\left(\Delta y, \chi_{\mathrm{e}}\right)
$$

The complexity involved with this problem comes from the non-uniqueness of the solution and the usually incomplete response data due to a limited number of measurement locations.

Figure 2.1 schematically illustrates the forward and inverse problem. They connect the potential damage scenarios in composite materials (left side) with the wide range of damage features (right side). Damage identification, first, aims to maximize the correlation between the damage parameter and the selected damage feature. Second, it is practically also desired to condense the information to a lower dimensional parameter space. The deviations in the measured time domain parameters $\Delta \boldsymbol{y}(t)$ are therefore often replaced by parameters from the frequency $\Delta Y(\omega)$ or modal $\Delta Y\left(\omega_{n}\right)$ domain. For both purposes, the selection of an appropriate damage feature is an important step in the vibration based damage identification approach. Many additional aspects (e.g. sensing system, operational conditions, computational costs, etc.) should be taken into account in this process. The selection is also significantly complicated by the wide range of potential damage scenarios and the large variety of damage features. None of the approaches is, at the moment, able to solve all problems in all structures. The selection of an appropriate approach is, therefore, often a matter of compromise.

\subsection{Literature overview vibration based methods}

The amount of literature that is focused on vibration based damage identification methods is immense. This is clearly illustrated by the number of available review papers [3, 5-9]. One of the most recent overviews is given by Fan et al. [9], but 


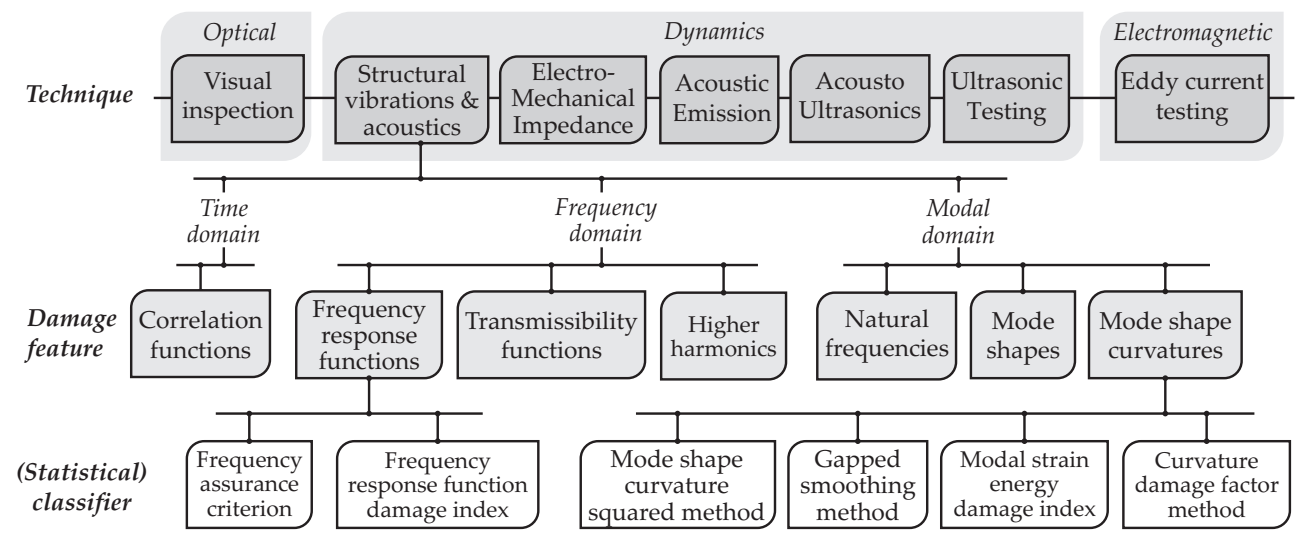

Figure 2.2 A concise overview of the wide range of damage identification approaches. The vibration based methods are categorized according to their damage sensitive feature and (statistical) classifier.

can also be found in the books of Boller et al. [10] and Balageas et al. [11]. More specifically, Montalvão et al. [1] and Zou et al. [2] provide reviews that are dedicated to vibration based health monitoring of composite materials. The review by Li [12] is specifically focused on strain based methods. Reviews only concentrating on nonlinear damage identification methods are presented by Worden et al. [13] and Jhang [14].

The vibration based damage identification methods can be categorized according to their damage sensitive feature and (statistical) classifier, as schematically shown in Figure 2.2. The earliest studies on this subject report on the relation between natural frequency shift or modal damping changes and structural damage. Adams and Cawley [15-18] were among the first to actively research this subject back in the seventies. These modal domain methods comprise a large part of the available literature. Nowadays, research is however also directed towards statistical time series methods [19] (e.g. cross-correlations and auto-regressive moving average representations) and advanced signal processing techniques (e.g. Wavelet transforms [20] and Hilbert-Huang transforms [21]) to extract damage features in the time and frequency domain. A comprehensive list of the damage features that are used in the literature is presented in Table 2.1. Appendix B provides an overview of the wide variety of classifiers associated with these features.

The comparison and assessment of the performance of the different methods is rather difficult. Each method can have individual advantages and disadvantages regarding the specific application, structure and damage case under investigation. The review studies primarily list the available literature, but do not allow for a detailed comparison of the performance of each method. It lies beyond the scope of this chapter to discuss each method individually. Several experimental and numerical comparison studies by different authors can be found in the 
Table 2.1 An overview of the vibration based damage features categorized according to the time, frequency and modal domain. An elaborate overview of the classifiers associated with these features is presented in Appendix B.

\begin{tabular}{lll}
\hline Time domain & Frequency domain & Modal domain \\
\hline - Time response / & - Fourier / power spectra & - Natural frequencies \\
waveform & - Frequency response & - Mode shapes \\
- Statistical time series & function & - Mode shape curvatures \\
analysis: & - Frequency response & - Modal damping \\
○ Correlation functions & function curvature & - Dynamic stiffness \\
$\quad$ (non-parametric) & - Mechanical impedance & - Dynamic flexibility \\
○ Autoregressive models & - Transmissibility function & - Updating methods \\
$\quad$ (parametric) & - Antiresonances & \\
- Time-frequency responses & - Higher harmonics & \\
& (nonlinear) & \\
& - Modulations (nonlinear) & \\
\hline
\end{tabular}

1 Time-frequency parameters are sometimes considered as a separate domain in the literature.

literature [9, 12, 22-27]. Although these studies are limited to a selection of methods, structures and damage cases, they provide a general perception of the strengths and weaknesses of the evaluated methods. In summary, the comparative studies concluded that mode shape curvatures (damage feature) combined with the modal strain energy damage index (MSE-DI) algorithm [28, 29] (classifier) outperforms other frequently applied damage identification methods based on natural frequencies [16, 30], mode shapes [31,32], dynamic flexibility [33-35] and other mode shape derivative based classifiers [36, 37]. Mode shape curvatures tend to be a relatively sensitive damage feature [9]. Humar et al. [25] stated that, among the evaluated methods, the MSE-DI formulation is most successful in detecting and localizing damage, but is lacking in the quantification of the damage. These observations are supported by Alvandi and Cremona [24]. They also concluded that this approach showed a good stability regarding noisy signals. Drawbacks of using mode shape curvatures are the number of required data points to accurately describe the mode shapes and the numerical errors introduced with the calculation of the second derivative $[9,27,37]$.

\subsection{Damage feature selection}

As explained in Section 2.2, many aspects need to be considered in the process of finding an appropriate damage feature and classifier. The present section discusses two basic principles to aid in this process. Firstly, the effect of damage on the structural properties is addressed. The skin-stiffener structure considered in this thesis is expected to be primarily prone to delamination type of damage at the skin- 
stiffener connection. An analytical model of a composite beam with a delamination is analyzed to gain a more general understanding of how delamination damage can affect the dynamic behavior of a beam-like structure. Special attention is paid to the feasibility of modal curvatures, since they tend to be a strong indicator of damage according to the literature. Secondly, determination of modal domain parameters are accompanied by data condensation and reduction. The consequences involved with this process are explained and demonstrated based on a mass-spring-damper system with a bilinear stiffness. A delamination damage can potentially open and close under an appropriate loading and can introduce nonlinear effects. These nonlinear effects set requirements to the features that can be used for damage characterization purposes.

\subsubsection{Effect of damage on dynamic properties}

Damage in a composite laminate can affect the material parameters in a highly directional nature. This directional behavior sets the requirements for a vibration based damage identification approach in two ways. First of all, for the selection of the type and orientation of the excitation. A high sensitivity is only obtained when the damaged area is stressed in the direction that shows the most severe change in the structural properties. For example, a delamination in a plate structure will barely affect the inplane stiffness properties, but is expected to be more pronounced in the flexural behavior. Secondly, for the selection of the location, orientation and type of sensors. They should be selected in such a way that the damage information can be extracted from the structural response.

\section{Delaminated composite beam}

Several dynamic models have been developed for the analysis of the effect of delaminations on dynamic behavior of beam structures. To overcome difficulties associated with potential nonlinear dynamic effects introduced by a delamination, many modeling attempts assume that the dynamic behavior of the structure remains linear, i.e. the effect of the damage on the material parameters (e.g. stiffness) is independent of the deformation. Della and Shu [38] categorize the linear dynamic models of delaminated structures into two classes: the 'free mode' and the 'constraint mode' models. The 'free mode' models assume that the delaminated layers deformed 'freely' without interacting with each other. On the other hand the 'constraint mode' models assume that the delaminated layers are 'constrained' and will have identical transverse deformations. In addition, the delaminated layers are assumed to be free to slide over each other in the axial direction. Both representations show discrepancies with respect to what is expected in practice. Nevertheless, the predicted frequencies based on the 'constrained model' were closer to the experimental values [39]. 

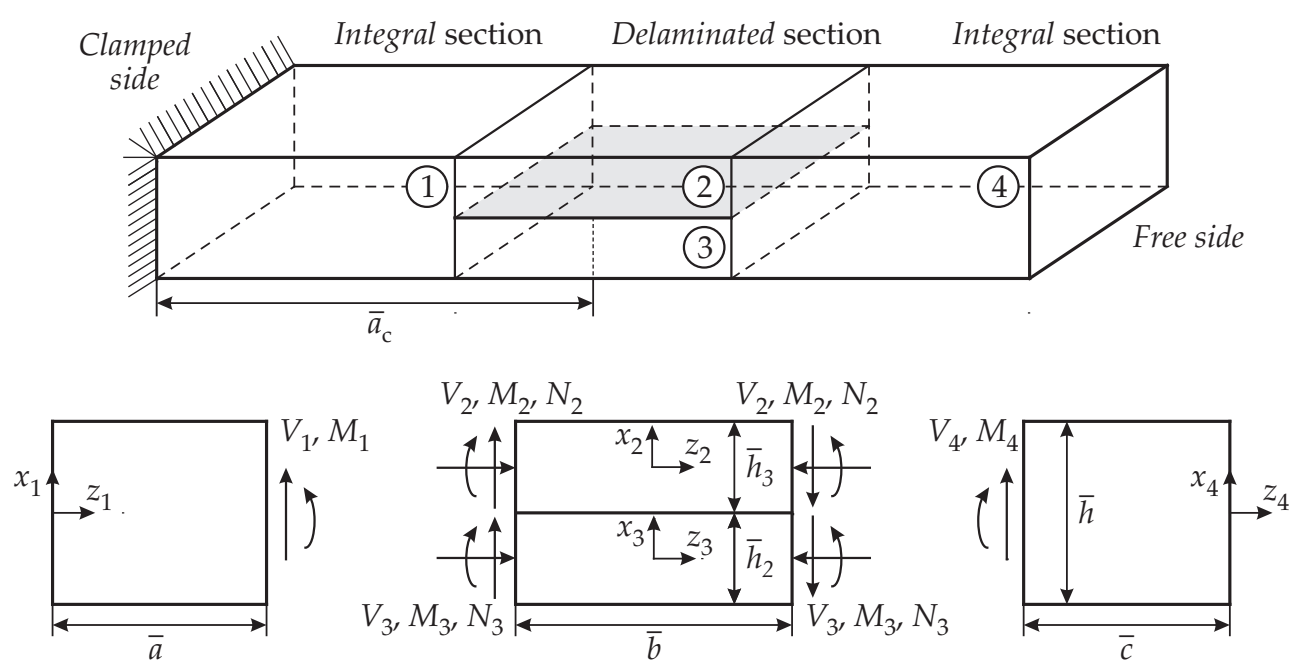

Figure 2.3 An analytical model of a beam with a single through-width delamination. The $V_{s}$ represents the shear force, $M_{s}$ the bending moment and $N_{s}$ the normal force for beam segment $s=1,2,3,4$. The dimensions of the beam are indicated by $\bar{a}, \bar{b}, \bar{c}$ and height $\bar{h}$. The delamination location is given by $\overline{a_{\mathrm{c}}}$ and $\bar{h}_{2}$.

The first 'constraint mode' model was presented by Mujumdar and Suryanarayan [39]. This model determines the natural frequencies and mode shapes of an isotropic beam containing a single through-width delamination in flexural vibration. The delaminated beam model consists of three spanwise regions, a delaminated section and two integral sections (see Figure 2.3). The delaminated section is composed of two separate beams above and below the delamination plane and they are joined at their ends to the integral beam segment. It is assumed that no gap exists between the delaminated components and that they are free to slide, i.e. there is no friction between the components. Each beam is treated as a Bernoulli-Euler beam. The equations of motion are formulated for each beam segment. The dynamic solution for the complete beam is obtained by imposing appropriate boundary conditions at the ends of the two integral segments and continuity conditions at the delamination junctions.

The basic theory is based on variations in the distribution of shear stress. Both normal and shear stresses are developed in a beam that exhibits non-uniform bending. In a beam without a delamination, the shear stress is distributed as shown in Figure 2.4a. However, in case a delamination is present, the layers are free to slide and the shear stress on the delaminated surface therefore equals zero by definition. The shear stress distribution for this case is shown in Figure 2.4b. This discontinuity in shear stress results in a decrease in the flexural rigidity of the delaminated segment, which will affect the dynamic properties of the beam.

The two separate beams in the delaminated segment also give rise to coupling between the axial and flexural deformation. Therefore, continuity of axial forces 


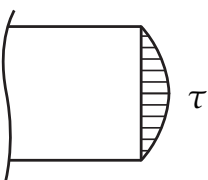

(a)

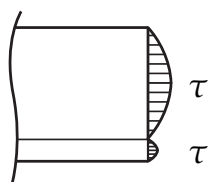

(b)
Figure 2.4 Distribution of shear stress $\tau$ in (a) a pristine and (b) a delaminated beam segment.

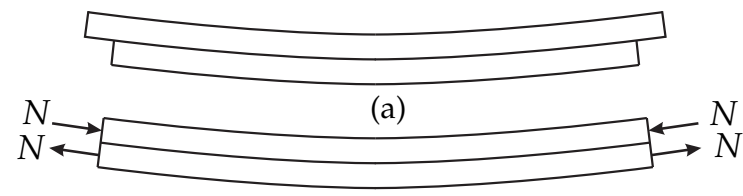

(b)

Figure 2.5 Delaminated layers without (a) and with (b) continuity conditions at the junctions between the delaminated and integral sections.

and displacements at the junctions between the integral and delaminated segments is required. A normal force $N$ is introduced, as indicated in Figure 2.5. These normal forces compress one segment and stretch the other such that their ends lie in the same plane. This internal loading results in an internal bending moment, which partly compensates for the loss of flexural rigidity due to the new shear stress distribution.

Grouve et al. [40] extended the analytical model of Mujumdar and Suryanarayan [39] for laminated beams. Experimental validation showed an averaged difference between theoretical and experimental resonance frequencies for the delaminated beams equal to $3.3 \%$. The differences between experimental and calculated resonance are partly caused by the model assumptions made. The delaminated segments are modeled to stay in contact during the vibration and slide without friction. This is a requirement which cannot be satisfied in practice. Opening of the delamination during vibration will result in a decrease of stiffness, while friction between the segments will increase the flexural rigidity.

\section{Analytical results}

The model proposed by Grouve et al. [40] is used to analyze the effect of a delamination on the dynamic behavior. A cantilever composite beam structure (dimensions $300 \times 20 \times 2.0 \mathrm{~mm}$ ) built from 16 unidirectional plies of carbon fiber AS4D is considered in the analysis. The thermoplastic matrix is PEKK. The laminate has a $[0 / 90]_{4, \mathrm{~s}}$ lay-up with the material properties as in Table 2.2. The dimensionless delamination parameters $\left(\bar{a}_{\mathrm{c}}, \bar{b}\right.$ and $\left.\bar{h}_{2}\right)$ as defined in Figure 2.3 are used in the investigation.

Table 2.2 The material properties of a unidirectional layer of carbon AS4D/PEKK. The material properties are obtained from data provided by Fokker Aerostructures B.V., Hoogeveen, The Netherlands.

\begin{tabular}{ccccc}
\hline $\begin{array}{c}E_{1} \\
{[\mathrm{GPa}]}\end{array}$ & $\begin{array}{c}E_{2} \\
{[\mathrm{GPa}]}\end{array}$ & $\begin{array}{c}\mathrm{G}_{12} \\
{[\mathrm{GPa}]}\end{array}$ & $\begin{array}{c}v_{12} \\
{[-]}\end{array}$ & $\begin{array}{c}\rho \\
{\left[\mathrm{kg} / \mathrm{m}^{3}\right]}\end{array}$ \\
\hline 133 & 10.5 & 5.56 & 0.3 & 1590 \\
\hline
\end{tabular}


The effect of the delamination on the dynamic behavior of the composite beam is a combination of two effects: one is the discontinuity in shear stress over the beam thickness, the other is the stretching and compressing of the delaminated beam segments. The first effect results in a reduction of flexural rigidity, while the second effect tends to compensate for this. The weakening effect of a delamination is only noticed in case a shear force is acting in the beam. This means that the effect of a delamination vanishes if the delamination is located in regions where the shear force approaches zero, but is the largest at locations where the shear force is maximum. The non-uniform distribution of shear stress across the length of the beam causes the effect to be dependent on the axial location $\bar{a}_{\mathrm{c}}$ of the delamination. As the shear stress distribution differs for every vibration mode, the delamination will also affect each mode differently. These effects are clearly demonstrated in Figure 2.6, showing the second and third vibration mode shape and its derivatives for a through-width delamination $\left(\bar{a}_{\mathrm{c}}=0.5, \bar{b}=0.2, \bar{h}_{2}=0.5\right)$ in a composite beam. Note that the shear force is a function of the third derivative of the displacement. The delamination is located near a point where the third derivative of the second mode approaches zero, but is large for the third mode. Consequently, the delamination has a negligible effect on the second mode, while the third mode is clearly affected. Figure 2.7 shows that a similar but opposite effect on the second and third mode is observed when the delamination moves to the axial location $\bar{a}_{\mathrm{c}}=0.3$.

The effect of the local delamination is more pronounced in the mode shape curvatures than observed in the mode shapes themselves. The delamination causes clear discontinuities in the mode shape curvature at the boundaries of the delaminated segment. These discontinuities are different for each vibration mode and reveal the presence, the location, as well as the size of the delamination. The size of the discontinuity is described by the continuity equation for bending moments at the junction between the integral and delaminated segment [39]. The discontinuities are the largest when the delamination is located at a nodal point in the mode shape and at the neutral plane. They vanish for locations near the surface and at an antinode. The 'constrained mode' model, however, does not incorporate the potential opening of the delaminated segment in the results. The opening of the delamination allows for additional curvature changes for delamination locations where the shear related curvature effects are minimal.

Besides the literature studies discussed in Section 2.3, the analytical results also showed that modal curvatures are an appropriate damage feature in the case of delamination damage. The discontinuities caused at the delamination boundaries are significantly more pronounced than, for example, deviations in mode shapes. This makes curvatures an interesting candidate for damage identification. The direct relation between curvature and strain for a beam in bending also opens possibilities for integrated sensing technologies based on, for example, optical fiber Bragg gratings [40] or piezoelectric strain sensors [41]. 


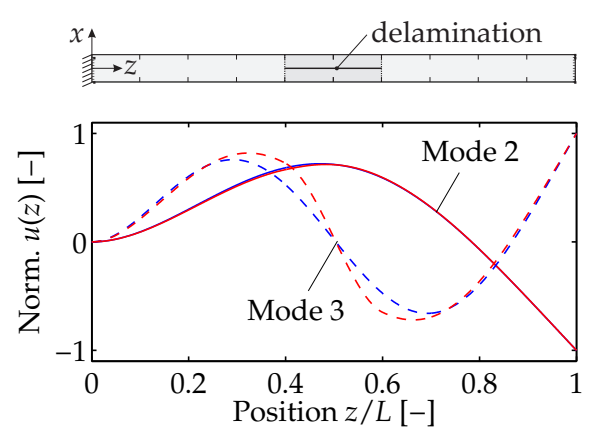

(b) Mode shape.

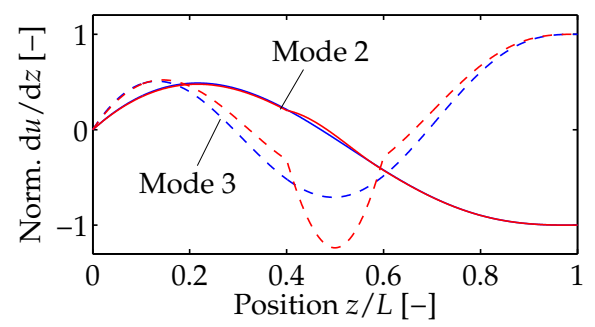

(c) Mode shape, first derivative.

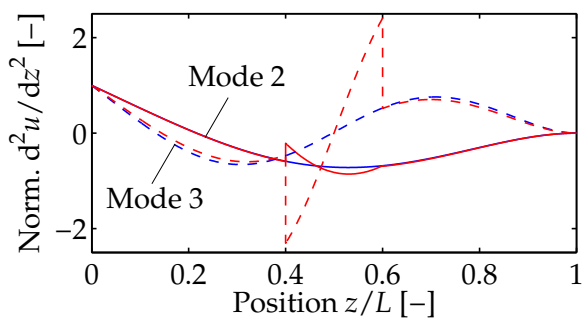

(d) Mode shape, second derivative.

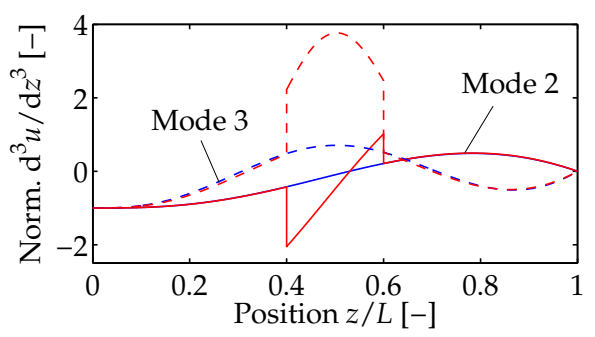

(e) Mode shape, third derivative.

Figure 2.6 The second and the third vibration mode shape $u(z)$ and the derivatives for a pristine (blue) and delaminated (red) composite beam $\left(\bar{a}_{\mathrm{c}}=0.5, \bar{b}=0.2, \bar{h}_{2}=0.5\right)$.

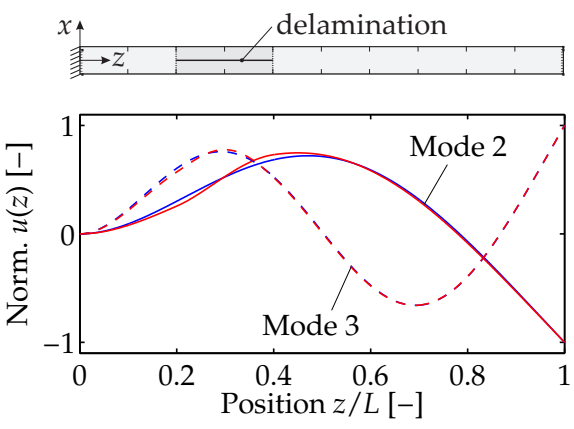

(b) Mode shape.

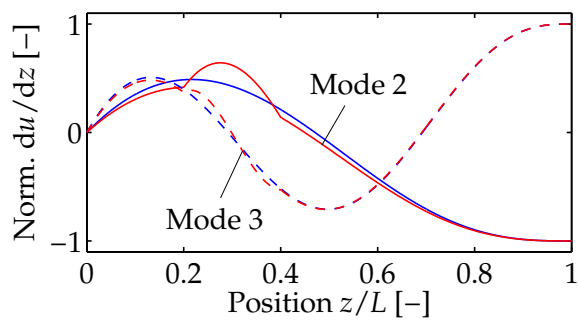

(c) Mode shape, first derivative.

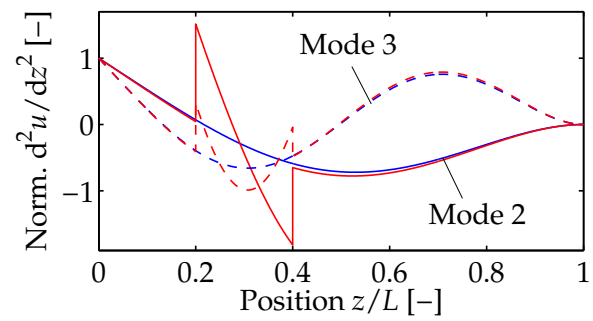

(d) Mode shape, second derivative.

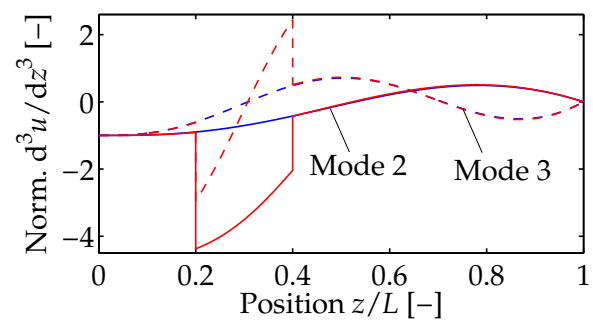

(e) Mode shape, third derivative.

Figure 2.7 The second and the third vibration mode shape $u(z)$ and the derivatives for a pristine (blue) and delaminated (red) composite beam $\left(\bar{a}_{\mathrm{c}}=0.3, \bar{b}=0.2, \bar{h}_{2}=0.5\right)$. 


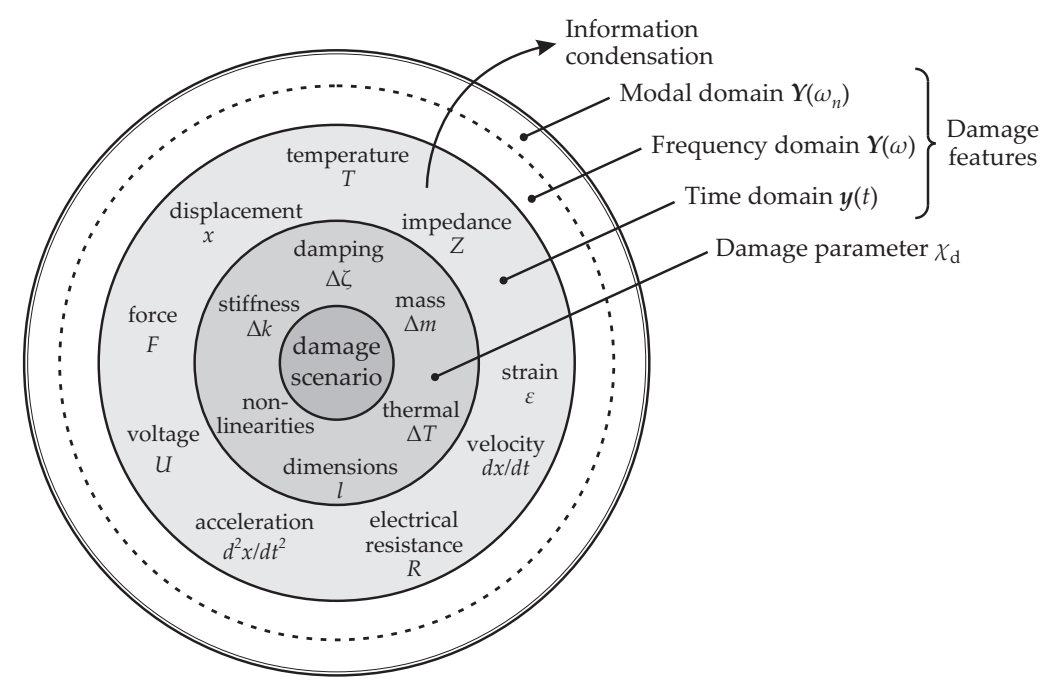

Figure 2.8 Damage features classified according to the amount of information condensation. The outer circles represent a higher level of information condensation.

\subsubsection{Information condensation}

A second aspect that needs to be considered in the selection of a damage sensitive parameter is the reduction and condensation of the measured information. The challenge is to condense the damage related information to a lower dimensional parameter space (e.g. modal domain) to obtain a robust indicator, while preserving the correlation with the damage scenario. Figure 2.8 schematically illustrates the condensation process. The damage parameter $\chi_{\mathrm{d}}$ provides the best description of the damage, but is often not directly measurable. The system response parameters $\boldsymbol{y}(t)$ (e.g. strain, acceleration) are, therefore, acquired. These time domain representations are related to the damage parameter $\chi_{d}$, but often provide an incomplete system description caused by a limited number of measurement points. Moreover, the time series consists of large data sets, which makes it hard to attribute measured deviations to the structural changes caused by the damage. Consequently, the time series is often transferred to the frequency domain. The frequency domain parameters (e.g. power spectral densities, frequency response functions) are typically obtained under the assumption that the responses are periodic. Depending on the time scale of the evolving damage, the system is also assumed to be invariant during the measurement. Modal analysis will further condense the damage information to a linear system description based on the natural frequencies, modal damping factors and modal vectors. Subsequently, slightly complex modal vectors are generally considered to be real normal, by neglecting non-proportional damping effects. Moreover, the modal vectors are 


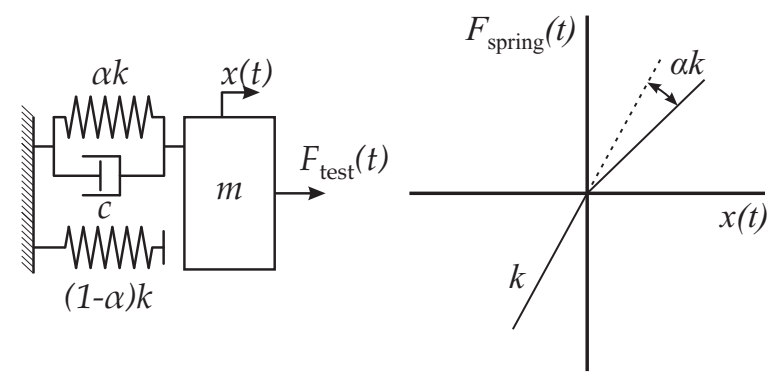

Figure 2.9 A simplified representation of the opening and closing behavior of damage by a mass-springdamper system with a bilinear stiffness subjected to a dynamic loading $F_{\text {test }}(t)$. The force exerted by the spring is given by: $F_{\text {spring }}(t)=k(x) x(t)$.

often scaled vectors without a physical quantity. Finally, for damage identification purposes typically a selection of the most sensitive modes is considered to obtain an indicator. The compressed subset of parameters must be able to describe the damage scenario. Information condensation can result in a robust indicator that has a strong correlation with the damage scenario. Each transformation is, however, also accompanied by the loss of potentially valuable information caused by the intermediate assumptions. These assumptions can inherently limit the applicability of the selected damage features depending on the desired performance level, as defined in Section 1.3.2.

\section{Bilinear system representation}

The consequences involved with the information condensation process for modal parameters can easily be demonstrated by considering a mass-spring-damper system. Damage can open and close under an appropriate dynamic loading. The dynamic effects induced by the opening and closing motion are represented in a simplified way by a mass-spring-damper system with a bilinear stiffness, depicted in Figure 2.9. The governing dynamic equation reads:

$$
m \ddot{x}(t)+c \dot{x}(t)+k(x) x(t)=F_{\text {test }}(t),
$$

with:

$$
k(x)= \begin{cases}\alpha k & x \geq 0 \\ k & x<0\end{cases}
$$

and where $m$ represents the mass, $c$ the damping, $k(x)$ the stiffness, $x(t)$ the time-dependent displacement and $F_{\text {test }}(t)$ the (harmonic) force. The parameter $\alpha$ describes the extent of the bilinearity. The system properties are chosen arbitrary and equal: $m=1 \mathrm{~kg}, k=10^{5} \mathrm{Nm}^{-1}, c=5 \mathrm{Ns} \mathrm{m}^{-1}, \alpha=0.5$. The time response 


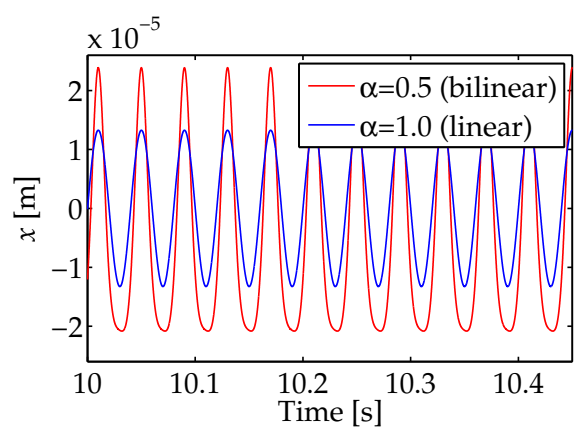

(a) Time responses $x(t)$.

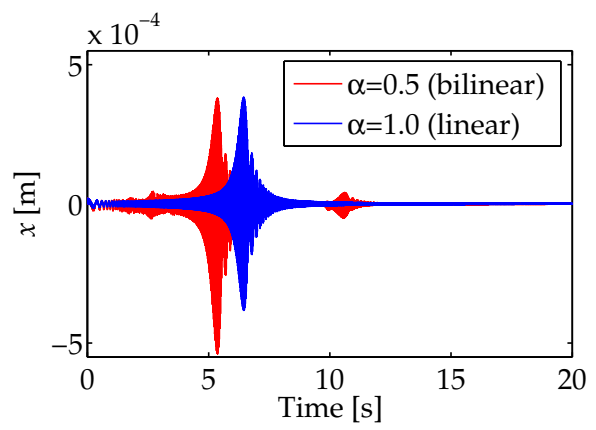

(c) Time responses $x(t)$.

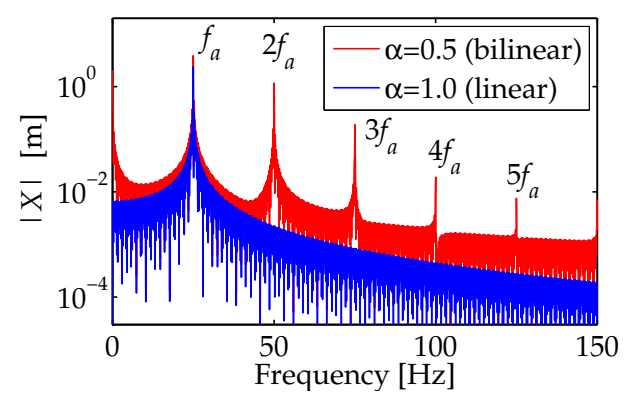

(b) Magnitude of the Fourier spectra $|X(f)|$.

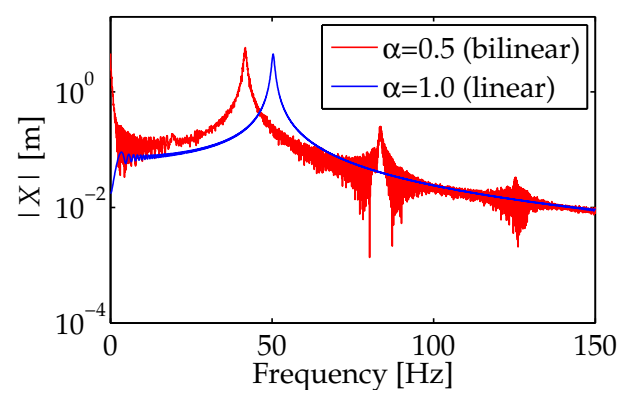

(d) Magnitude of the Fourier spectra $|X(f)|$.

Figure 2.10 The time responses and the magnitudes of their Fourier transformed signals obtained for a ( $a$, $b)$ single tone $\left(f_{\mathrm{a}}=25 \mathrm{~Hz}\right)$ and $a(c, d)$ linear swept harmonic $\left(f_{\mathrm{a}}=1-150 \mathrm{~Hz}\right)$ excitation of a mass-springdamper system with a linear $(\alpha=1.0)$ and a bilinear $(\alpha=0.5)$ stiffness.

$x(t)$ for a single tone harmonic excitation at frequency $f_{\mathrm{a}}=25 \mathrm{~Hz}$ is presented in Figure 2.10(a) for a linear $(\alpha=1.0)$ and bilinear $(\alpha=0.5)$ system. The bilinear stiffness affects the steady state time response. Their windowed Fourier spectra $X(f)$ are given in Figure 2.10(b). The spectrum for the system with the bilinear stiffness reveals clear higher harmonic components. These higher harmonics are integer multiples of the excitation frequency $\left(n f_{\mathrm{a}}\right.$ with $\left.n=1,2,3, \ldots\right)$ and are characteristic indicators of a nonlinear system response [42].

Dynamic analysis usually relies on broadband excitation signals to characterize a dynamic system. The time and frequency domain responses for a linearly swept harmonic excitation $\left(f_{\mathrm{a}}=1-150 \mathrm{~Hz}\right)$ are presented in Figures 2.10(c) and 2.10(d). The highest response amplitudes are obtained at the natural frequencies. The bilinear system shows, besides a shift in natural frequency, clear scattering in the frequency response compared to the smooth linear system response. The swept excitation causes a different set of higher harmonics to be generated for each time instance. Each set of harmonics has a different participation in the total response. The scattering is consequently the result of calculating the Fourier transform over 
the total response signal. The transformation of the time domain information to the frequency domain significantly complicates, in this case, the interpretation of the nonlinear response.

Transformation to the modal domain will further condense the system information. Modal analysis essentially assumes a time invariant and a linear system. Several modal analysis methods are available in the literature [43]. The method used in the present work extracts the modal parameters by applying an experimental modal analysis (EMA) procedure to the frequency response functions (FRFs) between the excitation and the response location. These frequency response functions $H_{F x}(\omega)$ can be calculated in different ways. By assuming that mainly the response signal is subject to noise, a least square estimate is given by [44]:

$$
H_{F x}(\omega)=\frac{S_{F x}(\omega)}{S_{F F}(\omega)},
$$

with $S_{F F}(\omega)$ the auto-power spectral density of the excitation signal and $S_{F x}(\omega)$ the cross-power spectral density between the excitation and response signal.

When the frequency response functions have been calculated, the modal parameters can be estimated. The experimental modal analysis procedure used in the present work consists of two steps. In the first step, the number of modes, the damped natural frequencies and the associated damping factors are determined from the complete set of frequency response functions with the help of a singular value decomposition. A detailed description of this process is presented in [45]. The second step concerns the estimation of the modal parameters by curve fitting a mathematical modal-parameter model to all measured frequency response functions. The modal model in partial fraction form for a multi-degree of freedom system is given by $[46,47]$ :

$$
\boldsymbol{H}(\omega)=\sum_{n=1}^{N_{\text {modes }}}\left[\frac{\boldsymbol{R}_{n}}{j \omega-\lambda_{n}}+\frac{\boldsymbol{R}_{n}^{*}}{j \omega-\lambda_{n}^{*}}\right],
$$

where the frequency response function matrix $\boldsymbol{H}(\omega)$ is described in terms of a sum of individual modes. The number of modes $N_{\text {modes }}$ is equal to one for the massspring-damper system. The ${ }^{*}$ denotes the complex conjugate. During the curve fitting step, the numerator and denominator of Equation (2.10) are written in a polynomial form and are estimated by a least squared error fitting process, referred to as the global polynomial method [48]. If these polynomials fit to the measured frequency response functions then the modal parameters can be calculated. Each mode $n$ is represented by modal residues $\boldsymbol{R}_{n}$ and poles $\lambda_{n}$. The poles appear in complex conjugate pairs given by:

$$
\lambda_{n}, \lambda_{n}^{*}=-\sigma_{n} \pm j \omega_{\mathrm{d} n}=-\zeta_{n} \omega_{n} \pm j \omega_{n} \sqrt{1-\zeta_{n}^{2}},
$$




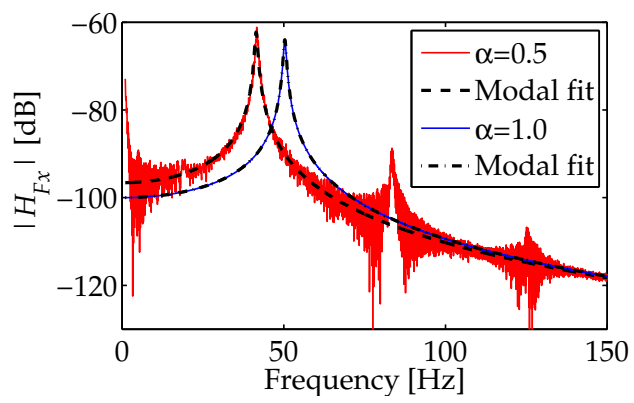

Figure 2.11 The curve fitted modal model and the magnitude of the original frequency response functions between the harmonic sweep $\left(f_{\mathrm{a}}=1-150 \mathrm{~Hz}\right)$ excitation and the displacement response of a mass-springdamper system with a linear $(\alpha=1.0)$ and a bilinear $(\alpha=0.5)$ stiffness.

where $\sigma_{n}$ is the damping factor, $\omega_{\mathrm{d} n}$ is the damped natural frequency, $\omega_{n}$ is the undamped natural frequency and $\zeta_{n}$ the relative damping of mode $n$. The residue matrix $\boldsymbol{R}_{n}$ describes the mode strength and is related to the mode shape vector [49]:

$$
\boldsymbol{R}_{n}=Q_{n} \boldsymbol{\psi}_{n} \boldsymbol{\psi}_{n}^{\mathrm{T}}
$$

where $Q_{n}$ is a scaling constant and $\psi_{n}$ is the mode shape vector for the $n^{\text {th }}$ mode.

The curve fitted mathematical model and the original frequency response function for the linear $(\alpha=1.0)$ and bilinear $(\alpha=0.5)$ mass-spring-damper system are presented in Figure 2.11. The frequency responses are reduced to a set of modal parameters as shown in Table 2.3. The modal vectors are not presented here because a single degree of freedom system is considered. An exact description is obtained for the linear system. The modal representation of the bilinear system, however, largely ignores the nonlinear effects and only provides a linear description of the nonlinear system. The estimated natural frequency corresponds to a linear system with a stiffness of $k=0.68 \cdot 10^{5} \mathrm{~N} \mathrm{~m}^{-1}$ (32\% degradation). This stiffness is essentially the result of a variable stiffness $\left(k=1.0 \cdot 10^{5}\right.$ and $\left.\alpha k=0.5 \cdot 10^{5} \mathrm{~N} \mathrm{~m}^{-1}\right)$ within each oscillation and therefore provides an incorrect characterization of the damage. These results show that the modal parameter changes can be used to indicate the presence of structural changes, but that the information is reduced

Table 2.3 Modal parameters estimated by curve fitting the modal model to the frequency response functions of the linear $(\alpha=1.0)$ and the nonlinear $(\alpha=0.5)$ system.

\begin{tabular}{lccc}
\hline Case & \multicolumn{2}{c}{ Modal model } & Analytical \\
& $f_{n}[\mathrm{~Hz}]$ & $\zeta_{n}[\%]$ & $f_{n}[\mathrm{~Hz}]$ \\
\hline Linear $(\alpha=1.0)$ & 50.33 & 0.79 & 50.33 \\
Bilinear $(\alpha=0.5)$ & 41.46 & 0.96 & - \\
\hline
\end{tabular}


beyond the point where it allows for an adequate description of the damaged system. This is primarily the case when damage causes severe nonlinear dynamic effects. An adequate description is obtained if weakly nonlinear dynamic effects are present.

\subsection{Concluding remarks}

An overview of vibration based structural health monitoring techniques is presented in this chapter. A generalized description of a damaged system is used to explain the basic concept of this technology. Damage identification aims to maximize the correlation between the damage and the damage sensitive feature, while it is also desired to condense the measured responses to a low dimensional parameter space. Both aspects are considered in the selection of an appropriate damage identification method for the skin-stiffener structure as considered in this thesis.

The literature study in Section 2.3 revealed that mode shape curvatures combined with the modal strain energy damage index algorithm are a potentially powerful damage feature and classifier for damage identification. A basic analytical model of a delaminated composite beam revealed that mode shape curvatures can show clear discontinuities at the boundaries of the delaminated region in the case of flexural vibrations. These discontinuities cause mode shape curvatures to be a strong indicator for the presence, location and size of the delaminated region compared to, for example, deviations in the mode shapes themselves. However, when severe nonlinear dynamic effects are introduced by the damage, the modal domain based methods suffer under their linear system assumption. Alternative methods in, for example, the time or frequency domain are in that case required to obtain a more adequate description of the nonlinear dynamic behavior introduced by the damage.

\section{References}

[1] D. Montalvão, N.M.M. Maia, and A.M.R. Ribeiro. A review of vibration-based structural health monitoring with special emphasis on composite materials. Shock and Vibration Digest, 38(4):295-326, 2006.

[2] Y. Zou, L. Tong, and G.P. Steven. Vibration-based model-dependent damage (delamination) identification and health monitoring for composite structures - A review. Journal of Sound and Vibration, 230(2):357-378, 2000.

[3] C.-P. Fritzen and P. Kraemer. Self-diagnosis of smart structures based on dynamical properties. Mechanical Systems and Signal Processing, 23(6):1830-1845, 2009.

[4] C.R. Farrar, H. Sohn, F.M. Hemez, M.C. Anderson, M.T. Bement, P.J. Cornwell, S.W. Doebling, J.F. Schultze, N. Lieven, and A.N. Robertson. Damage prognosis: current status and future needs. Technical report, Los Alamos National Laboratory, Los Alamos, NM, 2001. 
[5] S.W. Doebling, C.R. Farrar, M.B. Prime, and D.W. Shevitz. Damage identification and health monitoring of structural and mechanical systems from changes in their vibration characteristics: a literature review. Technical report, Los Alamos National Laboratory, NM, USA, 1996.

[6] S.W. Doebling, C.R. Farrar, and M.B. Prime. A summary review of vibration-based damage identification methods. The Shock and Vibration Digest, 30(2):91-105, 1998.

[7] H. Sohn, C.R. Farrar, F.M. Hemez, D.D. Shunk, D. Stinemans, and B.R. Nadler. A review of structural health monitoring literature: 1996-2001. Technical report, Los Alamos National Laboratory, Los Alamos, NM, 2003.

[8] E.P. Carden and P. Fanning. Vibration based condition monitoring: a review. Structural Health Monitoring, 3(4):355-377, 2004.

[9] W. Fan and P. Qiao. Vibration-based damage identification methods: a review and comparative study. Structural Health Monitoring, 10(1):83-111, 2011.

[10] C. Boller, F.-K. Chang, and Y. Fujino. Encyclopedia of structural health monitoring. John Wiley \& Sons, Ltd, Chichester, UK, 2009.

[11] D. Balageas, C.-P. Fritzen, and A. Güemes. Structural health monitoring. ISTE Ltd, 2006.

[12] Y.Y. Li. Hypersensitivity of strain-based indicators for structural damage identification: a review. Mechanical Systems and Signal Processing, 24(3):653-664, 2010.

[13] K. Worden, C.R. Farrar, J. Haywood, and M. Todd. A review of nonlinear dynamics applications to structural health monitoring. Structural Control and Health Monitoring, 15:540-567, 2008.

[14] K.-Y. Jhang. Nonlinear ultrasonic techniques for nondestructive assessment of micro damage in material: a review. Precision Engineering and Manufacturing, 10(1):123-135, 2009.

[15] R.D. Adams, D. Walton, J.E. Flitcroft, and D. Short. Vibration testing as a nondestructive test tool for composite materials. ASTM Special Technical Publication 580, Composite Reliability, pages 159-175, 1975.

[16] P. Cawley and R.D. Adams. The location of defects in structures from measurements of natural frequencies. Journal of Strain Analysis, 14(2):49-57, 1979.

[17] P. Cawley and R.D. Adams. A vibration technique for non-destructive testing of fibre composite structures. Journal of Composite Materials, 13(2):161-175, 1979.

[18] P. Cawley and R.D. Adams. Improved frequency resolution from transient tests with short record lengths. Journal of Sound and Vibration, 64(1):123-132, 1979.

[19] S.D. Fassois and J.S. Sakellariou. Time-series methods for fault detection and identification in vibrating structures. Philosophical Transactions of the Royal Society A: Mathematical, Physical and Engineering Sciences, 365(1851):411-48, 2007.

[20] M. Rucka and K. Wilde. Application of continuous wavelet transform in vibration based damage detection method for beams and plates. Journal of Sound and Vibration, 297(3-5):536-550, 2006.

[21] H.F. Hu, W.J. Staszewski, N.Q. Hu, R.B. Jenal, and G.J. Qin. Crack detection using nonlinear acoustics and piezoceramic transducers - Instantaneous amplitude and frequency analysis. Smart Materials and Structures, 19(6):065017, 2010.

[22] C.R. Farrar and D.A. Jauregui. Comparative study of damage identification algorithms applied to a bridge: I. Experiment. Smart Materials and Structures, 7:704-719, 1998.

[23] C.R. Farrar and D.A. Jauregui. Comparative study of damage identification algorithms applied to a bridge: II. Numerical study. Smart Materials and Structures, 7:720-731, 1998.

[24] A. Alvandi and C. Cremona. Assessment of vibration-based damage identification 
techniques. Journal of Sound and Vibration, 292(1-2):179-202, 2006.

[25] J. Humar, A. Bagchi, and H. Xu. Performance of vibration-based techniques for the identification of structural damage. Structural Health Monitoring, 5(3):215-241, 2006.

[26] J.-M. Ndambi, J. Vantomme, and K. Harri. Damage assessment in reinforced concrete beams using eigenfrequencies and mode shape derivatives. Engineering Structures, 24(4):501-515, 2002.

[27] A.P. Adewuyi, Z. Wu, and N.H.M. Kammrujaman Serker. Assessment of vibration-based damage identification methods using displacement and distributed strain measurements. Structural Health Monitoring, 8(6):443-461, 2009.

[28] N. Stubbs and C.R. Farrar. Field verification of a nondestructive damage localization and severity estimation algorithm. In Proceedings of the 13th International Modal Analysis Conference (IMAC XIII), pages 210-218, 1995.

[29] P.J. Cornwell, S.W. Doebling, and C.R. Farrar. Application of the strain energy damage detection method to plate-like structures. Journal of Sound and Vibration, 224(2):359-374, 1999.

[30] O.S. Salawu. Detection of structural damage through changes in frequency: a review. Engineering Structures, 19(9):718-723, 1997.

[31] E. Parloo, P. Guillaume, and M. van Overmeire. Damage assessment using mode shape sensitivities. Mechanical Systems and Signal Processing, 17(3):499-518, 2003.

[32] L.M. Khoo, P.R. Mantena, and P. Jadhav. Structural damage assessment using vibration modal analysis. Structural Health Monitoring, 3(2):177-194, 2004.

[33] A.K. Pandey and M. Biswas. Damage detection in structures using changes in flexibility. Journal of Sound and Vibration, 169(1):3-17, 1994.

[34] T. Toksoy and A.E. Aktan. Bridge-condition assessment by modal flexibility. Experimental Mechanics, 34(3):271-278, 1994.

[35] F.N. Catbas, M. Gul, and J.L. Burkett. Damage assessment using flexibility and flexibility-based curvature for structural health monitoring. Smart Materials and Structures, 17(1):1-12, 2008.

[36] A.K. Pandey, M. Biswas, and M.M. Samman. Damage detection from changes in curvature mode shapes. Journal of Sound and Vibration, 145(2):321-332, 1991.

[37] M.M. Abdel Wahab and G. De Roeck. Damage detection in bridges using modal curvatures: application to a real damage scenario. Journal of Sound and Vibration, 226(2):217-235, 1999.

[38] C.N. Della and D. Shu. Vibration of delaminated composite laminates: a review. Applied Mechanics Reviews, 60(1-6):1-20, 2007.

[39] P.M. Mujumdar and S. Suryanarayan. Flexural vibrations of beams with delaminations. Journal of Sound and Vibration, 125(3):441-461, 1988.

[40] W.J.B. Grouve, L.L. Warnet, A. de Boer, R. Akkerman, and J. Vlekken. Delamination detection with fibre Bragg gratings based on dynamic behaviour. Composites Science and Technology, 68(12):2418-2424, 2008.

[41] W. Lestari, P. Qiao, and S. Hanagud. Curvature mode shape-based damage assessment of carbon/epoxy composite beams. Journal of Intelligent Material Systems and Structures, 18(3):189-208, 2007.

[42] N. Krohn, R. Stoessel, and G. Busse. Acoustic non-linearity for defect selective imaging. Ultrasonics, 40(1-8):633-7, 2002.

[43] Á. Cunha and E. Caetano. Experimental modal analysis of civil engineering structures. 
Sound and Vibration, pages 12-20, 2006.

[44] B.J. Schwarz and M.H. Richardson. Experimental modal analysis. In CSI Reliability Week, Orlando, FL, pages 1-12, 1999.

[45] R.J. Allemang and D.L. Brown. A complete review of the complex mode indicator function (CMIF) with applications. In Proceedings of International Conference on Noise and Vibration Engineering (ISMA2006), pages 3209-3246. Leuven, 2006.

[46] M.H. Richardson and D.L. Formenti. Parameter estimation from frequency response measurements using rational fraction polynomials. In Proceedings of the 1st International Modal Analysis Conference (IMAC I), pages 1-15, 1982.

[47] M.H. Richardson and B.J. Schwarz. Modal parameter estimation from operating data. Sound and Vibration, 37(1):28-39, 2003.

[48] M.H. Richardson and D.L. Formenti. Global curve fitting of frequency response measurements using the rational fraction polynomial method. In 3rd International Modal Analysis Conference, pages 1-8, 1985.

[49] B. Schwarz and M. Richardson. Scaling mode shapes obtained from operating data. Sound and Vibration, 37(11):18-23, 2003. 


\title{
CHAPTER 3
}

\section{Vibration based structural health monitoring of a composite T-beam ${ }^{1}$}

\begin{abstract}
A vibration based damage identification method is investigated experimentally for a 2.5-dimensional composite structure. The dynamic response of an intact and a locally delaminated 16-layer unidirectional carbon fiber PEKK reinforced T-beam is considered. A force-vibration set-up, including a laser vibrometer system, is employed to measure the dynamic behavior of the T-beam. The modal strain energy damage index (MSE-DI) algorithm is applied using the bending and torsion modes. Special attention is paid to the effect of the number of measurement points required to detect and localize the delamination accurately.
\end{abstract}

1 Reproduced from: T.H. Ooijevaar, R. Loendersloot, L.L. Warnet, A. Boer, R. Akkerman. Vibration based structural health monitoring of a composite T-beam. Composite Structures, 92(9):2007-2015, 2010. 


\subsection{Introduction}

Development of structural health monitoring (SHM) technologies for composite based structural components for aircraft is one of the objectives of the European research program Clean Sky, Eco-Design ITD. An increase of the part's service life reduces its cost and long-term ecological impact.

One of the key issues in composite structures is the early detection and localization of damage. Often service induced damage does not involve visible plastic deformation, but internal matrix related damage, like transverse cracks and delaminations. Their detection imposes costly maintenance techniques. Vibration based damage identification methods are promising as an alternative for the timeconsuming and costly nondestructive testing (NDT) methods currently available. These methods also offer the potential to be used as a real-time health monitoring system. The change of the dynamic properties is employed to identify damage such as delaminations.

Grouve et al. [1] used a vibration based structural health monitoring technique by monitoring shifts in natural frequencies to detect a delamination in a simple composite beam structure. However, it is often complicated to localize damage uniquely. Stubbs et al. [2] proposed a technique which is capable of detecting and localizing damage in beam-like one-dimensional structures. They were the first to introduce a damage identification method based on the observation that local changes in the modal strain energy of the vibration modes of a structure are a sensitive indicator of damage. Cornwell et al. [3] extended the method for plate-like, hence two-dimensional, structures. Only recently, the step to three-dimensional frame structures was made $[4,5]$.

Until now, the modal strain energy damage index (MSE-DI) algorithm is hardly used on anisotropic, composite structures. Moreover, this methodology is mainly applied to one-dimensional beam and two-dimensional plate-like structures with only flexural vibrations. The question is whether the methodology is applicable for more complex and larger structures with a minimum amount of sensors. A step in this direction is to consider a 2.5-dimensional composite beam structure with a more general deformation pattern, including bending and torsion, in order to extract a maximum of damage related information from the measured vibration modes. Duffey et al. [6] are the only ones who included torsion modes and vibrations in their research. Torsion vibrations can become rather complex and tend to be more difficult to measure. However, beside bending modes, torsion modes could also provide damage related information. This could become advantageous, in particular for larger structures, if the number of measurable vibration modes is limited and the number of sensors is to be reduced. Therefore it is also important to investigate the effect of the number of measurement points on the damage identification results.

This chapter mainly presents the experimental work performed at the University 
of Twente. It reports on the application of the modal strain energy damage index algorithm, applied to a 2.5-dimensional composite structure vibrating under bending and torsion modes, in order to detect and localize a delamination. An experimental set-up around an intact and delaminated T-beam is used for this purpose. Use is made of an external measurement device for the characterization of the dynamic behavior, in order to easily vary the amount of measurement points. The results obtained in this study will set requirements on the methods and the instrumentation necessary to apply the method in a structural health monitoring environment.

\subsection{The modal strain energy damage index algorithm}

The strain energy of a vibration mode is referred to as the modal strain energy of that mode. Consequently, the total modal strain energy is the sum of the modal strain energy contributions of all modes considered. The modal strain energy is calculated by linking the deformation of a structure to the strain. A distinction can be made between axial, flexural and torsional deformation-strain relations [6]. Only the bending and the torsional deformations are considered in the present work. The mechanical relations read (see Figure 3.1 for the coordinate system used):

$$
\frac{\partial^{2} u_{x / y}}{\partial z^{2}}=\frac{M_{y / x}}{E I_{y / x}} \quad, \quad \frac{\partial \theta_{x y}}{\partial z}=\frac{T_{z}}{G J_{x y}}
$$

with $u$ the displacement, $\theta$ the rotation, $M$ the bending moment, $T$ the torque, $E I$ and $G J$ respectively the bending and torsion rigidity of the beam. The subscript ' $(x / y)^{\prime}$ refers either to $x$ or $y$. The rotation angle for small rotations is defined as: $\theta_{x y}(z)=\partial u_{y}(x, z) / \partial x$. The strain energies for the bending and torsional deformations are obtained by integrating the squared strains over the length $l$ of the structure [6]:

$$
U_{\mathrm{B}}=\frac{1}{2} \int_{0}^{l} E I_{y / x}\left(\frac{\partial^{2} u_{x / y}}{\partial z^{2}}\right)^{2} \mathrm{~d} z \quad, \quad U_{\mathrm{T}}=\frac{1}{2} \int_{0}^{l} G J_{x y}\left(\frac{\partial \theta_{x y}}{\partial z}\right)^{2} \mathrm{~d} z
$$

Consider the structure to vibrate in the $n^{\text {th }}$ bending mode. The modal strain energy of this bending mode is given by:

$$
U_{\mathrm{B}}^{(n)}=\frac{1}{2} \int_{0}^{l} E I_{y / x}\left(\frac{\partial^{2} u_{x / y}^{(n)}}{\partial z^{2}}\right)^{2} \mathrm{~d} z
$$


with $u_{x / y}^{(n)}(z)$ the normalized amplitude of the mode shape. Subsequently, the structure is discretized in $N$ elements in axial direction (i.e. $z$-coordinate). The strain energy $U_{\mathrm{B}, i}^{(n)}$ for the $n^{\text {th }}$ mode and associated with the $i^{\text {th }}$ element is then given by:

$$
U_{\mathrm{B}, i}^{(n)}=\frac{1}{2} \int_{z_{i-1}}^{z_{i}} E I_{y / x}\left(\frac{\partial^{2} u_{x / y}^{(n)}}{\partial z^{2}}\right)^{2} \mathrm{~d} z \quad \text { with: } \quad U_{\mathrm{B}}^{(n)}=\sum_{i=1}^{N} U_{\mathrm{B}, i}^{(n)},
$$

and $z_{i-1}, z_{i}$ the boundaries of element $i$ of the discretized structure in $z$-direction. Similar quantities can be defined for a damaged structure, using the normalized mode shapes $\tilde{u}^{(n)}$ of the damaged structure. The local fractional strain energies, as defined by Cornwell et al. [3], are:

$$
F_{\mathrm{B}, i}^{(n)}=\frac{U_{\mathrm{B}, i}^{(n)}}{U_{\mathrm{B}}^{(n)}} \quad, \quad \tilde{F}_{\mathrm{B}, i}^{(n)}=\frac{\tilde{U}_{\mathrm{B}, i}^{(n)}}{\tilde{U}_{\mathrm{B}}^{(n)}},
$$

for the intact and damaged structure respectively. The fractional strain energy remains relatively constant in the undamaged elements, under the assumption that the damage is small and primarily located at element $k[3,7]$ :

$$
\tilde{F}_{\mathrm{B}, i}^{(n)} \approx F_{\mathrm{B}, i}^{(n)} \quad \text { for } \quad i \neq k .
$$

This equation is rearranged and after substituting Equations (3.3), (3.4) and (3.5) it can be derived that:

$$
1 \approx \frac{\int_{z_{i-1}}^{z_{i}} \widetilde{E I}_{y / x}\left(\partial^{2} \tilde{u}_{x / y}^{(n)} / \partial z^{2}\right)^{2} \mathrm{~d} z / \int_{0}^{l} \widetilde{E I}_{y / x}\left(\partial^{2} \tilde{u}_{x / y}^{(n)} / \partial z^{2}\right)^{2} \mathrm{~d} z}{\int_{z_{i-1}}^{z_{i}} E I_{y / x}\left(\partial^{2} u_{x / y}^{(n)} / \partial z^{2}\right)^{2} \mathrm{~d} z / \int_{0}^{l} E I_{y / x}\left(\partial^{2} u_{x / y}^{(n)} / \partial z^{2}\right)^{2} \mathrm{~d} z} \text { for } i \neq k,
$$

The mean value theorem for integrals [8] is applied to the flexural rigidities $E I_{y / x}(z)$ and $\widetilde{E I}_{y / x}(z)$ in Equation (3.7) to obtain an average rigidity estimate for each integral. For the integral over element $i$ of the pristine case:

$$
\int_{z_{i-1}}^{z_{i}} E I_{y / x}(z)\left(\partial^{2} u_{x / y}^{(n)} / \partial z^{2}\right)^{2} \mathrm{~d} z=E I_{y / x}\left(z_{0}\right) \int_{z_{i-1}}^{z_{i}}\left(\partial^{2} u_{x / y}^{(n)} / \partial z^{2}\right)^{2} \mathrm{~d} z,
$$

where $z_{0}$ is a point within the integration interval and $E I_{y / x}\left(z_{0}\right)=\left(E I_{y / x}\right)_{i}$ is the weighted average flexural rigidity of element $i$. Similar estimates can be obtained for the other integrals in Equation (3.7). Subsequently, a ratio of the flexural rigidities is obtained by assuming that the change in the average value of the flexural rigidity 
for the integrals over the entire length $l$ of the beam is negligible for small damage:

$$
\frac{\left(E I_{y / x}\right)_{i}}{\left(\widetilde{E I}_{y / x}\right)_{i}} \approx \frac{\int_{z_{i-1}}^{z_{i}}\left(\partial^{2} \tilde{u}_{x / y}^{(n)} / \partial z^{2}\right)^{2} \mathrm{~d} z / \int_{0}^{l}\left(\partial^{2} \tilde{u}_{x / y}^{(n)} / \partial z^{2}\right)^{2} \mathrm{~d} z}{\int_{z_{i-1}}^{z_{i}}\left(\partial^{2} u_{x / y}^{(n)} / \partial z^{2}\right)^{2} \mathrm{~d} z / \int_{0}^{l}\left(\partial^{2} u_{x / y}^{(n)} / \partial z^{2}\right)^{2} \mathrm{~d} z}=\frac{\tilde{\gamma}_{i}^{(n)} / \tilde{\gamma}^{(n)}}{\gamma_{i}^{(n)} / \gamma^{(n)}} \text { for } i \neq k,
$$

where $\gamma_{i}^{(n)}$ is the integral over element $i$ and $\gamma^{(n)}$ the integral over the entire length l. Stubbs et al. [2] and Cornwell et al. [3] used the right-hand side of Equation (3.9) to define a local damage index $\beta_{i}^{(n)}$. This indicator is approximately equal to 1 for the undamaged elements, i.e. $i \neq k$, but can change at the damaged element, i.e. $i=k$. Finally, the information of each mode shape is combined into a single damage index $\beta_{i}$ by using the definition proposed by Cornwell et al. [3], which is a summation over the number of modes $N_{\text {modes }}$ considered:

$$
\beta_{i}=\sum_{n=1}^{N_{\text {modes }}}\left[\tilde{\gamma}_{i}^{(n)} / \tilde{\gamma}^{(n)}\right] / \sum_{n=1}^{N_{\text {modes }}}\left[\gamma_{i}^{(n)} / \gamma^{(n)}\right] .
$$

The derivation of the damage indicator for the torsional deformations follows the same route. The starting point is the strain energy formulation for torsional deformations as presented in Equation (3.2).

\subsection{Composite T-beam structure}

The structure investigated in this work is a composite T-shaped stiffener section. This type of stiffener is frequently used in aerospace components to increase the bending stiffness of the component without a severe weight penalty. Recently, a new type of stiffener, depicted in Figure 3.1, was developed by Fokker Aerostructures, in collaboration with the Dutch National Aerospace Laboratories (NLR). The fabrication process for this type of stiffener is presented in [9]. This type of stiffener connection is referred to as a T-joint.

The T-beam is built from 16 individual plies of unidirectional co-consolidated carbon AS4D reinforced PEKK. A [0/90] $]_{4, \mathrm{~s}}$ lay-up is used for all specimens, see Figure 3.1. A PEKK injection molded filler is used as a connection. The lay-up was selected to create a structure with a relatively high bending rigidity and a relatively low torsional rigidity. The torsion modes will be more pronouncedly present, hence easier to detect. As a result, it is more straightforward to assess the feasibility of including the torsion modes in the analysis. The component is relatively long, so as to obtain a sufficient deflection to be measured conveniently with the equipment available at the laboratory of the University of Twente. The dimensions of the T- 


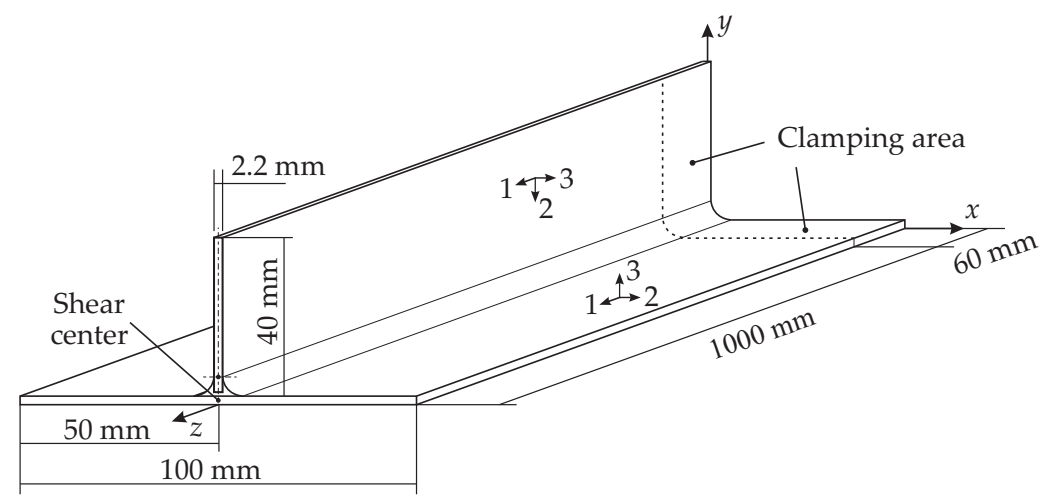

Figure 3.1 The composite T-beam with a $[0 / 90]_{4, s}$ laminate lay-up. The global and material coordinate systems are indicated.

beam are indicated in Figure 3.1.

A typical damage occurring to composite structures is delamination. The location with the highest risk of failure of the structure is the injection molded thermoplastic T-joint profile which connects the base to the stiffener. The aim of this research is to identify and localize such damage, hence undamaged and damaged Tbeams are manufactured. The damaged T-beam contains a $100 \mathrm{~mm}$ long artificial delamination, right under the T-joint. The location is indicated in Figure 3.2. The delamination was created by inserting a $0.1 \mathrm{~mm}$ thick Polyimide film before consolidating the beam in the autoclave.

\subsection{Experimental analysis of a sub-structure}

\subsubsection{Experimental outline}

Vibration measurements are performed on an intact and delaminated T-beam in order to detect and localize the delamination and to validate the numerical model and results [10]. The frequency response functions (FRFs) between the fixed

Side view

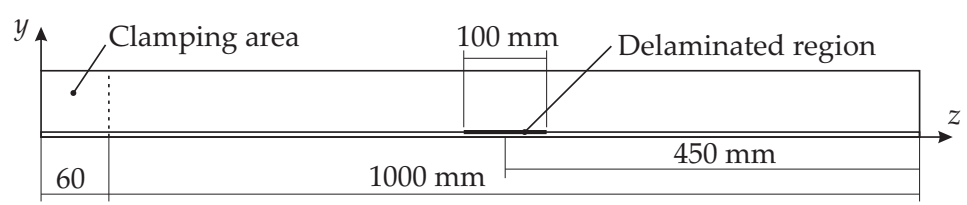

Figure 3.2 A side view of the composite T-beam. The location and dimensions of the artificial delamination at the T-joint are indicated. 
point of excitation and the measuring points along the T-beam are determined using a laser vibrometer. The modal parameters, i.e. the natural frequencies, the damping values and the mode shapes, are obtained from these frequency response functions by using experimental modal analysis (EMA) [11]. Firstly, the effect of the delamination on the natural frequencies and mode shapes is investigated. Secondly, the modal strain energy damage index algorithm is evaluated using the mode shape data from the intact and delaminated T-beam.

\subsubsection{Set-up and vibration measurements}

The complete dynamic set-up and data acquisition scheme used for the experimental validation are shown in Figure 3.3. The T-beam is horizontally and vertically clamped at one side employing the hydraulic clamps of an Instron 8516 Fatigue system. For all tests a $6 \mathrm{kN}$ vertical clamping force is combined with a clamping pressure of 200 bar applied to the horizontal clamps. These clamping conditions are obtained by analyzing the robustness of a frequency response plot to changes in the clamping conditions. The repeatability of the experimental set-up has been checked in Section 3.4.3. The T-beam was excited by a shaker with a stinger and force transducer connected to a fixed point at the beam and a spring connected to its support. A chirp excitation force has been applied to the structure. The laser vibrometer sensor head is mounted on a traverse system, which has a horizontal scanning range restricted to $590 \mathrm{~mm}$. The laser vibrometer is used to measure the velocities at an equally spaced measuring grid containing $3 \times 30$ points (L1/M1/R1 until L30/M30/R30, see Figure 3.4) within the range of the traverse system. These grid lines were selected to be able to distinguish between torsion and bending modes and to approximate the torsion angle. Two accelerometers, one at the point of excitation and one at grid point R1, were used for validation of the responses measured by the laser vibrometer. The frequency response functions between the excitation force at the fixed excitation point and the velocities at all laser vibrometer grid points are recorded by a Siglab system. A frequency range of $25-1025 \mathrm{~Hz}$, with a resolution of $0.313 \mathrm{~Hz}$ was selected. A measurement at each grid point consists of 20 averages, without overlap.

The modal parameters (i.e. natural frequency, mode shapes and damping values) were obtained from the FRFs by using experimental modal analysis [11, 12]. A Complex Mode Indicator Function (CMIF) together with a global curve fitting procedure, based on a Rational Fraction Polynomial (RFP) function [13], was used to estimate the poles and residue mode shape vectors. Slightly complex modal vectors were considered to be real normal, by neglecting non-proportional damping effects. The mode shapes from both T-beams were used for damage identification by the modal strain energy damage index algorithm. 


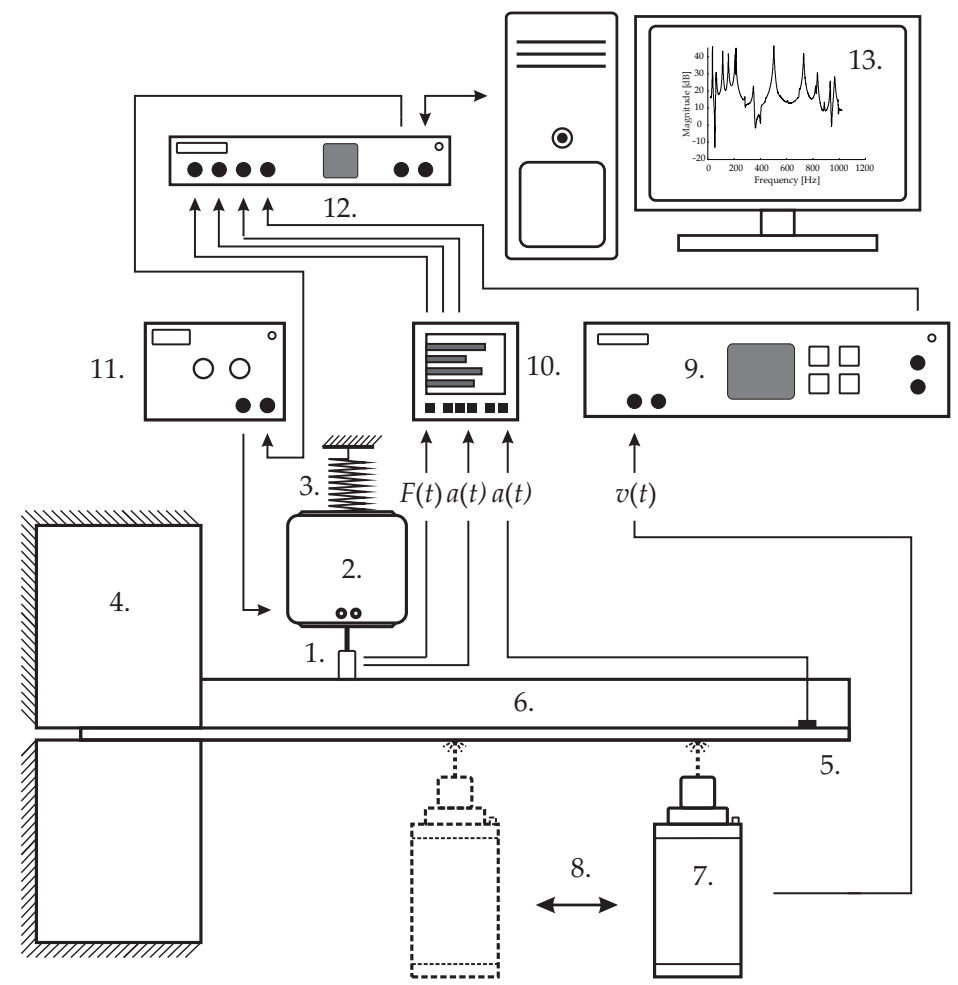

\begin{tabular}{|c|c|c|c|}
\hline No.Description & Hardware & No.Description & Hardware \\
\hline 1. Force transducer & B\&K 8001 & 8. Traverse system & Dantec \\
\hline 2. Shaker & B\&K 4809 & 9. Laser: controller & Polytec OFV 3001 \\
\hline 3. Spring & & 10. Conditioning amplifier & B\&K Nexus \\
\hline 4. Clamping device & Instron 8516 & 11. Power amplifier & B\&K 2706 \\
\hline 5. Accelerometer & B\&K 4517C-001 & 12. Data acquisition & Siglab Model 20-42 \\
\hline \multicolumn{2}{|c|}{ 6. Composite T-beam specimen } & \multicolumn{2}{|c|}{ 13. Computer, Siglab \& ME'scope Analysis Software } \\
\hline 7. Laser: sensor head & Polytec OFV-303 & & \\
\hline
\end{tabular}

Figure 3.3 Dynamic set-up and data acquisition systems used for the experimental investigation.

\subsubsection{Results}

\section{Repeatability of the testing approach and set-up}

The repeatability of the testing approach and experimental set-up is studied by performing separate tests with constant conditions at distinct times. The specimen was removed after each test. The resulting variations in the measured frequency response plots, natural frequencies and mode shapes give an indication of the repeatability of the testing method. 


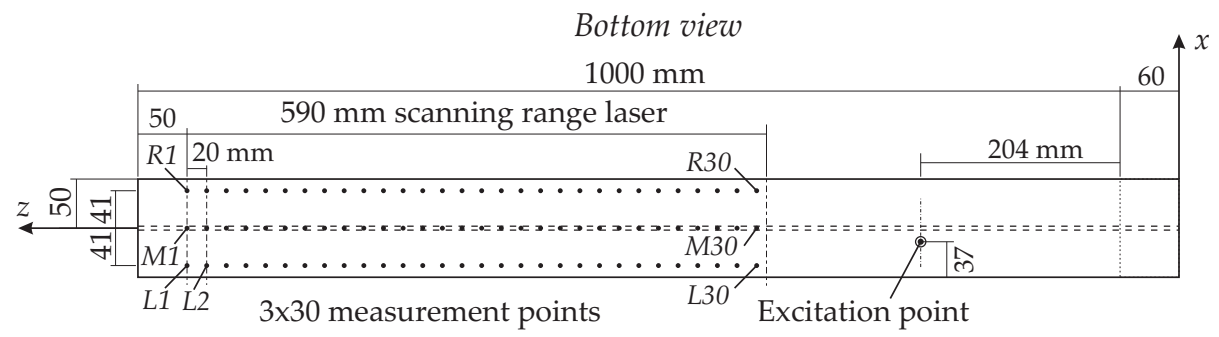

Figure 3.4 A bottom view of the composite T-beam. The location of the excitation point and the $3 \times 30$ measurement points is indicated.

First of all the repeatability on the frequency response plot was tested. Three tests were performed on each T-beam with the laser vibrometer positioned at grid point R1. Figure 3.5 shows the frequency response plots of the intact T-beam. The different curves compare well. The average standard deviation over all measured peak values was $0.56 \%$. Overall, the peak values of the torsion modes show a higher standard deviation (average: $0.75 \%$ ) than for the bending modes (average: $0.31 \%$ ). Even smaller standard deviations over the measured peak values (average $0.33 \%$ ) were found for the delaminated T-beam. The largest standard deviation in this case was $0.61 \%$ for the $5^{\text {th }}$ bending mode with an average frequency of $814.0 \mathrm{~Hz}$. The natural frequencies used for comparison of the intact and delaminated T-beam are obtained from curve fitted data of the complete set of $3 \times 30$ FRF measurements instead of a single FRF measurement. The standard deviations are of the same order of magnitude.

The repeatability on the mode shapes was assessed in terms of the modal assurance criterion (MAC). This criterion provides a measure for the degree of consistency between two modal vectors. A value close to one indicates a good correspondence between the modal vectors, whereas a value close to zero indicates that the modal

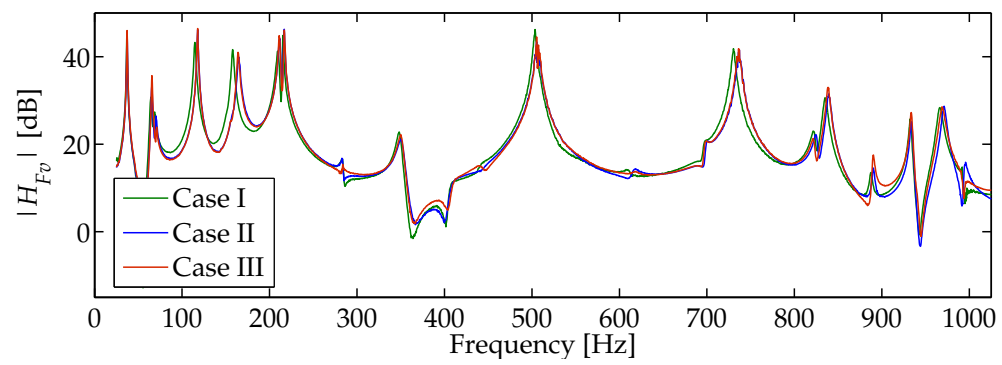

Figure 3.5 The repeatability of the frequency response function based on three measurements performed at grid point R1 of the pristine T-beam. 


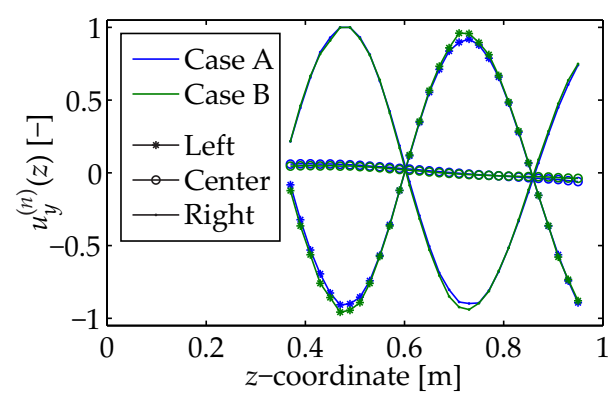

(a) $4^{\text {th }}$ torsion mode shape $(M A C=0.999)$.

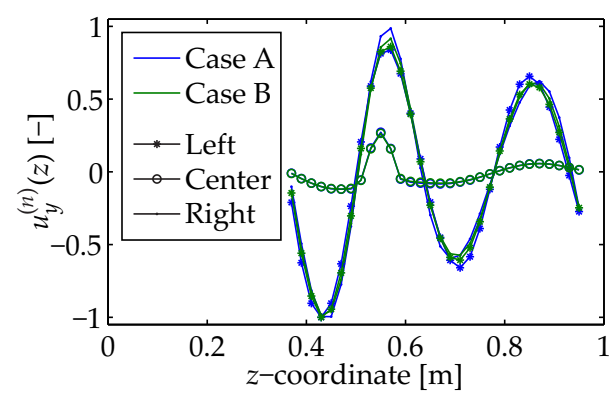

(b) $7^{\text {th }}$ bending mode shape $(M A C=0.995)$.

Figure 3.6 The repeatability of the (a) $4^{\text {th }}$ torsion and $(b)$ 7th bending mode shape of the delaminated T-beam measured at the $3 \times 30$ grid points according to the left, center and right grid line.

vectors are not consistent. The MAC criterion is defined as [14]:

$$
\operatorname{MAC}(m, n)=\frac{\left|\left(\boldsymbol{\psi}_{m}^{\mathrm{A}}\right)^{\mathrm{T}}\left(\boldsymbol{\psi}_{n}^{\mathrm{B}}\right)^{*}\right|^{2}}{\left(\boldsymbol{\psi}_{m}^{\mathrm{A}}\right)^{\mathrm{T}}\left(\boldsymbol{\psi}_{m}^{\mathrm{A}}\right)^{*}\left(\boldsymbol{\psi}_{n}^{\mathrm{B}}\right)^{\mathrm{T}}\left(\boldsymbol{\psi}_{n}^{\mathrm{B}}\right)^{*}},
$$

with $\psi_{m}^{\mathrm{A}}$ the modal vector of mode $m$ obtained at the first measurement (case A), $\psi_{n}^{\mathrm{B}}$ the modal vector of mode $n$ obtained at the second measurement (case B), ${ }^{*}$ the complex conjugate and ${ }^{\mathrm{T}}$ the transpose. Figures 3.6(a) and 3.6(b) show the comparison of two mode shape measurements for the $4^{\text {th }}$ torsion mode and the $7^{\text {th }}$ bending mode of the delaminated T-beam. The mode shapes of the two measurements correspond well. Overall, this holds also for the other measured bending and torsion mode shapes with, respectively, average $M A C$ values of 0.960 and 0.975 . Only a few mode shapes show slightly larger deviations. The reason for these deviations can be various. Possible explanations are the effects caused by the clamping, the spring tension of the shaker support, the positioning and alignment of the set-up and several other noise-sensitive aspects.

Since all average standard deviations do not exceed the $1 \%$ and the average $M A C$ values of the delaminated T-beam exceed the 0.950 , it is concluded that the natural frequencies and mode shapes obtained at the experimental set-up satisfy the demands in terms of repeatability. Results on the fabrication repeatability of the intact and delaminated T-beams are not available yet. Equal process conditions, materials and tools are used. The weight of the intact (518 grams) and delaminated (514 grams) T-beam correspond well. 


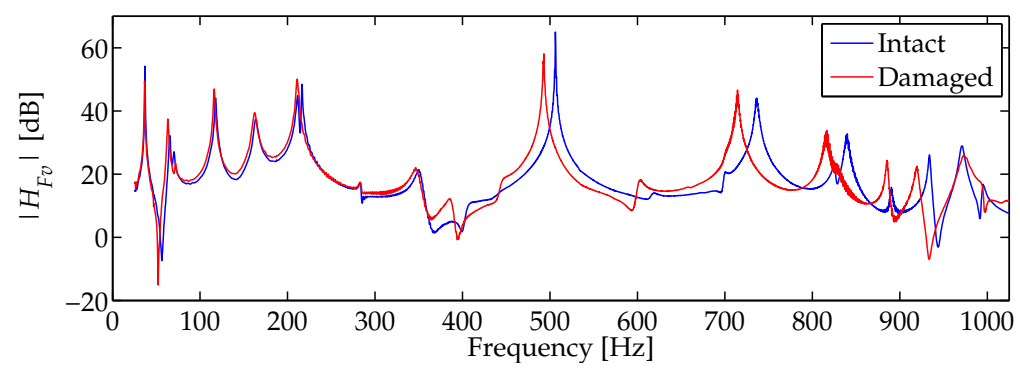

Figure 3.7 FRF comparison of the intact and delaminated T-beam at grid point R1.

\section{Damage identification based on modal parameters}

First of all the effect of the delamination on the natural frequencies and mode shapes is investigated. In Figure 3.7 the frequency response plots of the intact and delaminated T-beam at grid point R1 are compared. This figure indicates that the natural frequencies of the delaminated T-beams are lower than for the intact T-beam. Qualitatively this corresponds well with the literature $[15,16]$. It can also be observed that the difference in natural frequency is larger for higher modes.

Table 3.1 provides an overview of the natural frequencies $f^{(n)}$ and damping values $\zeta^{(n)}$ obtained from the curve fitted FRF data of the intact and delaminated T-beam. The frequencies are grouped based on their dominating type of mode shape. The bending modes in the $y z$-plane and torsion modes about the $z$-axis are respectively referred by $B_{y z}$ and $T_{z}$. Coupling between some successive modes was found. Some modes are experimentally not measured due to various reasons. The natural frequency of the first torsion mode is smaller than the lowest frequency of $25 \mathrm{~Hz}$ of the excitation signal. Other modes, like the $6^{\text {th }}$ torsion mode, are not measured because of the low response. In that case, the point of excitation almost coincides with a point of zero amplitude in the mode shape. This overview also confirms the shift in natural frequencies to lower values of the delaminated T-beam in the case of the bending modes. Note that the natural frequencies of the torsion modes hardly change. The delamination underneath the T-joint mainly affects the natural frequencies of the bending modes and has less influence on the natural frequencies of the torsion modes. Numerical results presented in [10] confirm this conclusion. This observation can be explained by the fact that the delamination is located close to the shear center of the cross section of the T-beam. The (viscous) damping values $\zeta^{(n)}$ are also determined (see Table 3.1) but no solid conclusions could be drawn from these values. The statistic variations exceed the changes caused by the delamination.

Each mode of the intact and delaminated T-beam, mentioned in Table 3.1, is related to a mode shape. A selection of experimentally obtained mode shapes is shown in Figures 3.8, 3.9 and 3.10. The mode shapes are determined for a section of the 
Table 3.1 Experimentally obtained natural frequencies $f^{(n)}$ and damping values $\zeta^{(n)}$ of mode $n$.

\begin{tabular}{|c|c|c|c|c|c|c|c|c|}
\hline \multirow[b]{2}{*}{$\begin{array}{c}\text { Mode } \\
n\end{array}$} & \multicolumn{4}{|c|}{ Intact T-beam } & \multicolumn{4}{|c|}{ Delaminated T-beam } \\
\hline & $\begin{array}{l}\text { Bendin } \\
f_{\mathrm{B}}^{(n)}[\mathrm{Hz}]\end{array}$ & $\begin{array}{l}\lg B_{y z} \\
\zeta_{\mathrm{B}}^{(n)}[\%]\end{array}$ & $f_{\mathrm{T}}^{(n)} \begin{array}{l}\text { Torsic } \\
{[\mathrm{Hz}]}\end{array}$ & $\begin{array}{l}T_{z} \\
\zeta_{\mathrm{T}}^{(n)}[\%]\end{array}$ & $\begin{array}{c}\text { Bendir } \\
\tilde{f}_{\mathrm{B}}^{(n)}[\mathrm{Hz}]\end{array}$ & $\begin{array}{l}\lg B_{y z} \\
\tilde{\zeta}_{\mathrm{B}}^{(n)}[\%]\end{array}$ & $\begin{array}{ll} & \text { Torsic } \\
\tilde{f}_{\mathrm{T}}^{(n)} & {[\mathrm{Hz}]}\end{array}$ & $\begin{array}{l}\mathrm{n}_{z} \\
\tilde{\zeta}_{\mathrm{T}}^{(n)}[\%]\end{array}$ \\
\hline 1 & 37.2 & 0.272 & - & - & 36.7 & 0.414 & - & - \\
\hline 2 & 217 & 0.194 & 65.5 & 1.014 & $211^{1}$ & 0.387 & 63.1 & 0.917 \\
\hline 3 & 506 & 0.018 & 117.8 & 0.602 & 493 & 0.079 & 116.1 & 0.532 \\
\hline 4 & 736 & 0.239 & 163.7 & 1.124 & 714 & 0.197 & 162.1 & 1.111 \\
\hline 5 & 840 & 0.254 & 212 & 0.494 & 816 & 0.200 & $211^{1}$ & 0.387 \\
\hline 6 & - & - & - & - & 886 & 0.048 & - & - \\
\hline 7 & 934 & 0.131 & 351 & 0.210 & 920 & 0.198 & 348 & 0.095 \\
\hline 8 & 994 & 0.172 & - & - & 996 & 0.209 & 444 & 0.942 \\
\hline 9 & - & - & 616 & 0.726 & - & - & 601 & 0.619 \\
\hline 10 & - & - & 699 & 0.124 & - & - & 699 & 0.018 \\
\hline 11 & - & - & 826 & 0.256 & - & - & 827 & 0.001 \\
\hline 12 & - & - & 971 & 0.273 & - & - & 973 & 0.538 \\
\hline
\end{tabular}

1 The mode shapes of these modes showed clear coupling between the bending and torsion mode.

T-beam due to the limited scanning range of the laser vibrometer. In most cases it is possible to extrapolate the mode shapes, supported by the numerical model [10].

It is observed that the difference in mode shapes, caused by the delamination, is less for the lowest frequencies. Mainly the mode shapes at higher frequencies are affected, but every mode shape is affected differently by the delamination. The $4^{\text {th }}$ and higher bending mode shapes $\left(f_{\mathrm{B}}^{(n)}>700 \mathrm{~Hz}\right)$ clearly show the presence, location and size of the delamination in the T-beam. The global behavior of the T-beam is affected by the local delamination. This implies that measurements at the left and right grid line, at a certain distance from the local delamination, can be used to indicate the delamination. The $9^{\text {th }}$ torsion mode shape (Figure 3.10) is nearly the only torsion mode shape which is clearly affected by the delamination. The wave of the mode shape nicely coincides with the position of the delamination. These observations match well with the conclusions drawn from the natural frequencies.

\section{Damage identification employing the MSE-DI algorithm}

The mode shapes from the intact and delaminated T-beam are used for damage identification by the modal strain energy damage index algorithm, presented in Section 3.2. One of the advantages of this algorithm is that damage related information of separate modes is combined to obtain a damage index distribution, using Equation (3.10). The required derivatives of the mode shapes are obtained after applying a cubic spline interpolation (piecewise function) to the data points of 

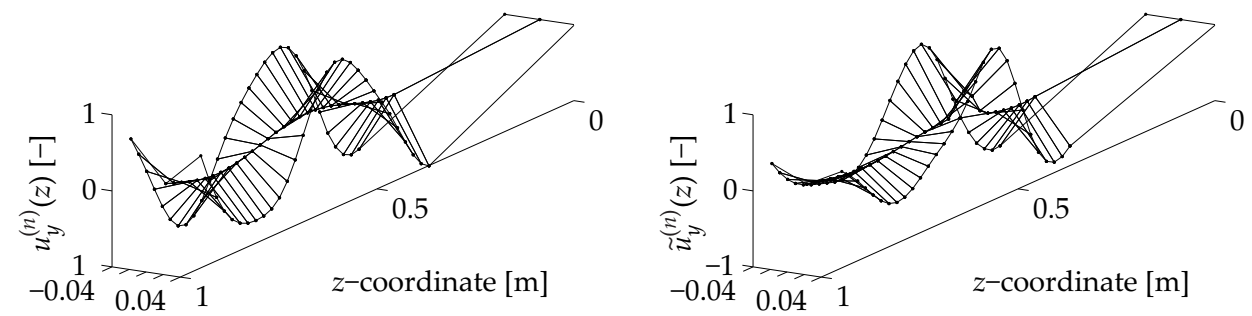

$x$-coordinate $[\mathrm{m}]$

$x$-coordinate $[\mathrm{m}]$

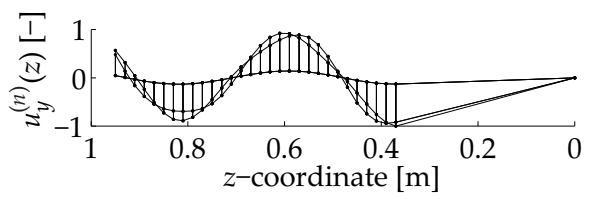

(a) $\operatorname{Intact}\left(f_{\mathrm{B}}^{(5)}=840 \mathrm{~Hz}\right)$.

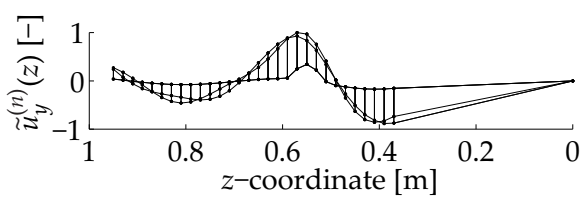

(b) Delaminated $\left(\tilde{f}_{\mathrm{B}}^{(5)}=816 \mathrm{~Hz}\right)$.

Figure 3.8 Experimentally obtained $5^{\text {th }}$ bending mode shapes $(M A C=0.852)$.
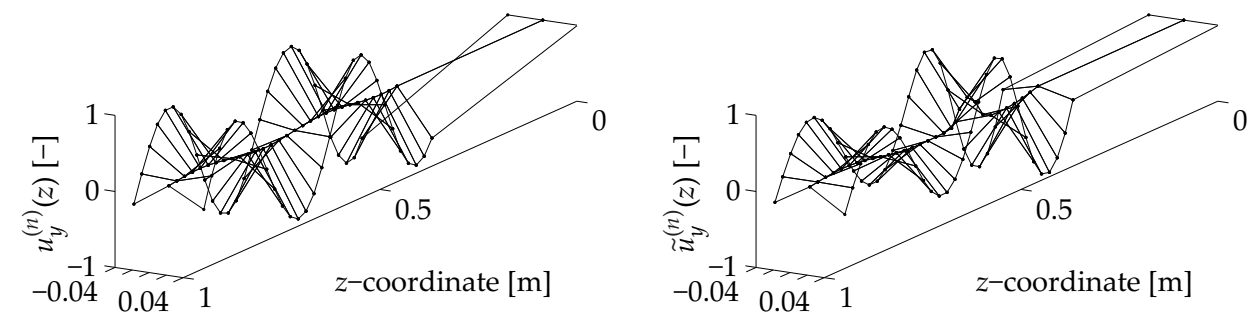

$x$-coordinate $[\mathrm{m}]$

$x$-coordinate $[\mathrm{m}]$
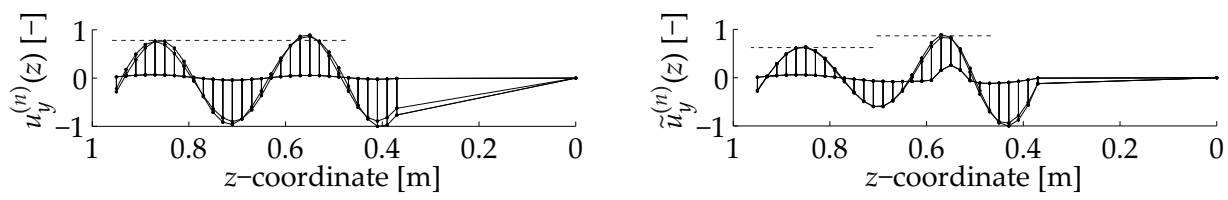

(a) Intact $\left(f_{\mathrm{B}}^{(7)}=934 \mathrm{~Hz}\right)$.

(b) Delaminated $\left(\tilde{f}_{\mathrm{B}}^{(7)}=920 \mathrm{~Hz}\right)$.

Figure 3.9 Experimentally obtained $7^{\text {th }}$ bending mode shapes $(M A C=0.833)$. 

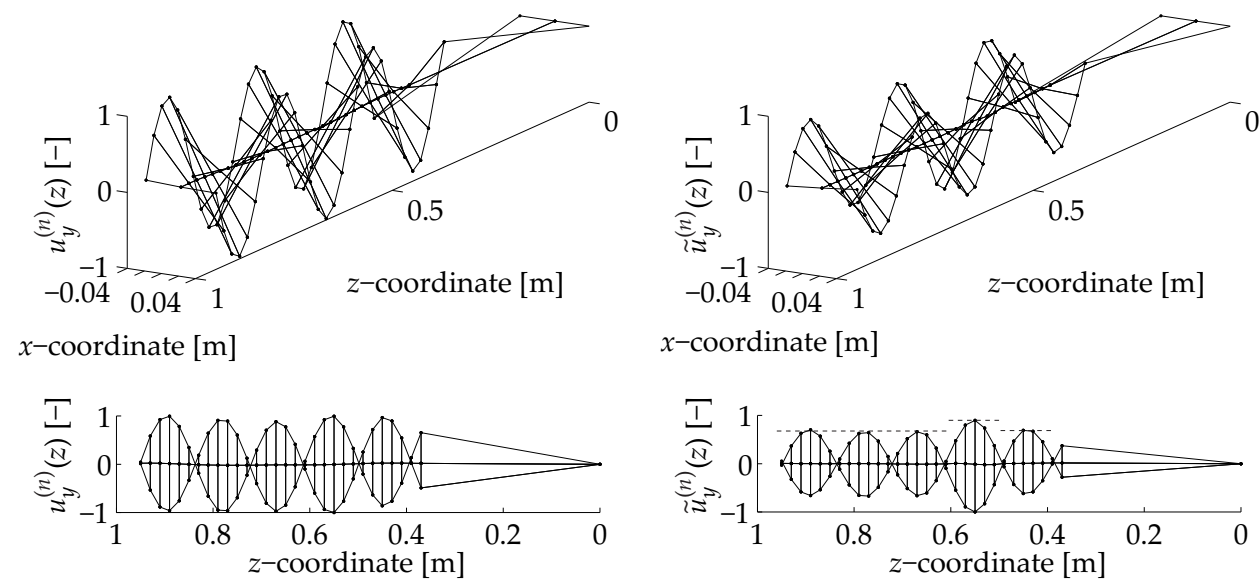

(a) $\operatorname{Intact}\left(f_{\mathrm{T}}^{(9)}=616 \mathrm{~Hz}\right)$.

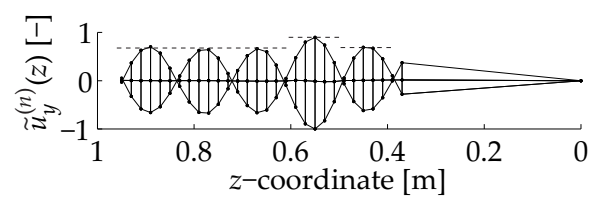

(b) Delaminated $\left(\tilde{f}_{\mathrm{T}}^{(9)}=601 \mathrm{~Hz}\right)$.

Figure 3.10 Experimentally obtained $9^{\text {th }}$ torsion mode shapes $(M A C=0.971)$.

the mode shapes. The interpolation is used to improve the calculation of the mode shape derivatives at discrete points in the $z$-direction. In the analysis, the scanning area is subdivided into 40 elements.

The results obtained by considering only the $4^{\text {th }}, 5^{\text {th }}, 7^{\text {th }}$ and $8^{\text {th }}$ bending dominated mode shapes and the full set of $3 \times 30$ grid points, are shown in Figure 3.11. The mode shapes of the lowest bending modes are not taken into account. These modes show some coupling or other kind of distortions and contain less information about the presence and location of the delamination. The data obtained at the center grid line clearly identifies the presence, location and size of the delamination. This is mainly due to the fact that the measuring points are close to the delamination. The left and right grid line also show higher damage indices at the delaminated region, apart from some fitting related artifacts. The ratio between the damage index of the damaged area and the intact area is lower, but the location is still predicted correctly. It was shown that the value of the damage index is a measure for the sensitivity to identify damage at a certain distance from the measurement points.

The same analysis is performed by using less data points. Figure 3.12 shows the results obtained by using $3 \times 30,3 \times 15,3 \times 10,3 \times 8,3 \times 6$ and $3 \times 5$ equally spaced measurement points at each grid line to define the mode shape of the T-beam. The bending modes incorporated into the analysis remains unchanged. The ratio between the damage indices of the damaged area and the intact area is lower for a decreasing number of data points. It is shown that the number of measurement points affects the sensitivity to identify damage at a certain distance from the 


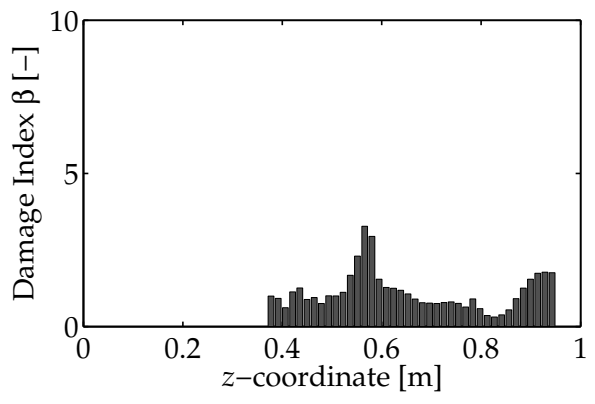

(a) Left grid line.

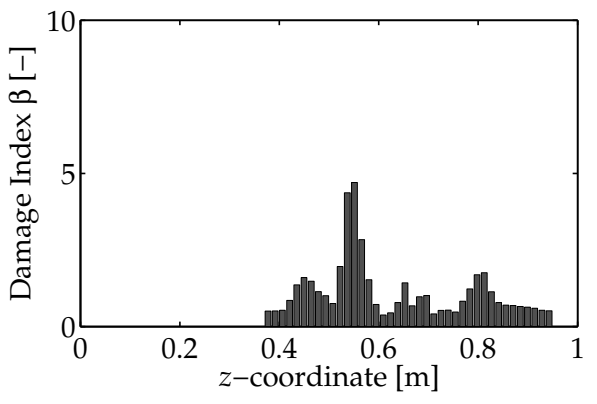

(b) Right grid line.

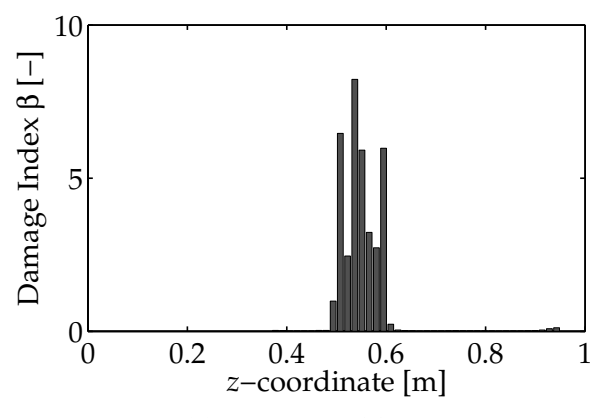

(c) Center grid line.

Figure 3.11 Damage index $\beta_{i}$ distributions obtained for the bending dominated modes $\left(4^{\text {th }}, 5^{\text {th }}, 7^{\text {th }}\right.$ and $\left.8^{\text {th }}\right)$ defined by $3 \times 30$ grid points and using 40 MSE-DI elements.

measured points. The damage indices obtained from the center grid line of the T-beam clearly indicate the presence, location and size of the delamination using 8 equally spaced data points within the scanning range. The left and right grid line show higher damage indices at the delaminated region in case 10 equally spaced data points were used. The location of the delamination is predicted correctly, despite the lower absolute values of the damage index compared to the damage indices at the center grid line. The difference between the results obtained from the left and right grid line can be allocated to differences between mode shapes, and therefore derivatives, at the left and right grid line.

The damage identification algorithm is also applied by incorporating torsion dominated mode shapes. Therefore the first derivative of the torsion angle is required. The normalized torsion angle at the shear center (see Figure 3.1) is approximated using the mode shapes in $y$-direction at the left and right grid line and the distance in $x$-direction between these two grid lines. Figure 3.13 shows the results by incorporating the approximated torsion angle at the spline interpolated 


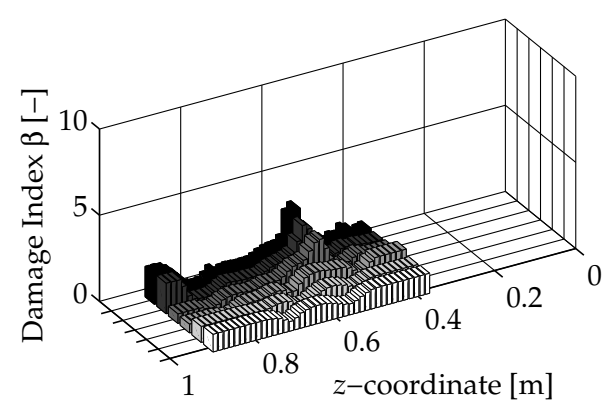

(a) Left grid line.

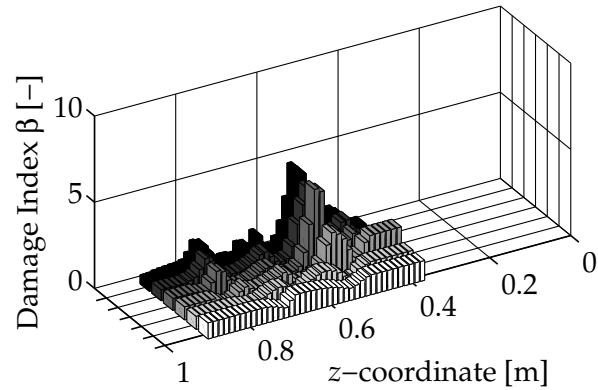

(b) Right grid line.
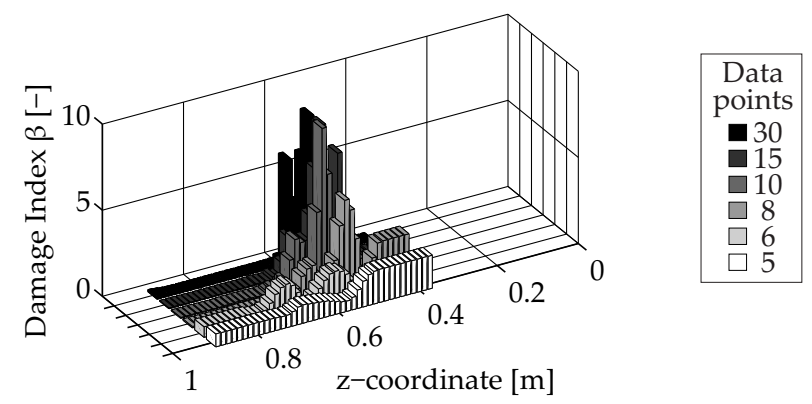

(c) Center grid line.

Figure 3.12 Damage index $\beta_{i}$ distributions obtained for the bending dominated modes defined by $3 \times 30$, $3 \times 15,3 \times 10,3 \times 8,3 \times 6$ and $3 \times 5$ equally spaced grid points.

grid points of the $2^{\text {nd }}, 3^{\text {rd }}, 4^{\text {th }}, 7^{\text {th }}, 9^{\text {th }}, 10^{\text {th }}$ and $12^{\text {th }}$ torsion mode shape. The damage index based on torsion dominated mode shapes gives no indication of presence, location and size of the delamination. This conclusion matches the conclusions drawn based on the modal parameters. The explanation for this is the small distance between delamination and shear center at the cross section of the T-beam.

\subsection{Conclusions}

The results of the vibration experiments show that the modal strain energy damage index algorithm can be used to identify a delamination in a composite T-beam structure in the case of bending vibrations. Although measurements of changes in natural frequencies of the bending modes only indicate the presence of the delamination easily, the $4^{\text {th }}$ and higher bending mode shapes and the damage 


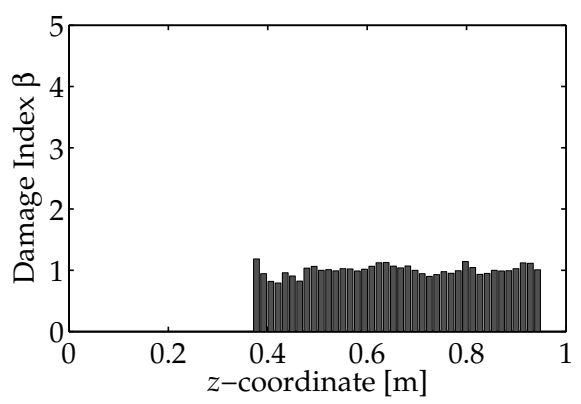

Figure 3.13 Damage index $\beta_{i}$ distribution obtained for the torsion dominated modes $\left(2^{\text {nd }}, 3^{\text {rd }}, 4^{\text {th }}, 7^{\text {th }}\right.$, $9^{\text {th }}, 10^{\text {th }}$ and $12^{\text {th }}$ ) defined by 30 grid points and using 40 MSE-DI elements.

index algorithm also predict the location and size of the defect. The damage index distributions provide a more pronounced identification of the delamination compared to the single mode shapes. The combination of the different mode shape derivatives in the damage index algorithm makes the methodology sensitive, even with a low number of measurement points.

The small distance between the location of the delamination and the shear center of the cross section of the structure causes the torsion modes to be hardly affected for this structure. Only a few mode shapes indicate the presence and location of the delamination. The natural frequencies and damage index remain inconclusive, as was shown by the measurements. No solid conclusions can be drawn in this particular case. Perhaps there are other cases where torsional deformations will have an influence on the damage identification results.

It was shown that measurements at a certain distance from the local delamination, like the left and right grid line, can be used to identify the delamination. The damage index is affected by the distance between the measured points and the delamination.

A reduction in the number of measurement points affects the sensitivity to identify damage at a certain distance from the measured points. The ratio between the damage index of the damaged area and the intact area is lower, but the location is still predicted correctly by using a minimum of eight equally spaced measurement points within the limited scanning range at the center grid line.

A next step towards the practical application of vibration based structural health monitoring is to use integrated sensor systems for the mode shape measurements used in the damage identification process. For this purpose, the numerical model, as proposed in [10] can be used to optimally place the different sensors. Moreover, larger structures with multiple stiffeners should be investigated to further study the capabilities of the vibration based damage identification approach. 


\section{Acknowledgements}

The authors would like to acknowledge the support of Fokker Aerostructures B.V., Hoogeveen, The Netherlands, for the manufacturing of the composite T-beam structures on which the experiments were performed. This work was carried out in the framework of the European project Clean Sky, Eco-Design ITD (grant agreement number CSJU-GAM-ED-2008-001).

\section{References}

[1] W.J.B. Grouve, L.L. Warnet, A. de Boer, R. Akkerman, and J. Vlekken. Delamination detection with fibre Bragg gratings based on dynamic behaviour. Composites Science and Technology, 68(12):2418-2424, 2008.

[2] N. Stubbs and C.R. Farrar. Field verification of a nondestructive damage localization and severity estimation algorithm. In Proceedings of the 13th International Modal Analysis Conference (IMAC XIII), pages 210-218, 1995.

[3] P.J. Cornwell, S.W. Doebling, and C.R. Farrar. Application of the strain energy damage detection method to plate-like structures. Journal of Sound and Vibration, 224(2):359-374, 1999.

[4] H. Li, H. Yang, and S.-L.J. Hu. Modal strain energy decomposition method for damage localization in 3D frame structures. Journal of Engineering Mechanics, 132(9), 2006.

[5] H. Li, H. Fang, and S.-L.J. Hu. Damage localization and severity estimate for three-dimensional frame structures. Journal of Sound and Vibration, 301(3-5):481-494, 2007.

[6] T.A. Duffey, S.W. Doebling, C.R. Farrar, W.E. Baker, and W.H. Rhee. Vibration-based damage identification in structures exhibiting axial and torsional response. Journal of Vibration and Acoustics, 123(1):84, 2001.

[7] A. Alvandi and C. Cremona. Assessment of vibration-based damage identification techniques. Journal of Sound and Vibration, 292(1-2):179-202, 2006.

[8] J. Stewart. Calculus: early transcendentals. 5th edition. Brooks/Cole - Thomson Learning, 2003.

[9] A. Offringa, J. List, J. Teunissen, and H. Wiersma. Fiber reinforced thermoplastic butt joint development. In Proceedings of the International SAMPE Conference, pages 1-16, 2008.

[10] R. Loendersloot, T.H. Ooijevaar, L.L. Warnet, A. de Boer, and R. Akkerman. Vibration based structural health monitoring and the modal strain energy damage index algorithm applied to a composite T-beam. In C.M.A. Vasques and J.D. Rodrigues, editors, Vibration and Structural Acoustics Analysis: Current Research and Related Technologies, Chapter 6, pages 121-150. Springer, 2011.

[11] B.J. Schwarz and M.H. Richardson. Experimental modal analysis. In CSI Reliability Week, Orlando, FL, pages 1-12, 1999.

[12] M.H. Richardson and B.J. Schwarz. Modal parameter estimation from operating data. Sound and Vibration, 37(1):28-39, 2003.

[13] M.H. Richardson and D.L. Formenti. Global curve fitting of frequency response measurements using the rational fraction polynomial method. In 3rd International Modal Analysis Conference, pages 1-8, 1985. 
[14] R.J. Allemang. The modal assurance criterion - Twenty years of use and abuse. Journal of Sound and Vibration, 1:14-21, 2003.

[15] P.M. Mujumdar and S. Suryanarayan. Flexural vibrations of beams with delaminations. Journal of Sound and Vibration, 125(3):441-461, 1988.

[16] J. Lee. Free vibration analysis of delaminated composite Beams. Computers and Structures, 74(2):121-129, 2000. 



\title{
Impact damage identification in composite skin-stiffener structures based on modal curvatures ${ }^{1}$
}

\begin{abstract}
The feasibility of a vibration based damage identification approach for impact damage in two advanced composite skin-stiffener structures is investigated in this chapter. Mode shape curvatures combined with the modal strain energy damage index (MSE-DI) algorithm are utilized to identify the damage. Special attention is paid to the effective application of this vibration based methodology by investigating the relation between the damage location, the structural design and the dynamic behavior. The performance of a $1 \mathrm{D}$ and 2D formulation of the MSE-DI algorithm is compared for several damage scenarios. Experiments demonstrated the capabilities of the MSE-DI algorithm to detect, localize and roughly quantify the size of barely visible impact damage in advanced composite structures. It is concluded that the method is particularly effective for health monitoring of skin-stiffener connections. The most effective results were obtained by considering the 1D formulation in the direction of the stiffeners for the stiffener mid-section and perpendicular to the stiffeners for the stiffener run-out. The method remained inconclusive in the case of pure skin related damage. The results obtained in this study contribute to the development of guidelines for vibration based structural health monitoring of advanced composite skin-stiffener structures.
\end{abstract}

1 Reproduced from: T.H. Ooijevaar, L.L. Warnet, R. Loendersloot, R. Akkerman and T. Tinga, Impact damage identification in composite skin-stiffener structures based on modal curvatures. In preparation for: Structural Control and Health Monitoring, 2014. 


\subsection{Introduction}

One of the key issues in composite structures is the early identification of damage. Often service induced damage does not involve visible plastic deformation, but internal matrix related damage, like transverse cracks and delaminations. Their identification often imposes time-consuming and costly nondestructive inspection techniques. Structural health monitoring (SHM) technologies propose to be a promising alternative.

A wide range of technologies is currently employed for health monitoring purposes [1]. The majority of these technologies utilizes local or global dynamic characteristics [2,3]. This classification is based on the relative size of the wave length with respect to the overall structural dimensions. Global methods, typically structural vibration based technologies, provide data that is relatively easy to interpret, but the frequency range and hence the resolution are limited [3]. As a consequence, only relatively severe damage can be identified. Typical applications are found in civil and offshore structures [4-8]. The local methods, comprising higher frequency wave propagation technologies, are capable of detecting small damage such as cracks [9-13], but it is often more complicated to interpret the data, in particular in the case of non-flat or complex structures. The selection of the best technology for a SHM system is often a matter of compromise. None of the local or global approaches is, at the moment, able to solve all problems in all structures [14].

The number of successful practical applications of the SHM technologies on composite aircraft structures is limited compared to applications in civil and offshore industry [14-17]. This is mainly due to the complexity of the components, the variety of potential damage scenarios and the high demands on safety and reliability of the SHM system. As a consequence, the unique identification (presence, location and severity) of damage in realistic composite structures by methodologies operating under field conditions is considered as one of the key challenges for these technologies.

This chapter addresses an experimental feasibility study on the identification of impact damage in two advanced (i.e. multiple stiffeners, non-uniform skin thickness, large dimensions) composite skin-stiffener structures, representing typical aircraft structures. The present study is an extension of earlier performed research by the authors on a $1 \mathrm{~m}$ composite T-beam specimen with an artificial delamination [18, 19]. A global vibration based method is considered. This approach allows for a relatively easy and physical interpretation of the measured responses, which is desired for the investigation of complex composite structures. Mode shape curvatures combined with the modal strain energy damage index (MSE-DI) algorithm $[20,21]$ are respectively utilized as damage feature and classifier to detect and localize the naturally originated defects. Studies by different authors [4, 22-26] showed that this mode shape curvature based approach outperforms other frequently applied modal domain damage identification methods 
based on natural frequencies [27-29], mode shapes [30, 31], dynamic flexibility [32$34]$ and other mode shape derivative based features [35, 36]. The MSE-DI algorithm essentially utilizes the curvature changes that locally arise under dynamic loading of damaged structures. The performance of a 1D and 2D formulation of the MSE-DI algorithm is compared for several local damage scenarios. Up to now, the feasibility of the method is mainly demonstrated on concrete and metallic structures $[4,6,24,37]$. Application to composite structures is limited to relatively simple composite beams and plates [38-40] with mainly severe and well-defined artificial damage, such as a saw cut. The present work aims to extend this to more advanced composite structures and impact induced damage scenarios.

Although the low frequency technologies allow for a relatively easy interpretation of the responses, their sensitivity to identify small and local damage is rather limited [16, 23, 41]. Special attention is therefore paid to the effective application of the vibration based methodology. The effectiveness of the methodology is directly related to aspects such as the frequency level, the location, orientation, type and size of the damage, the design of the structure, the location and number of sensors, etc $[18,22]$. This chapter addresses the relation between the damage location, the structural design and the dynamic behavior in order to extract recommendations for the effective application of the methodology. The results obtained in this study contribute to the development of guidelines for vibration based structural health monitoring of advanced composite skin-stiffener structures. Numerical studies performed on the same skin-stiffener structures were presented in two book chapters $[42,43]$.

\subsection{Composite skin-stiffener structures}

This research concentrates on carbon AS4D fiber reinforced thermoplastic (PEKK) skin-stiffener structures. Stiffeners are frequently used in aerospace components to increase the bending stiffness of the component without a severe weight penalty. A new type of skin-stiffener connection was developed by Fokker Aerostructures [44]. Flat preforms are butt-joined to the composite skin in a co-consolidation process, employing an injection molded thermoplastic filler for the connection. The filler is made from PEKK and contains $20 \mathrm{wt} \%$ short carbon fibers. This stiffener connection concept allows for a low cost and simplified manufacturing of a large number of stiffening ribs compared to conventional techniques. The fabrication process and mechanical performances are discussed in more detail in [45].

The two composite skin-stiffener structures used in this research were produced by Fokker Aerostructures according to the new joining concept. The first structure is shown in Figure 4.1 and consists of a $400 \times 282 \mathrm{~mm}$ composite plate with two Tshaped stiffener sections. A quasi-isotropic lay-up [45/90/-45/0 $]_{2, \mathrm{~s}}$ consisting of 16 unidirectional layers is used for both skin and stiffeners. 


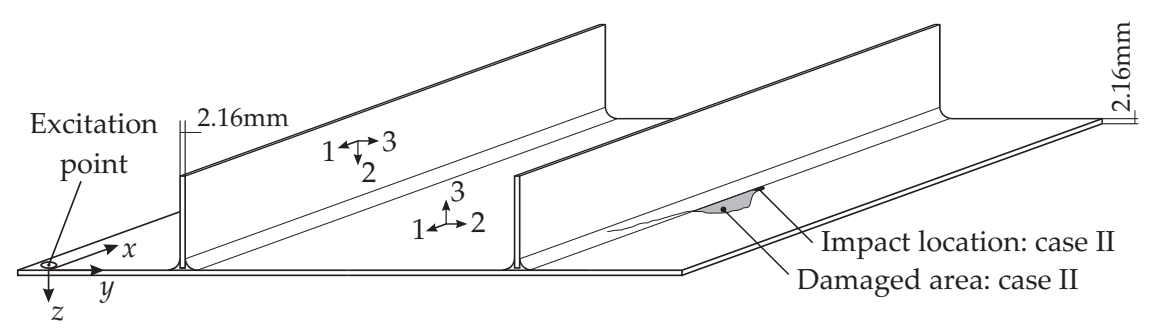

Bottom view

Side view

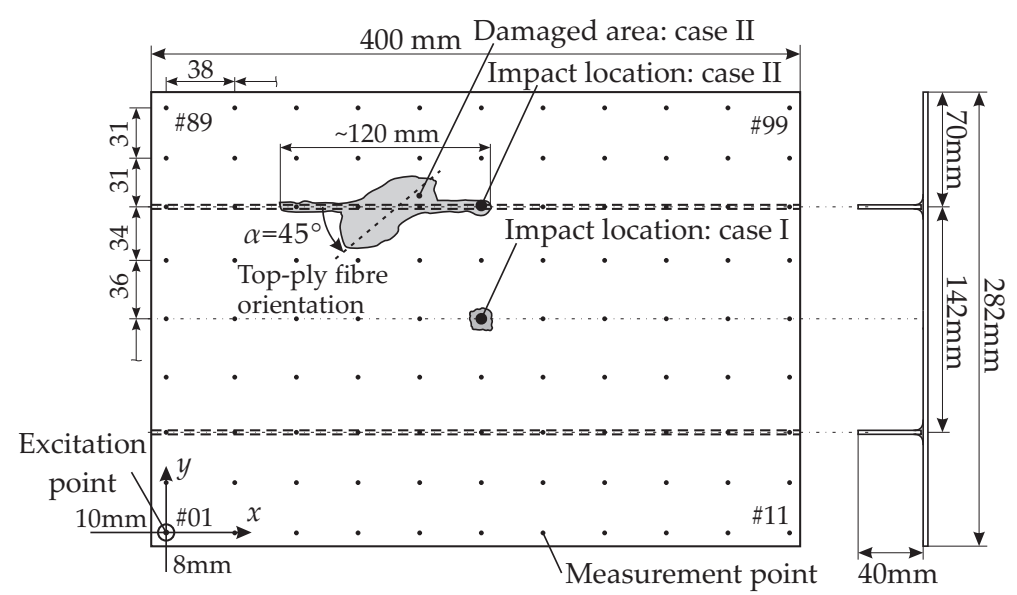

Figure 4.1 Three dimensional and bottom view of the composite skin-stiffener specimen with 2 butt-joint stiffeners. The dimensions, the measurement points (dots) and the impact locations are indicated.

The second structure is a larger and more advanced three stiffener plate structure $(1304 \times 456 \mathrm{~mm})$ with a non-uniform skin thickness distribution, as shown in Figure 4.2. It represents a more realistic aircraft structure. The plate consists of a 16-layer quasi-isotropic mid-section and 44-layer and 30-layer end-sections. The stiffeners are made of a 15-layer quasi-isotropic stack. The structure contains a Zshaped preform based stiffener run-out with a titanium insert. Offringa et al. [45] stated that this run-out design allows the structure to withstand a $50 \mathrm{~J}$ impact on the stiffener from the outside, satisfying airliner and business jet impact requirements. Only limited damage should be visible at this impact level.

The skin-stiffener structures are vulnerable for impact damage. The connection between skin and stiffener is considered as the location where damage due to impact would have the largest effect on the integrity of the structure. A small delamination at this connection can significantly reduce the local bending stiffness and hence the performance of the skin-stiffener structure. This direct structural effect along with the potential long-term delamination growth make the skinstiffener connection a good candidate for health monitoring. 


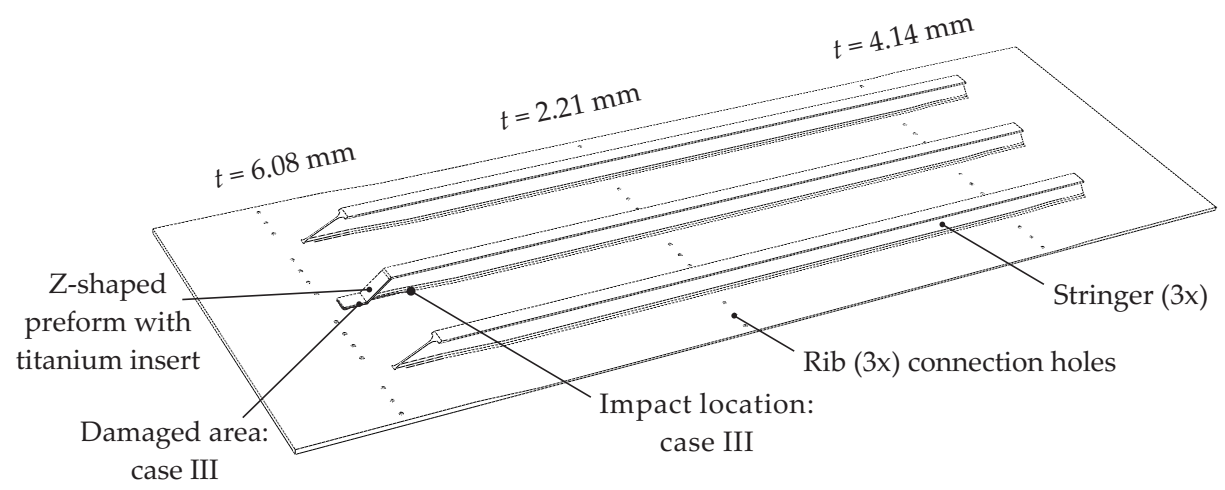

Bottom view

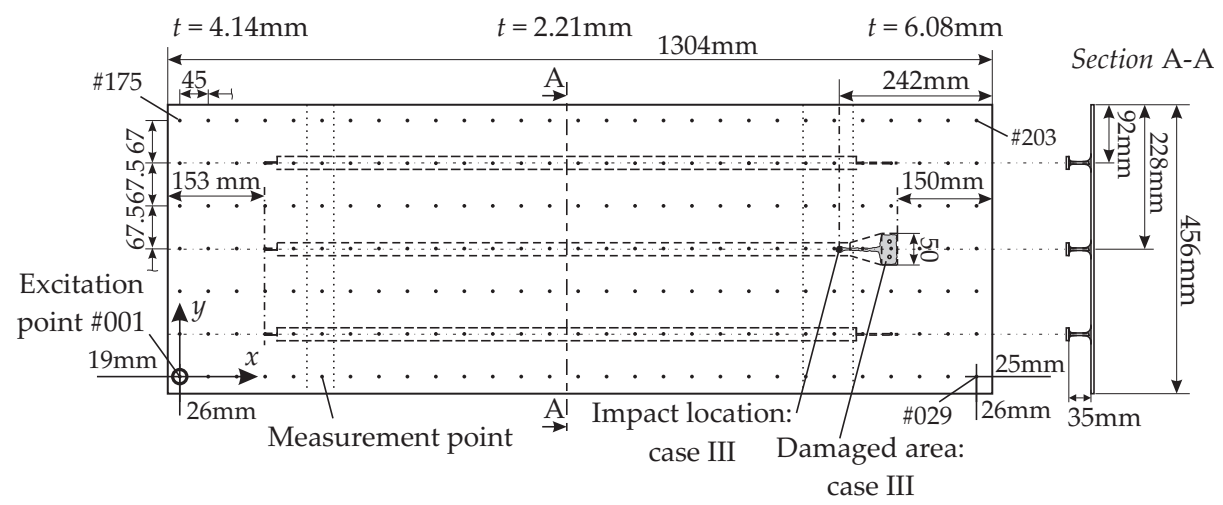

Figure 4.2 Three dimensional and bottom view of the composite aircraft structure with three stiffeners, a non-uniform skin thickness and the impact resistant stringer run-out design. The dimensions, the measurement points (dots) and the impact location are indicated. The dotted vertical lines indicate the edges of the transition zones between the sections with different thicknesses.

Three impact induced damage scenarios, summarized in Table 4.1, are considered in this study. Naturally originated defects are obtained by applying local impact at several locations from the outside (i.e. the side of the skin without the stiffeners) of the structure with the help of a Dynatup 8250 falling weight impact machine. A repeated impact of $10 \mathrm{~J}$ was used for the two stiffener structure, while a single $50 \mathrm{~J}$ impact was applied in the case of the three stiffener structure. Visual and ultrasonic inspections revealed the damage mechanisms occurring.

Figure 4.1 depicts the impact location and damaged area of damage scenario I and II in the structure with two stiffeners. The first damage scenario, shown in Figure 4.3(a), consists of local transverse cracks and a small delamination at the skin in between both stiffeners. More severe damage is obtained for the second damage case at the skin-stiffener connection of the same structure. This damage consists of first-ply transverse cracks and a delamination between the first two 
Table 4.1 Overview of the impact induced damage scenarios.

\begin{tabular}{|c|c|c|c|c|}
\hline $\begin{array}{c}\text { Damage } \\
\text { case }\end{array}$ & Structure & Description & $\begin{array}{l}\text { Failure } \\
\text { mechanism }\end{array}$ & $\begin{array}{l}\text { Dimensions } \\
\text { (approx.) }\end{array}$ \\
\hline I & $\begin{array}{c}\text { Two } \\
\text { stiffener }\end{array}$ & $\begin{array}{l}\text { Impact damage at skin in between } \\
\text { both stiffeners due to repeated } \\
10 \mathrm{~J} \text { impact, see Figure } 4.3(\mathrm{a})\end{array}$ & $\begin{array}{l}\text { Local transverse } \\
\text { cracks and small } \\
\text { delamination }\end{array}$ & $15 \times 10 \mathrm{~mm}$ \\
\hline II & $\begin{array}{c}\text { Two } \\
\text { stiffener }\end{array}$ & $\begin{array}{l}\text { Impact damage at skin-stiffener } \\
\text { connection due to repeated } 10 \mathrm{~J} \\
\text { impact, see Figure } 4.3(\mathrm{~b})\end{array}$ & $\begin{array}{l}\text { Skin delamination } \\
\text { and interface } \\
\text { failure }\end{array}$ & $\begin{array}{l}\text { Length: } \\
\approx 80 \mathrm{~mm}\end{array}$ \\
\hline III & $\begin{array}{l}\text { Three } \\
\text { stiffener }\end{array}$ & $\begin{array}{l}\text { Impact damage at stringer run-out } \\
\text { due to } 50 \mathrm{~J} \text { impact, see Figure } 4.3(\mathrm{c})\end{array}$ & $\begin{array}{l}\text { Interface failure } \\
\text { and delamination }\end{array}$ & $\begin{array}{l}\text { Length: } \\
\approx 90 \mathrm{~mm}\end{array}$ \\
\hline
\end{tabular}

layers of the skin, as shown in Figure 4.3(b). The interface between the injection molded filler and skin also failed over a significant length. The structure with three stiffeners was impacted at a stiffener run-out, shown in Figure 4.2. This part of the skin-stiffener connection is most vulnerable for failure under impact [45]. The impact resulted in failure of the connection between the skin and the Z-shaped stiffener run-out. Cracks are indicated in Figure 4.3(c). An ultrasonic inspection also revealed delamination damage between the titanium insert and the skin.

The three damage scenarios considered show typical fiber reinforced material related failure mechanisms. They were, except for a small dent, invisible from the outside of the structure. The damage scenarios are referred to as barely visible impact damage (BVID), according to the criteria used in aircraft industry [46]. Aircraft structures have historically relied on visual methods to identify BVID. Presently, the dent depth is used as the damage metric to define BVID. The largest dent depth measured for the two composite structures equaled $0.16 \mathrm{~mm}$, which is smaller than the $0.3 \mathrm{~mm}$ BVID threshold as stated in [46]. Structures containing BVID must sustain ultimate load (UL) for the life of the aircraft structure.

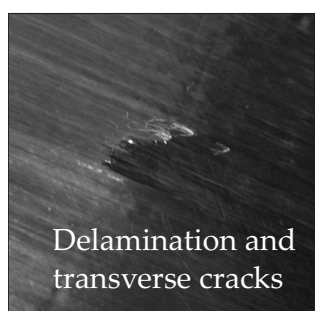

(a) Damage case I.

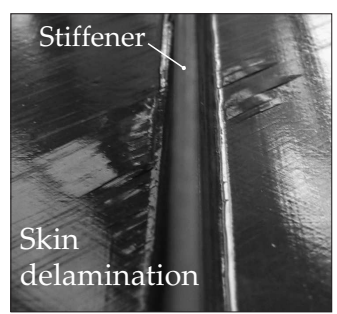

(b) Damage case II.

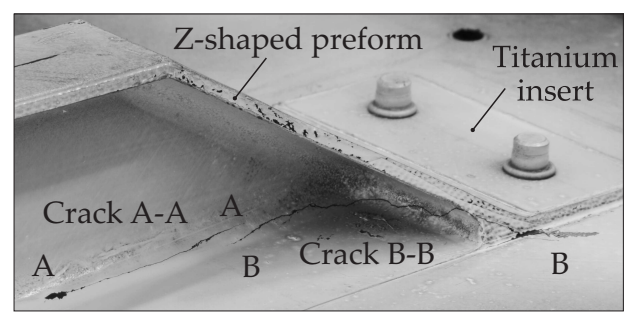

(c) Damage case III.

Figure 4.3 Visible part of the impact damage introduced in the $(a, b)$ two stiffener composite structure and (c) three stiffener composite structure. 
This criterion sets the lower bounds for the identification capabilities of an SHM approach.

\subsection{Damage identification procedure}

The diagnostic part of the damage identification procedure, according to Figure 4.4, consists of two steps. In the first step the mode shape curvatures, referred to as damage features, are extracted. This process comprises the estimation of the modal parameters by utilizing modal analysis and the calculation of the second derivatives of the mode shapes in $x$ - and $y$-direction. Delaminations in, for example, a beamlike structure under bending deformation theoretically cause a discontinuity in the curvature at the boundaries of the damaged region [25]. These changes in curvature between the pristine and damaged structure are the input for the second step. This step comprises the damage classification process. The local change in the curvature of a range of modes is combined to obtain a single indicator, the damage metric.

One of the first publications that adopted mode shape curvatures as a means to identify structural damage is from Pandey et al. [35]. Since this paper, many different curvature based damage metrics have been proposed, including the MSEDI algorithm. The MSE-DI algorithm has not only been used by several researchers, but it has also appeared in a number of different variants [26, 43]. Modifications have been made to improve the performance and robustness of the algorithm. It lies beyond the scope of this article to address all variants that have appeared throughout the years. The present work is focused on the original and most frequently used formulation of the MSE-DI algorithm, since the validation of the modified variants is limited. A 1D formulation of the MSE-DI algorithm was introduced by Stubbs et al. [20], while Cornwell et al. [21] extended this approach for the 2D case. Both formulations are employed in the present work. Only the basics of the 2D formulation according to Cornwell et al. [21] are explained in this

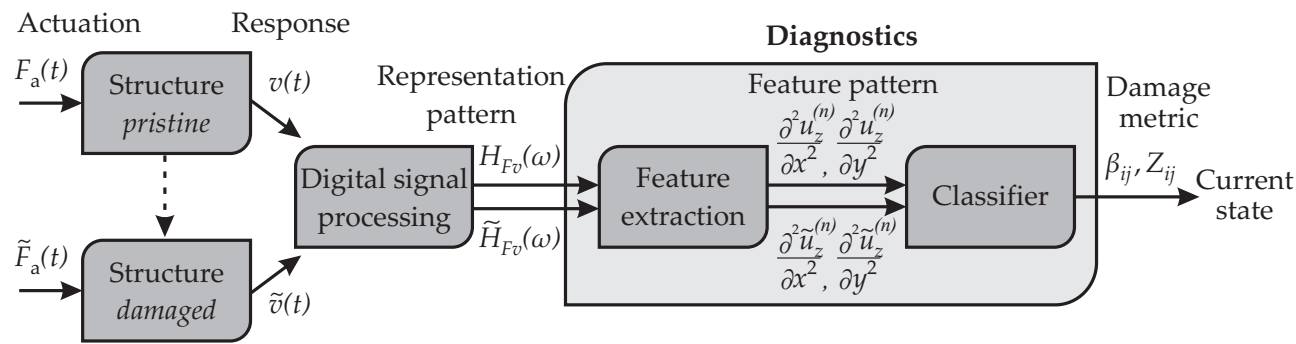

Figure 4.4 A schematic representation of the damage identification procedure. The $F_{\mathrm{a}}(t)$ is the excitation force, $v(t)$ the velocity response, $H_{F v}(\omega)$ the frequency response function between an excitation and measurement point, $u_{z}^{(n)}(x, y)$ is the normalized mode shape of mode $n$, the tilde represents the damaged case. 


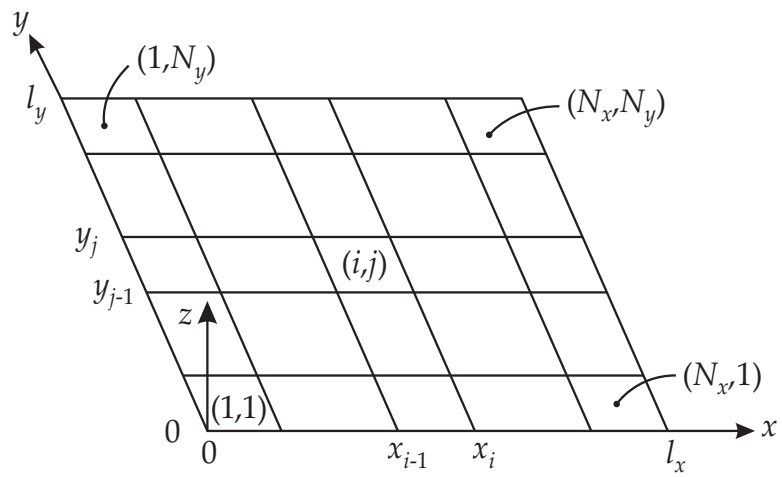

Figure 4.5 A plate structure divided into $N_{x} \times N_{y}$ elements in $x$-and $y$-direction respectively.

section. The quasi-isotropic laminate properties are approximated by an isotropic description. The derivation and assumptions of the 2D formulation are analogous to the one used for the $1 \mathrm{D}$ formulation in $x$ - or $y$-direction $[18,22]$.

The strain energy of a vibration mode is referred to as the modal strain energy of that mode. The modal strain energy can be obtained by linking the flexural, axial and/or shear modal deformation of a structure to the strain [47]. The present work concentrates on the flexural deformations of the skin-stiffener structures. This type of deformation is expected to be dominant for the vibration modes that are excited by the shaker. The strain energy $U$, based on the normalized flexural mode shape $u_{z}^{(n)}(x, y)$ in $z$-direction, of each individual mode $n$ of an isotropic vibrating plate-like structure is represented by:

$$
\begin{aligned}
U^{(n)}=\frac{1}{2} \int_{0}^{l_{y}} \int_{0}^{l_{x}} D(x, y)\left[\left(\frac{\partial^{2} u_{z}^{(n)}}{\partial x^{2}}\right)^{2}+\left(\frac{\partial^{2} u_{z}^{(n)}}{\partial y^{2}}\right)^{2}\right. \\
\left.+2 v\left(\frac{\partial^{2} u_{z}^{(n)}}{\partial x^{2}}\right)\left(\frac{\partial^{2} u_{z}^{(n)}}{\partial y^{2}}\right)+2(1-v)\left(\frac{\partial^{2} u_{z}^{(n)}}{\partial x \partial y}\right)^{2}\right] \mathrm{d} x \mathrm{~d} y,
\end{aligned}
$$

with $D(x, y)$ the flexural rigidity of the plate, $v$ the Poisson's ratio, $l_{x}$ and $l_{y}$ the dimensions of the plate structure in $x$ - and $y$-direction respectively. The total modal strain energy is approximated by the sum of Equation (4.1) over a limited set of $N_{\text {modes }}$ modes, using the theory of modal superposition. The plate-like structure can be discretized in $N_{x} \times N_{y}$ elements in $x$-and $y$-direction respectively, as shown 
in Figure 4.5. Each element ij contains a modal strain energy described by:

$$
\begin{aligned}
U_{i j}^{(n)}=\frac{1}{2} \int_{y_{j-1}}^{y_{j}} \int_{x_{i-1}}^{x_{i}} D(x, y)\left[\left(\frac{\partial^{2} u_{z}^{(n)}}{\partial x^{2}}\right)^{2}+\left(\frac{\partial^{2} u_{z}^{(n)}}{\partial y^{2}}\right)^{2}\right. \\
\left.+2 v\left(\frac{\partial^{2} u_{z}^{(n)}}{\partial x^{2}}\right)\left(\frac{\partial^{2} u_{z}^{(n)}}{\partial y^{2}}\right)+2(1-v)\left(\frac{\partial^{2} u_{z}^{(n)}}{\partial x \partial y}\right)^{2}\right] \mathrm{d} x \mathrm{~d} y,
\end{aligned}
$$

with:

$$
U^{(n)}=\sum_{j=1}^{N_{y}} \sum_{i=1}^{N_{x}} U_{i j}^{(n)}
$$

and $x_{i-1}, x_{i}$ and $y_{j-1}, y_{j}$ the boundaries of element $i j$ of the discretized structure in $x$ - and $y$-direction respectively. Similar quantities can be defined for a damaged structure, using the normalized mode shapes $\tilde{u}_{z}^{(n)}(x, y)$ of the damaged structure. Subsequently, the local fractional strain energies, as defined by Cornwell et al. [21], are:

$$
F_{i j}^{(n)}=\frac{U_{i j}^{(n)}}{U^{(n)}}, \quad \tilde{F}_{i j}^{(n)}=\frac{\tilde{U}_{i j}^{(n)}}{\tilde{U}^{(n)}},
$$

for the pristine and damaged structure respectively. The fractional strain energy remains relatively constant in the undamaged elements, under the assumption that the damage is small and primarily located at element $k l[21,22]$ :

$$
\tilde{F}_{i j}^{(n)} \approx F_{i j}^{(n)} \text { for } \quad i, j \neq k, l
$$

This equation is rearranged and by substituting Equations (4.1), (4.2) and (4.4) it can be derived that:

$$
1 \approx \frac{\int_{y_{j-1}}^{y_{j}} \int_{x_{i-1}}^{x_{i}} \widetilde{D} \tilde{w}^{(n)} \mathrm{d} x \mathrm{~d} y / \int_{0}^{l_{y}} \int_{0}^{l_{x}} \widetilde{D} \tilde{w}^{(n)} \mathrm{d} x \mathrm{~d} y}{\int_{y_{j-1}}^{y_{j}} \int_{x_{i-1}}^{x_{i}} D w^{(n)} \mathrm{d} x \mathrm{~d} y / \int_{0}^{l_{y}} \int_{0}^{l_{x}} D w^{(n)} \mathrm{d} x \mathrm{~d} y} \text { for } i, j \neq k, l,
$$

where $w^{(n)}(x, y)$ represents all terms between the square brackets in the integrand of Equation (4.2), representing the information of the mode shape derivatives. The mean value theorem for integrals [48] is applied to the stiffness terms $D(x, y)$ and $\widetilde{D}(x, y)$ in Equation (4.6) to obtain an average stiffness estimate for each double integral. For the integral over element $i j$ of the pristine case:

$$
\int_{y_{j-1}}^{y_{j}} \int_{x_{i-1}}^{x_{i}} D(x, y) w^{(n)}(x, y) \mathrm{d} x \mathrm{~d} y=D\left(x_{0}, y_{0}\right) \int_{y_{j-1}}^{y_{j}} \int_{x_{i-1}}^{x_{i}} w^{(n)}(x, y) \mathrm{d} x \mathrm{~d} y,
$$


where $x_{0}, y_{0}$ is a point within the integration intervals and $D\left(x_{0}, y_{0}\right)=D_{i j}$ is the weighted average flexural rigidity of element $i j$. Similar estimates can be obtained for the other integrals in Equation (4.6). Subsequently, a ratio of the flexural rigidities is obtained by assuming that the change in the average value of the flexural rigidity for the integrals over the entire plate dimensions $l_{x}$ and $l_{y}$ is negligible for small damage:

$$
\frac{D_{i j}}{\widetilde{D}_{i j}} \approx \frac{\int_{y_{j-1}}^{y_{j}} \int_{x_{i-1}}^{x_{i}} \tilde{w}^{(n)} \mathrm{d} x \mathrm{~d} y / \int_{0}^{l_{y}} \int_{0}^{l_{x}} \tilde{w}^{(n)} \mathrm{d} x \mathrm{~d} y}{\int_{y_{j-1}}^{y_{j}} \int_{x_{i-1}}^{x_{i}} w^{(n)} \mathrm{d} x \mathrm{~d} y / \int_{0}^{l_{y}} \int_{0}^{l_{x}} w^{(n)} \mathrm{d} x \mathrm{~d} y}=\frac{\tilde{\gamma}_{i j}^{(n)} / \tilde{\gamma}^{(n)}}{\gamma_{i j}^{(n)} / \gamma^{(n)}} \text { for } \quad i, j \neq k, l,
$$

where $\gamma_{i j}^{(n)}$ is the integral of $w^{(n)}(x, y)$ over element $i j$ and $\gamma^{(n)}$ the integral of $w^{(n)}(x, y)$ over the entire dimensions $l_{x}$ and $l_{y}$. Stubbs et al. [20], Cornwell et al. [21] and Alvandi [22] used the right-hand side of Equation (4.8) to define a local damage index $\beta_{i j}^{(n)}$. This indicator is approximately equal to 1 for the undamaged elements, i.e. $i, j \neq k, l$, but can change at the damaged element, i.e. $i, j=k$, $l$. Finally, the information of each mode shape is combined into a single damage index $\beta_{i j}$ by using the definition proposed by Cornwell et al. [21], which is a summation over the number of modes $N_{\text {modes }}$ considered:

$$
\beta_{i j}=\sum_{n=1}^{N_{\text {modes }}}\left[\tilde{\gamma}_{i j}^{(n)} / \tilde{\gamma}^{(n)}\right] / \sum_{n=1}^{N_{\text {modes }}}\left[\gamma_{i j}^{(n)} / \gamma^{(n)}\right]
$$

An overview of the most common alternative damage index formulations was presented by Loendersloot et al. [43]. The indicators obtained by these formulations are metrics for the detection and localization of damage but do not have a direct physical quantity. The damage index $\beta_{i j}$ is usually normalized using the standard deviation $\sigma$ and the mean $\mu$ of the damage index $\beta_{i j}$ over all elements. This results in a normalized damage index $Z_{i j}$ [49]:

$$
Z_{i j}=\frac{\beta_{i j}-\mu}{\sigma} .
$$

This normalized indicator provides a statistical measure for the detection of outliers in the damage index distributions, which are expected to be the damaged elements.

A strength of the MSE-DI algorithm is that it utilizes mode shape curvatures, which showed to be a relatively sensitive damage feature compared to other modal parameters $[15,35,36]$. The algorithm also combines damage related information of a range of modes. This allows for a more robust damage index distribution, according to Equation (4.9), because every mode is affected differently by the local damage [18]. Weak points are the number of required data points to accurately describe the mode shapes and the numerical errors introduced with the calculation 
of the second derivative $[15,36,50,51]$. Although not extensively considered in this chapter, many different publications address the problem of finding optimum positions of the measurement points. Savananoz [52] particularly focused on the estimation of the optimum spatial sampling interval for the calculation of curvatures in beams. The present formulation of the MSE-DI algorithm also does not allow to directly link the value of the damage index $\beta_{i j}$ to a damage severity in terms of a stiffness loss ratio [22]. The ratio between the damage indices $\beta_{i j}$ at the damaged and intact area showed to be a measure for the relative change in the dynamic behavior of the structure due to the local damage [18]. The damage index $\beta_{i j}$ is merely a qualitative and mathematical rather than a physical quantity [43].

\subsection{Experimental set-up and signal processing}

Vibration measurements were performed on both composite structures before and after impact is applied. The complete dynamic set-up and data acquisition scheme used for the experiments are presented in Figure 4.6. The structures were freely suspended in vertical direction by two elastic wires in order to isolate the plate from environmental vibrations.

A random excitation force was applied by a shaker. The shaker was connected by a force transducer and stringer to driving point \#01, according to Figures 4.1 and 4.2. A laser vibrometer, mounted on a traverse system, measured the velocities along an equidistant $x \times y$ measurement grid containing $11 \times 9$ and $29 \times 7$ points for the two and three stiffener structure respectively. The mobility Frequency Response Functions (FRFs) between the fixed point of excitation and the measurement points were recorded by a Siglab data acquisition system. A frequency range of $50-2050 \mathrm{~Hz}$ (resolution: $0.625 \mathrm{~Hz}$ ) was selected for the two stiffener structure, while this was 50-1050 Hz (resolution: $0.3125 \mathrm{~Hz}$ ) for the larger structure with three stiffeners. These frequency ranges were selected based on the modal density. A measurement at each grid point consisted of 20 windowed averages, with $50 \%$ overlap. The modal parameters (i.e. natural frequency, mode shapes and damping values) were obtained from the FRFs by using Experimental Modal Analysis [53, 54]. A Complex Mode Indicator Function (CMIF) together with a global curve fitting procedure, based on a Rational Fraction Polynomial (RFP) function [55], was used to estimate the poles and residue mode shape vectors. Slightly complex modal vectors are considered to be real normal, by neglecting non-proportional damping effects.

Successive measurements at distinct times showed sufficient repeatability of the experimental set-up and testing approach. The natural frequencies measured for the pristine two and three stiffener structure showed an average standard deviation of respectively $0.20 \%$ and $0.05 \%$. The largest standard deviation of the natural frequencies equaled $0.95 \%$ and was measured for the two stiffener structure. The residue mode shapes are assessed in terms of the modal assurance criterion (MAC). 


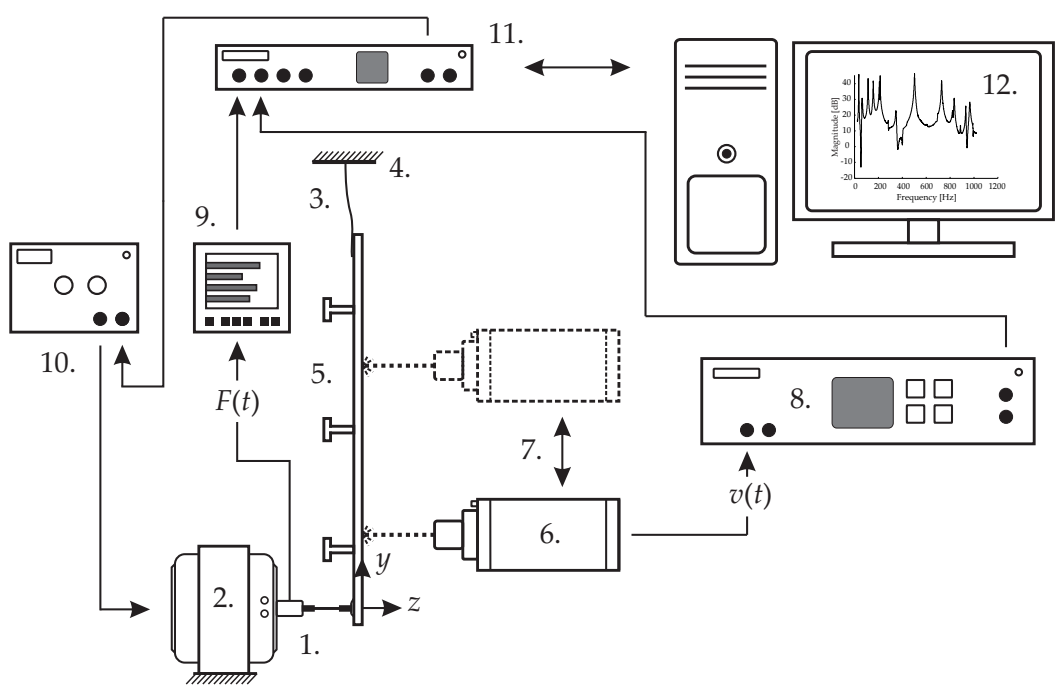

\begin{tabular}{llll}
\hline No.Description & Hardware & No.Description & Hardware \\
\hline 1. Force transducer & B\&K 8001 & 7. Traverse system $x / y$ & Dantec \\
2. Shaker & B\&K 4809 & 8. Laser: controller & Polytec OFV 3001 \\
3. Elastic wires & & 9. Conditioning amplifier & B\&K Nexus \\
4. Fixed frame & 10. Power amplifier & B\&K 2706 \\
5. Composite structure & 11. Data acquisition & Siglab Model 20-42 \\
6. Laser: sensor head Polytec OFV-303 & 12. Computer, Siglab \& ME'scope analysis software \\
\hline
\end{tabular}

Figure 4.6 Schematic representation of the experimental set-up and data acquisition systems used for the dynamic measurements of both stiffened structures.

This criterion provides a measure for the degree of consistency between two modal vectors. A value close to one indicates a good correspondence between the modal vectors, whereas a value close to zero indicates that the modal vectors are not consistent. The MAC criterion is defined as [56]:

$$
\operatorname{MAC}(m, n)=\frac{\left|\left(\boldsymbol{\psi}_{m}^{\mathrm{A}}\right)^{\mathrm{T}}\left(\boldsymbol{\psi}_{n}^{\mathrm{B}}\right)^{*}\right|^{2}}{\left(\boldsymbol{\psi}_{m}^{\mathrm{A}}\right)^{\mathrm{T}}\left(\boldsymbol{\psi}_{m}^{\mathrm{A}}\right)^{*}\left(\boldsymbol{\psi}_{n}^{\mathrm{B}}\right)^{\mathrm{T}}\left(\boldsymbol{\psi}_{n}^{\mathrm{B}}\right)^{*}},
$$

with $\psi_{m}^{\mathrm{A}}$ the modal vector of mode $m$ obtained by a first measurement (case A), $\psi_{n}^{\mathrm{B}}$ the modal vector of mode $n$ obtained by a second measurement (case B), * the complex conjugate and ${ }^{\mathrm{T}}$ the transpose. Average MAC values of 0.997 and 0.996 were obtained for successive measurements at the two and three stiffener structure respectively. The $M A C$ values exceeded the 0.968 in all cases.

The residue mode shapes were subsequently cubic spline interpolated (piecewise function) and normalized to their maximum amplitude. The interpolation is used to improve the calculation of the second derivatives of the mode shapes at 
discrete points in $x$ - and $y$-direction. The mode shape curvatures from the pristine and damaged structures were combined in the MSE-DI algorithm to investigate the effect of the damage scenarios on the damage index distributions $\beta_{i j}$ or $Z_{i j}$, according to the equations presented in Section 4.3.

\subsection{Experimental results}

The results obtained for the $2 \mathrm{D}$ and the $1 \mathrm{D}$ formulation in $x$ - and $y$-direction of the MSE-DI algorithm are evaluated for the three damage scenarios. The damage indices for the two and three stiffener structure are evaluated at an $x \times y$ grid of $40 \times 30$ and $60 \times 20$ discrete elements respectively. All modes of the two and three stiffener structure, identified within a frequency range of respectively 500-2000 $\mathrm{Hz}$ and 250-1000 Hz, are considered in the analysis. The matching pristine and damaged mode shape combinations within these frequency ranges are found by considering the highest $M A C$ values. Figure 4.7 presents the calculated $M A C$ values for all mode combinations in the case of the three considered damage scenarios. A minimum $M A C$ value of 0.5 is adopted as the lower bound to incorporate the mode combination in the analysis.

\subsubsection{Two stiffener structure with damage scenario I and II}

The damage index $\beta_{i j}$ distributions obtained for damage scenario I and II are respectively shown in Figures 4.8 and 4.9. The MSE-DI algorithm remains inconclusive for the first damage scenario where the damage was introduced at the skin in between the two stiffeners. The results obtained for the $2 \mathrm{D}$ and both 1D formulations show damage index $\beta_{i j}$ distributions with all values close to one (with standard deviations: $\sigma_{\beta_{(2 \mathrm{D})}}=0.05, \sigma_{\beta_{(1 \mathrm{Dx})}}=0.15, \sigma_{\beta_{(1 \mathrm{Dy})}}=0.05$ ). This indicates a negligible effect caused by the damage. The failure mechanism, consisting of local transverse cracks and a small delamination $(15 \times 10 \mathrm{~mm})$, hardly affects the structural stiffness or mass of the structure. As a result, the modal curvature based MSE-DI algorithm could not detect and localize the impact damage at the composite skin, for the frequency range and measurement point density considered in the analysis. Note that the minor effect of the damage is also expressed by the $M A C$ values, as shown in Figure 4.7(a). They remain close to one for all matching mode combinations.

Applying the MSE-DI algorithm to the damage at the skin-stiffener connection, damage scenario II, shows more successful results. The skin-stiffener failure has a larger effect on the global structural dynamic behavior, as indicated by the reduced $M A C$ values in Figure 4.7(b). Small damage at the skin-stiffener interface can result in a significant local reduction of the bending stiffness of the structure. The enhanced effect on the dynamic behavior is also depicted by the MSE-DI results 


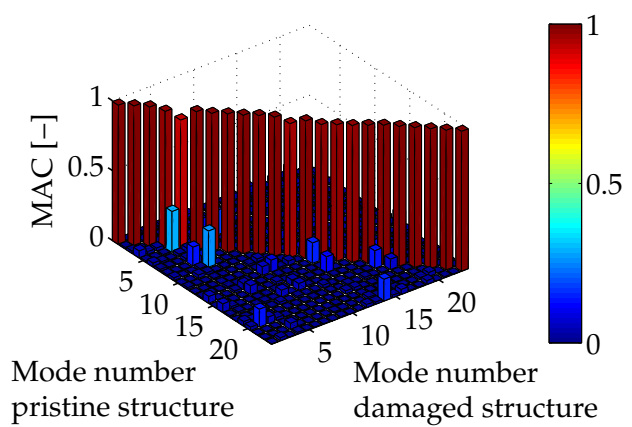

(a) Two stiffener structure: damage scenario I.

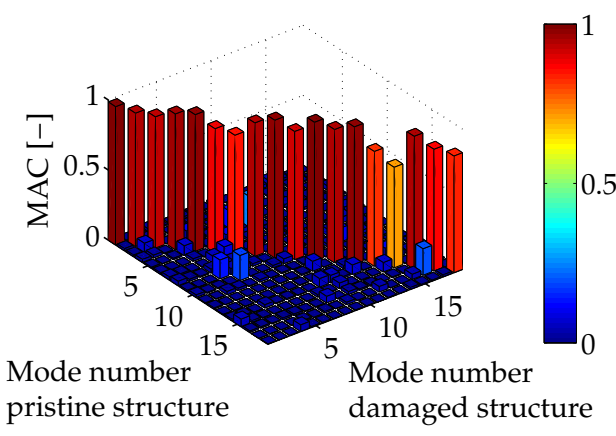

(b) Two stiffener structure: damage scenario II.

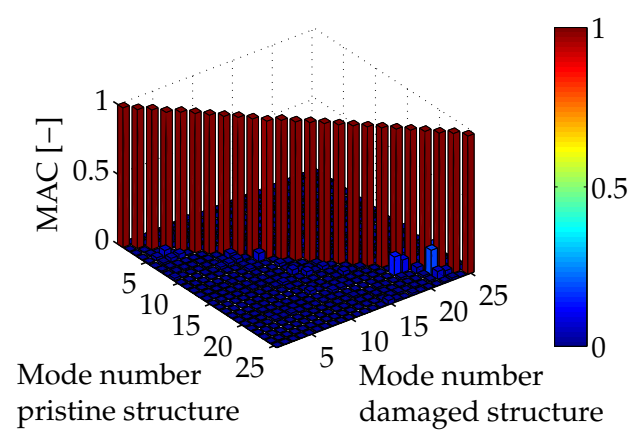

(c) Three stiffener structure: damage scenario III.

Figure 4.7 Comparison of the experimental mode shapes, in terms of MAC values, of the pristine and impact damaged structures. The mode numbers correspond to the modes within the considered frequency ranges, i.e. 500-2000 $\mathrm{Hz}$ and $250-1000 \mathrm{~Hz}$ for the two and three stiffener structure respectively.

of the 2D formulation, shown in Figure 4.9(a). The highest damage indices are obtained at the damaged area, indicating the presence and location of the damage correctly. However, the ratio between the damage index $\beta_{i j}$ of the damaged area and the intact area is rather low. The relatively noisy damage index distribution also tends to show a propensity for false damage predictions (indication of damage, but no actual change in the structure). These false positives can be caused by aspects such as inaccuracies in the mode shape data, misalignment of measurement points, errors introduced by the numerical methods used in the algorithm, but also by considering a small number of modes in the analysis.

The presence and location of the impact damage is predicted in a more pronounced way by the 1D formulation in $x$-direction, as shown in Figure 4.9(b). The most distinct damage indices are obtained by considering the measurement points on top of the skin-stiffener connection. The damage index distribution also provides a rough estimation of the dimensions of the damaged area. A delamination length of roughly $105 \mathrm{~mm}$ is found. Earlier research by authors [18] showed that the accuracy of this result highly depends on the number of measurement points and 


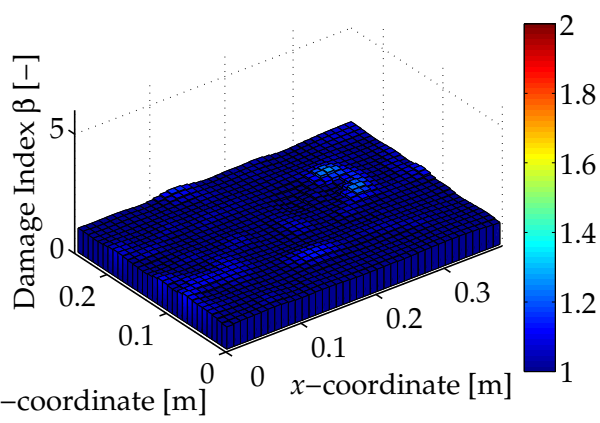

(a) 2D formulation.

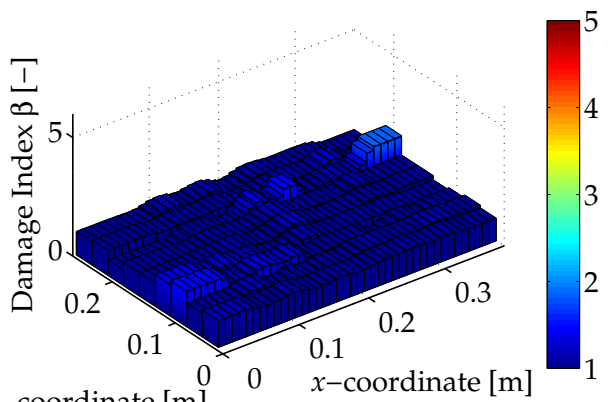
$y$-coordinate $[\mathrm{m}]$

(b) $1 \mathrm{D}$ formulation in $x$-direction.

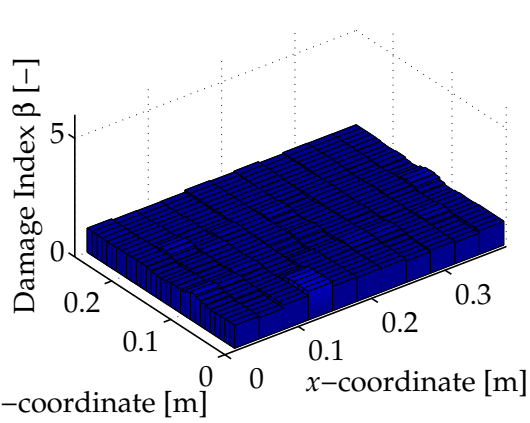

(c) $1 \mathrm{D}$ formulation in $y$-direction.

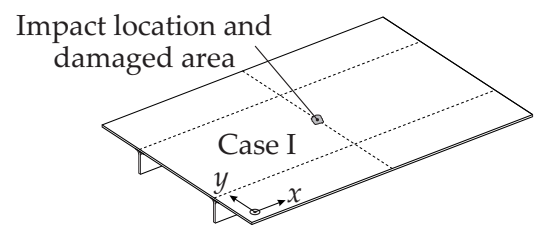

Figure 4.8 Damage index $\beta_{i j}$ distribution for damage scenario I in the two stiffener structure. All modes within 500-2000 Hz and $40 \times 30$ MSE-DI elements are used in the analysis.

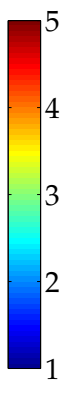

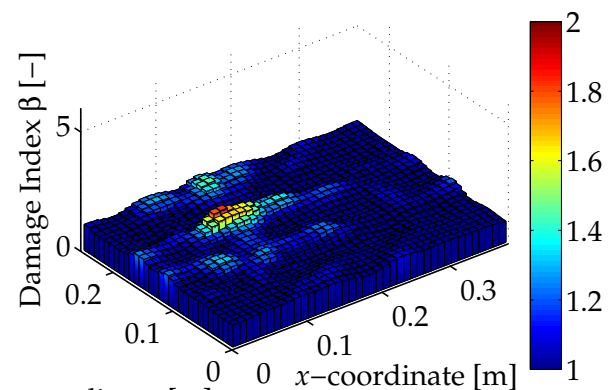

$y$-coordinate $[\mathrm{m}]$

(a) 2D formulation.

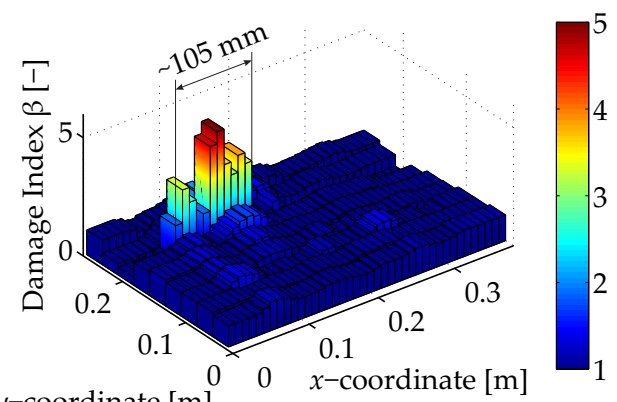
$y$-coordinate $[\mathrm{m}]$

(b) $1 \mathrm{D}$ formulation in $x$-direction.

$y$-coordinate $[\mathrm{m}]$

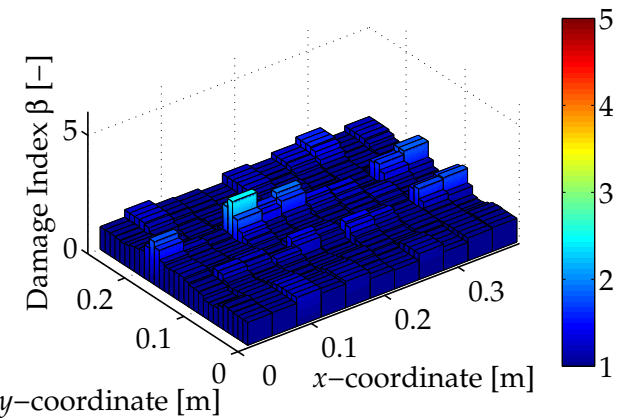

(c) $1 \mathrm{D}$ formulation in $y$-direction.

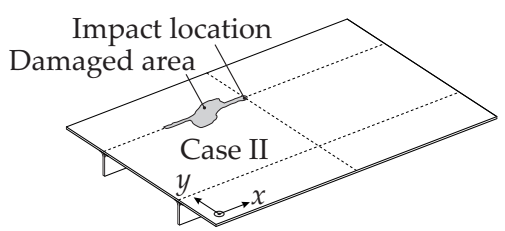

Figure 4.9 Damage index $\beta_{i j}$ distribution for damage scenario II in the two stiffener structure. All modes within 500-2000 Hz and $40 \times 30 \mathrm{MSE}$ DI elements are used in the analysis. 
the frequency range considered in the analysis. The real damage length $(\approx 120 \mathrm{~mm})$ is underestimated by approximately $12 \%$ for the situation considered here. Despite the fact that the MSE-DI algorithm does not allow for a physical interpretation of the damage severity in terms of mechanical properties [22, 43], the elements with the highest damage index values are predicted at the center of the damaged area. These elements belong to the region within the damaged area with the most severe change in the local dynamic behavior.

Figure 4.9(c) presents the results obtained by the 1D formulation in $y$-direction. Slightly higher damage indices are predicted at the location of the skin-stiffener damage. However, also several other potential damage locations are predicted, hence showing a propensity for false damage predictions.

The results presented until now show that the sensitivity of the method depends on the extent to which the dynamic behavior is affected by the local damage. This effect is defined by the failure mechanism and the location of the damage with respect to the structural design. Hence, the highest sensitivity is obtained for skin-stiffener damage by considering the 1D formulation underneath and in the direction of the stiffeners. This is caused by the fact that mainly the flexural stiffness in this direction is affected by the skin-stiffener interface failure. The flexural stiffness perpendicular to the stiffener is hardly affected by the interface damage. This directional behavior is also clearly illustrated by comparing the normalized mode shape curvatures in $x$ - and $y$-direction of the pristine $\left(f_{n}=996.4 \mathrm{~Hz}\right)$ and damaged $\left(f_{n}=987.3 \mathrm{~Hz}\right)$ structure in Figure 4.10. Locally higher amplitudes are found near the damaged interface for the curvature in $x$-direction, while the curvature in $y$-direction seems hardly affected. This difference in $x$ - and $y$-direction also explains the reduced sensitivity of the 2D formulation of the MSE-DI algorithm, since data obtained in both directions is used in that case.

\subsubsection{Three stiffener structure with damage scenario III}

The distributions of the damage index $\beta_{i j}$ and normalized damage index $Z_{i j}$ for damage scenario III in the three stiffener structure are respectively shown in Figures 4.11 and 4.12. The 2D formulation of the MSE-DI algorithm, Figure 4.11(a), presents the highest indices at the impact damaged area. This indicates that the damaged area is detected and localized by the 2D MSE-DI algorithm. The results also allow for a very rough estimation of the geometry of the damaged area, although the damage index values at the damaged area are relatively small.

The normalized damage index $Z_{i j}$, described by Equation (4.10), provides a statistical measure for outliers caused by the local damage. It indicates by how many standard deviations $\sigma$ the damage index $\beta_{i j}$ in each element deviates from the mean value $\mu$. The damage index $\beta_{i j}$ tends to show a normal distribution with values close to one for the undamaged regions. Elements with a $Z_{i j}$ value larger than 2 (95\% confidence interval) are generally classified as damaged. Figure 4.12(a) 


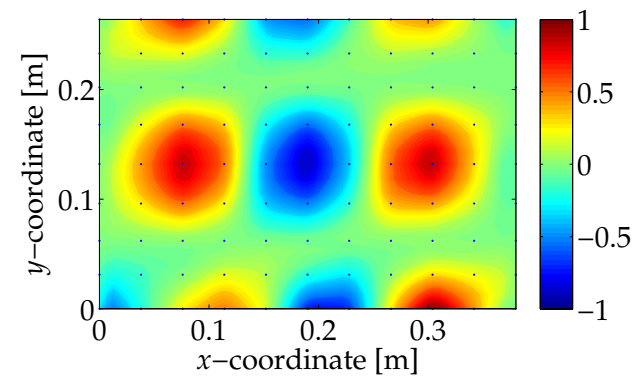

(a) Normalized mode shape curvature [-] in $x$-direction of the pristine structure.

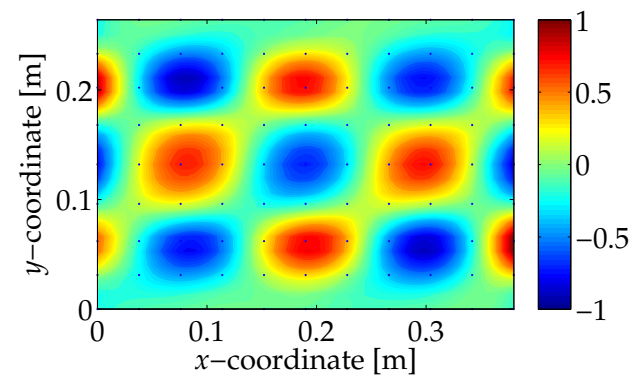

(c) Normalized mode shape curvature [-] in $y$-direction of the pristine structure.

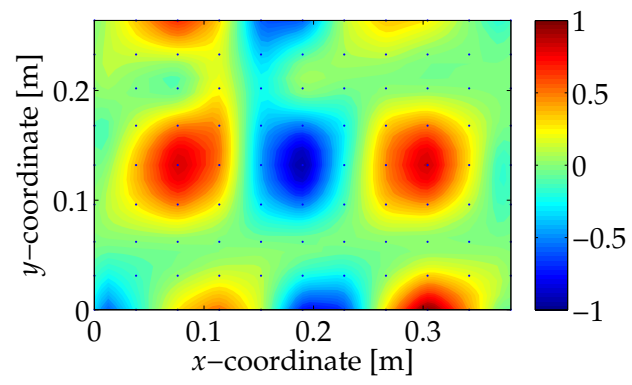

(b) Normalized mode shape curvature [-] in $x$-direction of the damaged structure.

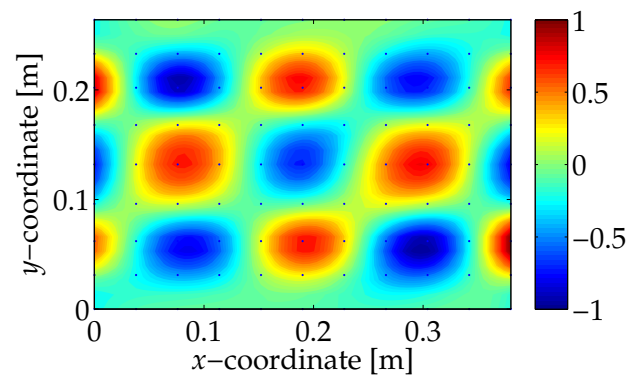

(d) Normalized mode shape curvature [-] in $y$-direction of the damaged structure.

Figure 4.10 Normalized mode shape curvatures $\partial^{2} u_{z}^{(n)} / \partial x^{2}$ and $\partial^{2} u_{z}^{(n)} / \partial y^{2}$ of the $(a, c)$ pristine $\left(f_{n}=996.4 \mathrm{~Hz}\right)$ and the $(b, d)$ damaged $\left(f_{n}=987.3 \mathrm{~Hz}\right)$ two stiffener structure for damage scenario II.

shows for the $2 \mathrm{D}$ formulation that the damage index values $Z_{i j}$ at the damaged region deviate up to 9 times the standard deviation $\sigma$ from the mean value $\mu$, indicating the significance of the obtained result. Comparison of $Z_{i j}$ results between different cases is often rather difficult due to its dependency on the number of elements selected in the MSE-DI algorithm.

In contrast to the obtained result, it must be noticed that the modal parameters themselves are hardly affected by the impact damage. The average change in the natural frequency was $\Delta f_{n}=0.06 \%$ (maximum: $\Delta f_{n}=0.31 \%$ ) within the considered frequency range. The mode shapes within this range provide an average $M A C$ value of 0.992 (minimum: $M A C=0.930$ ), as shown in Figure 4.7(c).

In the previous section it was shown that, in the case of skin-stiffener damage, the best results were obtained by considering the 1D formulation of the MSE-DI algorithm in the direction of the stiffeners. The opposite behavior is shown for the impact damage at the stiffener run-out as considered here. Figures 4.11(b) 


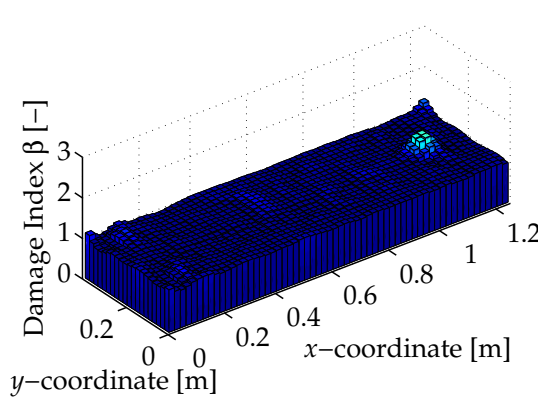

(a) 2D formulation.

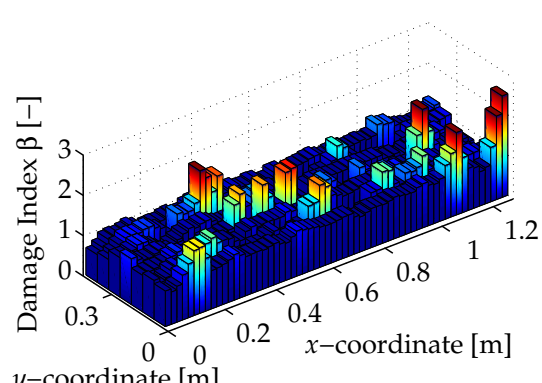
$y$-coordinate $[\mathrm{m}]$

(b) $1 \mathrm{D}$ formulation in $x$-direction.

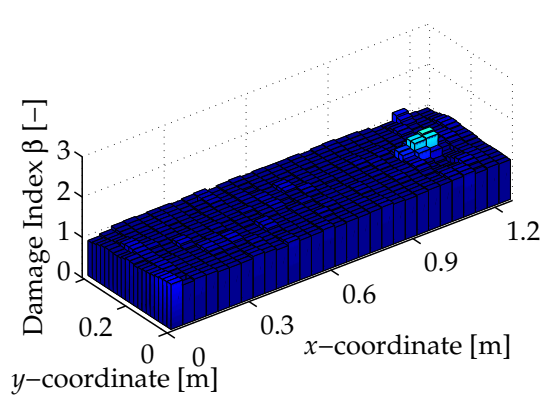

(c) $1 \mathrm{D}$ formulation in $y$-direction.

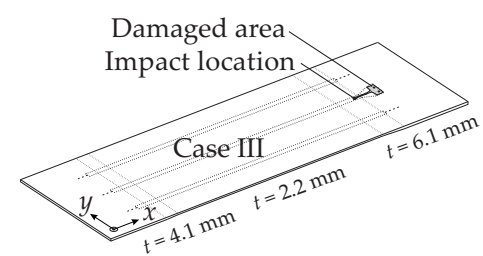

Figure 4.11 Damage index $\beta_{i j}$ distribution for damage scenario III in the three stiffener structure. All modes within 250-1000 Hz and 60×20 MSEDI elements are used in the analysis.

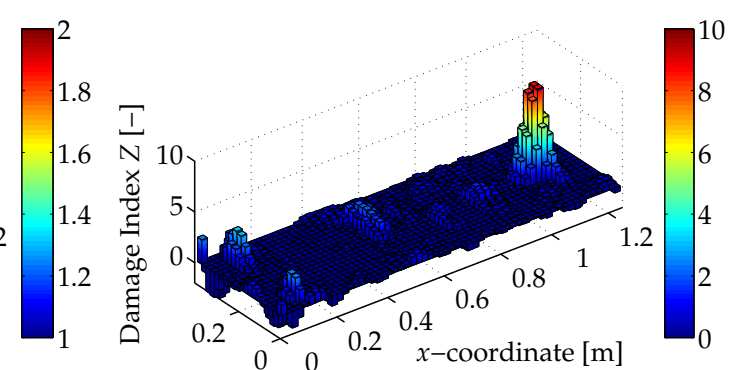
$y$-coordinate

(a) 2D formulation.

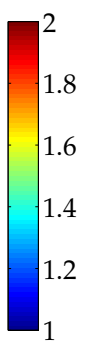

$$
y \text {-coordinate }[\mathrm{m}]
$$

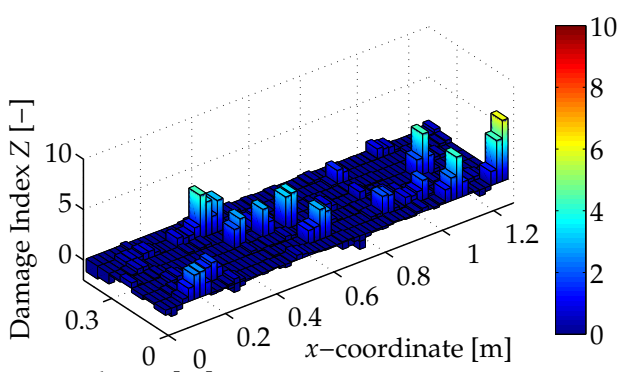

(b) $1 \mathrm{D}$ formulation in $x$-direction.

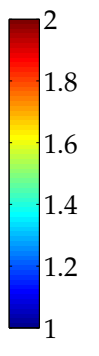
$y$-coordinate $[\mathrm{m}]$

(c) $1 \mathrm{D}$ formulation in $y$-direction.

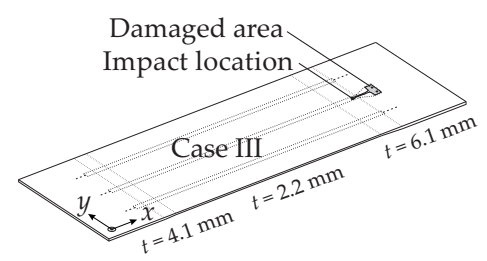

Figure 4.12 Normalized damage index $Z_{i j}$ for damage scenario III in the three stiffener structure. All modes within 250-1000 Hz and 60×20 MSEDI elements are used in the analysis. 


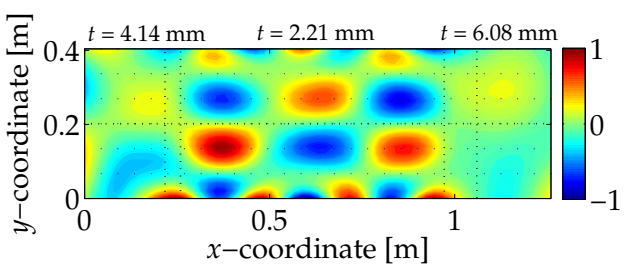

(a) Local torsion $\left(f_{n}=538.2 \mathrm{~Hz}\right)$.

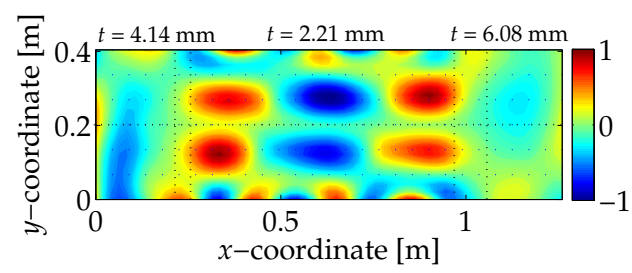

(b) Local bending $\left(f_{n}=617.6 \mathrm{~Hz}\right)$.

Figure 4.13 Normalized mode shapes $u_{z}^{(n)}(x, y)$ of the pristine structure with (a) local torsion $\left(f_{n}=538.2 \mathrm{~Hz}\right)$ and $(b)$ local bending $\left(f_{n}=617.6 \mathrm{~Hz}\right)$ deformation around the central stiffener. Both mode shapes show a wavelength transition in $x$-direction at the thicker sections of the structure.

and 4.11(c) show the damage index $\beta_{i j}$ distributions obtained by applying the MSEDI algorithm in respectively $x$ - and $y$-direction. Figures 4.12(b) and 4.12(c) represent the same directions in the case of the normalized damage index $Z_{i j}$. Several false positives appear for the $x$-direction, while the $y$-direction clearly predicts the presence and the location of the impact damage correctly.

The most likely explanation for the reduced effect in $x$-direction is threefold. Firstly, the damage is located at a region that already shows a geometrical discontinuity in $x$-direction (end of stiffened section) for the pristine case. This causes a transition in the local deformation patterns and reduces the possibility for the run-out damage to be expressed in the measured curvatures in this direction. Secondly, the damage is located at the thickest part of the skin. Generally, the thickest skin section showed a relatively large wavelength of the mode shape in $x$-direction, analogous to lower vibration modes, compared to the wavelength in $x$-direction at the mid-section and the wavelength in $y$-direction. The reduced sensitivity for the $x$-direction is understandable, since lower vibration modes are in general less affected by local damage compared to higher vibration modes [18]. The differences in wavelength are clearly depicted in Figures 4.13(a) and 4.13(b). Thirdly, a substantial amount of mode shapes show a local torsional deformation around the central stiffener in $x$-direction, similar to Figure 4.13(a). An earlier study on a composite T-beam [18] revealed that the extent of the influence depends on the type of local deformation around the damaged area. The mode shape in $x$-direction will be hardly affected if the deformation around the damage represents local torsion in the $y z$-plane, since the damage is located close to the local rotational axis. Figure 4.14 schematically demonstrates the difference between local torsion and local bending behavior around a skin-stiffener connection. Any potential nonlinear effect (e.g. opening and closing behavior of the delamination) in the measured structural response is not considered in the MSE-DI analysis, since it relies on a linear structural model. The modal data obtained from the random excitation reflects a linear and stationary representation of the system.

The more pronounced effect of the damage in the MSE-DI results for the $y$-direction 


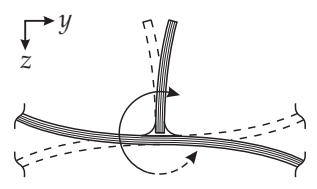

(a) Pristine.

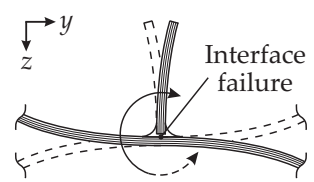

(b) Damaged.

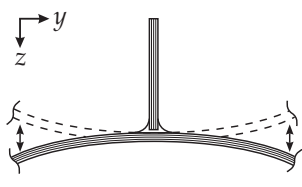

(c) Pristine.

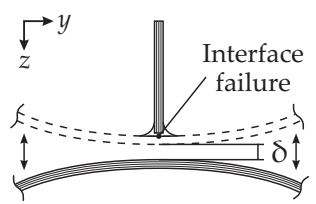

(d) Damaged.

Figure 4.14 Schematic representation of $(a, b)$ local torsion and $(c, d)$ local bending deformation around $a$ skin-stiffener connection for a $(a, c)$ pristine and $(b, d)$ damaged structure.

can be explained by the widening of the stiffener towards its end, as shown in Figure 4.3(c). The delamination underneath the titanium insert locally reduces the bending stiffness in $y$-direction. Moreover, the wavelengths in $y$-direction are for many mode shapes relatively short compared to the wavelengths in $x$-direction at the damaged area. As explained before, this causes a larger sensitivity to changes by local damage.

\subsection{Discussion}

The derivation of the damage identification algorithm, presented in Section 4.3, relies on a number of assumptions and simplifications. One of the most important simplifications concerns the 1D and 2D formulation of the algorithm. The 2D formulation assumes an isotropic description of the plate flexural rigidity. On the other hand, the 1D formulation assumes that the flexural rigidity in one direction is dominant and that all twisting and Poisson related effects are neglectable. In reality, the stiffeners cause a local anisotropic design of the structures. As a consequence, the validity of the $2 \mathrm{D}$ formulation is essentially only justified at the unstiffened skin sections, whereas the 1D formulation provides the most realistic representation at the stiffened skin sections. The results obtained for the two stiffener structure complies with this decomposition, since the $1 \mathrm{D}$ formulation outperforms the $2 \mathrm{D}$ formulation at the stiffeners. The damage of the three stiffener structure showed a different behavior due to the fact that the damage is located at the stiffener run-out. The results presented in Section 4.5 demonstrated the capabilities of the modal curvature based approach to identify damage in composite skin-stiffener structures. Several researchers [16, 23], however, question the suitability of modal data for damage identification due to a relatively low sensitivity. The present work showed that a refinement of this statement is justified. First of all, there is the tradeoff between the sensitivity to damage of the algorithm and its noise rejection capability. A high sensitivity is desired to identify damage at an early stage. On the other hand, it also increases the sensitivity to uncertainties, hence potentially causing false damage identifications. Secondly, the minimum required sensitivity of an approach is generally defined by the allowable damage limit (ADL) of 
the structural component. Visual inspection of aircraft components according to the BVID criteria [46] allows for the identification of macroscopic damage rather than microscopic defects. It is therefore not inherently relevant to require submacroscopic damage identification capabilities for all components. Finally, the specific application of the methodology is also of importance. The potential of the method can be utilized by applying the method in an adequate way. Analyzing the relation between the damage location, the structural design and the dynamic behavior revealed that the current method tends to be primarily effective for health monitoring of the skin-stiffener connections.

In view of application there are still a number of factors to consider. High resolution monitoring requires a relatively large number of measurement points. This contradicts with the practical application of a vibration based technology, since the number of sensors is often limited. There is a need to optimize the amount and location of the data points used to describe the mode shapes accurately. The results obtained for the two stiffener structure showed that a reduced measurement grid, that only contains measurement points at the skinstiffener connection (i.e. $2 \times 11$ measurement points), would still allow for a successful identification of the skin-stiffener failure. This approach provides an effective way of monitoring the most critical areas (i.e. the 'hotspots') of a skinstiffener structure. The practical application of the approach also requires an integrated sensor system, since a laser vibrometer is not feasible in most situations. Distributed strain sensing technologies based on, for example, piezoelectric or fiber optic sensing technologies provide a potential solution [25, 29]. The direct relation between strain and curvature could also be beneficial to overcome the numerical errors involved with the calculation of the curvatures, as discussed in various studies [15, 25, 50,57]. Another factor to consider is the sensitivity of the dynamic parameters to environmental changes. Constant environmental conditions were assumed during the experimental investigation presented. The numerical models discussed in $[42,43]$ could be employed to account for the effects of changing environmental conditions.

\subsection{Conclusions}

The aim of this chapter was to experimentally investigate the feasibility of a vibration based damage identification approach to identify impact damage in advanced composite skin-stiffener structures. Mode shape curvature changes, that locally arise under dynamic loading of damaged structures, combined with the modal strain energy damage index (MSE-DI) algorithm were utilized to identify the defects. Special attention was paid to the effective application of this vibration based methodology by investigating the relation between the damage location, the structural design and the dynamic behavior. 


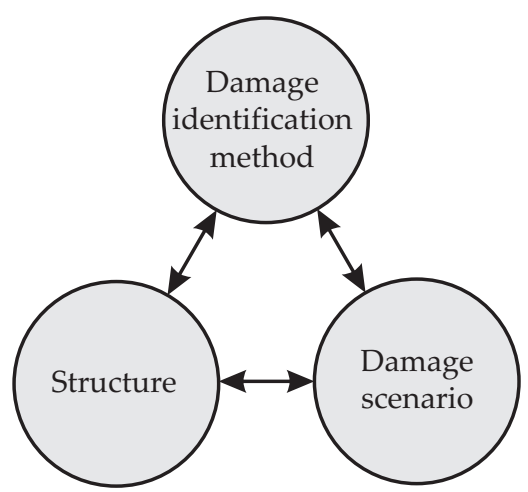

Figure 4.15 The multidisciplinary framework associated with the development of a structural health monitoring approach.

Experiments on two advanced composite skin-stiffener structures demonstrated the capability of a modal curvatures based MSE-DI algorithm to detect and localize barely visible impact damage at the skin-stiffener connections. The method allows for a rough estimation of the geometry of the damaged area, even in a stiffened structure with non-uniform skin thickness distribution. Each of the individual formulations (1D in $x$-direction and 1D in $y$-direction) can be beneficial, depending on the damage location with respect to the structural design.

The 1D formulation of the MSE-DI outperforms the 2D formulation in terms of sensitivity, due to the anisotropic design of the specimen. The most effective results were obtained by considering the $1 \mathrm{D}$ formulation underneath and in the direction of the stiffeners for damage at the stiffener mid-section and perpendicular to the stiffeners for damage at the stiffener run-out. These results are explained by the location of the damage with respect to the structural design and to what extent this affects the measured dynamic behavior in terms of curvature in $x$ - and $y$-direction.

Impact damage at the skin in between stiffeners could not be identified by considering mode shape curvatures and the MSE-DI method. The local failure mechanism hardly affects the structural stiffness or mass. The methodology requires a substantial change in bending stiffness or mass. This limits the effective application of this method to health monitoring of skin-stiffener connections. The method can be utilized as an approach for 'hotspot' monitoring by only considering the measurement points underneath the skin-stiffener connections. Failure primarily located in the skin tends to require a different SHM approach. A combination of several damage identification technologies, operating at different frequency levels, can be a potentially strong solution.

Finally, it can be concluded that SHM is a design related problem (see Figure 4.15). It was shown that the design of a structure and the position of the damage affect the effectiveness of the methodology. The development, selection and application 
of damage identification algorithms is made-to-measure work and requires a thorough physical understanding of the critical damage locations, the potential failure mechanisms and their effect on the dynamic behavior. Therefore, this process has to become an integral part of the structural design process. A scenario based approach, based on the results obtained in this study, contributes to the development of guidelines for effective health monitoring of advanced composite skin-stiffener structures.

\section{Acknowledgments}

The authors kindly acknowledge the support of Fokker Aerostructures B.V., Hoogeveen, The Netherlands, for manufacturing the composite panels used in this research. This work is carried out in the framework of the European project Clean Sky, Eco-Design ITD (grant agreement number CSJU-GAM-ED-2008-001).

\section{References}

[1] C. Boller, F.-K. Chang, and Y. Fujino. Encyclopedia of structural health monitoring. John Wiley \& Sons, Ltd, Chichester, UK, 2009.

[2] K. Diamanti and C. Soutis. Structural health monitoring techniques for aircraft composite structures. Progress in Aerospace Sciences, 46(8):342-352, 2010.

[3] C.-P. Fritzen and P. Kraemer. Self-diagnosis of smart structures based on dynamical properties. Mechanical Systems and Signal Processing, 23(6):1830-1845, 2009.

[4] C.R. Farrar and D.A. Jauregui. Comparative study of damage identification algorithms applied to a bridge: I. Experiment. Smart Materials and Structures, 7:704-719, 1998.

[5] C.R. Farrar and D.A. Jauregui. Comparative study of damage identification algorithms applied to a bridge: II. Numerical study. Smart Materials and Structures, 7:720-731, 1998.

[6] J.J. Lee and C.B. Yun. Damage diagnosis of steel girder bridges using ambient vibration data. Engineering Structures, 28(6):912-925, 2006.

[7] C.-P. Fritzen. Vibration-based structural health monitoring - Concepts and applications. Key Engineering Materials, 293-294:3-18, 2005.

[8] N. Stubbs, S. Park, C. Sikorsky, and S. Choi. A global non-destructive damage assessment methodology for civil engineering structures. International Journal of Systems Science, 31(11):1361-1373, 2000.

[9] Z. Su, L. Ye, and Y. Lu. Guided lamb waves for identification of damage in composite structures: a review. Journal of Sound and Vibration, 295(3-5):753-780, 2006.

[10] A. Raghavan and C.E.S. Cesnik. Review of guided-wave structural health monitoring. The Shock and Vibration Digest, 39(2):91-114, 2007.

[11] J.-B. Ihn and F.-K. Chang. Pitch-catch active sensing methods in structural health monitoring for aircraft structures. Structural Health Monitoring, 7(1):5-19, 2008.

[12] W.J. Staszewski, S. Mahzan, and R. Traynor. Health monitoring of aerospace composite structures - Active and passive approach. Composites Science and Technology, 69(11-12):1678-1685, 2009. 
[13] G. Park and D.J. Inman. Structural health monitoring using piezoelectric impedance measurements. Philosophical Transactions of the Royal Society A: Mathematical, Physical and Engineering Sciences, 365(1851):373-392, 2007.

[14] D. Montalvão, N.M.M. Maia, and A.M.R. Ribeiro. A review of vibration-based structural health monitoring with special emphasis on composite materials. Shock and Vibration Digest, 38(4):295-326, 2006.

[15] W. Fan and P. Qiao. Vibration-based damage identification methods: a review and comparative study. Structural Health Monitoring, 10(1):83-111, 2011.

[16] E.P. Carden and P. Fanning. Vibration based condition monitoring: a review. Structural Health Monitoring, 3(4):355-377, 2004.

[17] M. Dilena and A. Morassi. Dynamic testing of a damaged bridge. Mechanical Systems and Signal Processing, pages 1-23, 2011.

[18] T.H. Ooijevaar, R. Loendersloot, L.L. Warnet, A. de Boer, and R. Akkerman. Vibration based structural health monitoring of a composite T-beam. Composite Structures, 92(9):2007-2015, 2010.

[19] R. Loendersloot, T.H. Ooijevaar, L.L. Warnet, A. de Boer, and R. Akkerman. Vibration based structural health monitoring and the modal strain energy damage index algorithm applied to a composite T-beam. In C.M.A. Vasques and J.D. Rodrigues, editors, Vibration and Structural Acoustics Analysis: Current Research and Related Technologies, Chapter 6, pages 121-150. Springer, 2011.

[20] N. Stubbs and C.R. Farrar. Field verification of a nondestructive damage localization and severity estimation algorithm. In Proceedings of the 13th International Modal Analysis Conference (IMAC XIII), pages 210-218, 1995.

[21] P.J. Cornwell, S.W. Doebling, and C.R. Farrar. Application of the strain energy damage detection method to plate-like structures. Journal of Sound and Vibration, 224(2):359-374, 1999.

[22] A. Alvandi and C. Cremona. Assessment of vibration-based damage identification techniques. Journal of Sound and Vibration, 292(1-2):179-202, 2006.

[23] J. Humar, A. Bagchi, and H. Xu. Performance of vibration-based techniques for the identification of structural damage. Structural Health Monitoring, 5(3):215-241, 2006.

[24] J.-M. Ndambi, J. Vantomme, and K. Harri. Damage assessment in reinforced concrete beams using eigenfrequencies and mode shape derivatives. Engineering Structures, 24(4):501-515, 2002.

[25] W. Lestari, P. Qiao, and S. Hanagud. Curvature mode shape-based damage assessment of carbon/epoxy composite beams. Journal of Intelligent Material Systems and Structures, 18(3):189-208, 2007.

[26] Y.Y. Li. Hypersensitivity of strain-based indicators for structural damage identification: a review. Mechanical Systems and Signal Processing, 24(3):653-664, 2010.

[27] P. Cawley and R.D. Adams. The location of defects in structures from measurements of natural frequencies. Journal of Strain Analysis, 14(2):49-57, 1979.

[28] O.S. Salawu. Detection of structural damage through changes in frequency: a review. Engineering Structures, 19(9):718-723, 1997.

[29] W.J.B. Grouve, L.L. Warnet, A. de Boer, R. Akkerman, and J. Vlekken. Delamination detection with fibre Bragg gratings based on dynamic behaviour. Composites Science and Technology, 68(12):2418-2424, 2008.

[30] E. Parloo, P. Guillaume, and M. van Overmeire. Damage assessment using mode shape sensitivities. Mechanical Systems and Signal Processing, 17(3):499-518, 2003. 
[31] L.M. Khoo, P.R. Mantena, and P. Jadhav. Structural damage assessment using vibration modal analysis. Structural Health Monitoring, 3(2):177-194, 2004.

[32] A.K. Pandey and M. Biswas. Damage detection in structures using changes in flexibility. Journal of Sound and Vibration, 169(1):3-17, 1994.

[33] T. Toksoy and A.E. Aktan. Bridge-condition assessment by modal flexibility. Experimental Mechanics, 34(3):271-278, 1994.

[34] F.N. Catbas, M. Gul, and J.L. Burkett. Damage assessment using flexibility and flexibility-based curvature for structural health monitoring. Smart Materials and Structures, 17(1):1-12, 2008.

[35] A.K. Pandey, M. Biswas, and M.M. Samman. Damage detection from changes in curvature mode shapes. Journal of Sound and Vibration, 145(2):321-332, 1991.

[36] M.M. Abdel Wahab and G. De Roeck. Damage detection in bridges using modal curvatures: application to a real damage scenario. Journal of Sound and Vibration, 226(2):217-235, 1999.

[37] H. Hu and C. Wu. Development of scanning damage index for the damage detection of plate structures using modal strain energy method. Mechanical Systems and Signal Processing, 23(2):274-287, 2009.

[38] P. Qiao, K. Lu, W. Lestari, and J. Wang. Curvature mode shape-based damage detection in composite laminated plates. Composite Structures, 80(3):409-428, 2007.

[39] H. Hu and J. Wang. Damage detection of a woven fabric composite laminate using a modal strain energy method. Engineering Structures, 31(5):1042-1055, 2009.

[40] A.A. Cury, C.C. Borges, and F.S. Barbosa. A two-step technique for damage assessment using numerical and experimental vibration data. Structural Health Monitoring, 10(4):417-428, 2010.

[41] S. Banerjee, F. Ricci, E. Monaco, and A. Mal. A wave propagation and vibration-based approach for damage identification in structural components. Journal of Sound and Vibration, 322(1-2):167-183, 2009.

[42] R. Loendersloot, T.H. Ooijevaar, L.L. Warnet, A. de Boer, and R. Akkerman. Vibration based structural health monitoring of a composite plate with stiffeners. In Proceedings of International Conference on Noise and Vibration Engineering (ISMA2010), pages 909-924, 2010.

[43] R. Loendersloot, T.H. Ooijevaar, A. de Boer, and R. Akkerman. Development of a damage quantification model for composite skin-stiffener structures. In C. Boller and H. Janocha, editors, New Trends in Smart Technologies, pages 99-108. Fraunhofer Verlag, 2013.

[44] A. Offringa, J. List, J. Teunissen, and H. Wiersma. Fiber reinforced thermoplastic butt joint development. In Proceedings of the International SAMPE Conference, pages 1-16, 2008.

[45] A. Offringa, J.W. van Ingen, and A. Buitenhuis. Butt-joined, thermoplastic stiffened-skin concept development. SAMPE Journal, 48(2):7-15, 2012.

[46] J. Baaran. Visual inspection of composite structures. Technical report, Institute of Composite Structures and Adaptive Systems, DLR Braunschweig, 2009.

[47] T.A. Duffey, S.W. Doebling, C.R. Farrar, W.E. Baker, and W.H. Rhee. Vibration-based damage identification in structures exhibiting axial and torsional response. Journal of Vibration and Acoustics, 123(1):84, 2001.

[48] J. Stewart. Calculus: early transcendentals. 5th edition. Brooks/Cole - Thomson 
Learning, 2003.

[49] R.E. Shiffler. Maximum Z scores and outliers. The American Statistician, 42(1):79-80, 1988.

[50] A.P. Adewuyi, Z. Wu, and N.H.M. Kammrujaman Serker. Assessment of vibration-based damage identification methods using displacement and distributed strain measurements. Structural Health Monitoring, 8(6):443-461, 2009.

[51] B. Samali, J. Li, F.C. Choi, and K. Crews. Application of the damage index method for plate-like structures to timber bridges. Structural Control and Health Monitoring, pages 1-23, 2009.

[52] E.S. Sazonov and P. Klinkhachorn. Optimal spatial sampling interval for damage detection by curvature or strain energy mode shapes. Journal of Sound and Vibration, 285(4-5):783-801, 2005.

[53] B.J. Schwarz and M.H. Richardson. Experimental modal analysis. In CSI Reliability Week, Orlando, FL, pages 1-12, 1999.

[54] M.H. Richardson and B.J. Schwarz. Modal parameter estimation from operating data. Sound and Vibration, 37(1):28-39, 2003.

[55] M.H. Richardson and D.L. Formenti. Global curve fitting of frequency response measurements using the rational fraction polynomial method. In 3rd International Modal Analysis Conference, pages 1-8, 1985.

[56] R.J. Allemang. The modal assurance criterion - Twenty years of use and abuse. Journal of Sound and Vibration, 1:14-21, 2003.

[57] C.S. Hamey, W. Lestari, P. Qiao, and G. Song. Experimental damage identification of carbon/epoxy composite beams using curvature mode shapes. Structural Health Monitoring, 3(4):333-353, 2004. 


\title{
Nonlinear dynamic behavior of an impact damaged composite skin-stiffener structure ${ }^{1}$
}

\begin{abstract}
One of the key issues in composite structures for aircraft applications is the early identification of damage. Often, service induced damage does not involve visible plastic deformation, but internal matrix related damage. A wide range of technologies, comprising global vibration and local wave propagation methods, can be employed for health monitoring purposes. Traditional modal analysis based methods are linear methods. The effectiveness of these methods is sometimes limited since they rely on a stationary and linear description of the system. The nonlinear interaction between a low frequency wave field and a local impact induced damage in a composite skin-stiffener structure is experimentally demonstrated in this work. The different mechanisms linked to the distorted waveforms are separated with the help of phase portraits. The harmonic waveform distortions are concentrated at the damaged region and increased for higher excitation amplitudes. It is shown that linear damage identification methods are feasible for low excitation amplitudes, but that the presence of nonlinear dynamic effects cannot remain silent for higher amplitudes. Analyzing the damage induced nonlinear effects can provide useful information about the current state of the structure.
\end{abstract}

1 Reproduced from: T.H. Ooijevaar, M.D. Rogge, R. Loendersloot, L.L. Warnet, R. Akkerman, T. Tinga, Nonlinear dynamic behavior of an impact damaged composite skin-stiffener structure. In preparation for: Composite Science and Technology, 2014. 


\subsection{Introduction}

Composite skin-stiffener structures are a typical aerospace structural component used to increase the bending stiffness of a component without a severe weight penalty [1]. These skin-stiffener structures are considered to be safety-critical components. Small defects at the skin-stiffener connection, caused by for example impact, can significantly affect the performance of such a component. Often, the damage does not involve visible plastic deformations, but is barely visible and internal matrix related. This makes skin-stiffener connections a suitable candidate for health monitoring.

A wide range of technologies, comprising global vibration and local wave propagation methods, can be employed to monitor the integrity of structural components [2-6]. The selection of the best technology is often a matter of compromise. Traditional low frequency modal analysis based damage identification methods are linear methods [3, 7]. Damage sensitive features are extracted by fitting a mathematical model to the responses measured. Despite various successful applications [8,9], the effectiveness of these methods is sometimes limited since they rely on a stationary and linear description of the system. A more realistic damage description requires a physical understanding of the effect of the damage on the dynamic behavior of the structure. The interaction between damage and an acoustic wave field can yield dynamic phenomena that exhibit complicated material (e.g. nonlinear elasticity) and geometrical (e.g. contact and friction) nonlinear behavior $[10,11]$. The symptoms related to these nonlinear phenomena can be utilized for nonlinear system characterization and damage identification purposes.

The most commonly used nonlinear feature is probably the generation of higher harmonics in the structural response. Selective imaging of these higher harmonics was used by Krohn et al. [12] and Solodov et al. [13] to localize and characterize small defects. Alternative nonlinear features are the generated sub-harmonics, DC offsets, wave form distortions, frequency shifts, coherence functions, signal modulations, etc. [3, 14]. Various researchers [15-17] state the potentially higher sensitivity involved with these characteristics over the classical linear methods. However, difficulties concern the experimental evidence and understanding of the physical mechanisms related to the nonlinearities combined with the diversity of the nonlinear mechanisms originating at different scales of the composite component (micro-, meso- and macroscopic) [10]. Similar nonlinear effects can be a result of different mechanisms, hence hampering the separation of the mechanisms. Nonlinear elasticity and contact nonlinearities can, for example, both yield higher harmonics in a dynamic response [14].

Researchers try to obtain a better understanding of the mechanisms involved with the help of modeling. Della and Shu [18] reviewed models for the vibration of delaminated structures, while Friswell and Penny [19] did the same for crack-like damage. The complexity of the nonlinear effects introduced when non-bonded 
surfaces come into contact is one of the difficulties encountered in obtaining a realistic model representation. Solodov et al. [11] describe two of the nonlinear mechanisms involved with contact, the clapping and the friction mechanism. The clapping nonlinearity is assumed to be concerned with the lack of stiffness symmetry across the damage interface. One of the studies focusing on this delamination induced mechanism is presented by Müller et al. [20, 21]. They experimentally analyzed the vibro-impacting motion, including energy dissipation effects, along the contact interface of the delamination to establish a finite element description. As in many other investigations, their study is limited to an artificial delamination, in this case in a simple aluminium beam.

This chapter focuses on a composite skin-stiffener-like structure featuring impact induced damage. An experimental time domain analysis of the nonlinear dynamic behavior introduced by the damage is presented. The impact induced damage is located at the connection between skin and stiffener and mainly consists of delamination damage. The objective is to gain an understanding of the interaction between a dynamic wave field and the local skin-stiffener failure in order to support the development of damage identification approaches that are able to characterize skin-stiffener damage. A low frequency steady state harmonic shaker excitation was used. Responses were measured by a laser vibrometer at multiple points underneath the skin-stiffener connection. The dynamic mechanisms related to the nonlinear dynamic effects in the harmonic waveforms are identified with the help of phase portraits. Special attention is paid to the spatial effects and the influence of the excitation parameters. The study presented in this chapter can lead to guidelines for the applicability of the linear damage identification methods, but can also trigger the development of enhanced damage identification methodologies.

\subsection{Composite skin-stiffener structure}

Thermoplastic composites provide specific opportunities due to their relatively high toughness and unique processing capabilities [1]. The ambition for automated manufacturing of large quantities of large composite structures has fueled the development of new cost-reducing joining concepts. Recently, a new butt-joint skin-stiffener concept was developed by Fokker Aerostructures [1]. This simplified manufacturing concept uses preforms, which are connected by an injection molded filler in a co-consolidation process.

The structure investigated in this study is a thermoplastic skin-stiffener section made by Fokker Aerostructures according to their new joining concept. The structure is schematically illustrated in Figure 5.1. Both the skin and the stiffener are built from 16 individual plies of unidirectional carbon AS4D fiber reinforced thermoplastic (PEKK) material with a $[90 / 0]_{4, s}$ lay-up. The filler is made from PEKK and contains $20 \mathrm{wt} \%$ short carbon fibers. 


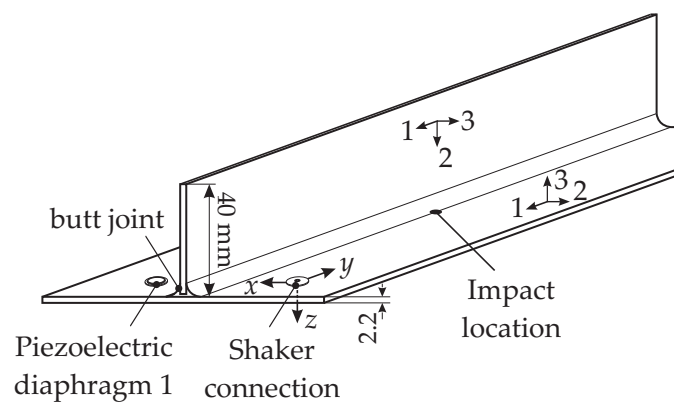

Piezoelectric diaphragm 2

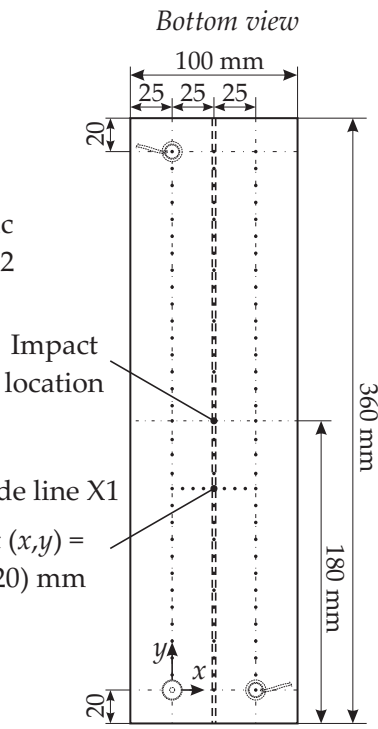

Node line Y1 Y2 Y3

Figure 5.1 Three dimensional and bottom view of the composite skin-stiffener structure with a butt-joint stiffener. The dimensions, the measurement points (dots), the position of the shaker and the impact location are indicated.

The damage scenario analyzed in this study comprises an impact damage located at the connection between skin and stiffener. This connection is considered as a safety-critical area, because damage at this connection can have major implications for the integrity of the entire component. Damage was introduced by utilizing a falling weight impact device and applying a repeated impact up to $15 \mathrm{~J}$. The ultrasonic C-scan in Figure 5.2 reveals a relatively complex, but typical fiber reinforced material related damage scenario. The damage consists of delamination at the interface between the skin and stiffener accompanied by a limited amount of damage between the first and second ply of the skin. Local delaminations were also introduced underneath one of the supports that was used during the impact testing.

\subsection{Experimental work}

The experimental process used to investigate the interaction between the dynamic wave field and the local damage consists of two steps. The global dynamic behavior of the pristine and damaged skin-stiffener structure is characterized in the first step. These dynamic characteristics are used as an input for the second step to study the nonlinear dynamic behavior of the damaged structure in detail. The current section 


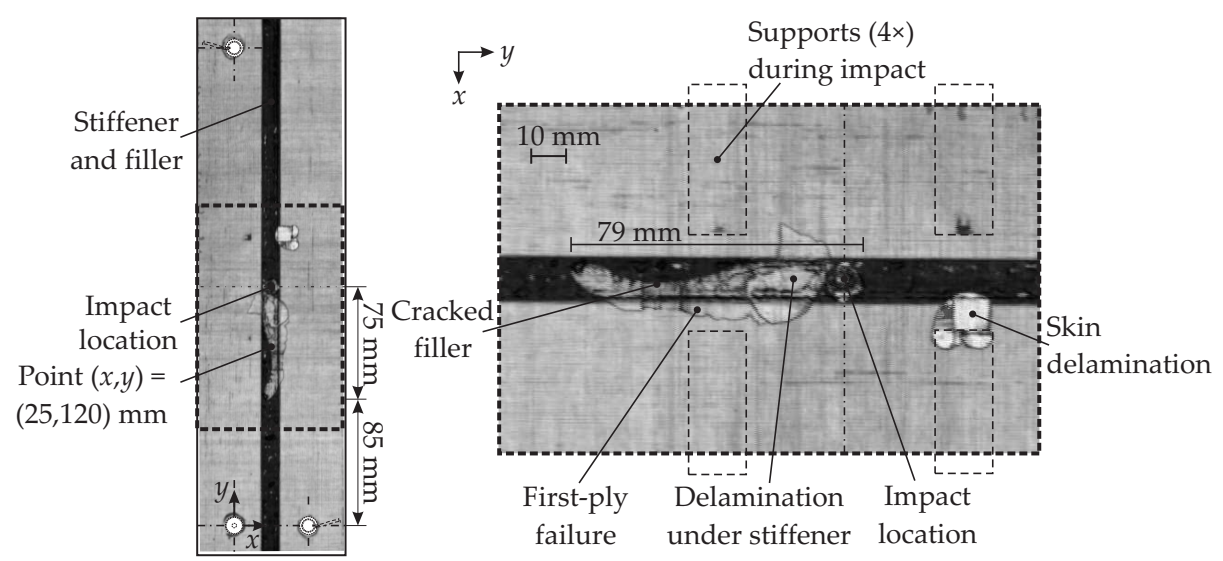

Figure 5.2 Ultrasonic C-scan of the impact damaged skin-stiffener structure showing a complex combination of failure mechanisms near the skin-stiffener interface.

addresses both steps, but starts with an introduction of the experimental set-up used in this work.

\subsubsection{Set-up and signal processing}

The set-up and data acquisition systems used for all experiments are schematically illustrated in Figure 5.3. Responses were measured before and after the impact damage was introduced in the composite skin-stiffener structure. The structure was freely suspended by an elastic wire, glued to the butt-joint, in order to isolate the structure from environmental vibrations. An electromechanical shaker was connected by a stringer and a force transducer to a corner of the structure. This position is selected in order to excite a large number of vibrational modes. A laser vibrometer, mounted on an $x / y$ traverse system, measured the velocities at different points at the skin of the structure. The measurement points are ordered according to three lines in $y$-direction ('Y1', 'Y2', 'Y3') and one line in $x$-direction $\left({ }^{\prime} \mathrm{X} 1^{\prime}\right)$, as shown in Figure 5.1. The location of line ' $\mathrm{X} 1$ ' matches with the center of the damaged area. A data acquisition system, controlled by a Labview application, was utilized to simultaneously send an excitation signal to the shaker and acquire the force and velocity responses of the structure.

\subsubsection{Initial global dynamic characterization}

In the first set of experiments, the global dynamic behavior of the structure is determined in terms of natural frequencies and the frequency dependent deflection patterns, referred to as operational deflection shapes (ODS). An excitation signal 


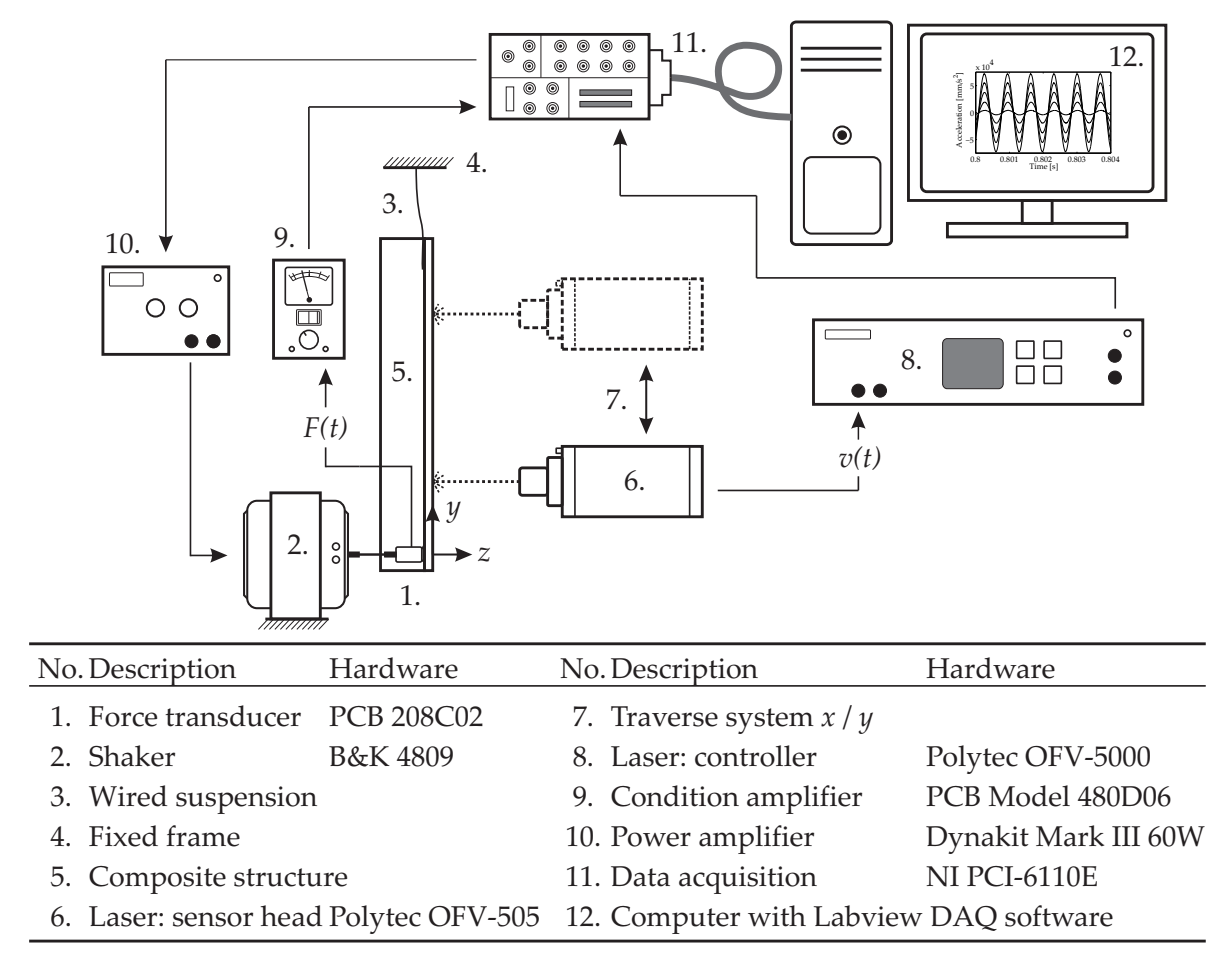

Figure 5.3 Experimental set-up.

composed of a linear sweep between 150 and $3050 \mathrm{~Hz}$ was sent to the shaker. The force response was measured at the fixed excitation point. The velocities were acquired at $51(3 \times 17)$ points, matching the node lines in $y$-direction according to Figure 5.1. All signals were acquired for 2.62 seconds ( $2^{17}$ samples) at a rate of $50 \mathrm{kHz}$. A measurement at each point was repeated 10 times. The acquired time responses were subsequently windowed, Fourier transformed and averaged to obtain the power spectral densities. The auto-power spectral density $S_{F_{i} F_{i}}(\omega)$ and cross-power spectral density $S_{F_{i} v_{j}}(\omega)$ are used to calculate the mobility frequency response functions $H_{F_{i} v_{j}}(\omega)$ between the fixed point of excitation $i$ and the roving measurement points $j$ according to [22]:

$$
H_{F_{i} v_{j}}(\omega)=\frac{S_{F_{i} v_{j}}(\omega)}{S_{F_{i} F_{i}}(\omega)}
$$

Figure 5.4 shows the magnitude of the total set of frequency response functions (FRFs) of the pristine structure. Sharp peaks correspond to the natural frequencies of the structure.

The operational deflection shapes of the structure are extracted at the natural 


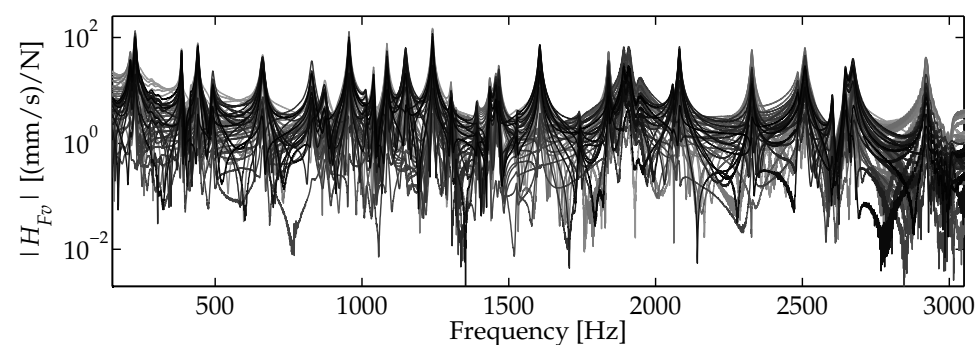

Figure 5.4 The magnitude of the frequency response functions for all $51(3 \times 17)$ measurement points of the pristine structure.

frequencies with the help of peak picking. At these frequencies, the complex operational deflection shapes become predominantly real valued and are a close approximation of the associated mode shapes [22]. Bending and torsion dominant operational deflection shapes are distinguished by considering the dominant real part of the operational deflection shapes, as shown in Figure 5.5. Table 5.1 provides an overview of the natural frequencies of the first six bending and torsion shapes for the pristine and damaged structure.

The present work concentrates on bending dominant operational deflection shapes in the $y z$-plane. Earlier research [8] showed that skin-stiffener damage hardly affects
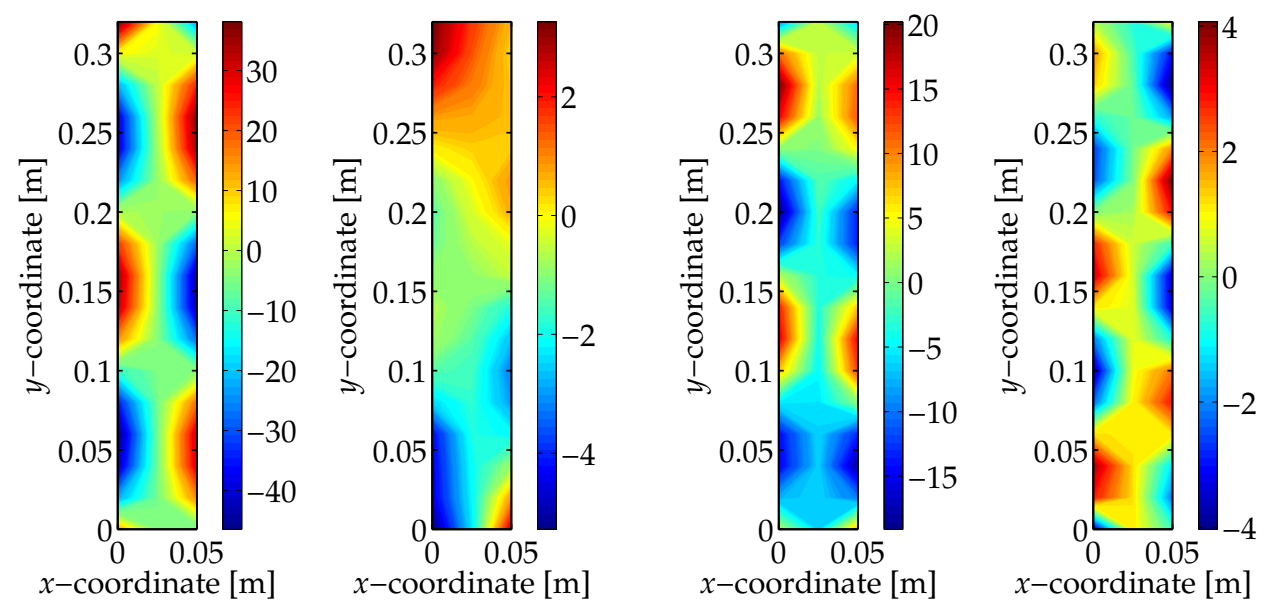
(a) $\quad \Re\left(H_{F v}\right)$ in $[(\mathrm{mm} / \mathrm{s}) / \mathrm{N}]$ at $f_{\mathrm{T}}^{(4)}=662 \mathrm{~Hz}$.
(b) $\quad \Im\left(H_{F v}\right)$ in $[(\mathrm{mm} / \mathrm{s}) / \mathrm{N}]$ at $f_{\mathrm{T}}^{(4)}=662 \mathrm{~Hz}$.
(c) $\Re\left(H_{F v}\right)$ in $[(\mathrm{mm} / \mathrm{s}) / \mathrm{N}]$ at $f_{\mathrm{B}}^{(4)}=1456 \mathrm{~Hz}$.
(d) $\Im\left(H_{F v}\right)$ in
$[(\mathrm{mm} / \mathrm{s}) / \mathrm{N}]$ at $f_{\mathrm{B}}^{(4)}=1456 \mathrm{~Hz}$.

Figure 5.5 Real $(a, c)$ and imaginary $(b, d)$ part of the operational deflection shapes of the pristine structure at the natural frequencies of the $4^{\text {th }}$ torsion mode $(a, b)$ and the $4^{\text {th }}$ bending mode $(c, d)$. 
Table 5.1 Natural frequencies of the $1^{\text {st }}$ till the $6^{\text {th }}$ bending and torsion modes of the pristine and damaged (indicated by a tilde) structure.

\begin{tabular}{ccccc}
\hline Mode & \multicolumn{2}{c}{ Bending $B_{y z}$} & \multicolumn{2}{c}{ Torsion $T_{y}$} \\
$n$ & $f_{\mathrm{B}}^{(n)}[\mathrm{Hz}]$ & $\tilde{f}_{\mathrm{B}}^{(n)}[\mathrm{Hz}]$ & $f_{\mathrm{T}}^{(n)}[\mathrm{Hz}]$ & $\tilde{f}_{\mathrm{T}}^{(n)}[\mathrm{Hz}]$ \\
\hline 1 & 956 & 949 & - & - \\
2 & 1040 & $1076^{1}$ & 228 & 221 \\
3 & 1241 & 1215 & 441 & 414 \\
4 & 1456 & 1455 & 662 & $664^{1}$ \\
5 & 1839 & 1833 & 1149 & 1119 \\
6 & 2328 & $2340^{1}$ & 1606 & 1586 \\
\hline 1 & \multicolumn{3}{l}{ A shaker replacement in between the measurements at the } \\
pristine and damaged structure caused some frequencies \\
to increase slightly (while they were expected to decrease). \\
The type of deflection shape remained unchanged.
\end{tabular}

torsional deformation shapes around the $y$-axis in these kinds of structures due to the small distance between the damage and the rotational axis.

\subsubsection{Harmonic waveform distortion}

In the second set of experiments, the interaction between the damage and the dynamic deformation of the structure is studied by applying a single tone harmonic excitation signal. The frequency of this signal corresponds to one of the bending frequencies according to Table 5.1 and is varied in strength. The force and velocity responses were simultaneously acquired at a sample rate of $1 \mathrm{MHz}$ for 1.05 seconds ( $2^{20}$ samples). No averaging was applied. Only the steady state response is considered in the analysis because it is independent of the initial conditions. The structure vibrates at steady state after the transient (start-up) responses have disappeared. A period of 0.8 seconds was revealed to be sufficiently long for these transient effects to become negligible.

Figures 5.6(a) and 5.7(a) show steady state velocity responses obtained for, respectively, the pristine and damaged structure by a forced excitation at a frequency matching the $4^{\text {th }}$ bending mode $\left(f_{\mathrm{B}}^{(4)}=1456 \mathrm{~Hz}, \tilde{f}_{\mathrm{B}}^{(4)}=1455 \mathrm{~Hz}\right)$ and 5 different excitation amplitudes. The velocity responses are measured at location $(x, y)=(0.025,0.120) \mathrm{m}$ according to the coordinate system presented in Figure 5.1. This point is located at the skin near the skin-stiffener connection and matches the damaged region in the case of the damaged structure. A low pass filter (zerophase finite impulse response) is used to remove high frequency measurement noise from the responses. A cutoff frequency of $50 \mathrm{kHz}$ is selected to maintain the dominant frequency components. The accelerations, shown in Figures 5.6(b) and 5.7(b), are calculated from the measured velocity responses by a central difference approximation. 


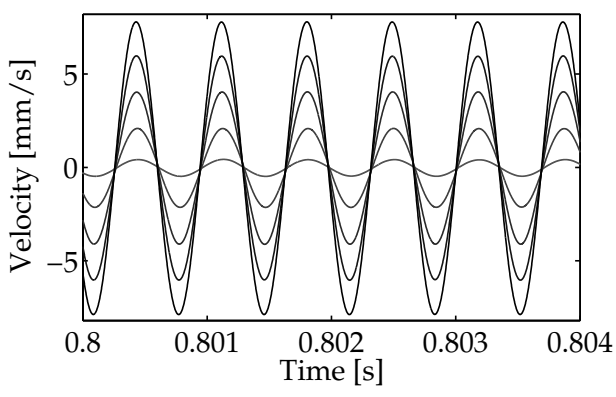

(a) Velocity.

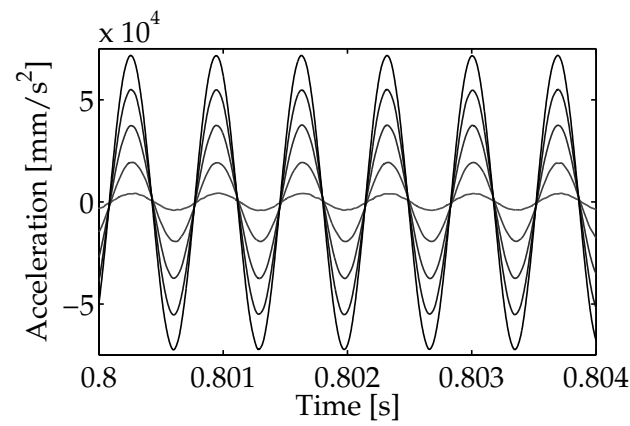

(b) Acceleration.

Figure 5.6 Velocity and acceleration responses measured at location $(x, y)=(0.025,0.120) m$ of the pristine structure for a forced excitation at the $4^{\text {th }}$ bending mode $\left(f_{\mathrm{B}}^{(4)}=1456 \mathrm{~Hz}\right)$ and five excitation amplitude levels.

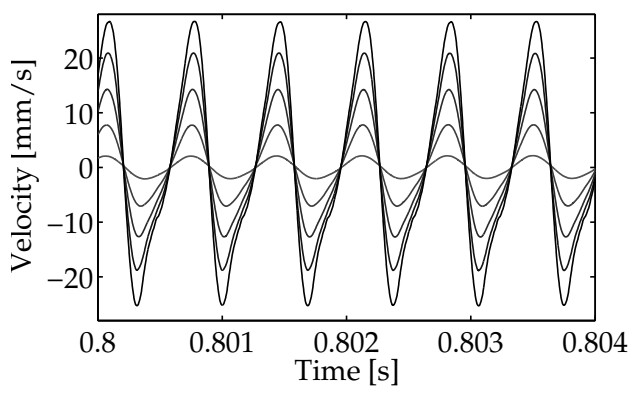

(a) Velocity.

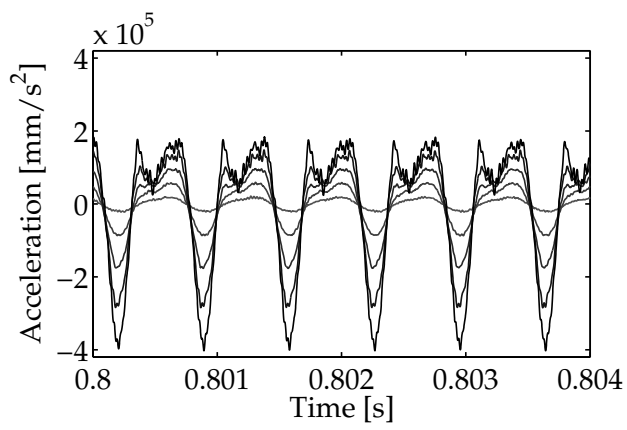

(b) Acceleration.

Figure 5.7 Velocity and acceleration responses measured at location $(x, y)=(0.025,0.120) \mathrm{m}$ of the damaged structure for a forced excitation at the $4^{\text {th }}$ bending mode $\left(\tilde{f}_{\mathrm{B}}^{(4)}=1455 \mathrm{~Hz}\right)$ and five excitation amplitude levels.

The velocity and acceleration responses of the pristine structure show nearly purely harmonic oscillations for all excitation amplitudes, while the waveforms are clearly distorted in the damaged case. The amount of harmonic waveform distortion is most pronounced in the acceleration response and increases for higher shaker excitation amplitudes.

The velocity and acceleration responses are combined to obtain the phase portraits in Figure 5.8. Each trajectory represents a different excitation amplitude. The concentric circles around an equilibrium for the pristine structure indicate that the motion is periodic, stable and purely harmonic. The damaged structure also shows periodic and stable behavior, but the pure harmonic motion is distorted by the skinstiffener damage. The motion approaches nearly fundamental harmonic behavior for the lowest excitation amplitude, while the harmonic distortion increases with increasing excitation amplitude. Higher harmonics are also generated in the case of the higher excitation amplitudes. The damage causes the motion of the skin at 


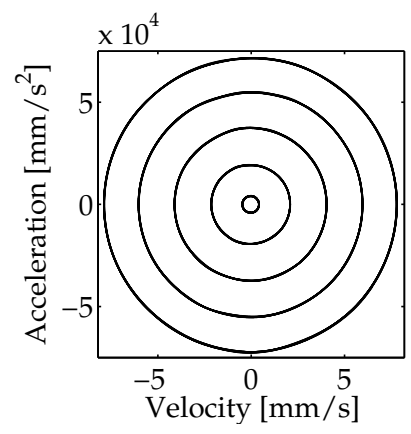

(a) Pristine structure.

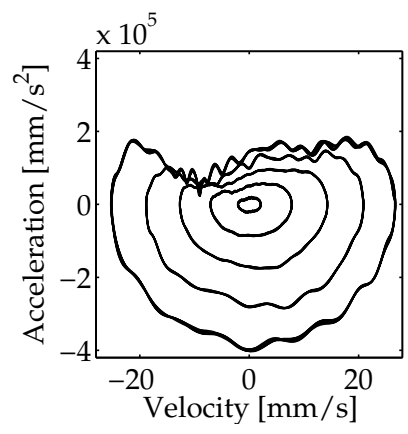

(b) Damaged structure.

Figure 5.8 Phase portraits measured at location $(x, y)=(0.025,0.120) m$ of the pristine and damaged structure for a forced excitation at the $4^{\text {th }}$ bending mode $\left(f_{\mathrm{B}}^{(4)}=1456 \mathrm{~Hz}, \tilde{f}_{\mathrm{B}}^{(4)}=1455 \mathrm{~Hz}\right)$ and five excitation amplitude levels. Each trajectory represents a different excitation amplitude.

the damaged region to behave nonlinearly for the bending mode considered. The nonlinearities mainly occur at one side of the phase portrait while the rest of the motion keeps behaving rather linearly with respect to the excitation amplitude.

\subsubsection{Damage induced dynamic mechanisms}

The skin at the damaged region behaves dynamically nonlinearly for the bending mode considered. The physical mechanisms related to these nonlinear effects are still unknown. The phase portrait revealed that the nonlinearities mainly occurred at one side of the phase portrait, but did not link these nonlinear effects to physical mechanisms. Therefore, the displacement, velocity and acceleration signals are analyzed in more detail.

The skin-stiffener damage, although fairly complex, locally separates the skin from the stiffener. This separation will potentially allow the damage to open under a forced excitation at a bending dominant operational deflection shape. The relative motion between skin and stiffener at the damaged area is required to verify the opening of the delamination. The current set-up did not allow to directly measure the deformation of the stiffener and to calculate the relative motion between the skin and the stiffener. Alternatively, the motion of the stiffener at the damaged region is approximated by analyzing the motion of the skin at multiple spatial points underneath the skin-stiffener connection, i.e. 34 points at node line ' $Y 2$ ' according to Figure 5.1. The motion of the stiffener at the undamaged interface regions is equal to the motion of the skin, since both are connected. The high flexural rigidity of the stiffener controls the skin motion at the undamaged regions. At the damaged region, the skin and stiffener behave more independently. It is assumed that the changes in the flexural motion of the stiffener due to the damage 


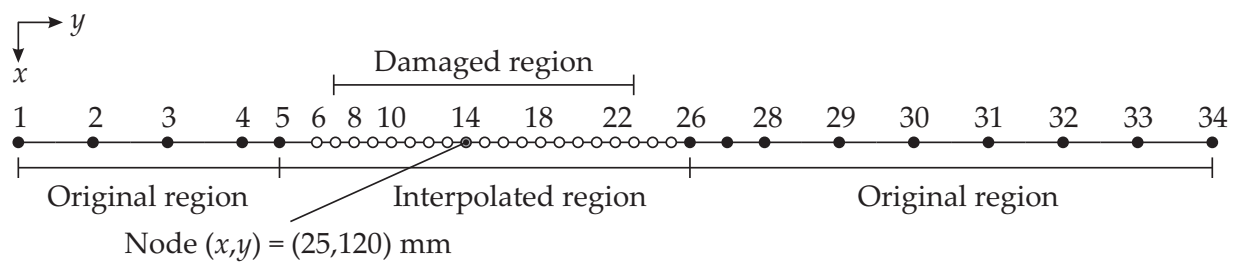

Figure 5.9 Interpolated nodes to approximate the motion of the stiffener at the damaged region.

are minor compared to the changes in the motion of the skin. This is justified by the fact that the stiffener has a significantly higher flexural rigidity (approximately 150 times) than the skin. As a result, the motion of the stiffener at the damaged region is approximated by spatially interpolating the motion of the skin at the undamaged regions on both sides of the damaged region. Figure 5.9 schematically shows the interpolated region within the node set. A piecewise cubic spline interpolation, based on nodes 1-5 and 26-34, is utilized to estimate the velocity and acceleration patterns as a function of the position and the time for nodes 6-25.

Figure 5.10 shows the spatial velocity and acceleration distributions of the skin and stiffener for the forced excitation at the $4^{\text {th }}$ bending mode $\left(\tilde{f}_{\mathrm{B}}^{(4)}=1455 \mathrm{~Hz}\right)$ and the highest excitation amplitude. The three snapshots match with three different time instances according to the phase portrait presented in Figure 5.11. Despite the fact that the interpolation only provides an approximation of the stiffener motion, the snapshots reveal a significant local difference in the velocity and acceleration amplitudes between the skin and the stiffener. A difference in speed between the skin and the stiffener causes the delamination to open or close.

These physical mechanisms are linked to sections in the phase portrait with the help of the associated displacement, velocity and acceleration waveforms for the skin at the damaged region, as shown in Figure 5.11. A relative estimation of the skin displacement is obtained by time integrating the velocity response. The skin at location $(x, y)=(0.025,0.120) \mathrm{m}$ showed a $5 \mu \mathrm{m}$ peak-to-peak displacement for the highest excitation amplitude considered. A detailed analysis of the waveforms makes it possible to distinguish three damage related dynamic mechanisms within each oscillation:

\section{Opening phase $\mid \mathbf{A}$}

The first mechanism, assigned to section A, represents the movement of the skin towards the laser vibrometer. In this phase, the velocity of the skin is positive, while the acceleration is getting negative up to the point where the skin obtains its maximum positive displacement. The snapshot in Figure 5.10(a) shows that the skin at the damaged region reaches significantly higher velocities than those of the stiffener. This positive difference indicates the opening of the delamination at the skin-stiffener 


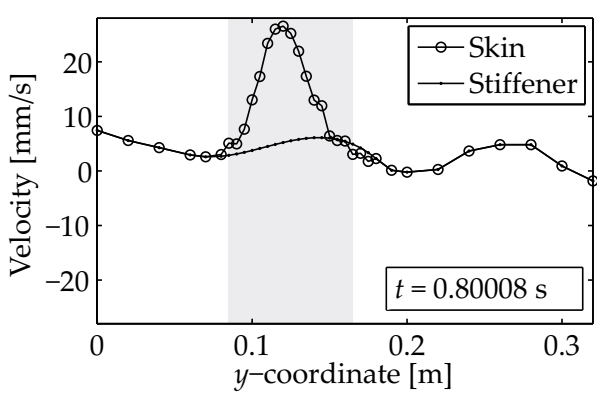

(a) Velocity at $t=\mathrm{t}_{0}$.

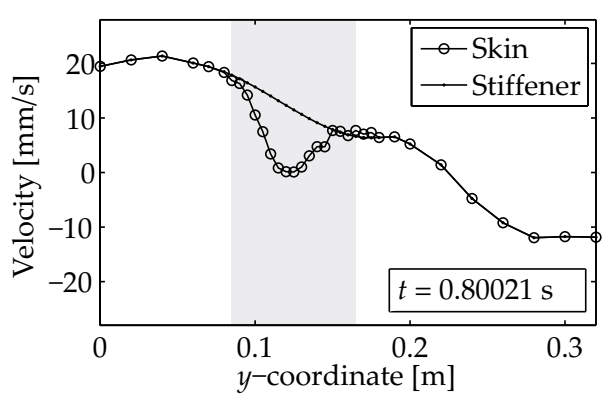

(c) Velocity at $t=\mathrm{t}_{1}$.

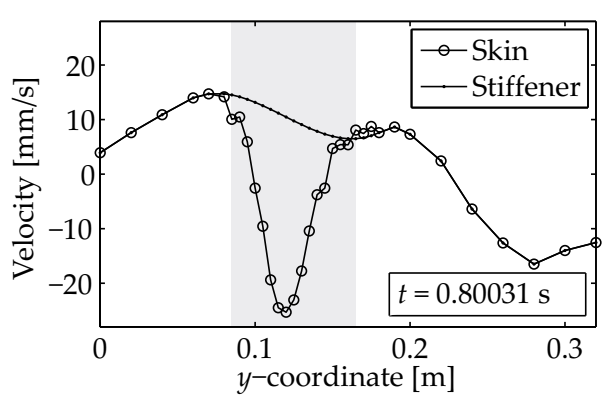

(e) Velocity at $t=\mathrm{t}_{2}$.

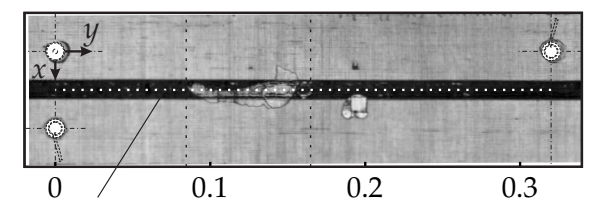

Node line $\mathrm{Y} 2 \quad y$-coordinate $[\mathrm{m}]$

(g) C-scan of the damaged structure.

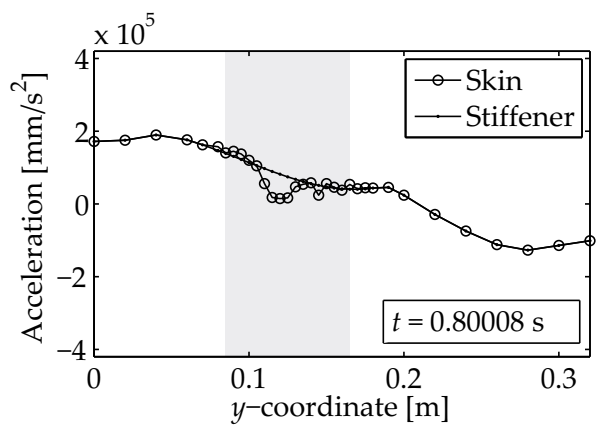

(b) Acceleration at $t=\mathrm{t}_{0}$.

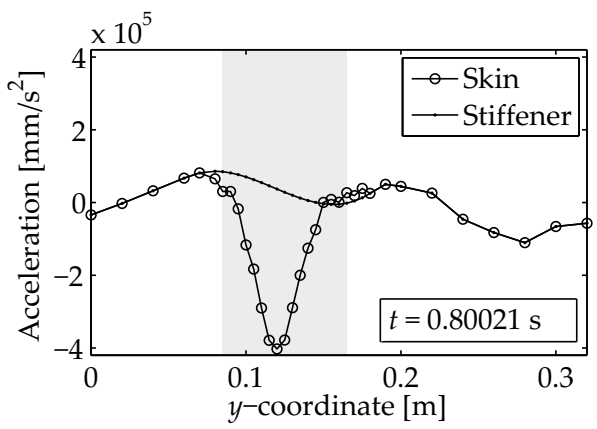

(d) Acceleration at $t=\mathrm{t}_{1}$.

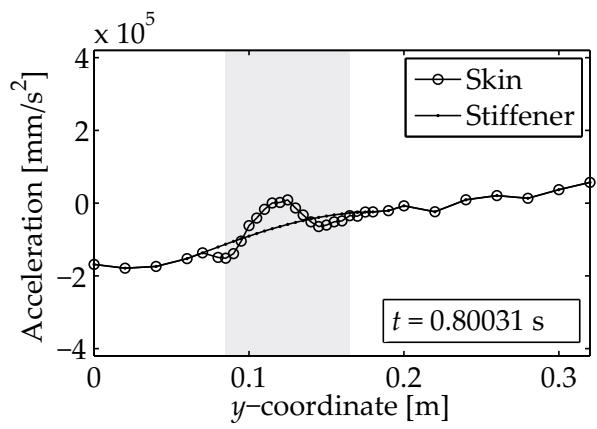

(f) Acceleration at $t=\mathrm{t}_{2}$.

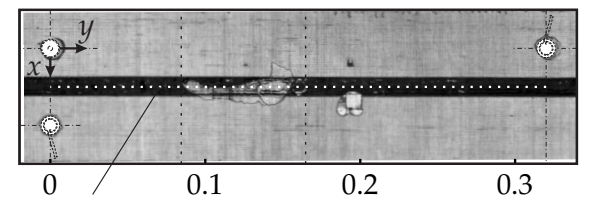

Node line Y2 $y$-coordinate $[\mathrm{m}]$

(h) C-scan of the damaged structure.

Figure 5.10 Snapshot of the skin and (approximated) stiffener velocity and acceleration distribution at node line ' $Y 2$ ' for the forced excitation at $\tilde{f}_{\mathrm{B}}^{(4)}=1455 \mathrm{~Hz}$ and the highest excitation amplitude. The three time instances match the time stamps presented in the phase portrait in Figure 5.11. 

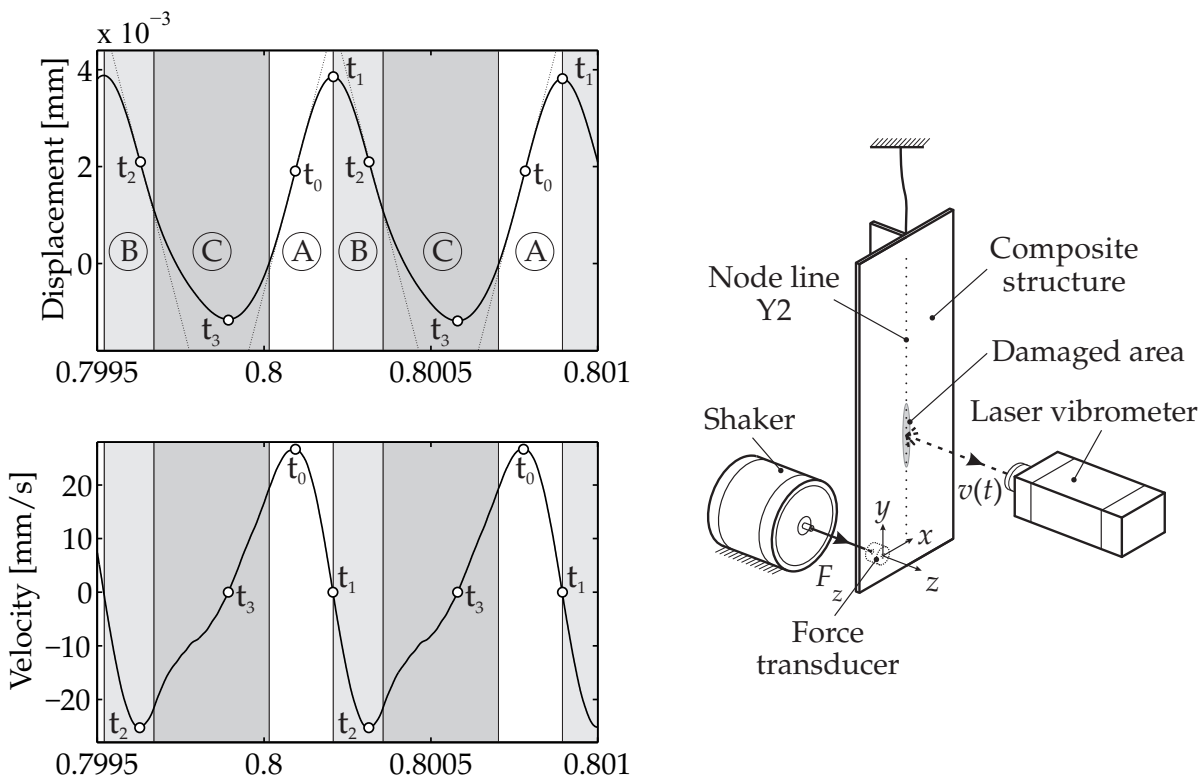

Force

transducer
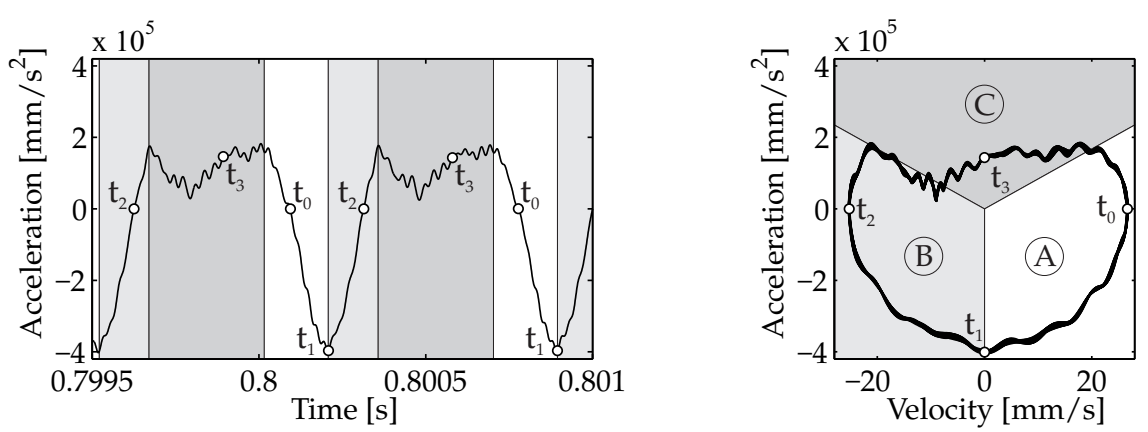

Figure 5.11 The displacement, velocity and acceleration responses measured at location $(x, y)=(0.025,0.120) \mathrm{m}$ of the damaged structure for a single tone harmonic excitation at the $4^{\text {th }}$ bending mode $\left(\tilde{f}_{\mathrm{B}}^{(4)}=1455 \mathrm{~Hz}\right)$ and the highest excitation amplitude. The capitals refer to the opening $(A)$, closing $(B)$ and contact $(C)$ phase of the skin stiffener failure. The time stamps $t_{0}-t_{3}$ correspond to the zero-crossings of the velocity and acceleration responses.

interface. The approximated flexural motion of the stiffener is smaller than the motion of the much more compliant skin at the damaged region.

\section{Closing phase $\mid \mathrm{B}$}

After the skin reached its maximum positive displacement towards the laser vibrometer at $t=\mathrm{t}_{1}$, the velocity of the skin starts to become negative. The approximated velocity of the stiffener remained slightly positive according to the snapshots given in Figure 5.10(c) and 5.10(e). The skin moves away from the laser vibrometer, while the stiffener is moving (although with a relatively low velocity) towards the skin. This part of the trajectory is referred to as the 
'closing phase' and is indicated by section B in Figure 5.11.

\section{Contact phase |C}

The last mechanism is related to the longest time interval where the most severe distortions of the harmonic waveform are found. These distortions are larger for the higher excitation amplitudes and only occur when the skin and the stiffener are moving towards each other. This mechanism suddenly generates higher harmonics, as clearly revealed in the acceleration signal. At the same time, the velocity of the skin starts to decrease, i.e. slowing down the motion of the skin when it approaches the stiffener. As a result, the displacement waveform is somewhat rounded near a local minimum compared to the sharpened peak around the positive displacement extrema. The slowing down of the skin and the suddenly generated higher harmonic distortions suggest that the skin at the damaged region is interacting with the underlying structural interface. A clapping type of behavior can occur when the skin interacts with the stiffener. It is observed that the velocity difference between skin and stiffener causes a smooth change in the displacement waveform. The interaction does not result in a hard impact-like contact behavior as was found by Müller et al. [20,21] for an artificial delamination in a slender aluminium beam.

The opening, closing and contact mechanisms are repeated periodically. Analyzing the different phases of this periodic motion revealed that the nonlinear dynamic behavior of the skin is mainly introduced when the skin and stiffener are interacting with each other. The motion of the skin at the damaged region is barely distorted during the opening and closing phase.

\subsubsection{Spatial effects}

A spatial analysis is performed to study the influence of the damage on the dynamic behavior of the skin-stiffener in more detail. The spatial dependency of the phase portrait is analyzed first, followed by a study of the influence of the damage on the local amplitude and phase. The time responses of the skin are considered at multiple points according to the node lines presented in Figure 5.1.

\section{Phase portrait}

Figure 5.12 shows five phase portraits, each containing five trajectories, at different positions along the damaged skin-stiffener interface for a single tone excitation at the $4^{\text {th }}$ bending mode, together with a snapshot of the velocities at $t=t_{2}$. The most severe asymmetric distortions of the phase portraits are obtained for the skin at the damaged region as illustrated by Figure 5.12(c). The motion of the skin is barely affected at the undamaged regions and only shows some small distortions for the 


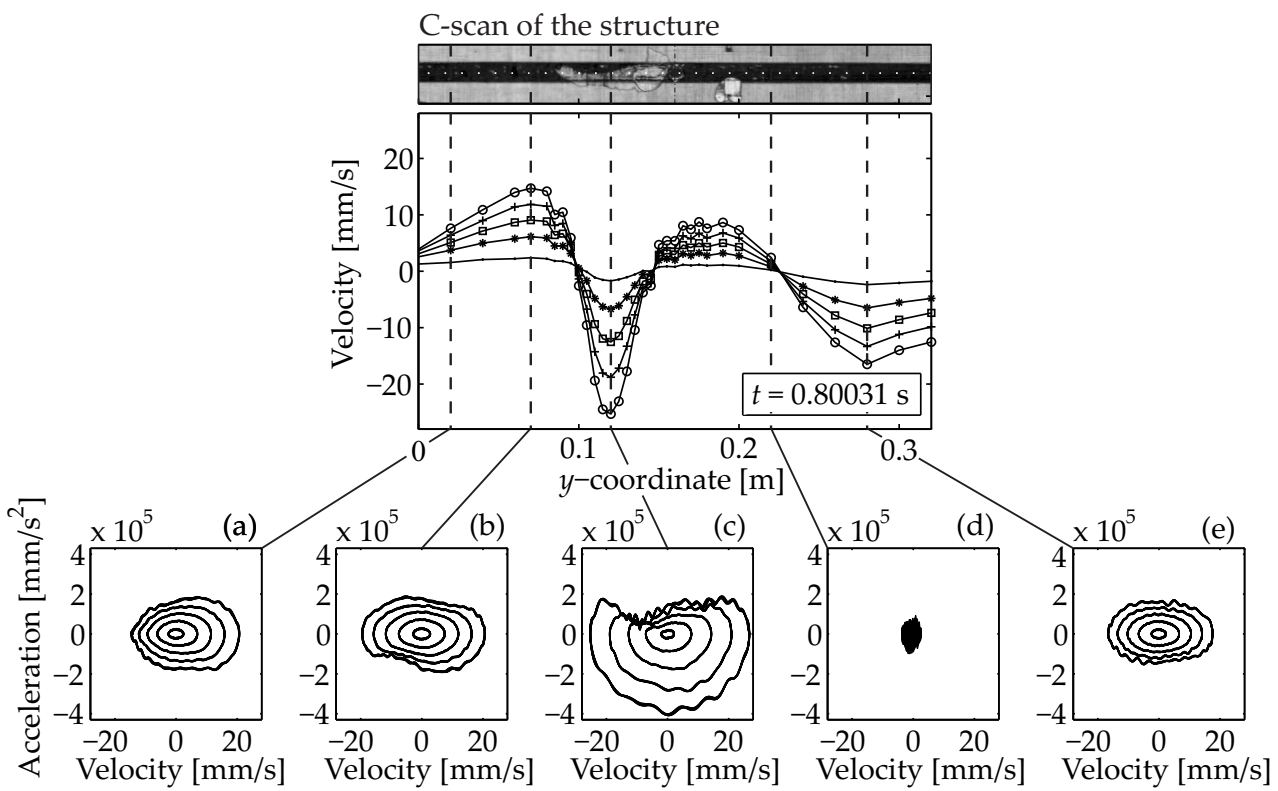

Figure 5.12 Phase portraits measured at different positions at node line ' $Y 2$ ' of the damaged structure for a forced excitation at $\tilde{f}_{\mathrm{B}}^{(4)}=1455 \mathrm{~Hz}$ and five excitation amplitude levels. Each trajectory represents a different excitation amplitude.

highest excitation amplitudes. The damage interface acts as a nonlinear diffuser in an otherwise predominantly linear system. The distortions reduce for positions at a larger distance from the damaged region.

\section{Amplitude and phase}

Figures 5.13 and 5.14 show the velocity and acceleration time responses at node line ' $Y 2$ ' of the pristine and damage structure when excited in the $4^{\text {th }}$ bending mode. Note that the amplitudes are indicated by different color scales. The velocity and acceleration amplitudes gradually vary around the nodal point at $y=0.23 \mathrm{~m}$. All points at the skin-stiffener connection move exactly in phase or out of phase by 180 degrees for the pristine case. The responses change considerably in the damaged case. The velocity distribution in Figure 5.14(a) shows a local increase in the negative and positive amplitudes at the damaged region, while the acceleration only shows a locally increased negative amplitude. The positive amplitude remains in the same order of magnitude for all points at node line ' $\mathrm{Y} 2$ '. The interaction between skin and stiffener restricts the acceleration of the skin to locally increase to higher positive values.

The motion of the skin at the damaged region also shows a local phase shift with 


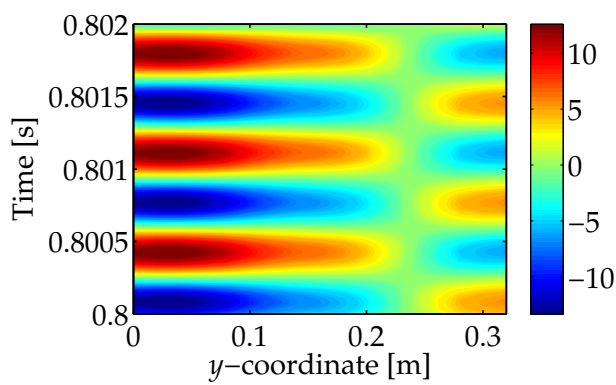

(a) Velocity $[\mathrm{mm} / \mathrm{s}]$.

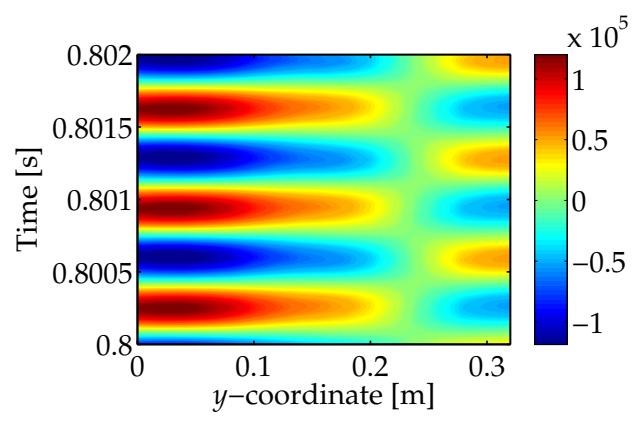

(b) Acceleration $\left[\mathrm{mm} / \mathrm{s}^{2}\right]$.

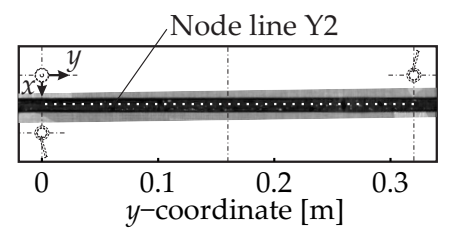

(c) C-scan of the pristine structure.

Figure $\mathbf{5 . 1 3}$ Velocity and acceleration responses measured at node line ' $Y 2$ ' of the pristine structure for a forced excitation at $f_{\mathrm{B}}^{(4)}=1456 \mathrm{~Hz}$ and the highest excitation amplitude.

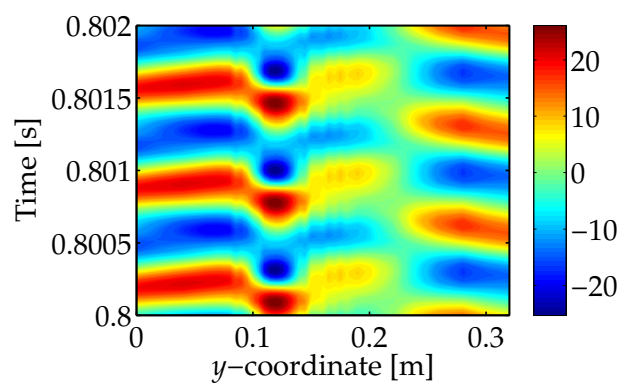

(a) Velocity $[\mathrm{mm} / \mathrm{s}]$.

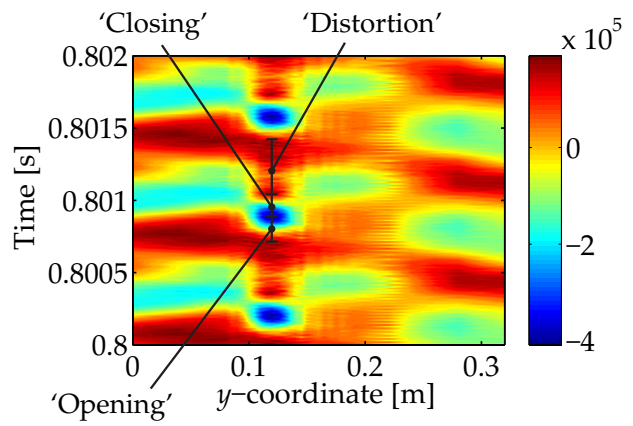

(b) Acceleration $\left[\mathrm{mm} / \mathrm{s}^{2}\right]$.

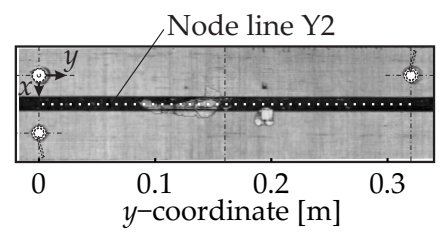

(c) C-scan of the damaged structure.

Figure 5.14 Velocity and acceleration responses measured at node line ' $Y 2$ ' of the damaged structure for a forced excitation at $\tilde{f}_{\mathrm{B}}^{(4)}=1455 \mathrm{~Hz}$ and the highest excitation amplitude.

respect to the undamaged regions of node line ' $Y 2$ '. This phase shift is a result of two effects. Firstly, the skin and the stiffener behave relatively independently at the damaged region underneath the stiffener, while the bending motion of the skin at the undamaged regions is controlled by the high flexural rigidity of the stiffener. Secondly, the damage is located at a region where the motion of the skin at both sides of the stiffener shows an antinode. These high amplitudes on both sides of the stiffener are clearly illustrated by the operational deflection shape in Figure 5.5(c). They drive the motion of the skin at the damaged region underneath the stiffener. 


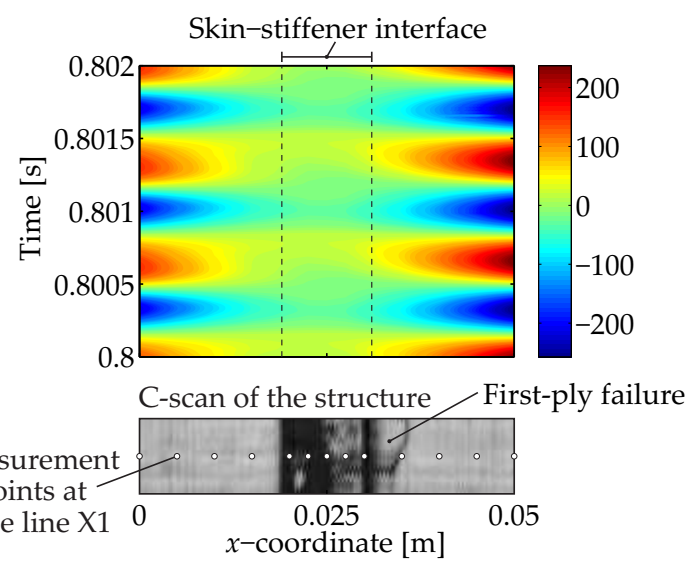

Figure 5.15 Velocity response $[\mathrm{mm} / \mathrm{s}]$ measured at node line ' $\mathrm{X} 1$ ' of the damaged structure for a forced excitation at $\tilde{f}_{\mathrm{B}}^{(4)}=1455 \mathrm{~Hz}$. The skin at the damaged skin-stiffener connection moves nearly in phase with the motion of the skin on both sides of the stiffener.

As a consequence, the skin-stiffener damage opens and closes nearly in phase with the motion of the skin on both sides of the stiffener, as demonstrated by the velocity time response at node line ' $\mathrm{X} 1$ ' in Figure 5.15.

\subsubsection{Influence of excitation frequency}

Whether, when and to what extent the opening, closing and contact mechanisms take place depends on the relative motion between the skin and the stiffener at the damaged region. This relative motion is defined by the local deformation patterns and is therefore damage location, excitation amplitude and frequency dependent. The damage location could not be adjusted. The influence of the excitation amplitude was briefly discussed in Section 5.3.3, leaving the influence of the excitation frequency to be addressed in the current section.

When the structure is excited at the $5^{\text {th }}$ bending mode, the damaged region matches a nodal point in the deformation of the skin, hence resulting in minor distortions. An excitation frequency equal to the $6^{\text {th }}$ bending mode shows a clearly distorted motion of the skin at the damaged region in Figure 5.16. The phase portraits show some aberrant behavior compared to the phase portrait of the previously discussed $4^{\text {th }}$ bending mode. A smaller amount of high frequency scattering is generated during the contact phase, yielding an overall smoother phase portrait. Moreover, the phase portrait reveals wrinkles around the zero crossings of the acceleration. Analysis of the velocity and acceleration distributions at multiple points along the skin-stiffener connection in time (i.e. Figures 5.13, 5.14, 5.17 and 5.18) revealed a possible explanation for these differences. The skin at the damaged region shows a 'clapping' type of behavior for the $4^{\text {th }}$ bending mode, while the interaction in the 


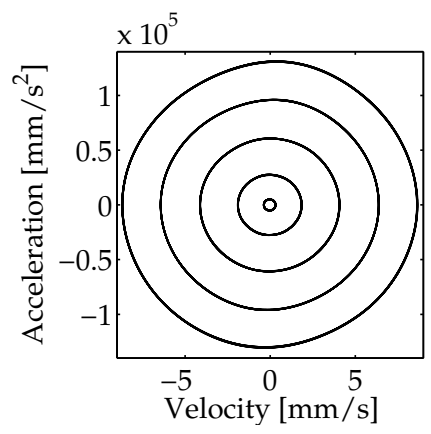

(a) Pristine.

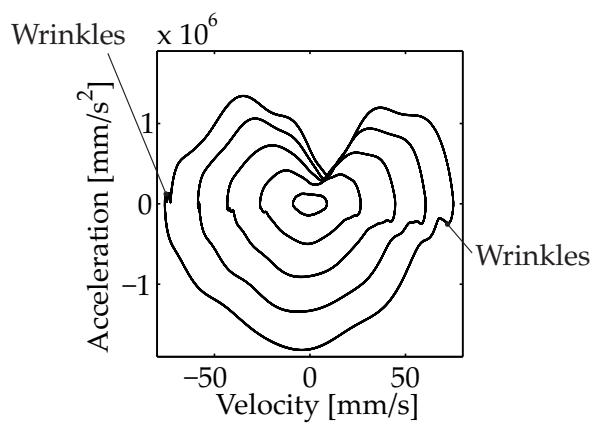

(b) Damaged.

Figure 5.16 Phase portraits measured at location $(x, y)=(0.025,0.120) m$ of the pristine and damaged structure for a forced excitation at the $6^{\text {th }}$ bending mode $\left(f_{\mathrm{B}}^{(6)}=2328 \mathrm{~Hz}, \tilde{f}_{\mathrm{B}}^{(6)}=2340 \mathrm{~Hz}\right)$ and five amplitude levels. Each trajectory represents a different excitation amplitude.

case of the $6^{\text {th }}$ bending mode is better described by a smoother 'rolling' motion. This 'rolling' motion is demonstrated by the acceleration distribution of the skin in Figure 5.18(b). The diagonal lines in the zoomed inset indicate traveling acceleration waves from left to right at the delaminated region during the closing phase. This propagating effect matches the wrinkles around the zero crossing of the acceleration in the phase portrait.

The smooth 'rolling' motion is attributed to the position of the damage with respect to the nodes and antinodes in the motion of the skin and the stiffener. Figure 5.19 shows that the damaged region is centered with respect to the nodal points on both sides $\left(l_{1} \approx l_{2}\right)$ in case of the $4^{\text {th }}$ bending mode. In contrast, the $6^{\text {th }}$ bending mode shows an off-centered position $\left(l_{1}<l_{2}\right)$ of the damaged region, causing the rolling motion in the acceleration of the skin.

\subsection{Discussion}

The present section provides a discussion of two aspects. Firstly, the underlying physical phenomena associated with the nonlinear dynamic behavior are discussed. Secondly, the higher harmonic components are addressed in more detail.

\subsubsection{Underlying physical phenomena}

A smooth change in the calculated displacement waveform demonstrated that the interaction between skin and stiffener does not result in a hard impact-like contact behavior as was found by Müller et al. [20,21] for an artificial delamination in an aluminum beam. However, a slowing down of the skin motion combined with the 


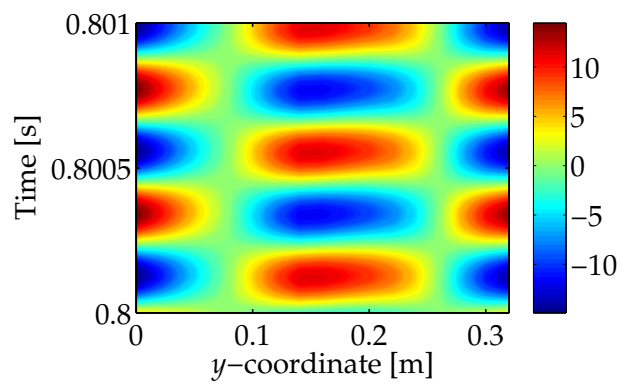

(a) Velocity $[\mathrm{mm} / \mathrm{s}]$.

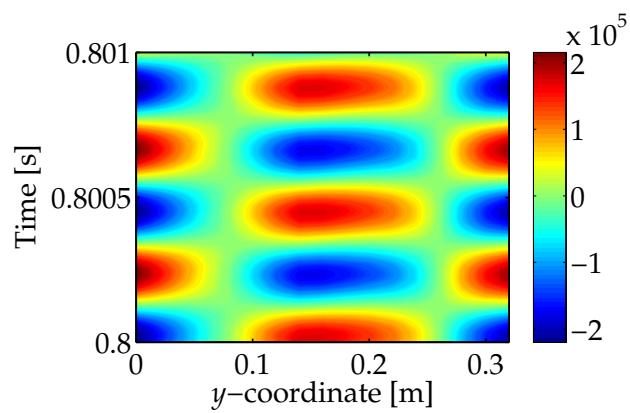

(b) Acceleration $\left[\mathrm{mm} / \mathrm{s}^{2}\right]$.

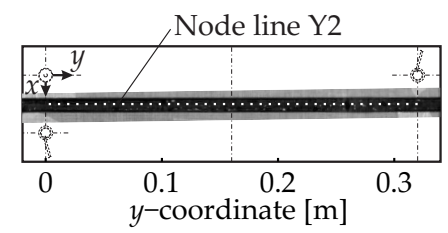

(c) C-scan of the pristine structure.

Figure 5.17 Velocity and acceleration responses measured at node line ' $Y 2$ ' of the pristine structure for a forced excitation at $f_{\mathrm{B}}^{(6)}=2328 \mathrm{~Hz}$ and the highest excitation amplitude.

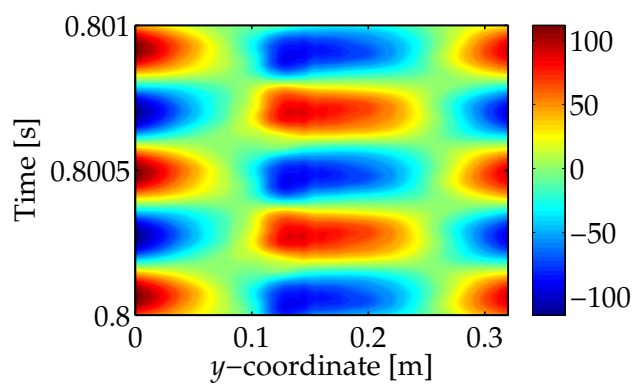

(a) Velocity $[\mathrm{mm} / \mathrm{s}]$.

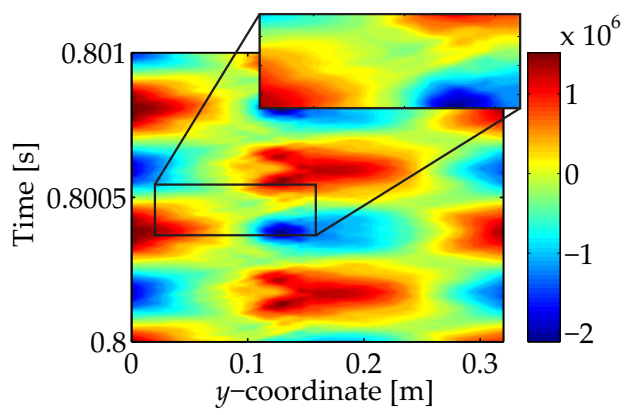

(b) Acceleration $\left[\mathrm{mm} / \mathrm{s}^{2}\right]$.

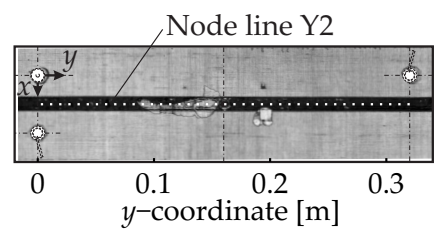

(c) C-scan of the damaged structure.

Figure 5.18 Velocity and acceleration responses measured at node line ' $Y 2$ ' of the damaged structure for a forced excitation at $\tilde{f}_{\mathrm{B}}^{(6)}=2340 \mathrm{~Hz}$ and the highest excitation amplitude.

generation of higher harmonic acceleration signals suggests a nonlinear interaction between the skin and the underlying stiffener. This interaction causes the phase portraits to distort at one side for the excitation amplitudes and frequencies considered (see Figures 5.8(b), 5.11, 5.12(c), 5.16(b)).

Various physical phenomena can cause the measured nonlinear waveform distortions. Although it was shown in Section 5.3.4 that the harmonic distortions at the damaged region are mainly introduced when the skin and stiffener approach each other, the experiments did not allow for a more detailed and unique separation of the 


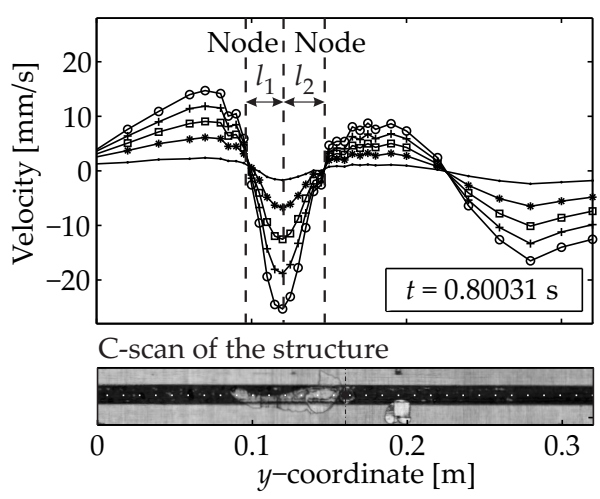

(a) $\tilde{f}_{\mathrm{B}}^{(4)}=1455 \mathrm{~Hz}$.

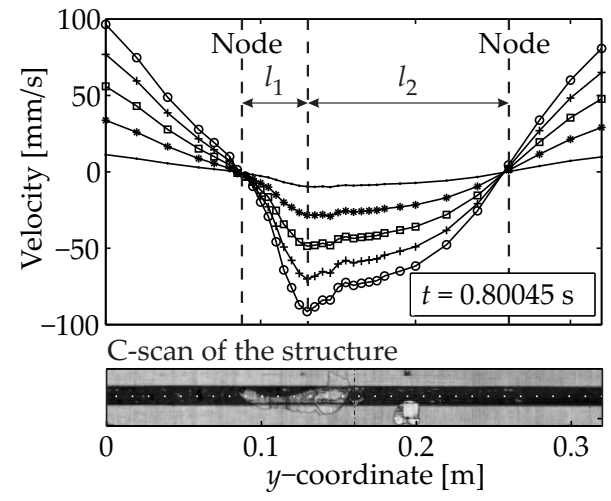

(b) $\tilde{f}_{\mathrm{B}}^{(6)}=2340 \mathrm{~Hz}$.

Figure 5.19 Snapshots at time instance $t=t_{2}$ of the velocity distributions at node line ' $Y 2$ ' of the damaged structure for the forced excitation at the $4^{\text {th }}$ and $6^{\text {th }}$ bending mode and five amplitude levels. The position of the damaged region with respect to the associated nodal points is indicated by $l_{1}$ and $l_{2}$.

underlying physical phenomena. The most obvious and commonly addressed phenomenon is the nonlinearly varying stiffness across the damage interface [13]. Contact is just one of the phenomena. Lateral stress-stiffening of the skin and fiber bridging across the damage interface could, although in the opposite direction, also lead to asymmetric stiffness effects. The opening and closing motion of the skinstiffener damage also allows for 'breathing' phenomena in the damaged zone, hence potentially leading to viscous effects at the interface. Other potential mechanisms involved are frictional, hysteretic or thermoelastic phenomena [23], all resulting in energy dissipation.

A model representation of the damage between the skin and stiffener could help to distinguish the most dominant underlying nonlinear phenomena. The number of models presented in the literature $[18,19]$ illustrates, however, the complexity of describing a realistic damage scenario.

\subsubsection{Higher harmonics}

The generated higher harmonics measured at the skin near the damaged skinstiffener interface are clearly presented by the Fourier transformed signals in Figure 5.20 for the highest excitation amplitude. Analogous to the phase portraits, the response obtained for an excitation at the $4^{\text {th }}$ bending mode shows more severe higher harmonic scattering than measured for the $6^{\text {th }}$ bending mode. However, this representation fails to unveil the timing of the waveform distortions. Time responses composed of a variable number of higher harmonics are obtained by applying a zero-phase finite impulse response (FIR) low pass filter with a high filter 


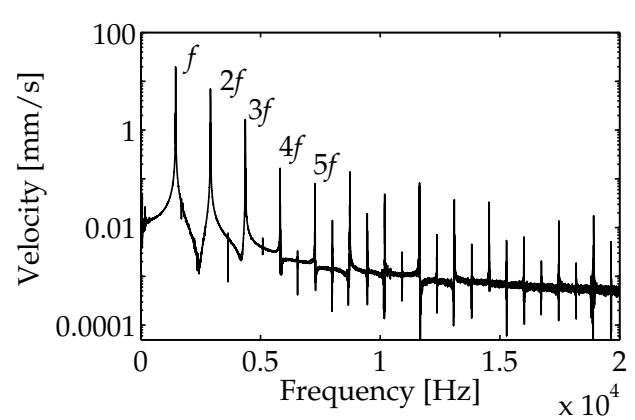

(a) $\tilde{f}_{\mathrm{B}}^{(4)}=1455 \mathrm{~Hz}$.

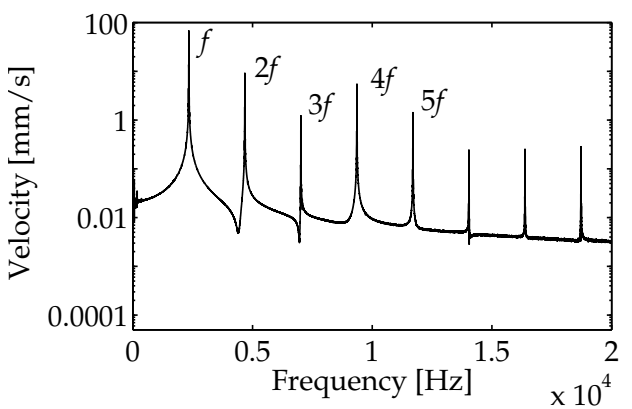

(b) $\tilde{f}_{\mathrm{B}}^{(6)}=2340 \mathrm{~Hz}$.

Figure 5.20 Fourier transforms, indicating multiple higher harmonics, of the responses measured at location $(x, y)=(0.025,0.120) m$ of the damaged structure for a single tone harmonic excitation at the $(a) 4^{\text {th }}$ and $(b) 6^{\text {th }}$ bending mode and the highest excitation amplitude.

order to the original time response. The associated phase portraits are shown in Figure 5.21. The differences between the original and the filtered phase portraits give an impression of the information that is discarded when the higher harmonics are not included in the analysis. The largest differences are obtained for the acceleration responses. This is caused by the fact that the majority of the distortions is introduced around the zero-crossing of the velocity response.

An FRF extracted for the damaged structure is dominated by fundamental harmonic components, but also contains higher harmonic information for a range of excitation frequencies. A classical FRF based operational deflection shape analysis, as was shown in Section 5.3.2, only considers the amplitude and phase at one selected frequency. The higher harmonic information associated with this frequency

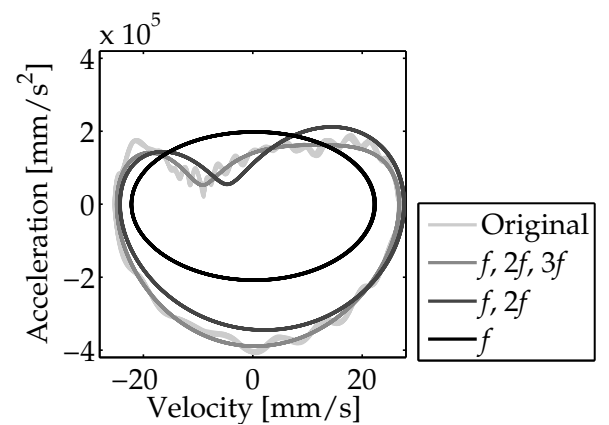

(a) $\tilde{f}_{\mathrm{B}}^{(4)}=1455 \mathrm{~Hz}$.

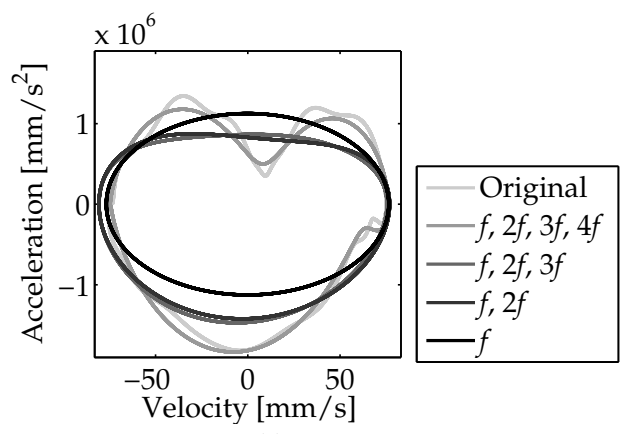

(b) $\tilde{f}_{\mathrm{B}}^{(6)}=2340 \mathrm{~Hz}$.

Figure 5.21 Phase portraits of the original time response and several low pass filtered time responses comprising a selection of harmonics. The responses are measured at location $(x, y)=(0.025,0.120) \mathrm{m}$ for a single tone harmonic excitation at the $(a) 4^{\text {th }}$ and $(b) 6^{\text {th }}$ bending mode and the highest excitation amplitude. 
is therefore not included in the operational deflection shape. Modal analysis based damage detection approaches are subject to similar issues. They rely on a stationary and linear representation of the system as was shown in Chapter 2. Nonlinear effects in the structural response are not identified, while they can provide very useful information about the health of the structure as shown in the present study.

\subsection{Conclusions \& future prospects}

The interaction between damage and an acoustic wave field can cause dynamic phenomena that exhibit complicated material and geometrical nonlinear behavior. The work presented has investigated this nonlinear dynamic interaction for impact induced damage in a composite skin-stiffener structure.

Analysis of the steady state responses resulting from a single tone harmonic excitation at a number of predetermined natural frequencies revealed that, besides amplitude and phase related effects, skin-stiffener damage can distort the harmonic motion of the skin at the damaged region. A phase portrait representation between velocity and acceleration at the damaged region showed that the motion approaches nearly fundamental harmonic behavior for the lowest excitation amplitude, while the harmonic distortion increases for higher excitation amplitudes.

The analysis of the periodic motion revealed three principle mechanisms within each oscillation: opening of the damage, closing of the damage and a section where the skin and stiffener are interacting with each other. The nonlinear dynamic behavior of the skin at the damaged region is mainly introduced during the last phase. Clear higher harmonics are generated, while the skin at the damaged region keeps behaving almost purely harmonic during the opening and closing phase. It is observed that the skin and stiffener are interacting, but that this interaction does not result in a hard impact-like behavior. The results show that the damage interface acts as a nonlinear diffuser, but the results did not allow for a unique separation of the underlying physical phenomena.

It is concluded that the interaction between skin and stiffener depends on the specific operational deflection shape of both components. The ('clapping' or 'rolling') interaction is an important parameter in the way the harmonic response of the system is distorted. A spatial analysis revealed that the opening and closing motion of the damage is mainly driven by the motion of the skin at both sides of the stiffener.

The analysis of the results and the discussion demonstrated the complexity of the interaction between damage and a harmonic wave field in a skin-stiffener structure for a specific set of modes. From a more general point of view, the damage induced nonlinear effects can provide very useful information about the current state of the structure. Linear damage identification methods are feasible for low excitation 
amplitudes, but the presence of nonlinear effects cannot remain silent for higher amplitudes.

Additional research is required on the separation of the underlying physical nonlinear phenomena. A model representation of the skin-stiffener damage can help to distinguish the most dominant physical phenomena and to provide a quantification of the experimental observations. Future research will also focus on methods to embed the nonlinear dynamics in a structural health monitoring method.

\section{Acknowledgments}

This material is based on work supported by National Aeronautics and Space Administration, Langley Research Center under Research Cooperative Agreement No. NNL09AA00A awarded to the National Institute of Aerospace.

The authors kindly acknowledge the support of Fokker Aerostructures B.V., Hoogeveen, The Netherlands, for manufacturing the composite structure used in this research. This work is funded by the European research project Clean Sky, Eco-Design ITD (grant agreement number CSJU-GAM-ED-2008-001).

\section{References}

[1] A. Offringa, J.W. van Ingen, and A. Buitenhuis. Butt-joined, thermoplastic stiffened-skin concept development. SAMPE Journal, 48(2):7-15, 2012.

[2] C. Boller, F.-K. Chang, and Y. Fujino. Encyclopedia of structural health monitoring. John Wiley \& Sons, Ltd, Chichester, UK, 2009.

[3] K. Worden, C.R. Farrar, J. Haywood, and M. Todd. A review of nonlinear dynamics applications to structural health monitoring. Structural Control and Health Monitoring, 15:540-567, 2008.

[4] D. Montalvão, N.M.M. Maia, and A.M.R. Ribeiro. A review of vibration-based structural health monitoring with special emphasis on composite materials. Shock and Vibration Digest, 38(4):295-326, 2006.

[5] K. Diamanti and C. Soutis. Structural health monitoring techniques for aircraft composite structures. Progress in Aerospace Sciences, 46(8):342-352, 2010.

[6] A. Raghavan and C.E.S. Cesnik. Review of guided-wave structural health monitoring. The Shock and Vibration Digest, 39(2):91-114, 2007.

[7] M.H. Richardson and B.J. Schwarz. Modal parameter estimation from operating data. Sound and Vibration, 37(1):28-39, 2003.

[8] T.H. Ooijevaar, R. Loendersloot, L.L. Warnet, A. de Boer, and R. Akkerman. Vibration based structural health monitoring of a composite T-beam. Composite Structures, 92(9):2007-2015, 2010.

[9] M. Dilena and A. Morassi. Dynamic testing of a damaged bridge. Mechanical Systems and Signal Processing, pages 1-23, 2011. 
[10] A. Klepka, W.J. Staszewski, R.B. Jenal, M. Szwedo, T. Uhl, and J. Iwaniec. Nonlinear acoustics for fatigue crack detection - Experimental investigations of vibro-acoustic wave modulations. Structural Health Monitoring, 11(2):197-211, 2011.

[11] I. Solodov, N. Krohn, and G. Busse. CAN: an example of nonclassical acoustic nonlinearity in solids. Ultrasonics, 40:621-625, 2002.

[12] N. Krohn, R. Stoessel, and G. Busse. Acoustic non-linearity for defect selective imaging. Ultrasonics, 40(1-8):633-7, 2002.

[13] I. Solodov, D. Döring, and G. Busse. New opportunities for NDT using non-linear interaction of elastic waves with defects. Journal of Mechanical Engineering, 57(03):169-182, 2011.

[14] K.-Y. Jhang. Nonlinear ultrasonic techniques for nondestructive assessment of micro damage in material: a review. Precision Engineering and Manufacturing, 10(1):123-135, 2009.

[15] P.B. Nagy. Fatigue damage assessment by nonlinear ultrasonic materials characterization. Ultrasonics, 36(1-5):375-381, 1998.

[16] K.E.-A. Van Den Abeele, P.A. Johnson, and A. Sutin. Nonlinear elastic wave spectroscopy (NEWS) techniques to discern material damage, part I: nonlinear wave modulation spectroscopy (NWMS). Research in Nondestructive Evaluation, 12:17-30, 2000.

[17] K.E.-A. Van Den Abeele, J. Carmeliet, J.A. Ten Cate, and P.A. Johnson. Nonlinear elastic wave spectroscopy (NEWS) techniques to discern material damage, part II: single-mode nonlinear resonance acoustic spectroscopy. Research in Nondestructive Evaluation, 12:31-42, 2000.

[18] C.N. Della and D. Shu. Vibration of delaminated composite laminates: a review. Applied Mechanics Reviews, 60(1-6):1-20, 2007.

[19] M.I. Friswell and J.E.T. Penny. Crack modeling for structural health monitoring. Structural Health Monitoring, 1(2):139-148, 2002.

[20] I. Müller. Clapping in delaminated sandwich-beams due to forced oscillations. Computational Mechanics, 39(2):113-126, 2005.

[21] I. Müller, A. Konyukhov, P. Vielsack, and K. Schweizerhof. Parameter estimation for finite element analyses of stationary oscillations of a vibro-impacting system. Engineering Structures, 27(2):191-201, 2005.

[22] M.H. Richardson. Is it a mode shape, or an operating deflection shape? Sound and Vibration, pages 1-11, 1997.

[23] C.J. Pye and R.D. Adams. Detection of damage in fibre reinforced plastics using thermal fields generated during resonant vibration. NDT International, 14(3):111-118, 1981. 


\title{
CHAPTER 6
}

\section{Vibro-acoustic modulation based damage identification in a composite skin-stiffener structure ${ }^{1}$}

\begin{abstract}
Vibro-acoustic modulation based damage identification relies on the modulation of a high-frequency carrier signal by an intenser low-frequency vibration signal due to damage induced structural nonlinearities. A time domain analysis of the vibro-acoustic modulation phenomena was presented at multiple spatial locations in an impact damaged composite skin-stiffener structure. The instantaneous amplitude and frequency of the carrier velocity response were extracted to analyze the intermodulations between the two excitation signals. Increased amplitude modulations at the damaged region revealed the presence, location and length of the skin-stiffener damage. The damage hardly modulated the frequency of the carrier response. This difference in behavior was attributed to the nonlinear skin-stiffener interaction introduced by the periodic opening and closing of the damage, according to earlier research by authors on the same structure. A parametric study showed that the amplitude and phase of the amplitude modulation are dependent on the selected carrier excitation frequency, and hence the high frequency wave field that is introduced. The present work demonstrates the potential, but also the complexity of the vibroacoustic modulation based damage identification approach.
\end{abstract}

1 Reproduced from: T.H. Ooijevaar, M.D. Rogge, R. Loendersloot, L.L. Warnet, R. Akkerman, T. Tinga, Vibro-acoustic modulation based damage identification in a composite skin-stiffener structure. In preparation for: Structural Health Monitoring, 2014. 


\subsection{Introduction}

\subsubsection{Background and motivation}

Composite materials can exhibit complex types of damage, like transverse cracks and delaminations. These damage scenarios can severely influence the structural performance of a component, and hence tremendously decrease its service life. Periodic inspections are required to ensure the integrity of a component during its lifetime. A wide range of technologies can be employed for damage identification purposes [1,2]. Some of these technologies utilize the change in structural dynamic characteristics as an indicator for damage. The low-frequency structural vibration based approaches generally allow for a relatively easy interpretation of the measured responses, have the ability to analyze complex structures and do not necessarily require the structure to be readily accessible [3]. Drawbacks are, however, the limited sensitivity compared to higher frequency approaches and the number of required sensors in case the standing wave patterns need to be described [4].

Traditional vibration based methods often rely on linear system descriptions [5], while more recent work also features the nonlinear dynamic effects introduced by local defects [6,7]. Despite various successful applications of classical linear methods [8], researchers state the potential benefits in terms of sensitivity [9-11] and environmental robustness $[12,13]$ involved in the monitoring of nonlinear dynamic effects. Frequently used nonlinear features for the identification of damage are the generated sub-/higher harmonics in the structural response, waveform distortions, frequency shifts as a function of the excitation amplitude, coherence functions, etc. [5, 7]. All these methods rely on the principle that the level of nonlinearity in the acoustic response of materials containing structural damage is greater than in materials with no structural damage.

\subsubsection{Vibro-acoustic modulation concept}

A recently introduced nonlinear approach that has been shown to be sensitive to the severity of damage in geometrically complex structures is the nonlinear vibro-acoustic modulation (VAM) method [10,14,15]. This approach relies on the modulation of a high-frequency ultrasonic wave ('carrier') by a more intense lowfrequency vibration ('pump'). This modulation occurs in the presence of structural nonlinearities, as schematically illustrated in Figure 6.1. Both excitation signals are applied to the structure simultaneously. The pump signal with frequency $f_{\mathrm{p}}$ excites the structure and any nonlinearity, while the more sensitive carrier signal at a frequency $f_{\mathrm{c}}$ is used to analyze the potential intermodulation effects. A linear structural response, illustrated in Figure 6.1(b), will be the combination of its response to each of the signals individually. The associated Fourier spectrum 
(a)

Pump and carrier excitation signals.
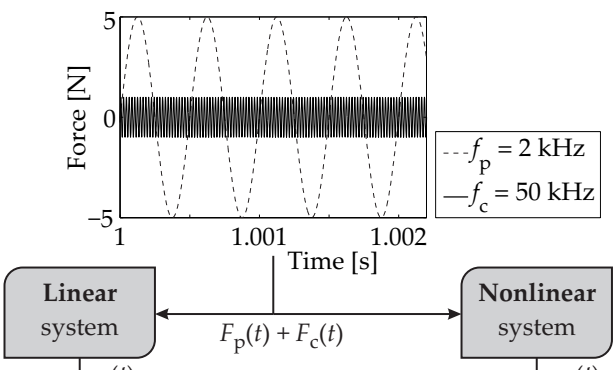

Linear response

$v_{1}(t)$

(b)

Superposition

(d)

Fundamental :

harmonics

$f_{\mathrm{p}}$ and $f_{\mathrm{c}}$.

(f)

Carrier response.
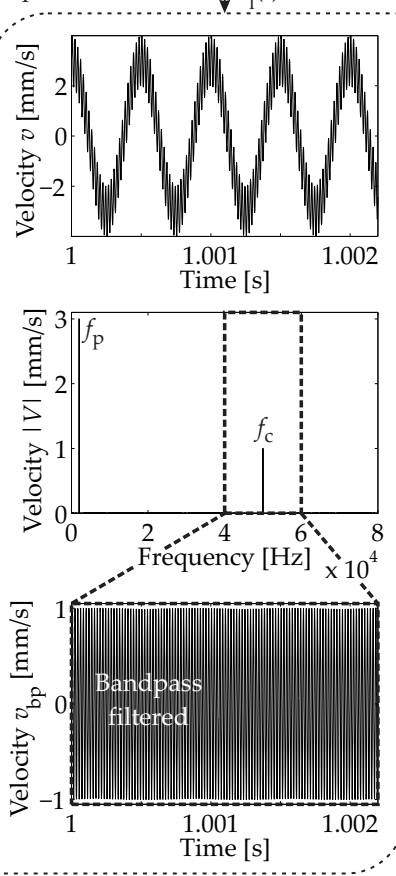

$v_{01}(t)$

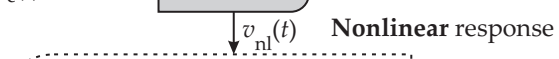

(c)

Modulated response.

(e)

Fundamental harmonics $f_{\mathrm{p}}$ and $f_{\mathrm{c}^{\prime}}$ higher harmonics and sidebands.

(g)

Modulated

carrier response.

Figure 6.1 A schematic illustration of the vibro-acoustic modulation concept. Two harmonic excitation signals (a) are simultaneously applied to the system. A linear system response $(b, d, f)$ will be the superposition of its response to each of the signals individually. The high-frequency system response (c) is modulated $(e, g)$ by the low-frequency pump excitation in case nonlinearities are present.

presented in Figure 6.1(d) will therefore only exhibit the two fundamental frequency components. In the presence of nonlinearities, the system response does not consist anymore of the linear superposition of the fundamental responses. The two signals interact in such a way that the carrier signal is modulated by the pump signal in amplitude, frequency, or both amplitude and frequency (see Figure 6.1(c)). The Fourier spectrum of the response signal reveals additional components, higher harmonics $\left(n f_{\mathrm{p}}\right.$ and $n f_{\mathrm{c}}$, with $\left.n=1,2,3, \ldots\right)$ and sidebands $\left(f_{\mathrm{c}}+n f_{\mathrm{p}}\right.$ and $f_{\mathrm{c}}-n f_{\mathrm{p}}$, with $\left.n=1,2,3, \ldots\right)$ around the high-frequency component, as shown in Figure 6.1(e). 
Despite the fact that many studies showed that the amount of modulation is correlated to the severity of the damage [16], the underlying physical phenomena of the modulations are still not well understood. The main difficulty concerns the diversity of the nonlinear phenomena originating at several material length scales (micro-, meso- and macroscopic) combined with the fact that similar nonlinear effects in an acoustic response can be a result of different physical phenomena. This consequently hampers the separation of these underlying phenomena. Initially, researchers claimed that the modulations are created by changes in the contact area at the damage interface caused by the pump signal [17]. Studies by Zaitsev et al. [15] and Klepka et al. [14], however, revealed that modulation can occur even when the cracks are not being opened fully by the pump signal. They concluded that energy dissipation based phenomena at the damaged area constitute the major mechanism behind the modulations.

Regardless of the exact physical phenomena that cause the nonlinear modulations, it has been demonstrated that a vibro-acoustic modulation based approach can be employed to detect defects in a wide variety of structures ranging from aluminum beams and plates [18, 19], bolt connections [20], to geometrically more complex structures such as metallic automotive as well as aircraft subcomponents [10, 21]. The amount of work focused on composite materials is, however, rather limited [16, 22].

The majority of current vibro-acoustic modulation based investigations rely on Fourier transformed responses obtained at one or a few measurement points [16, 22-24]. The sideband amplitudes of the carrier frequency are monitored to detect and track the progression of damage. Limitations of this approach are, firstly, the fact that the sidebands are represented by sharp peaks, while the frequency resolution is often limited. Consequently, it is rather difficult to obtain an accurate estimation of the amplitude of the sidebands. Secondly, the sideband amplitudes can be the combined result of two phenomena, amplitude and frequency modulations [25]. Analyzing only the sideband amplitudes is insufficient to separate these effects and hence complicates the understanding of the modulation phenomena. Alternative methods are required to overcome these difficulties. Nearly all studies regarding vibro-acoustic modulation are limited to one or a few measurement points. The spatial dependency of the modulations has hardly been investigated. Consequently, these studies are mainly focused on detection and quantification of defects, rather than on localizing them.

\subsubsection{Objective and outline}

The objective of this research is to analyze whether the vibro-acoustic modulation method can be utilized to detect, localize and characterize impact damage in a composite skin-stiffener structure. The work further aims to provide a better understanding of the modulation phenomena by identifying the dominant 
parameters involved in the modulations. For these purposes, a time domain analysis of the vibro-acoustic modulation phenomena at multiple spatial locations is presented. This approach is an alternative to the commonly considered sideband amplitudes at a single measurement point. The presented work intends, from a broader perspective, to contribute to the development of enhanced methods for the identification and characterization of damage in advanced composite structures.

This chapter starts with a theoretical description of the vibro-acoustic modulation effect in the next section. This is followed by a description of the experimental set-up and procedures in Section 6.3. The present work concentrates on the same composite specimen and set-up as was utilized in earlier research by the present authors [26]. Only the damaged structure was considered in the analysis. The low-frequency pump excitation was applied by a shaker, while a piezoelectric diaphragm was used to simultaneously apply a high-frequency carrier excitation. A laser vibrometer was utilized to measure the steady state velocity responses at multiple spatial locations on the structure. The modulated response signals were decomposed to extract the instantaneous amplitude and frequency of the carrier signal. These instantaneous characteristics were used to analyze the vibro-acoustic modulation phenomena in more detail. The influence of the carrier excitation signal on the measured modulations is then discussed, based on a parametric study. Finally, the conclusions and recommendations for future work are presented.

\subsection{Theoretical description}

The current section provides a more thorough description of the wave modulation phenomena. First, a basic theoretical description of the vibro-acoustic modulation phenomena is presented. The development of the sideband components is demonstrated based on a nonlinear single degree of freedom system. This is followed by a description of the signal decomposition approach that is used to extract the instantaneous characteristics of the modulated carrier response. The last part essentially combines the two previous parts. A single degree of freedom system is numerically solved for four different types of nonlinearities. The signal decomposition approach is used to qualitatively analyze the system responses.

\subsubsection{Two-tone forced vibration of a nonlinear system}

A generalized quasi-harmonic nonlinear system [27] can be described by a differential equation consisting of two parts, one part containing linear terms and a second part containing nonlinear terms:

$$
\ddot{q}+\omega_{0}^{2} q=-\epsilon f(q, \dot{q}),
$$


where $q(t)$ is the displacement, $\omega_{0}$ the natural frequency, $f(q, \dot{q})$ is a nonlinear function. This nonlinear function is controlled by the parameter $\epsilon$. For a weakly nonlinear system, the parameter $\epsilon$ is considered relatively small such that the solution of this system can be approximated by utilizing a perturbation technique based on a power series [27]:

$$
q(t)=q_{0}(t)+\epsilon q_{1}(t)+\epsilon^{2} q_{2}(t)+\ldots .
$$

An undamped system containing a quadratic nonlinearity subjected to a two-tone forced excitation is considered in this study to illustrate the modulation effects in the steady state response. A similar derivation can be followed for other types of nonlinearities [27]. The quadratic nonlinear system is described by:

$$
\ddot{q}+\omega_{0}^{2} q=-\epsilon q^{2}+F_{\mathrm{p}} \cos \left(\omega_{\mathrm{p}} t+\phi_{\mathrm{p}}\right)+F_{\mathrm{c}} \cos \left(\omega_{\mathrm{c}} t+\phi_{\mathrm{c}}\right),
$$

with $F_{\mathrm{p}}$ and $F_{\mathrm{c}}$ the amplitudes, $\omega_{\mathrm{p}}=2 \pi f_{\mathrm{p}}$ and $\omega_{\mathrm{c}}=2 \pi f_{\mathrm{c}}$ the frequencies in radians per second (where: $\omega_{\mathrm{p}} \ll \omega_{\mathrm{c}}$ ) and $\phi_{\mathrm{p}}$ and $\phi_{\mathrm{c}}$ the phases of respectively the pump and carrier excitation signals. Assuming a solution in the form of Equation (6.2) and separating orders of magnitude yields the following set of equations:

$$
\begin{array}{ll}
\mathcal{O}\left(\epsilon^{0}\right): & \ddot{q}_{0}+\omega_{0}^{2} q_{0}=F_{\mathrm{p}} \cos \left(\omega_{\mathrm{p}} t+\phi_{\mathrm{p}}\right)+F_{\mathrm{c}} \cos \left(\omega_{\mathrm{c}} t+\phi_{\mathrm{c}}\right), \\
\mathcal{O}\left(\epsilon^{1}\right): & \ddot{q}_{1}+\omega_{0}^{2} q_{1}=-q_{0}^{2}, \\
\mathcal{O}\left(\epsilon^{2}\right): & \ddot{q}_{2}+\omega_{0}^{2} q_{2}=-2 q_{0} q_{1},
\end{array}
$$

which can be solved recursively. The steady state solution of Equation (6.4) is:

$$
q_{0}(t)=G_{\mathrm{p}} \cos \left(\omega_{\mathrm{p}} t+\phi_{\mathrm{p}}\right)+G_{\mathrm{c}} \cos \left(\omega_{\mathrm{c}} t+\phi_{\mathrm{c}}\right),
$$

in which:

$$
G_{\mathrm{p}}=\frac{F_{\mathrm{p}}}{\omega_{0}^{2}-\omega_{\mathrm{p}}^{2}} \quad \text { and } \quad G_{\mathrm{c}}=\frac{F_{\mathrm{c}}}{\omega_{0}^{2}-\omega_{\mathrm{c}}^{2}} .
$$

Substituting $q_{0}(t)$ into Equation (6.5) and rearranging gives:

$$
\begin{array}{r}
\ddot{q}_{1}+\omega_{0}^{2} q_{1}=-\frac{1}{2} G_{\mathrm{p}} \cos \left(2 \omega_{\mathrm{p}} t+2 \phi_{\mathrm{p}}\right)-\frac{1}{2} G_{\mathrm{c}} \cos \left(2 \omega_{\mathrm{c}} t+2 \phi_{\mathrm{c}}\right) \\
-G_{\mathrm{p}} G_{\mathrm{c}} \cos \left(\left(\omega_{\mathrm{c}}-\omega_{\mathrm{p}}\right) t+\phi_{\mathrm{c}}-\phi_{\mathrm{p}}\right)-\frac{1}{2} G_{\mathrm{p}}^{2} \\
-G_{\mathrm{p}} G_{\mathrm{c}} \cos \left(\left(\omega_{\mathrm{c}}+\omega_{\mathrm{p}}\right) t+\phi_{\mathrm{c}}+\phi_{\mathrm{p}}\right)-\frac{1}{2} G_{\mathrm{c}}^{2} .
\end{array}
$$

Following from the nature of the excitation, the response $q_{1}(t)$ consists of a linear combination of harmonic components with frequencies equal to: $2 \omega_{p}, 2 \omega_{c}, \omega_{c}-\omega_{p}$, $\omega_{\mathrm{c}}+\omega_{\mathrm{p}}$ and a constant term. The fundamental harmonic frequency components 
$\omega_{\mathrm{p}}$ and $\omega_{\mathrm{c}}$ are added in the case of a first-order approximation of the solution $q(t)$ according to Equation (6.2). The carrier component $\omega_{\mathrm{c}}$ and its associated sidebands (i.e. $\omega_{\mathrm{c}}-\omega_{\mathrm{p}}, \omega_{\mathrm{c}}+\omega_{\mathrm{p}}$ ) are utilized for damage identification purposes. The system response is therefore analyzed in a narrow frequency band around the carrier frequency $\omega_{\mathrm{c}}$. Consequently, the first-order steady state solution of $q(t)$ reduces to the narrow band response $q_{\mathrm{bp}}(t)$ given by:

$$
\begin{aligned}
q_{\mathrm{bp}}(t)=\overbrace{A_{\mathrm{c}} \cos \left(\omega_{\mathrm{c}} t+\phi_{\mathrm{c}}\right)}^{\text {carrier }}+\overbrace{A_{\mathrm{sb} 1} \cos \left(\left(\omega_{\mathrm{c}}-\omega_{\mathrm{p}}\right) t+\phi_{\mathrm{c}}-\phi_{\mathrm{p}}\right)}^{\text {lower sideband }} \\
+\underbrace{A_{\mathrm{sb} 2 \cos \left(\left(\omega_{\mathrm{c}}+\omega_{\mathrm{p}}\right) t+\phi_{\mathrm{c}}+\phi_{\mathrm{p}}\right)},}_{\text {upper sideband }}
\end{aligned}
$$

in which:

$$
A_{\mathrm{c}}=G_{\mathrm{c}}, \quad A_{\mathrm{sb} 1}=\frac{-\epsilon G_{\mathrm{p}} G_{\mathrm{c}}}{\omega_{0}^{2}\left(\omega_{\mathrm{c}}-\omega_{\mathrm{p}}\right)^{2}} \quad \text { and } \quad A_{\mathrm{sb} 2}=\frac{-\epsilon G_{\mathrm{p}} G_{\mathrm{c}}}{\omega_{0}^{2}\left(\omega_{\mathrm{c}}+\omega_{\mathrm{p}}\right)^{2}} .
$$

This analytical solution demonstrates the intermodulation of the carrier response signal with the pump signal. The carrier response is only modulated in amplitude and not in frequency in this case. The response of a system containing another type of nonlinearity may show not only different combinations of harmonics, amplitudes and phase angles, but can also exhibit both amplitude and frequency modulation effects. A linear system (i.e. $\epsilon=0$ ) does not show amplitude or frequency modulation effects. The response will, in that case, only consist of harmonic components with frequencies equal to $\omega_{\mathrm{p}}$ and $\omega_{\mathrm{c}}$.

\subsubsection{Signal decomposition approach}

The time domain analysis utilized in the present work is schematically illustrated in Figure 6.2. This approach consists of two steps. In the first step, a zero-phase bandpass FIR (i.e. finite impulse response) filter in a narrow frequency band around the carrier frequency is applied to separate the carrier response and its potential sidebands from the rest of the system response. Subsequently, the Hilbert transform is applied to this filtered response $v_{\mathrm{bp}}(t)$ to extract the instantaneous amplitude $A_{\text {inst }}(t)$ (i.e. the signal envelope) and frequency $f_{\text {inst }}(t)$. A description of the Hilbert transform is presented in Appendix C. The instantaneous amplitude and frequency reveal whether amplitude and/or frequency modulation effects are present. These instantaneous characteristics are constant in the case of a purely linear system response, but start to oscillate when nonlinearities are present, as was illustrated in Figure 6.1. The peak-to-peak values of the oscillations in the instantaneous amplitude and instantaneous frequency, represented by $M_{\mathrm{a}}$ and $M_{\mathrm{f}}$ respectively, are used as a measure for the amount of modulation. 


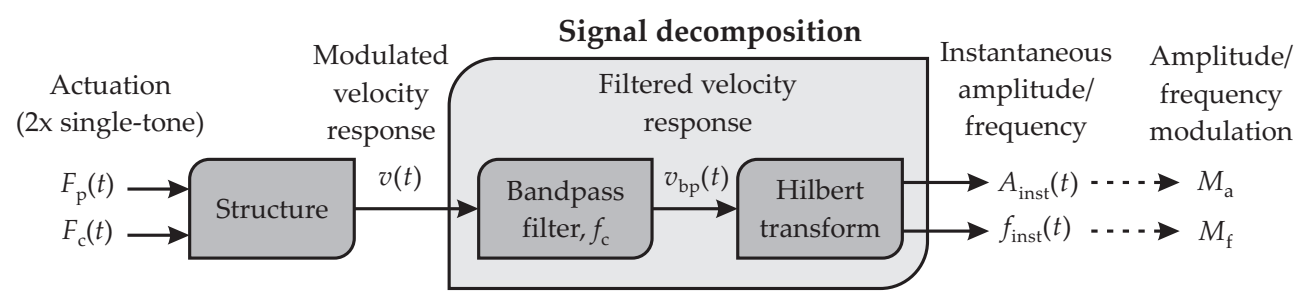

Figure 6.2 Time domain signal analysis process of the response signal $v(t)$ containing a bandpass filter around the carrier frequency $f_{\mathrm{c}}$ and the Hilbert transform to extract the instantaneous amplitude $A_{\text {inst }}(t)$ and frequency $f_{\text {inst }}(t)$. The peak-to-peak values of these instantaneous characteristics are used as a measure for the amount of amplitude modulation $M_{\mathrm{a}}$ and frequency modulation $M_{\mathrm{f}}$.

\subsubsection{Nonlinear response characteristics}

Numerical simulations were performed to qualitatively analyze the effect of different types of nonlinearities on the steady state system response of a single degree of freedom system. Response characteristics can be associated with the different system representations. A damped nonlinear system (mass $m=1 \mathrm{~kg}$, stiffness $k=10^{5} \mathrm{~N} / \mathrm{m}$ and damping coefficient $c=20 \mathrm{Ns} / \mathrm{m}$ ) was solved for a forced excitation by two single-tone excitation signals $\left(F_{\mathrm{p}}=10 \mathrm{~N}, F_{\mathrm{c}}=2 \mathrm{~N}\right.$, $\left.\omega_{\mathrm{p}}=2 \pi f_{\mathrm{p}}=40 \pi \mathrm{rad} / \mathrm{s}, \omega_{\mathrm{c}}=2 \pi f_{\mathrm{c}}=2000 \pi \mathrm{rad} / \mathrm{s}, \phi_{\mathrm{p}}=\phi_{\mathrm{c}}=0 \mathrm{rad}\right)$. Four systems with different types of nonlinearities were considered: quadratic and cubic with respect to displacement $q(t)$ and quadratic and cubic with respect to velocity $\dot{q}(t)$. The nonlinear factor $\epsilon$ was used to control the strength of the nonlinear function, according to Equation (6.1). The initial conditions were $q(t)=0 \mathrm{~m}$ and $\dot{q}(t)=0 \mathrm{~m} / \mathrm{s}$ for all cases. Only the steady state system response was considered in this analysis.

The Fourier transformed velocity responses of a quadratic and cubic nonlinear system with respect to displacement $q(t)$ are shown in Figure 6.3. Although both nonlinear responses show multiple higher harmonic components and carrier sidebands, there is a notable difference in the arrangement of these additional harmonics. The response of the system with the quadratic nonlinearity exhibits higher harmonics and sidebands that deviate $n f_{\mathrm{p}}$ (with $n=1,2,3, \ldots$ ) from the fundamental frequencies $f_{\mathrm{p}}$ and $f_{\mathrm{c}}$, while this is $2 n f_{\mathrm{p}}$ in the case of the cubic nonlinear system. This observation complies with the statements given in [10, 28] and can be verified by utilizing the perturbation approach shown in Section 6.2.1.

The time domain decomposition approach, as described in Section 6.2.2, is used to calculate the instantaneous amplitude and frequency of the carrier response signal. The results obtained for the four different nonlinear systems are shown in Figure 6.4. Each case contains three response signals corresponding to three different values for nonlinearity factor $\epsilon$. The systems containing a nonlinearity in terms of displacement $q(t)$ (see Figures 6.4(a) and 6.4(b)) only show amplitude modulated responses, while systems with a velocity $\dot{q}(t)$ related nonlinear term (see Figures 6.4(c) and 6.4(d)) exhibit both amplitude and frequency modulations. 


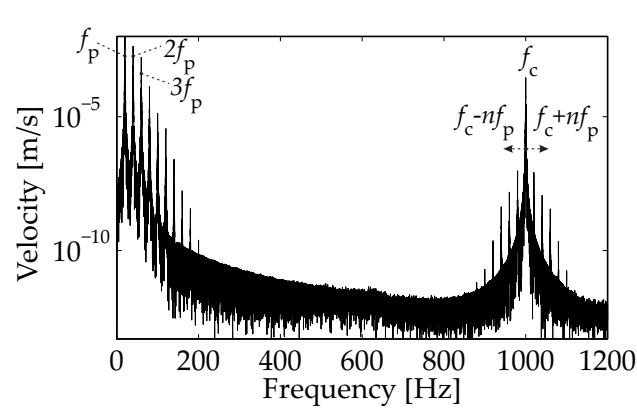

(a) Quadratic nonlinearity: $f\left(q^{2}\right)$.

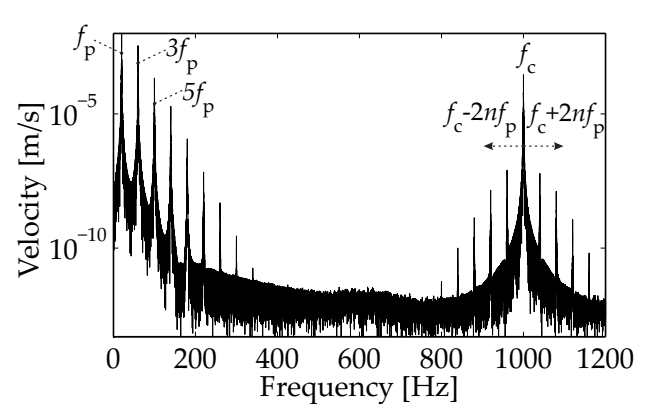

(b) Cubic nonlinearity: $f\left(q^{3}\right)$

Figure 6.3 Fourier transformed response signals for a system containing a (a) quadratic and (b) cubic nonlinearity with respect to displacement $q(t)$ showing sidebands at $f_{\mathrm{c}} \pm n f_{\mathrm{p}}$ and $f_{\mathrm{c}} \pm 2 n f_{\mathrm{p}}$ (with $n=1,2,3, \ldots)$ respectively.

This result is analogous to the fact that the response of an undamped system is in phase with its excitation, whereas the response of a viscously damped system can exhibit a phase deviation. A nonlinearity in terms of velocity can consequently result in varying phase deviations. Frequency modulations are obtained because the instantaneous frequency is calculated as the time derivative of the instantaneous phase as shown in Appendix C. Note that the frequency of the modulation effect is different for the quadratic and cubic nonlinear systems. The responses of the systems containing a quadratic nonlinearity show a dominant superimposed
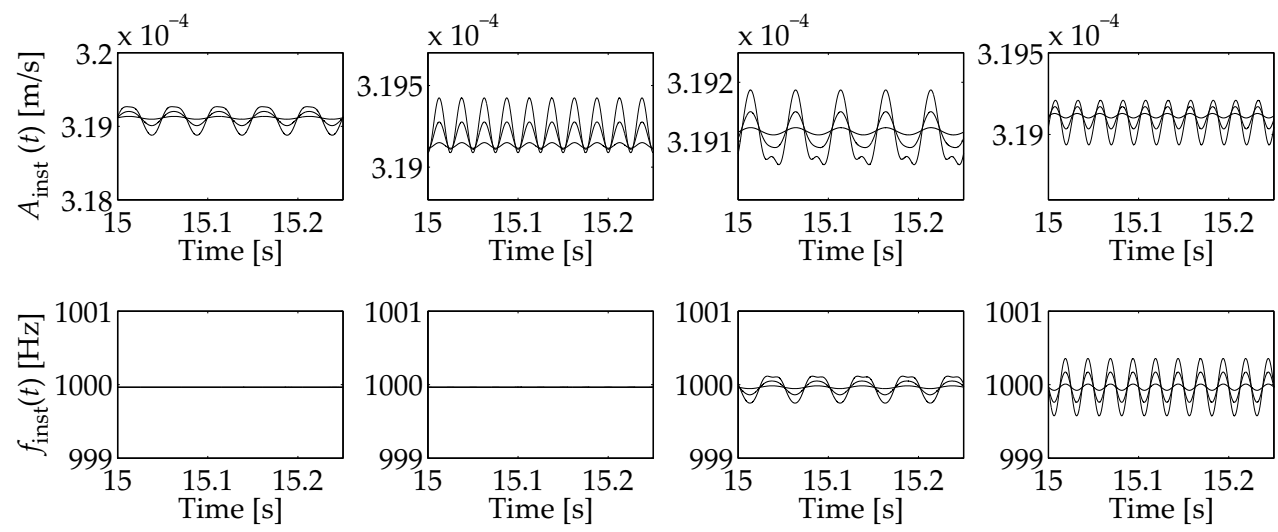

(a) $f\left(q^{2}\right)$

(b) $f\left(q^{3}\right)$

(c) $f\left(\dot{q}^{2}\right)$

(d) $f\left(\dot{q}^{3}\right)$

Figure 6.4 Instantaneous amplitude $A_{\text {inst }}(t)$ (top) and frequency $f_{\text {inst }}(t)$ (bottom) variations obtained for a system containing four different types of nonlinearity: (a) quadratic and (b) cubic with respect to displacement $q(t)$ and $(c)$ quadratic and $(d)$ cubic with respect to velocity $\dot{q}(t)$. Each case contains three response signals corresponding to three different values for nonlinearity factor $\epsilon$. 
frequency equal to $f_{\mathrm{p}}$, while this is $2 f_{\mathrm{p}}$ for the cubic nonlinear systems. This inherently corresponds to the frequency differences between the sidebands as shown in Figure 6.3.

\subsection{Experimental work}

The current section introduces the experimental work. The composite skin-stiffener structure will be presented in the first section, followed by a description of the experimental set-up. The last subsection addresses the two-step experimental procedure used to measure the vibro-acoustic modulation behavior. Only the responses measured at the damaged structure are utilized in the analysis.

\subsubsection{Composite skin-stiffener structure}

The structure investigated in this study is a thermoplastic skin-stiffener section made by Fokker Aerostructures according to the joining concept explained in [29]. Preformed skin and stiffener laminates are connected by an injection molded filler in a co-consolidation process. The structure is schematically illustrated in Figure 6.5. Both the skin and the stiffener are built from 16 individual plies of unidirectional carbon AS4D fiber reinforced thermoplastic (PEKK) material with a $[90 / 0]_{4, s}$ lay-up. The filler is made from PEKK and contains $20 \%$ short carbon fibers.

The damage analyzed in this study is located at the connection between skin and stiffener. This connection is considered as a safety-critical area due to the high importance of the connection for the structural integrity of the component. Damage was introduced by utilizing a falling weight impact device and applying a repeated impact up to $15 \mathrm{~J}$. The ultrasonic C-scan in Figure 6.6 reveals damage consisting of a delamination at the interface between the skin and stiffener accompanied by a limited amount of damage between the first and second ply of the skin. Local delaminations were also introduced underneath one of the supports that was used during the impact testing.

\subsubsection{Experimental set-up}

The set-up and data acquisition systems used for all experiments are schematically illustrated in Figure 6.7. The composite structure was freely suspended by an elastic wire, glued to the butt joint, in order to isolate the structure from environmental vibrations. An electromechanical shaker was connected by a stringer and a force transducer to a corner of the structure. The shaker was used to introduce the low-frequency pump waves, while a piezoelectric diaphragm was glued at another corner of the structure to introduce the high-frequency carrier waves. A 


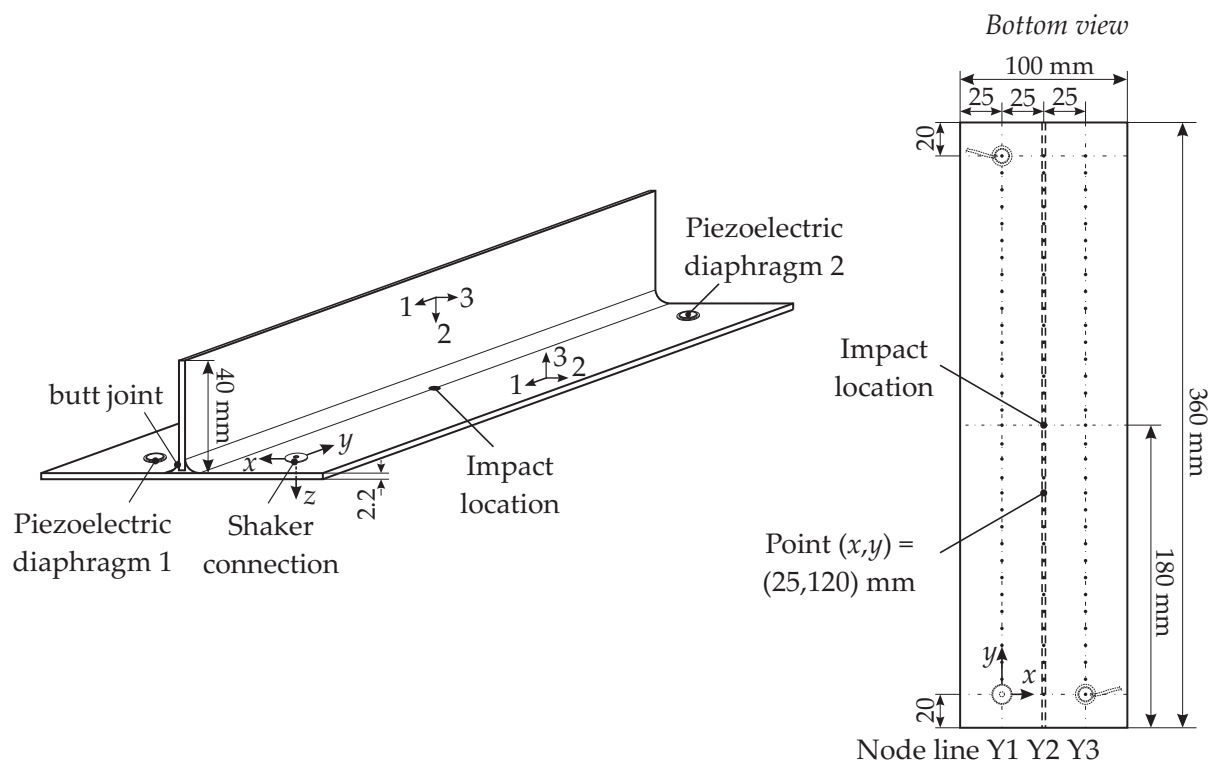

Figure 6.5 Three dimensional and bottom view of the composite skin-stiffener structure with a butt-joint stiffener. The dimensions, the measurement points (dots) and the impact location are indicated.

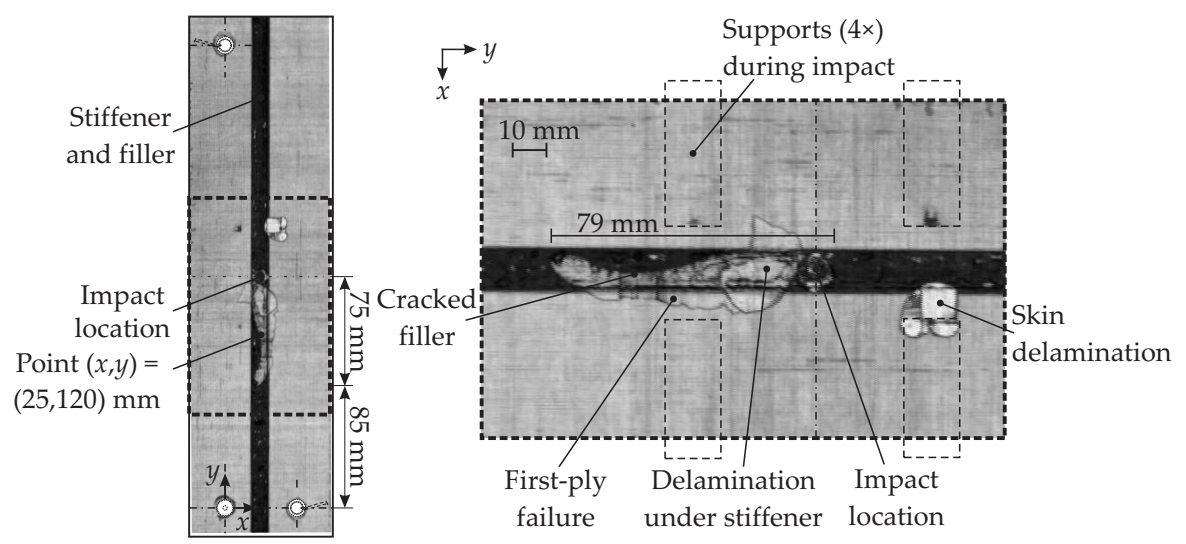

Figure 6.6 Ultrasonic C-scan of the impact damaged skin-stiffener structure showing a complex combination of failure mechanisms near the skin-stiffener interface. 


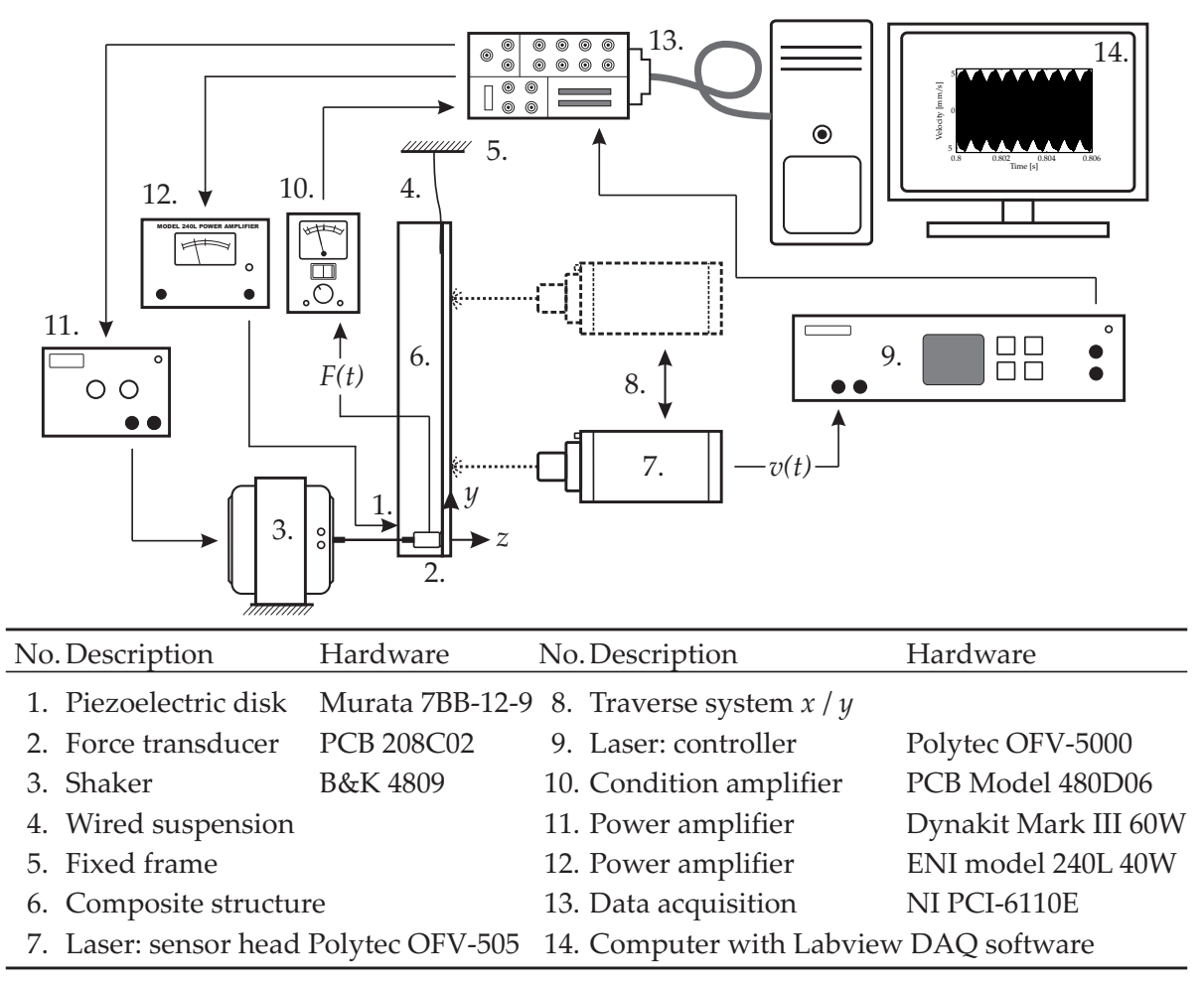

Figure 6.7 The experimental set-up.

laser vibrometer, mounted on a $x / y$ traverse system, measured the velocities at different points at the skin of the structure. The measurement points are ordered according to three node lines in $y$-direction ('Y1', 'Y2', 'Y3'), as shown Figure 6.5. A data acquisition system, controlled by a Labview application, was utilized to simultaneously send the excitation signals and to acquire the force and velocity responses.

\subsubsection{Experimental procedure}

The experimental process consisted of two steps: a global dynamic characterization of the skin-stiffener structure followed by the actual vibro-acoustic modulation experiments. The first step is used to extract the interesting vibrational modes of the structure. The frequencies of these modes are input for the second step to force the structure to vibrate in a distinct deformation pattern during the vibro-acoustic modulation experiment. Both steps are described in the present subsection. 


\section{Initial global dynamic characterization}

In the first set of experiments, the global dynamic behavior of the structure is determined in terms of natural frequencies and the frequency dependent deflection patterns, referred to as operational deflection shapes (ODS). An excitation signal composed of a linear sweep between 150 and $3050 \mathrm{~Hz}$ was sent to the shaker. The force response was measured at the fixed excitation point. The velocities were acquired at $51(3 \times 17)$ points, matching the node lines in Figure 6.5. All signals were sent and acquired for 2.62 seconds at a rate of $50 \mathrm{kHz}$ ( $2^{17}$ samples). A measurement at each point was repeated 10 times. These time responses were subsequently windowed, Fourier transformed and averaged to obtain the power spectral densities. The cross-power spectral density $S_{F_{i} v_{j}}(\omega)$ is divided by the autopower spectral density of the input force $S_{F_{i} F_{i}}(\omega)$ to obtain the mobility frequency response functions $H_{F_{i} v_{j}}(\omega)$ between the fixed point of excitation $i$ and the roving measurement points $j$ according to [30].

Figure 6.8 shows the magnitude of the total set of frequency response functions of the damaged structure. Sharp peaks correspond to the natural frequencies of the structure. The bending and torsion dominant operational deflection shapes of the structure are extracted at the natural frequencies with the help of peak picking. The natural frequencies of the first six bending and torsion dominant operational deflection shapes of the damaged structure are presented in Table 6.1. Note that the first torsion mode was not measured. The natural frequency of this mode is lower than the lowest frequency used in the excitation. Earlier research [8] showed that bending dominant deformations in the yz-plane are more affected by skinstiffener damage than torsional deformations around the $y$-axis. The present work is, therefore, focused on the vibro-acoustic modulation effects introduced by the bending dominant operational deflection shapes.

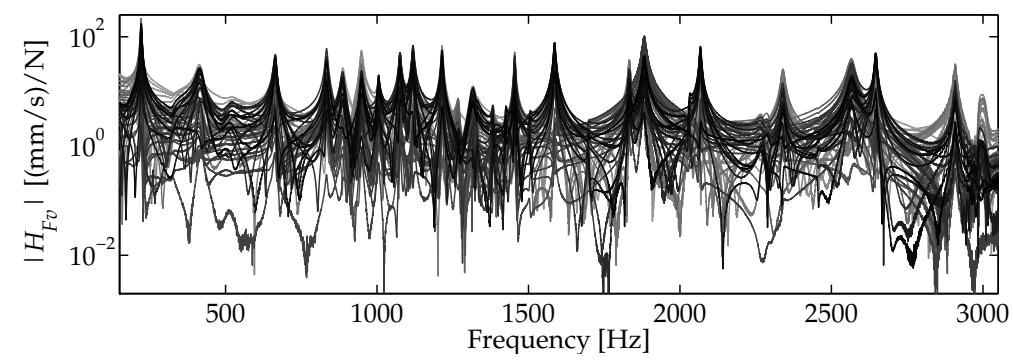

Figure 6.8 The magnitude of the frequency response functions for all $51(3 \times 17)$ measurement points of the damaged structure. 
Table 6.1 Natural frequencies of the first six bending and torsion modes of the damaged (indicated by a tilde) structure.

\begin{tabular}{ccc}
\hline $\begin{array}{c}\text { Mode } \\
n\end{array}$ & $\begin{array}{c}\text { Bending } B_{y z} \\
\tilde{f}_{\mathrm{B}}^{(n)}[\mathrm{Hz}]\end{array}$ & $\begin{array}{c}\text { Torsion } T_{y} \\
\tilde{f}_{\mathrm{T}}^{(n)}[\mathrm{Hz}]\end{array}$ \\
\hline 1 & 949 & - \\
2 & 1076 & 221 \\
3 & 1215 & 414 \\
4 & 1455 & 664 \\
5 & 1833 & 1119 \\
6 & 2340 & 1586 \\
\hline
\end{tabular}

\section{Vibro-acoustic modulation experiments}

The second set of experiments are the actual vibro-acoustic modulation measurements. Two single-tone harmonic signals with different amplitude and frequency were simultaneously sent to the shaker and the piezoelectric diaphragm. The pump excitation signal introduced by the shaker had a frequency $f_{\mathrm{p}}$ corresponding to one of the bending frequencies listed in Table 6.1 and was varied in strength. The piezoelectric diaphragm was subjected to a weaker $50 \mathrm{kHz}$ ultrasonic excitation signal. The amplitude of this carrier signal $A_{\mathrm{c}}$ was kept constant. The carrier frequency $f_{\mathrm{c}}$ is chosen in such a way that the carrier sideband components are well separated from the higher harmonics of the pump frequency, but that the highfrequency wave field can still be described by a limited number of measurement points. The shaker excitation force and the velocity response were simultaneously acquired at a sample rate of $1 \mathrm{MHz}$ for 1.05 seconds ( $2^{20}$ samples). No averaging was applied. Only the steady state response is considered in the analysis. The structure vibrates at steady state after the transient (start-up) response has disappeared. A period of 0.8 seconds was revealed to be sufficiently long for these transient effects to become negligible. The captured responses are processed by the time domain signal decomposition approach as explained in Section 6.2.2. The results are presented in the next section and are used to analyze the modulation phenomena in the composite skin-stiffener structure in detail.

\subsection{Experimental results and discussion}

The experimental results are presented in the current section. The results obtained for a single measurement point are discussed first, followed by the results obtained for multiple points underneath the stiffener. Possible explanations for the measured results are formulated and discussed. The effect of the underlying dynamic behavior on the measured modulations is addressed in the last subsection. 


\subsubsection{Response decomposition}

The steady state velocity response $v(t)$ of the damaged structure caused by two single-tone harmonic excitation signals is shown in Figure 6.9(a). The excitation consists of an intense pump excitation at the $4^{\text {th }}$ bending frequency $\left(f_{\mathrm{p}}=1455 \mathrm{~Hz}\right)$ and a weaker carrier excitation $\left(f_{\mathrm{c}}=50 \mathrm{kHz}\right)$. The velocity response $v(t)$ is measured at location $(x, y)=(25,120) \mathrm{mm}$ according to the coordinate system presented in Figure 6.5. This point is located at the skin near the skin-stiffener connection and coincides with the damaged region. Low and high frequency components can be distinguished in the velocity response. The amplitude of the Fourier spectrum of this response, i.e. $|V(f)|$, is shown in Figure 6.9(b) and reveals higher harmonic components $n f_{\mathrm{p}}$ and multiple carrier sidebands $f_{\mathrm{c}} \pm n f_{\mathrm{p}}$ (with $n=1,2,3, \ldots$ ). These additional components are indicative of a nonlinear response.

The low frequency part of the response matches the nonlinear response that was

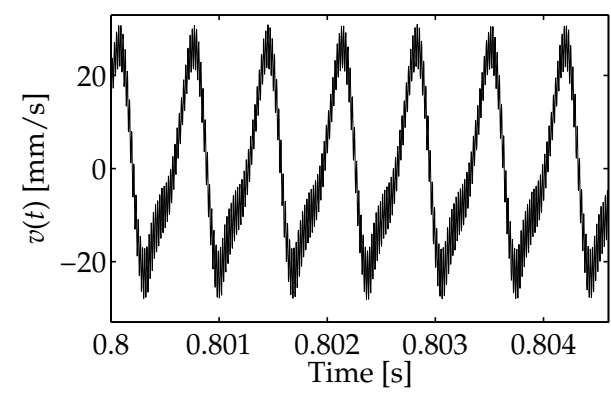

(a) Original velocity response $v(t)$.

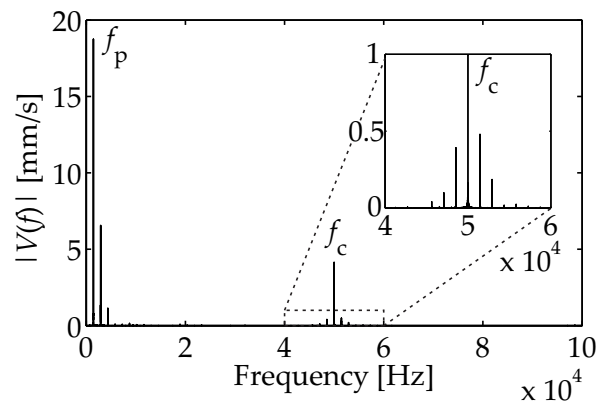

(b) Fourier spectrum of the original velocity response $v(t)$.

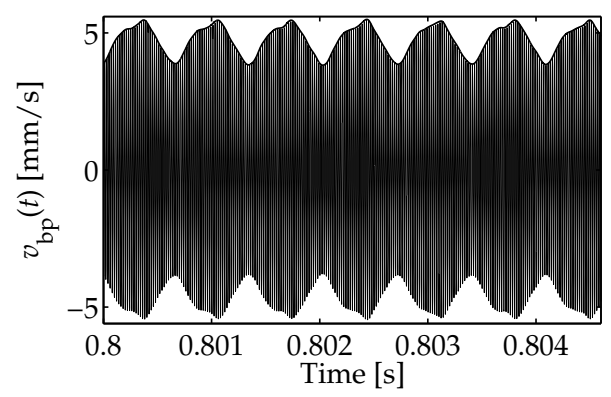

(c) Bandpass filtered velocity response $v_{\mathrm{bp}}(t)$.

Figure 6.9 The (a) original and (c) bandpass filtered (40-60 kHz) velocity response measured at location $(x, y)=(25,120) \mathrm{mm}$ of the damaged structure for two single-tone excitation signals with $f_{\mathrm{p}}=1455 \mathrm{~Hz}$ and $f_{\mathrm{c}}=50 \mathrm{kHz}$ and the highest shaker excitation amplitude. The Fourier spectrum of the original response $(b)$ shows the higher harmonic components $n f_{\mathrm{p}}$ and carrier sidebands $f_{\mathrm{c}} \pm n f_{\mathrm{p}}$ (with $\left.n=1,2,3, \ldots\right)$. 
measured and analyzed in earlier research by authors [26] on the same specimen using a single-tone harmonic shaker excitation. The distorted harmonic response of the skin in that study was linked to the opening, closing and contact phase of the skin-stiffener damage. In the present work, however, the high frequency of the response is utilized. The carrier response and its dominant sideband components are separated from the rest of the response by applying a bandpass filter within a $f_{\mathrm{c}} \pm 10 \mathrm{kHz}$ frequency range. The resulting narrow band velocity response $v_{\mathrm{bp}}(t)$ is depicted in Figure 6.9(c). The oscillating signal envelope clearly indicates that amplitude modulation effects are present.

The nonlinear modulation effects in the bandpass filtered velocity response are extracted by utilizing the Hilbert transform, as was described in Section 6.2.2. The periodic behavior of the instantaneous amplitude $A_{\text {inst }}(t)$ and frequency $f_{\text {inst }}(t)$ variations in Figures 6.10(a) and 6.10(b) shows that both amplitude and frequency modulation effects are present. The amount of modulation, represented by the

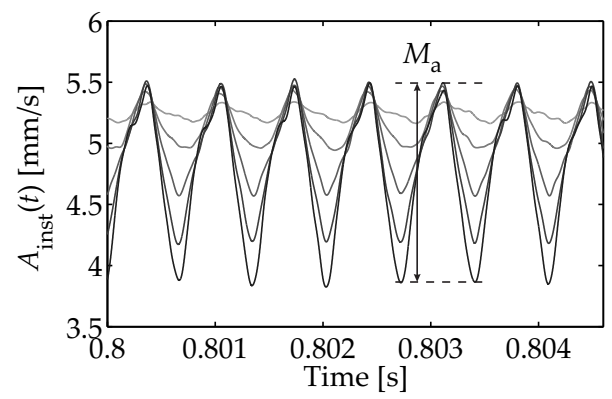

(a) Instantaneous amplitude $A_{\text {inst }}(t)$.

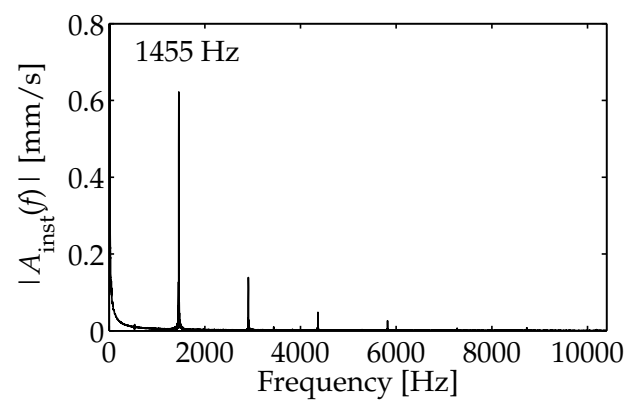

(c) Fourier spectrum of the instantaneous amplitude $A_{\text {inst }}(t)$.

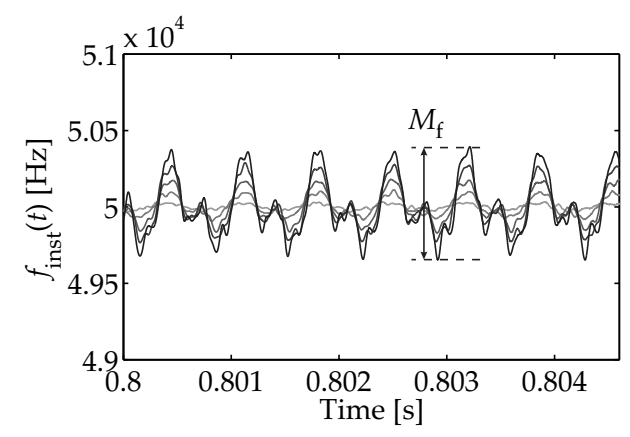

(b) Instantaneous frequency $f_{\text {inst }}(t)$.

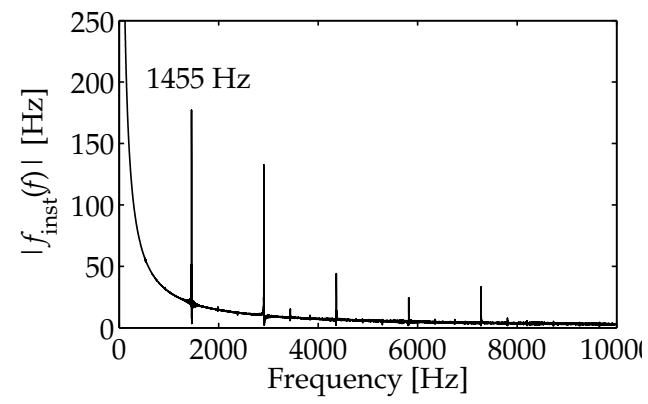

(d) Fourier spectrum of the instantaneous frequency $f_{\text {inst }}(t)$.

Figure 6.10 The (a) instantaneous amplitude $A_{\text {inst }}(t)$ and $(b)$ instantaneous frequency $f_{\text {inst }}(t)$ of the bandpass filtered velocity response $v_{\mathrm{bp}}(t)$ measured at location $(x, y)=(25,120) \mathrm{mm}$ of the damaged structure for five shaker excitation amplitudes. The associated Fourier spectra $(c, d)$, illustrated for the highest shaker excitation amplitude, reveal a dominant frequency equal to $f_{\mathrm{p}}=1455 \mathrm{~Hz}$. 
peak-to-peak value, increases for higher amplitude levels of the pump excitation. The dominant frequency of the amplitude and frequency modulation phenomena matches the pump excitation frequency $f_{\mathrm{p}}=1455 \mathrm{~Hz}$, as shown in Figures 6.10(c) and 6.10(d). According to the numerical results presented in Section 6.2.3, this indicates that the nonlinearity in the structure tends to be more a quadratic rather than a cubic type of nonlinearity.

\subsubsection{Spatial results}

The same vibro-acoustic measurement is performed at multiple locations at node line ' $Y 2$ ' and for multiple pump excitation frequencies. The velocity distribution of the damaged structure when excited by a $1455 \mathrm{~Hz}$ pump excitation and a $50 \mathrm{kHz}$ carrier excitation is shown in Figure 6.11(a). The local changes in amplitude and phase of the low frequency part of the response are caused by the damaged skin-stiffener interface, as was shown in earlier research by authors on the same specimen [26]. The velocity distribution obtained after applying the $f_{\mathrm{c}} \pm 10 \mathrm{kHz}$ bandpass filter is depicted in Figure 6.11(b). The local higher amplitudes within region ' $\mathrm{I}$ ' and 'III' nicely correspond to the location and geometry of the skinstiffener damage. Note that modulations in the amplitude are visible at, for example, $y=0.15 \mathrm{~m}$. The lower amplitudes at the intermediate region ' $\mathrm{II}^{\prime}$ are due to the fact that the corresponding measurement points are located at a region where

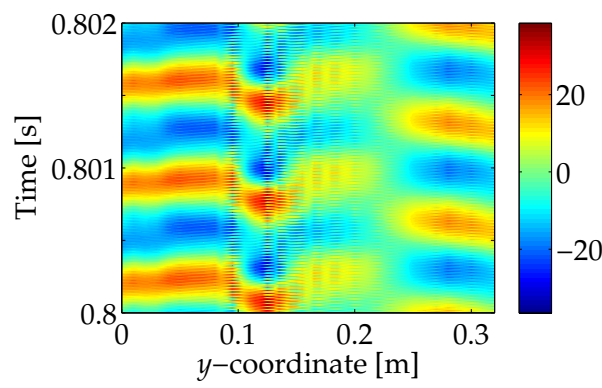

(a) Original velocity response $v(t)[\mathrm{mm} / \mathrm{s}]$.

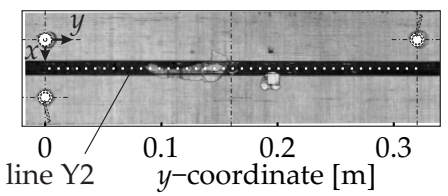

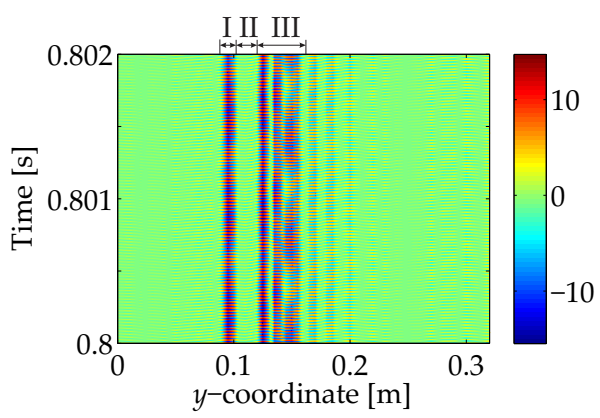

(b) Bandpass filtered velocity response $v_{\mathrm{bp}}(t)[\mathrm{mm} / \mathrm{s}]$.

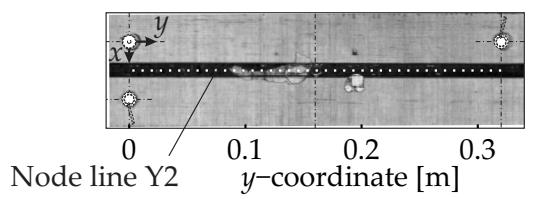

Figure 6.11 The (a) original and (b) bandpass filtered (40-60 kHz) velocity response measured at node line ' $Y 2$ ' of the damaged structure for two single-tone harmonic excitation signals with $f_{\mathrm{p}}=1455 \mathrm{~Hz}$ and $f_{\mathrm{c}}=50 \mathrm{kHz}$ and the highest shaker excitation amplitude. 
(a)

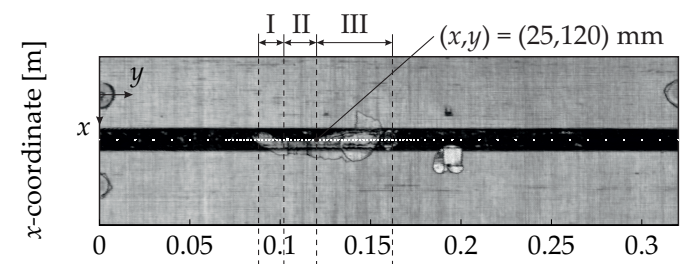

(b)
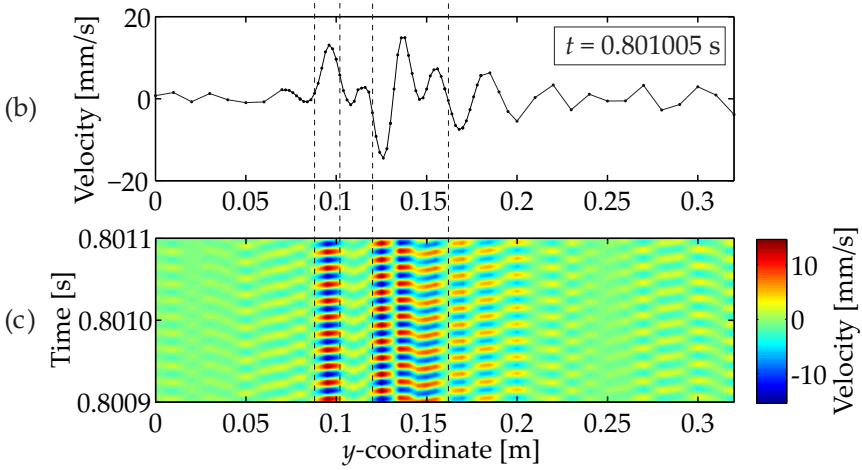

Figure 6.12 Comparison of the (a) damage location and geometry with the $(b, c)$ bandpass filtered velocity distribution $v_{\mathrm{bp}}(t)$ of the skin at node line ' $Y 2$ '.

the interface between the skin and the injection molded filler is not delaminated over the entire width of the filler. A more detailed comparison between the damage geometry and the bandpass filtered velocity response is presented in Figure 6.12.

The instantaneous amplitude and frequency of the bandpass filtered velocity distribution are subsequently extracted according to the procedure described in Section 6.2.2. The peak-to-peak values of the oscillations in these instantaneous characteristics, represented by $M_{\mathrm{a}}$ and $M_{\mathrm{f}}$, are utilized as a measure for the amount of modulation. Figures 6.13(a) and 6.13(b) show the results obtained for a pump excitation frequency equal to the $4^{\text {th }}$ bending mode $\left(f_{\mathrm{p}}=1455 \mathrm{~Hz}\right)$ and three pump excitation amplitudes $F_{\mathrm{p}}$. Figures 6.13(c) and 6.13(d) show the same results in the case of the $6^{\text {th }}$ bending mode $\left(f_{\mathrm{p}}=2340 \mathrm{~Hz}\right)$. Although the structure exhibits both amplitude and frequency modulation effects over the entire length of the structure, increased amplitude modulation effects are measured at the damaged area. The damage seems to hardly modulate the frequency of the carrier signal. Figure 6.15 provides a closer look to the bandpass filtered time responses measured at three successive points (i.e. $y=115 \mathrm{~mm}, y=120 \mathrm{~mm}$, and $y=125 \mathrm{~mm}$ ) at the damaged region. The dominant frequency of the amplitude modulation patterns again matches the pump excitation frequency $f_{\mathrm{p}}$. These figures also reveal that the phase of the amplitude modulation can significantly vary between the different measurement points.

The frequency modulation in Figures 6.13(b) and 6.13(d) shows several higher peaks. These peaks are attributed to a local low amplitude of the fundamental 


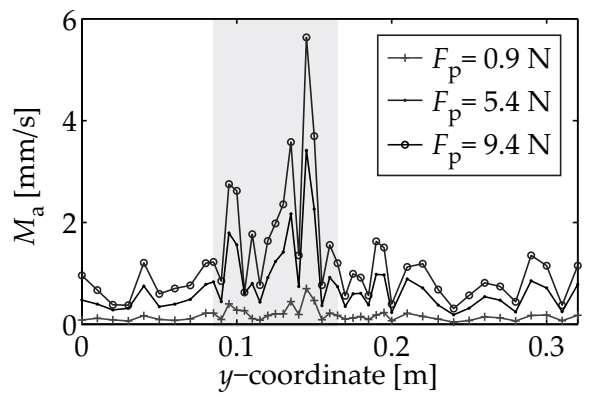

(a) Amplitude modulation for $f_{\mathrm{p}}=1455 \mathrm{~Hz}$.

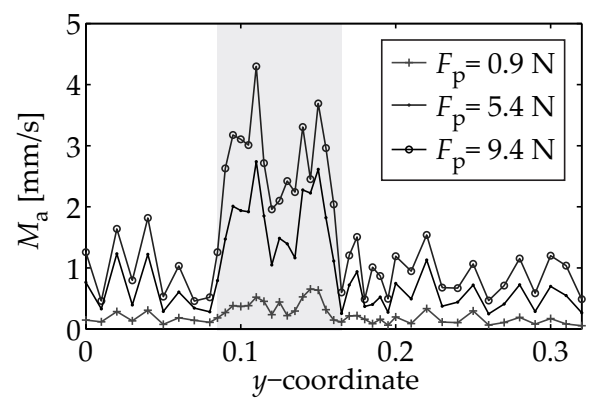

(c) Amplitude modulation for $f_{\mathrm{p}}=2340 \mathrm{~Hz}$.

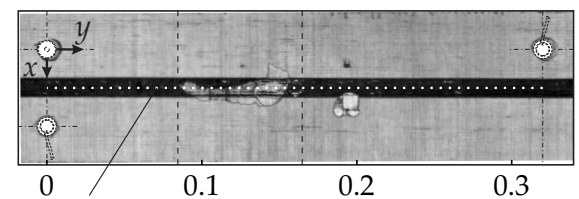

Node line Y2 $y$-coordinate $[\mathrm{m}]$

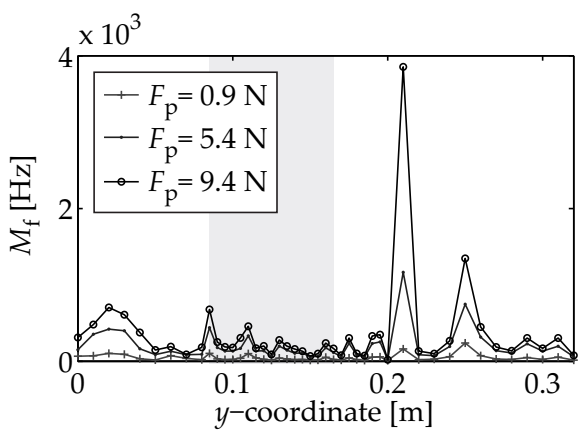

(b) Frequency modulation for $f_{\mathrm{p}}=1455 \mathrm{~Hz}$.

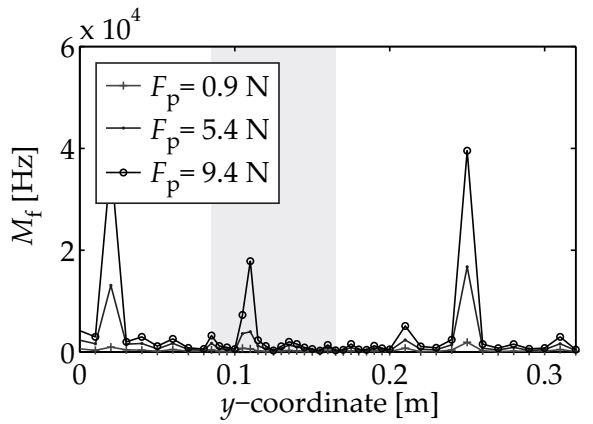

(d) Frequency modulation for $f_{\mathrm{p}}=2340 \mathrm{~Hz}$.

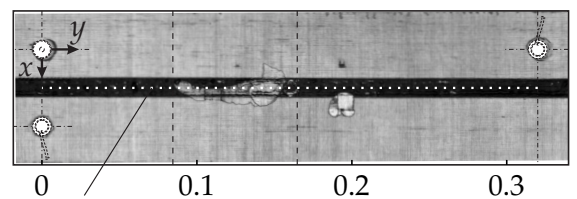

Node line Y2 $y$-coordinate $[\mathrm{m}]$

Figure 6.13 The $(a, c)$ amplitude and $(b, d)$ frequency modulation distributions of the carrier response measured at node line ' $Y 2$ ' of the damaged structure caused by two single-tone harmonic excitation signals for three pump excitation amplitudes $F_{\mathrm{p}}$. The results for $f_{\mathrm{p}}=1455 \mathrm{~Hz}$ are shown in $(a, b)$, while $(c, d)$ show the results for $f_{\mathrm{p}}=2340 \mathrm{~Hz}$. The carrier frequency $f_{\mathrm{c}}$ was $50 \mathrm{kHz}$ for all cases.

carrier response (e.g. near a nodal point) combined with a relatively large amount of amplitude modulation, almost leading to over-modulation effects [31]. For example, the peak at $y=250 \mathrm{~mm}$ in Figure 6.13(d). Figure 6.14 shows that the associated bandpass filtered velocity response is almost fully modulated in amplitude. Consequently, poor estimations of the instantaneous frequency are obtained at the time instances where the envelope of the response approaches zero.

The underlying physical phenomena associated with wave modulations are generally not well understood by researchers $[19,25]$. Although the theory 


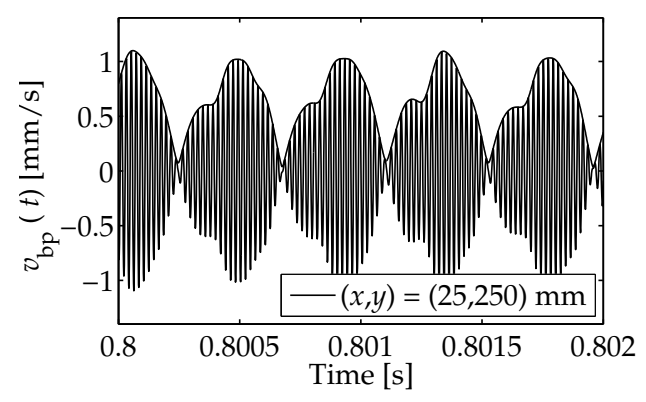

Figure 6.14 Severe amplitude modulations of the bandpass filtered $(40-60 \mathrm{kHz})$ velocity response measured at location $(x, y)=(25,250) \mathrm{mm}$ of the damaged structure for two single-tone harmonic excitation signals with $f_{\mathrm{p}}=2340 \mathrm{~Hz}$ and $f_{\mathrm{c}}=50 \mathrm{kHz}$ and the highest shaker excitation amplitude.

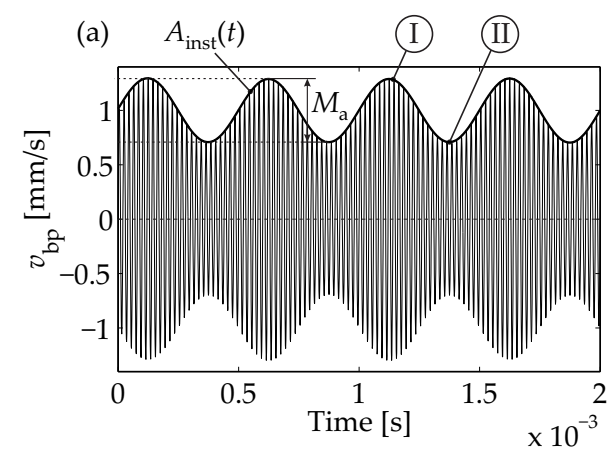

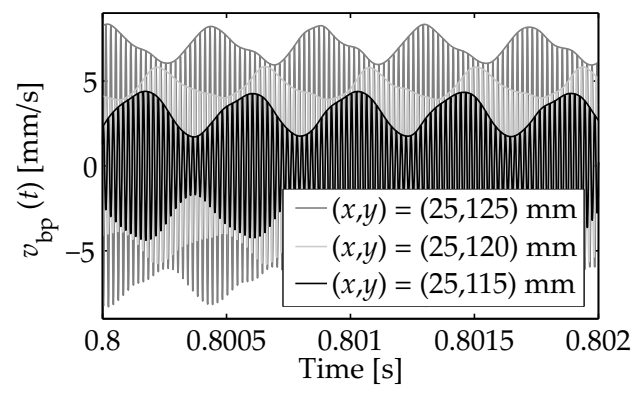

Figure 6.15 Phase differences in the amplitude modulations of the bandpass filtered $(40-60 \mathrm{kHz})$ velocity response measured at three successive points on the damaged area for two single-tone harmonic excitation signals with $f_{\mathrm{p}}=2340 \mathrm{~Hz}$ and $f_{\mathrm{c}}=50 \mathrm{kHz}$ and the highest shaker excitation amplitude.

Figure 6.16 A simplified and schematic explanation of the (a) carrier modulation principle introduced by the periodic opening and closing of the damage under an intense low-frequency pump excitation. In the (b) open state the skin is free to vibrate, whereas the carrier amplitudes are compressed in the $(c)$ closed situation.

presented in Section 6.2 provides an understanding of the relevant aspects involved, finding a physical explanation for the measured modulation behavior is still rather difficult. It was demonstrated by the present authors in [26] that the skin-stiffener damage can open and close under a low frequency excitation, but also that the skin can start to behave nonlinearly when the skin and stiffener are approaching each other. The same excitation frequencies and amplitude were used for the pump excitation in the vibro-acoustic experiments. Consequently, the nonlinear skinstiffener interaction is considered as the most likely reason why the modulation effects develop.

Based on this finding, a possible explanation is formulated for the increased 
amplitude modulations and the hardly modulated frequency of the carrier signal at the damaged region. The applied low-frequency pump excitation signal will change the damage interface conditions. In an ideal situation, the skin-stiffener damage is completely opened and closed by the flexural vibrations of the skin, as schematically illustrated in Figure 6.16. During the open state (b), the skin at the damaged region is free to vibrate under the simultaneously applied high-frequency carrier wave field. The amplitude of this wave field is, however, expected be to smaller during the closed state (c). As a result, the high-frequency carrier wave predominantly experiences periodic modulations of the amplitude, while the effects on the frequency are expected to be minor.

The most obvious description of an opening and closing defect is given by a varying stiffness across the damage interface [28]. There are two observations that correspond to the behavior that is expected in the case of the periodic opening and closing motion of the damage. Firstly, the fact that the frequency of the modulations corresponds to the pump excitation frequency. The numerical results presented in Section 6.2.3 revealed that this can indicate that the nonlinearity in the structure tends to be more a quadratic type of nonlinearity, which is also expected for the periodic opening and closing of a defect. Secondly, the numerical results also suggest that the dominant amplitude modulation effects measured at the damaged region indicate that the nonlinear dynamic behavior of the skin at the damaged region is dominated by a nonlinearity in terms of displacement rather than velocity. Both observations support the proposed explanation for the increased amplitude modulations according to Figure 6.16. Note that the observations based on the numerical results should be treated with some care; firstly, because the theoretical analysis was limited to a single degree of freedom system. Secondly, because only a few distinct types of nonlinearities were analyzed. Combinations of different nonlinear terms can potentially result in the same nonlinear response.

Following the explanation illustrated in Figure 6.16, the amplitude modulations are expected to be in phase with the low frequency part of the response. This behavior is confirmed for the theoretical description of a single degree of freedom system, as presented in Section 6.2. The experimental results, however, revealed that the phase of the amplitude modulation can significantly vary between the different measurement points. The complex geometry of the damage is expected to play a role in the timing of the modulations to develop. The damage, depicted in Figure 6.6, is geometrically complex, covers multiple levels and involves not only the interface between skin and filler, but also the skin and filler itself. This is likely to be one of the reasons, but may not be the only aspect, to explain the variations in the phase. The next section addresses, therefore, a brief parametric study to analyze the effect of the carrier excitation signal on the measured modulations. 


\subsubsection{Underlying dynamic behavior}

The variations in the phase of the amplitude modulation between the measurement points at node line ' $Y 2$ ' are studied in more detail by a parametric study. For this purpose, the influence of the carrier excitation signal on the modulation behavior was analyzed. Figures 6.17(a) and 6.17(b) show the effect of, respectively, the carrier excitation amplitude $F_{\mathrm{c}}$ and the frequency $f_{\mathrm{c}}$ on the instantaneous amplitude $A_{\text {inst }}(t)$ of the bandpass filtered response. The responses were measured at location $(x, y)=(25,120) \mathrm{mm}$ of the damaged structure for a pump excitation frequency equal to $f_{\mathrm{p}}=1455 \mathrm{~Hz}$. An increase in the amplitude of the carrier excitation causes larger amplitude modulations, whereas the phase of the modulation remains unchanged. On the other hand, a change in the carrier frequency, shown in Figure 6.17(b), affects both the amplitude as well as the phase of the amplitude modulation. Even a small shift in the carrier frequency can have a significant effect on the modulation behavior. These results imply that the amplitude and phase of the amplitude modulation are highly dependent on the high frequency wave field that is introduced by the selection of the carrier excitation frequency.

Yoder et al. [12] found that there is a strong correlation between the amplitude of the carrier sidebands and the magnitude of the underlying spectral response of the damaged structure. They state that the amount of modulation is directly related to the high frequency underlying dynamic behavior of the structure. A sideband will, for example, increase in amplitude if the frequency of the sideband coincides with a resonance frequency of the structure. Although for a single degree of freedom system, the theoretical description presented in Section 6.2 supports this observation. The sideband amplitudes in Equation (6.9) are a direct function of the natural frequency $\omega_{0}$ and will increase when the carrier frequency approaches this resonance frequency.

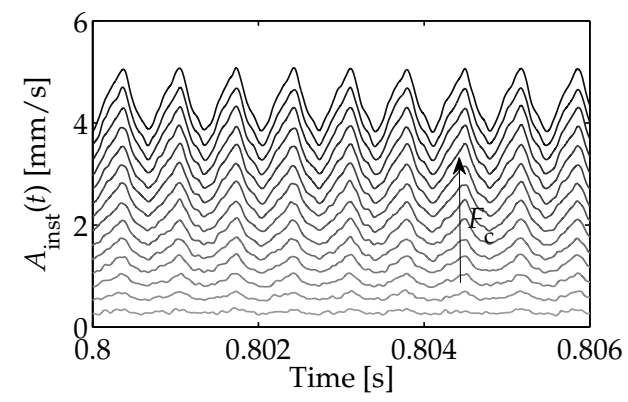

(a) Variable $F_{\mathrm{c}}=0.01-0.07 \mathrm{~V}, f_{\mathrm{c}}=50 \mathrm{kHz}$.

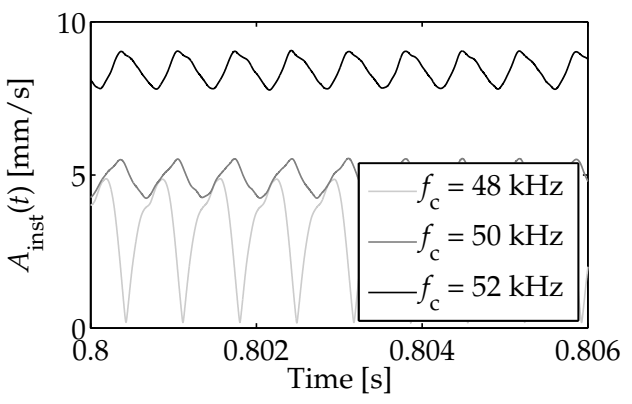

(b) Variable $f_{\mathrm{c}}=48 / 50 / 52 \mathrm{kHz}, F_{\mathrm{c}}=0.07 \mathrm{~V}$.

Figure 6.17 The effect of the carrier excitation amplitude $F_{\mathrm{c}}$ and frequency $f_{\mathrm{c}}$ on the instantaneous amplitude $A_{\text {inst }}(t)$. The responses are measured at location $(x, y)=(25,120) \mathrm{mm}$ of the damaged structure for a pump excitation frequency equal to $f_{\mathrm{p}}=1455 \mathrm{~Hz}$. 
(a)

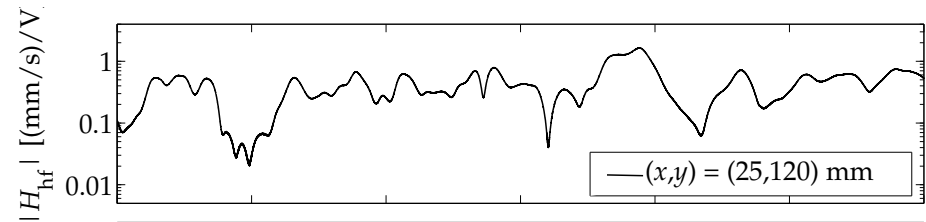

(b)

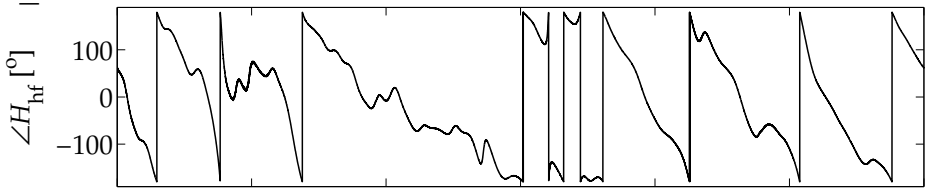

(c)

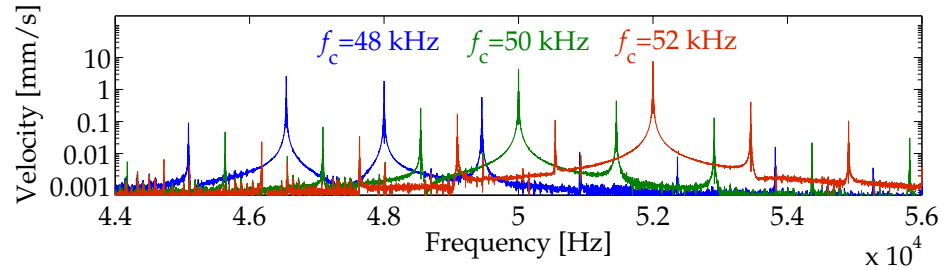

Figure 6.18 The (a) magnitude and (b) phase of the frequency response functions within the $44-56 \mathrm{kHz}$ range measured at location $(x, y)=(15,120) \mathrm{mm}$ on node line ' $Y 2$ ' of the damaged structure. The high modal density causes the sidebands of the (c) Fourier spectrum of the modulated velocity response at the same location to coincide with different modes, and hence introduces amplitude and phase deviations between the left sideband, the carrier and right sideband components. The Fourier spectra associated with three carrier excitation frequencies $f_{\mathrm{c}}$ and a pump excitation frequency $f_{\mathrm{p}}$ equal to $1455 \mathrm{~Hz}$ are presented.

In the experimental situation, the high modal density causes the frequencies of the carrier and its sideband components to coincide with different modes, as illustrated in Figure 6.18. This can lead to an unequal distribution of sideband amplitudes around the carrier as was shown in Figure 6.9(b), but can also cause phase deviations between the different harmonic components. Consequently, the spectral effects introduced by the underlying dynamic behavior affect the amplitude and phase of the amplitude modulation for each selected carrier frequency, as shown in Figure 6.17(b), but also for each measurement point, as was shown in Figure 6.15. The variations in the phase of the amplitude modulation distributions shown in the previous section are inherently expected to be a result of the underlying spectral response of the damaged structure, which are intensified by the high modal density and the spatial variability of the complex wave field.

\subsection{Conclusions \& future prospects}

The objective of this research was to analyze whether the vibro-acoustic modulation method can be utilized to detect, localize and characterize impact damage in a composite skin-stiffener structure. The work further aimed to obtain a better understanding of the modulation phenomena. Vibro-acoustic modulation 
experiments were performed by simultaneously applying a low-frequency pump signal and a higher frequency carrier excitation signal. The instantaneous amplitude and frequency of the carrier velocity responses were extracted to analyze the nonlinear intermodulations between the responses of these two excitation signals in the time domain at multiple spatial locations.

Increased amplitude modulations at the damaged region revealed the presence, location and length of the skin-stiffener damage. The damage hardly modulated the frequency of the carrier response. This difference in behavior was attributed to the nonlinear skin-stiffener interaction introduced by the periodic opening and closing of the damage according to earlier research by authors on the same structure. The dominant frequency of the amplitude modulation patterns matched the pump excitation frequency, whereas the phase of the modulation behavior varied between the different measurement points.

A parametric study shows that the amplitude and phase of the amplitude modulation are dependent on the selection of the carrier excitation frequency, and hence the high frequency wave field that is introduced. The high modal density causes the frequency of each harmonic component of the modulated response (i.e. carrier and sidebands) to coincide with a different dynamic system behavior. The modulations in the carrier response signal will consequently vary in amplitude and phase. The phase variations in the amplitude modulation distributions are therefore expected to be the combined result of the high modal density and its spatial variability.

The present study demonstrates the potential of the vibro-acoustic modulation based damage identification approach in the time domain. A traditional analysis purely based on sideband amplitudes in the frequency domain does not allow for a separation between amplitude and frequency modulation effects. Moreover, the sharp sideband peaks combined with a frequency resolution make it difficult to obtain an accurate estimation of the amplitude. This inherently complicates the understanding of the measured modulation phenomena.

Additional research is recommended on the selection of the ultrasonic carrier frequency and its effect on the modulation phenomena. Methods to normalize the modulated response signals could help to account for the spatial variations in the ultrasonic wave field. Moreover, swept excitation signals as well as propagating carrier signals (e.g. tone burst excitation signal) could enhance the damage identification capabilities and the practical applicability of the vibroacoustic modulation method for real-time monitoring.

\section{Acknowledgments}

This material is based on work supported by National Aeronautics and Space Administration, Langley Research Center under Research Cooperative Agreement 
No. NNL09AA00A awarded to the National Institute of Aerospace.

The authors kindly acknowledge the support of Fokker Aerostructures B.V., Hoogeveen, The Netherlands, for manufacturing the composite structure used in this research. This work is funded by the European research project Clean Sky, Eco-Design ITD (grant agreement number CSJU-GAM-ED-2008-001).

\section{References}

[1] C. Boller, F.-K. Chang, and Y. Fujino. Encyclopedia of structural health monitoring. John Wiley \& Sons, Ltd, Chichester, UK, 2009.

[2] K. Diamanti and C. Soutis. Structural health monitoring techniques for aircraft composite structures. Progress in Aerospace Sciences, 46(8):342-352, 2010.

[3] Y. Zou, L. Tong, and G.P. Steven. Vibration-based model-dependent damage (delamination) identification and health monitoring for composite structures - A review. Journal of Sound and Vibration, 230(2):357-378, 2000.

[4] C.-P. Fritzen and P. Kraemer. Self-diagnosis of smart structures based on dynamical properties. Mechanical Systems and Signal Processing, 23(6):1830-1845, 2009.

[5] K. Worden, C.R. Farrar, J. Haywood, and M. Todd. A review of nonlinear dynamics applications to structural health monitoring. Structural Control and Health Monitoring, 15:540-567, 2008.

[6] N. Krohn, R. Stoessel, and G. Busse. Acoustic non-linearity for defect selective imaging. Ultrasonics, 40(1-8):633-7, 2002.

[7] K.-Y. Jhang. Nonlinear ultrasonic techniques for nondestructive assessment of micro damage in material: a review. Precision Engineering and Manufacturing, 10(1):123-135, 2009.

[8] T.H. Ooijevaar, R. Loendersloot, L.L. Warnet, A. de Boer, and R. Akkerman. Vibration based structural health monitoring of a composite T-beam. Composite Structures, 92(9):2007-2015, 2010.

[9] P.B. Nagy. Fatigue damage assessment by nonlinear ultrasonic materials characterization. Ultrasonics, 36(1-5):375-381, 1998.

[10] K.E.-A. Van Den Abeele, P.A. Johnson, and A. Sutin. Nonlinear elastic wave spectroscopy (NEWS) techniques to discern material damage, part I: nonlinear wave modulation spectroscopy (NWMS). Research in Nondestructive Evaluation, 12:17-30, 2000.

[11] K.E.-A. Van Den Abeele, J. Carmeliet, J.A. Ten Cate, and P.A. Johnson. Nonlinear elastic wave spectroscopy (NEWS) techniques to discern material damage, part II: single-mode nonlinear resonance acoustic spectroscopy. Research in Nondestructive Evaluation, 12:31-42, 2000.

[12] N.C. Yoder and D.E. Adams. Vibro-acoustic modulation utilizing a swept probing signal for robust crack detection. Structural Health Monitoring, 9(3):257-267, 2010.

[13] S. Vanlanduit, E. Parloo, and P. Guillaume. Combined damage detection techniques. Journal of Sound and Vibration, 266(4):815-831, 2003.

[14] A. Klepka, W.J. Staszewski, R.B. Jenal, M. Szwedo, T. Uhl, and J. Iwaniec. Nonlinear acoustics for fatigue crack detection - Experimental investigations of vibro-acoustic wave modulations. Structural Health Monitoring, 11(2):197-211, 2011. 
[15] V. Zaitsev and P. Sas. Nonlinear response of a weakly damaged metal sample: a dissipative modulation mechanism of vibro-acoustic interaction. Journal of Vibration and Control, 6(6):803-822, 2000.

[16] F. Aymerich and W.J. Staszewski. Impact damage detection in composite laminates using nonlinear acoustics. Composites Part A: Applied Science and Manufacturing, 41(9):1084-1092, 2010.

[17] D. Donskoy, A. Sutin, and A. Ekimov. Nonlinear acoustic interaction on contact interfaces and its use for nondestructive testing. NDT $\mathcal{E}$ E International, 34:231-238, 2001.

[18] D. Dutta, H. Sohn, K.A. Harries, and P. Rizzo. A nonlinear acoustic technique for crack detection in metallic structures. Structural Health Monitoring, 8(3):251-262, 2009.

[19] Z. Parsons and W.J. Staszewski. Nonlinear acoustics with low-profile piezoceramic excitation for crack detection in metallic structures. Smart Materials and Structures, 15(4):1110-1118, 2006.

[20] F. Amerini and M. Meo. Structural health monitoring of bolted joints using linear and nonlinear acoustic/ultrasound methods. Structural Health Monitoring, 10(6):659-672, 2011.

[21] A. Zagrai, D. Donskoy, A. Chudnovsky, and E. Golovin. Micro- and macroscale damage detection using the nonlinear acoustic vibro-modulation technique. Research in Nondestructive Evaluation, 19(2):104-128, 2008.

[22] N.A. Chrysochoidis, A.K. Barouni, and D.A. Saravanos. Delamination detection in composites using wave modulation spectroscopy with a novel active nonlinear acousto-ultrasonic piezoelectric sensor. Journal of Intelligent Material Systems and Structures, 22(18):2193-2206, 2011.

[23] M. Meo and G. Zumpano. Nonlinear elastic wave spectroscopy identification of impact damage on a sandwich plate. Composite Structures, 71(3-4):469-474, 2005.

[24] U. Polimeno and M. Meo. Detecting barely visible impact damage detection on aircraft composites structures. Composite Structures, 91(4):398-402, 2009.

[25] H.F. Hu, W.J. Staszewski, N.Q. Hu, R.B. Jenal, and G.J. Qin. Crack detection using nonlinear acoustics and piezoceramic transducers - Instantaneous amplitude and frequency analysis. Smart Materials and Structures, 19(6):065017, 2010.

[26] T.H. Ooijevaar, M.D. Rogge, R. Loendersloot, L.L. Warnet, R. Akkerman, and T. Tinga. Nonlinear dynamic behavior of an impact damaged composite skin-stiffener structure. In preparation for: Composite Science and Technology, 2014.

[27] L. Meirovitch. Fundamentals of vibrations. McGraw-Hill Higher Education, New York, NY, 2001.

[28] I. Solodov, D. Döring, and G. Busse. New opportunities for NDT using non-linear interaction of elastic waves with defects. Journal of Mechanical Engineering, 57(03):169-182, 2011.

[29] A. Offringa, J.W. van Ingen, and A. Buitenhuis. Butt-joined, thermoplastic stiffened-skin concept development. SAMPE Journal, 48(2):7-15, 2012.

[30] M.H. Richardson. Is it a mode shape, or an operating deflection shape? Sound and Vibration, pages 1-11, 1997.

[31] Q. Li and L. Atlas. Over-modulated AM-FM decomposition. In Franklin T. Luk, editor, Proceedings of SPIE Volume 5559, Advanced Signal Processing Algorithms, Architectures, and Implementations XIV, pages 172-183, 2004. 


\section{CHAPTER 7}

\section{Discussion}

The work presented in previous chapters concerned the identification of damage in advanced composite skin-stiffener structures by employing changes in the dynamic behavior. This chapter broadens the discussions from the previous chapters with respect to the objective of this research. Firstly, the design of a vibration based structural health monitoring approach to identify damage in composite skin-stiffener structures is discussed. The results obtained in previous chapters are combined to extract additional recommendations for the development of a structural health monitoring approach. Secondly, a more general discussion on the practical application of the vibration based methodologies is presented.

\subsection{Design of an SHM strategy}

A damage identification strategy aims to provide a high probability of detection with a low number of false positive indications. Moreover, a high performance level, according to the classification presented in Section 1.3.2, is usually desired. A large number of damage identification methods are proposed in the literature, as was shown in Chapter 2. These damage identification methods are often developed from the standpoint of the algorithm rather than from the damage and the structure. The performance of a damage identification approach is, however, highly dependent on the actual structure and the damage scenario that is considered. The work presented in this thesis was therefore focused on a more holistic approach by incorporating the relations between the characteristics of the structure, the damage scenarios and the damage identification method. Figure 7.1 schematically illustrates the associated framework, which was introduced in Section 1.4. The characteristics of these three components together define the performance of the structural health monitoring strategy. 


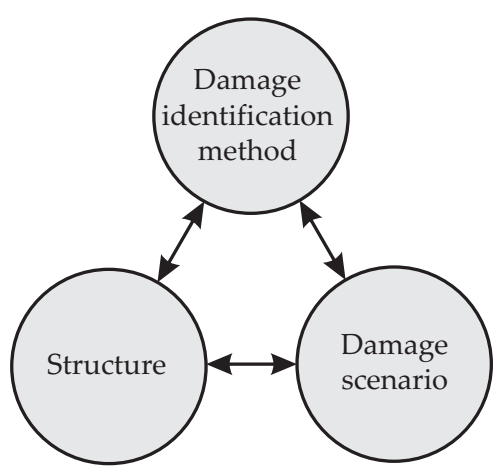

Figure 7.1 The multidisciplinary framework for the design of a structural health monitoring strategy.

\subsubsection{Scenario based design procedure}

The implementation of the framework shown in Figure 7.1 is application specific. Finding the most suitable damage identification method for a specific structure and damage scenario is therefore far from straightforward and is often a matter of compromise. This gives rise to the development of a tool that can be used to design a damage identification strategy depending on the type of structure and the potential threats. The results presented in this thesis provide an input for such a tool dedicated to composite skin-stiffener structures. A scenario based procedure for the design of a damage identification strategy is presented in Figure 7.2 and comprises four steps.

\section{Step 1: Potential damage scenarios}

The first step is illustrated in Figure 7.2(b) and concerns the analysis of the potential failure mechanisms and the potential damage scenarios of the structure that is under investigation. Knowledge about the loading conditions, historic failure data or structural models can provide useful information for this step. This step inherently encourages the development of a structural health monitoring approach to become an integral part of the design process of a component. This structural design process can provide information about, for example, the safety-critical damage locations or estimates of the damage tolerance of the component. Both aspects set the requirements for the performance of the structural health monitoring approach.

The need for repair of aircraft components is commonly assessed based on visual inspection according to the BVID criterion [1]. Visual inspection allows for the identification of macroscopic damage rather than microscopic defects. Three impact induced damage scenarios were considered for the skin-stiffener structures that 


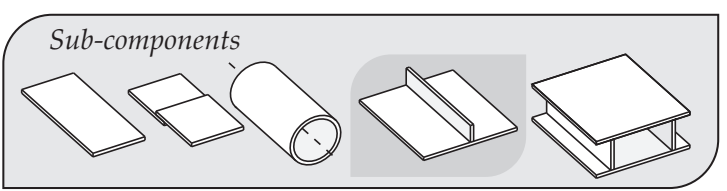

(a)

Structure

Step 1

Analysis potential failure mechanisms and potential damage scenarios.
Step 2

Understanding effect of damage on dynamic behavior.

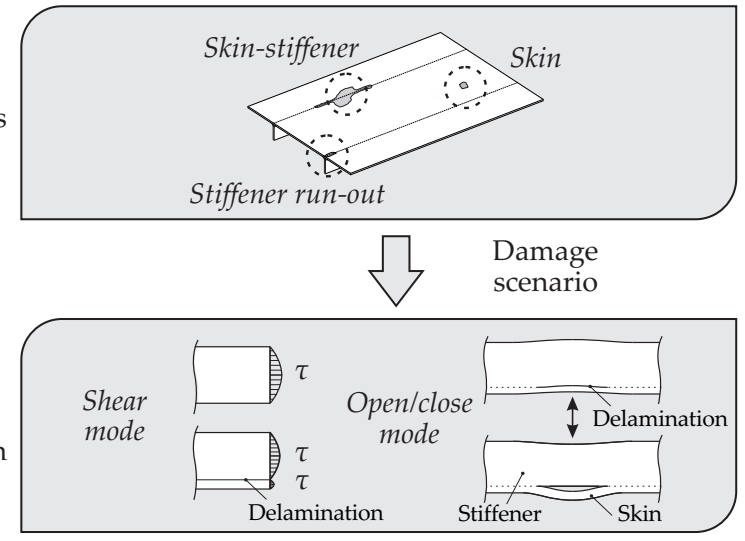

(b)

(c)

\section{Structural} dynamics

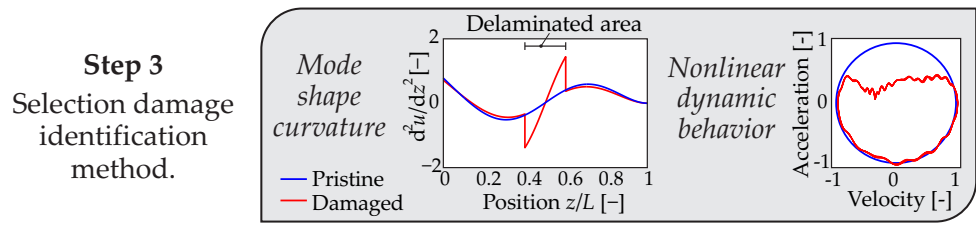

(d)

Damage identification method

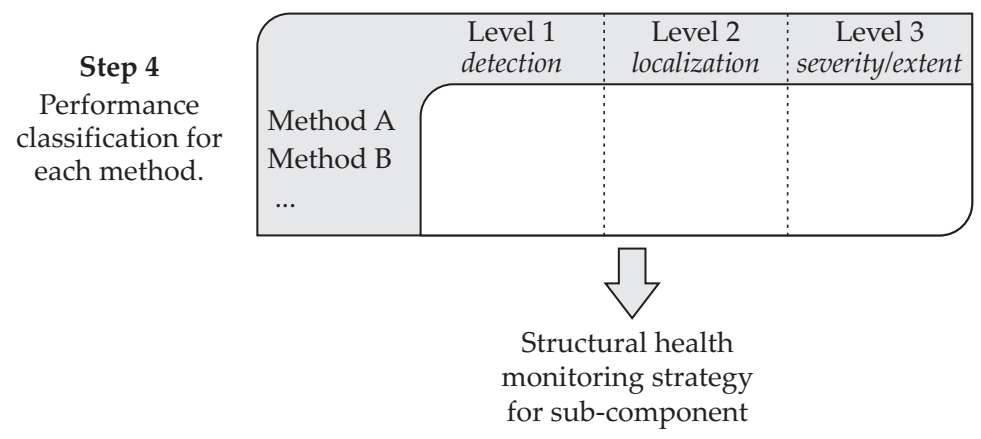

(e)

Figure 7.2 The scenario based design procedure of a vibration based structural health monitoring strategy. 
were used in the present work, i.e. damage at the skin, damage at the skinstiffener connection and damage at the stiffener run-out. These damage scenarios are all classified as barely visible impact damage based on the dent depth. This means that they may remain undetected according to the BVID criterion. The skin related damage is indeed considered to be less safety-critical and is therefore of lower importance. However, the damage at the skin-stiffener connection and the skin-stiffener run-out can significantly affect the performance of the structure. An evaluation of the potential consequences involved in the damage scenarios is therefore required in the first step of the design procedure in order to assess the importance of detection.

\section{Step 2: Effect of the damage on the dynamic behavior}

The second step is focused on the relation between the damage scenario and the dynamic behavior of the component, as depicted in Figure 7.2(c). This step aims to obtain a physical understanding of the effect of the potential damage scenarios on the dynamic behavior of the component. Both analytical and experimental analyses were used in the present research to investigate the effect of the damage on the dynamic behavior. The damage at the skin-stiffener connection is usually dominated by a delamination type of damage. The analysis of a delaminated beam model in Chapter 2 revealed that the effect of a delamination is more pronounced in the mode shape curvatures than in the mode shapes themselves. The mode shape curvatures can show clear discontinuities at the boundaries of a delamination in the case of flexural vibrations. The two driving phenomena behind these discontinuities in the mode shape curvatures are, firstly, the change in shear stress distribution (see Figure 7.3(a) ), and secondly, the potential opening and closing of the delaminated segments (see Figure 7.3(b)). The work presented in Chapter 5 experimentally confirmed the opening and closing behavior and revealed severe nonlinear dynamic effects associated with this motion. The study in Chapter 5 also showed that the opening and closing motion of delaminated segments is magnified by the motion of the skin at both sides of the stiffener, as schematically illustrated in Figure 7.3(c)). These geometrical effects can, on the one hand, result in larger discontinuities in the mode shape curvature during the opening phase. On the other hand, they can increase the nonlinear effects that are introduced during the contact phase.

\section{Step 3: Selection damage identification method}

The third step of the scenario based design procedure concentrates on the selection of a suitable damage identification method, i.e. damage features and classifiers. This step is schematically illustrated in Figure 7.2(d) and is an important step in the process to obtain an effective damage identification strategy. The damage identification method should match the observed changes in the dynamic behavior. 


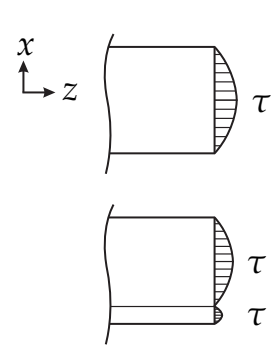

(a) Shear mode

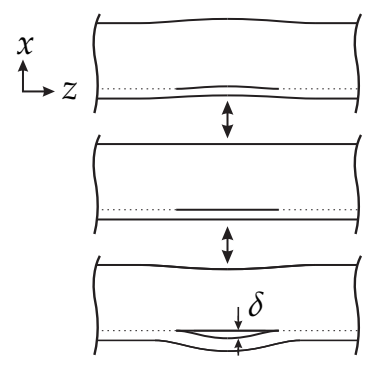

(b) Open/close mode

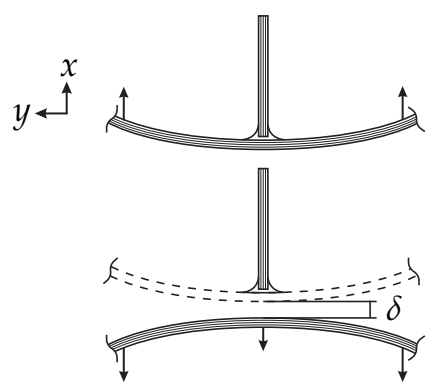

(c) Geometrical effects

Figure 7.3 Dynamic phenomena related to delamination type of damage in skin-stiffener structures.

Moreover, the consequences involved with information reduction in the signal processing need to be considered. Chapter 2 provides an elaborate description of this process.

The physical understanding of how the potential damage scenarios affect the dynamic behavior has led to the selection of two potentially strong indicators for skin-stiffener damage, i.e. mode shape curvatures and the nonlinear dynamic effects. Considering two different appearances of the damage in the dynamic behavior of the structure is a potentially strong solution. Section 7.1.2 provides a more elaborate discussion on the potential benefits involved in combining several damage features (e.g. natural frequencies, modal damping, mode shape curvatures, nonlinear behavior) in the damage identification process. The analysis of the nonlinear dynamic effects set the requirements to the damage features that can be used for damage characterization purposes. A linear dynamic system description, as obtained by modal analysis based methods, is feasible for low excitation amplitudes, while time domain or frequency domain methods are required for an adequate description of the nonlinear dynamic effects introduced by the damage in the case of the higher excitation amplitudes.

\section{Step 4: Performance classification}

The last step is a classification of the performance of each method in terms of its detection, localization and characterization capabilities, as depicted by Figure 7.2(e). This classification can be used to define a structural health monitoring strategy according to the desired performance level.

The work presented in Chapters 3 and 4 experimentally demonstrated the feasibility of using mode shape curvatures combined with the modal strain energy damage index algorithm to detect, localize and roughly estimate the size of barely visible impact damage in advanced composite skin-stiffener structures. The results showed that the effective application of the method is limited to health monitoring of 
skin-stiffener connections. Failure primarily located in the skin tends to require a different damage identification approach. The nonlinear dynamic effects caused by the skin-stiffener damage were analyzed as an alternative to the mode shape curvature based method. Studies dedicated to nonlinear damage identification methods, such as shown in Chapter 6, are therefore desired. The vibro-acoustic modulation phenomenon can be utilized as an indicator for damage, but also provides a first step towards a method that allows for the characterization of the nonlinear dynamic behavior caused by the skin-stiffener damage. For some applications linear damage identification techniques give adequate results and nonlinear methods do not, while in other cases the opposite is true. To circumvent this problem a combination of multiple damage identification approaches is usually required.

\subsubsection{Combination of approaches}

A combination of several damage features and classifiers (see Figure 7.4(a)) or combining several damage identification techniques (see Figure $7.4(\mathrm{~b})$ ) can potentially be strong structural health monitoring solutions to take advantage of the strengths of each approach. Firstly, because they can increase the probability of detection of a damage scenario by the diagnostic system. Secondly, they can provide a system with a higher level of performance, according to the categorization proposed in Section 1.3.2. Finally, a combination of approaches can also allow for the identification of a wider range of damage scenarios. This is particularly relevant for composite materials, considering the large diversity of potential damage scenarios. For example, Chapter 4 revealed that the mode shape curvature based approach worked well for impact damage at the skin-stiffener connection, but was not able to identify the damage at the skin in between the two stiffeners. The detection of defects primarily located in the skin tends to require a different technique. A combination of a wave propagation based technique (i.e. acoustoultrasonics) to monitor the skin and the curvature based approach to monitor the skin-stiffener connection utilizing a complementary sensor set can potentially be a strong solution (see Figure 7.5).

Another way to benefit from the strengths of different methods is to apply them in a more sequential manner, where one provides input for another. Typical examples are the combination of a passive and active technique or a global and local technique. In the former case, a passive technique, such as acoustic emission, can serve as a trigger for the execution of an active approach, such as acoustoultrasonics. In the latter case, a global approach could detect the presence and location of a structural anomaly, whereas the local method subsequently is used for a more detailed localization and an estimation of the severity of the defect. Both approaches would help to minimize the system requirements (e.g. computation time, data transfer, power consumption) of the structural health monitoring system. 


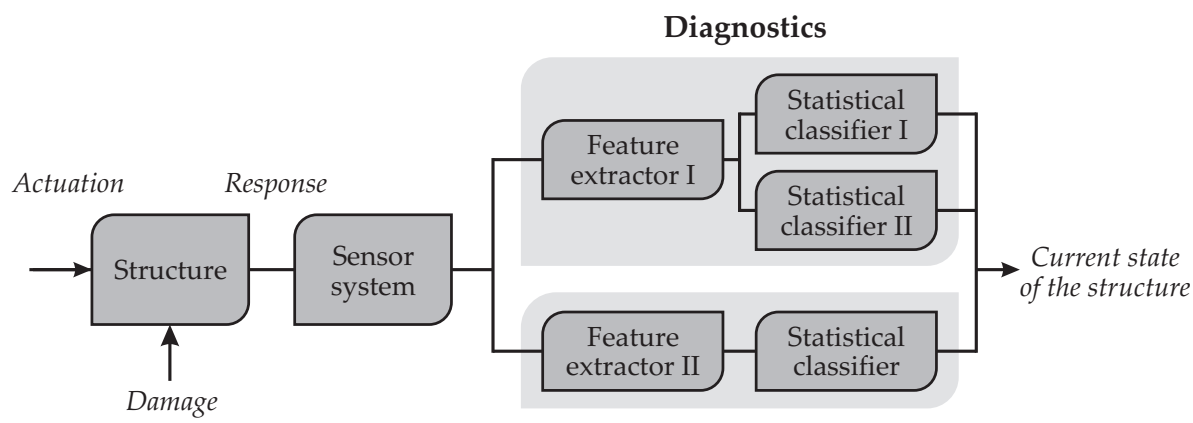

(a) Combining different damage sensitive features (e.g. natural frequency, mode shape curvatures, nonlinear dynamic behavior) and classifiers.

Technique I

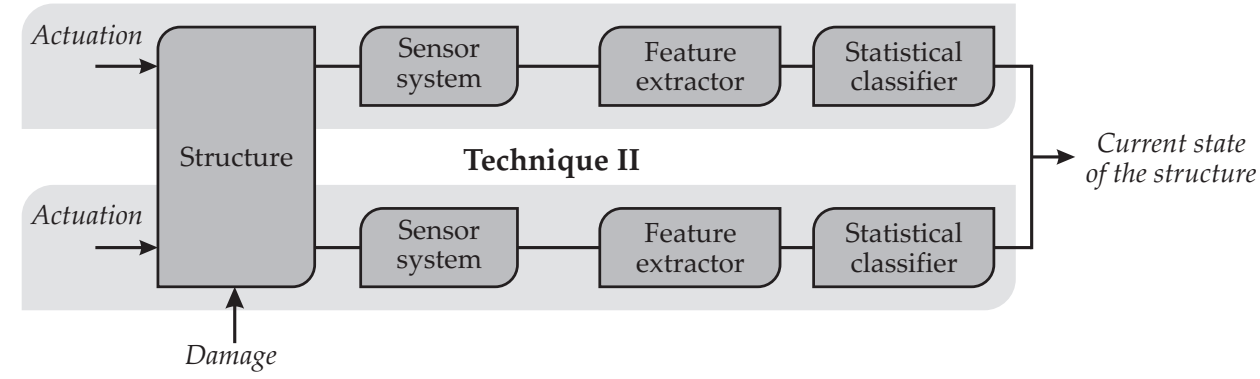

(b) Combining different damage identification techniques (e.g. structural vibration based methods, acoustic emission, acousto-ultrasonics).

Figure 7.4 A schematic illustration of the diagnostic part of a structural health monitoring process showing two ways to combine multiple damage identification methods: (a) for a combination of different damage sensitive features and classifiers.

\subsection{Application of vibration based SHM}

The results presented in this thesis contribute towards obtaining a higher level of maturity in the structural health monitoring technologies. However, several issues need to be considered before field application of the structural health monitoring technologies is possible. Five major technology gaps were described in Section 1.3.4:

- Complex composite structures

- Selection damage feature and classifier

- High performance level

- Integrated sensors and network

- Operational and environmental variability 


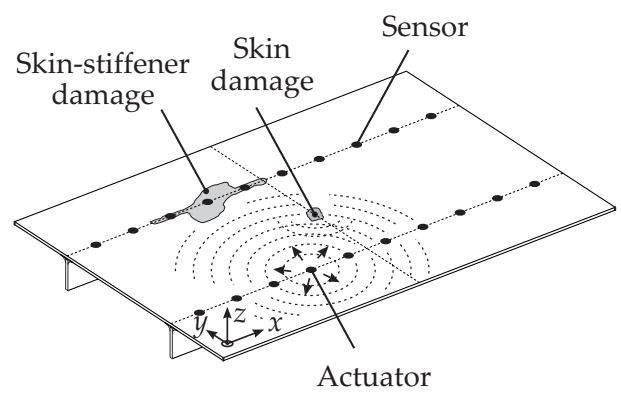

Figure 7.5 The skin-stiffener structure that was analyzed in Chapter 4. A combination of damage identification techniques (e.g. structural vibration based methods, acousto-ultrasonics) is required to identify the skin and the skin-stiffener interface damage.

The first three challenges were addressed in the present research. The extension to more complex composite structures was the main focus of the work presented in Chapters 3 and 4 . Chapters 5 and 6 provide a first step towards a higher performance level by characterizing the nonlinear dynamic behavior introduced by the damage. The selection of appropriate damage features and classifiers was one of the main topics addressed in this thesis. The scenario based design procedure, as described in the previous section, showed itself to be an important outcome and provides a useful guideline for the development of a suitable structural health monitoring solution for safety-critical structures. The remaining two challenges, i.e. the integrated sensing and the environmental effects, are discussed in the remainder of this chapter.

\subsubsection{Integrated sensing}

The studies presented in this thesis rely on laser vibrometer measurements. These measurement systems are less suitable for on-line health monitoring in, for example, aircraft. An on-line health monitoring system requires permanently attached or embedded sensor systems.

Sensor systems based on, for example, optical fiber Bragg gratings (FBGs) [2], can have a positive influence on the development of an applicable health monitoring system. Fiber Bragg gratings possess some advantages over conventional sensing systems. The ability of multiplexing, i.e. having multiple strain sensors on one fiber, offers great potential. A network of gratings provides opportunities to map the strain field in a structure during vibration. Other advantages can be found in the capabilities to withstand harsh environments. The practical application of fiber Bragg gratings also encounters some restrictions, like the rather low signal- 
to-noise ratio as was found by Grouve et al. [3]. Despite this limitation, successful applications are found for low-frequency vibration sensing $[4,5]$ as well as highfrequency sensing of propagating waves [6]. New developments of optical fiber distributed sensing systems provide the ability for strain sensing along the optical fiber with an extremely high spatial resolution [7]. A low sample rate, however, limits the current application of this technology to quasi-static measurements.

Alternatively, piezoelectric elements are widely used for actuation and sensing purposes in health monitoring [8-10]. These piezoelectric elements have the ability to convert mechanical energy into electrical energy, and vice versa [11]. They utilize the direct piezoelectric effect to sense structural deformations and the inverse effect to actuate the structure. One of the main advantages of piezoelectric elements is that they can be used over a broad frequency range. This makes them applicable for nearly all dynamics based damage identification techniques, i.e. structural vibration based methods [12], electromechanical-impedance based techniques [13], acousticemission [14] as well as acousto-ultrasonics [8]. Other advantages include the cost effectiveness, as well as the ability to harvest energy [15].

Distributed strain sensing based on fiber optic or piezoelectric sensors is potentially advantageous for the mode shape curvature based approach. The direct relation between bending strain and curvature can be beneficial to overcome the numerical errors involved in the calculation of the second derivative of the displacement mode shapes. This issue is addressed by several studies. Lestari et al. [16] and Qiao et al. [17] used MSE-DI algorithm in combination with strain mode shapes measured by PVDF film sensors in order to identify damage in a composite specimen. Adewuyi et al. [18] performed similar experiments utilizing long-gage optical fiber Bragg grating sensors.

An important challenge regarding the practical application of the vibration based damage identification techniques is the number and the position of the sensors. The vibration based methods utilize standing wave patterns. Consequently, high spatial resolution monitoring requires a relatively dense sensor network to avoid spatial aliasing (except for the natural frequencies and modal damping based methods). This contradicts the practical application of a vibration based technology, since the number of sensors is often limited. The optimal sensor placement has received considerable attention in the literature [19-21]. Savananoz [22] particularly addresses the optimum spatial sampling interval for damage detection based on curvatures.

There are some other ways to deal with the sensor issue. The first and most straightforward approach is to utilize new sensing technologies. Optical fiber distributed sensing systems as well as other distributed sensor technologies are under development [7]. The number of successful practical applications of these emerging technologies is, however, limited. Secondly, and the more feasible, is to monitor only the most safety-critical locations of the structure, which is referred to as 'hotspot' monitoring. These critical locations can follow from historic failure 


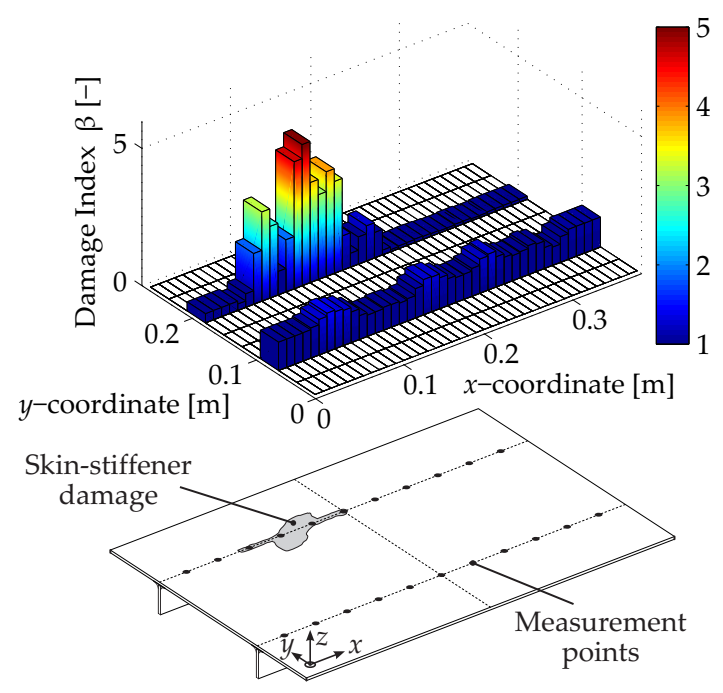

Figure 7.6 Damage index $\beta_{i j}$ distributions (1D formulation in $x$-direction) of the MSE-DI algorithm obtained by utilizing only the measurement points underneath the stiffeners of the skin-stiffener structure that was analyzed in Chapter 4.

data or from the structural design process. Chapter 4 showed that the effective application of the mode shape curvature based approach is limited to health monitoring of the skin-stiffener connections. Moreover, defects located at the skin are considered to be less safety-critical. Consequently, the number of measurement points can be reduced to only the measurement points underneath the skin-stiffener connection, as shown in Figure 7.6. This solution can provide an effective way of monitoring the most critical areas of a skin-stiffener structure. However, this requires good insight into the failure behavior and mechanisms of the structure and the most safety-critical damage locations. Finally, utilizing techniques based on propagating waves can also allow for a reduced number of sensors to cover large areas. This is also where the vibro-acoustic modulation based method, studied in Chapter 6, can potentially be advantageous. Although the current work is focused on the feasibility and the understanding of the approach in the case of the steady state behavior, it opens the ability to use pulsed carrier excitation signals traveling between an actuator and sensor, as was shown by Kazakov et al. [23]. In that case, the approach essentially corresponds to the more conventional acousto-ultrasonics techniques (pitch-catch or pulse-echo) $[8,24,25]$ supplemented with an additional lower-frequency pump source in order to produce the modulations. 


\subsubsection{Operational and environmental effects}

A general problem concerning structural vibration based health monitoring consists of the sensitivity of dynamic parameters to changes in the operational (ambient loading) and environmental (temperature or humidity) conditions [26]. Damage induced changes in the dynamic properties can be masked or magnified by the effects that are introduced due to variations in, for example, the temperature. Methods should therefore have the ability to separate the dynamic effects caused by the operational and environmental conditions from the changes caused by damage. A wide variety of methods, comprising model based methods and statistical techniques, is presented in the literature to compensate for these variations [27-29]. Constant environmental conditions were assumed during the experimental investigation presented. The effect of change has not been investigated. However, the numerical models presented by Loendersloot et al. [30,31] can be extended to account for the effects of changing environmental conditions.

\section{References}

[1] J. Baaran. Visual inspection of composite structures. Technical report, Institute of Composite Structures and Adaptive Systems, DLR Braunschweig, 2009.

[2] D. Balageas, C.-P. Fritzen, and A. Güemes. Structural health monitoring. ISTE Ltd, 2006.

[3] W.J.B. Grouve, L.L. Warnet, A. de Boer, R. Akkerman, and J. Vlekken. Delamination detection with fibre Bragg gratings based on dynamic behaviour. Composites Science and Technology, 68(12):2418-2424, 2008.

[4] J. Frieden, J. Cugnoni, J. Botsis, T. Gmür, and D. Ćorić. High-speed internal strain measurements in composite structures under dynamic load using embedded FBG sensors. Composite Structures, 92(8):1905-1912, 2010.

[5] M.D. Todd, G.A. Johnson, and S.T. Vohra. Deployment of a fiber Bragg grating-based measurement system in a structural health monitoring application. Smart Materials and Structures, 10:534-539, 2001.

[6] N. Takeda, Y. Okabe, J. Kuwahara, S. Kojima, and T. Ogisu. Development of smart composite structures with small-diameter fiber Bragg grating sensors for damage detection: quantitative evaluation of delamination length in CFRP laminates using Lamb wave sensing. Composites Science and Technology, 65(15-16):2575-2587, 2005.

[7] A. Guemes, A. Fernández-López, and B. Soller. Optical fiber distributed sensing Physical principles and applications. Structural Health Monitoring, 9(3):233-245, 2010.

[8] A. Raghavan and C.E.S. Cesnik. Review of guided-wave structural health monitoring. The Shock and Vibration Digest, 39(2):91-114, 2007.

[9] V. Giurgiutiu, A. Zagrai, and J. Jing Bao. Piezoelectric wafer embedded active sensors for aging aircraft structural health monitoring. Structural Health Monitoring, 1(1):41-61, 2002.

[10] V. Giurgiutiu. Structural health monitoring: with piezoelectric wafer active sensors. Elsevier, 2008. 
[11] J. Sirohi and I. Chopra. Fundamental understanding of piezoelectric strain sensors. Journal of Intelligent Material Systems and Structures, 11(4):246-257, 2000.

[12] W. Lestari and P. Qiao. Damage detection of fiber-reinforced polymer honeycomb sandwich beams. Composite Structures, 67(3):365-373, 2005.

[13] V. Giurgiutiu and A. Zagrai. Damage detection in thin plates and aerospace structures with the electro-mechanical impedance method. Structural Health Monitoring, 4(2):99-118, 2005.

[14] T. Kundu, S. Das, and K.V. Jata. Detection of the point of impact on a stiffened plate by the acoustic emission technique. Smart Materials and Structures, 18(3):035006, 2009.

[15] H.A. Sodano, D.J. Inman, and G. Park. A review of power harvesting from vibration using piezoelectric materials. The Shock and Vibration Digest, 36(3):197-205, 2004.

[16] W. Lestari, P. Qiao, and S. Hanagud. Curvature mode shape-based damage assessment of carbon/epoxy composite beams. Journal of Intelligent Material Systems and Structures, 18(3):189-208, 2007.

[17] P. Qiao, W. Lestari, M.G. Shah, and J. Wang. Dynamics-based damage detection of composite laminated beams using contact and noncontact measurement systems. Journal of Composite Materials, 41(10):1217-1252, 2007.

[18] A.P. Adewuyi, Z. Wu, and N.H.M. Kammrujaman Serker. Assessment of vibration-based damage identification methods using displacement and distributed strain measurements. Structural Health Monitoring, 8(6):443-461, 2009.

[19] E.B. Flynn and M.D. Todd. Optimal placement of piezoelectric actuators and sensors for detecting damage in plate structures. Journal of Intelligent Material Systems and Structures, 21(3):265-274, 2009.

[20] K. Worden and A.P. Burrows. Optimal sensor placement for fault detection. Engineering Structures, 23(8):885-901, 2001.

[21] H.Y. Guo, L. Zhang, L.L. Zhang, and J.X. Zhou. Optimal placement of sensors for structural health monitoring using improved genetic algorithms. Smart Materials and Structures, 13(3):528-534, 2004.

[22] E.S. Sazonov and P. Klinkhachorn. Optimal spatial sampling interval for damage detection by curvature or strain energy mode shapes. Journal of Sound and Vibration, 285(4-5):783-801, 2005.

[23] V.V. Kazakov, A. Sutin, and P.A. Johnson. Sensitive imaging of an elastic nonlinear wave-scattering source in a solid. Applied Physics Letters, 81(4):646, 2002.

[24] Z. Su, L. Ye, and Y. Lu. Guided lamb waves for identification of damage in composite structures: a review. Journal of Sound and Vibration, 295(3-5):753-780, 2006.

[25] J.-B. Ihn and F.-K. Chang. Pitch-catch active sensing methods in structural health monitoring for aircraft structures. Structural Health Monitoring, 7(1):5-19, 2008.

[26] H. Sohn. Effects of environmental and operational variability on structural health monitoring. Philosophical Transactions of the Royal Society A: Mathematical, Physical and Engineering Sciences, 365(1851):539-60, 2007.

[27] A. Deraemaeker, E. Reynders, G. Deroeck, and J. Kullaa. Vibration-based structural health monitoring using output-only measurements under changing environment. Mechanical Systems and Signal Processing, 22(1):34-56, 2008.

[28] A. Yan, G. Kerschen, P. Deboe, and J. Golinval. Structural damage diagnosis under varying environmental conditions - Part I: a linear analysis. Mechanical Systems and Signal Processing, 19(4):847-864, 2005.

[29] E. Figueiredo, G. Park, C.R. Farrar, K. Worden, and J. Figueiras. Machine learning 
algorithms for damage detection under operational and environmental variability. Structural Health Monitoring, 10(6):559-572, 2010.

[30] R. Loendersloot, T.H. Ooijevaar, L.L. Warnet, A. de Boer, and R. Akkerman. Vibration based structural health monitoring and the modal strain energy damage index algorithm applied to a composite T-beam. In C.M.A. Vasques and J.D. Rodrigues, editors, Vibration and Structural Acoustics Analysis: Current Research and Related Technologies, Chapter 6, pages 121-150. Springer, 2011.

[31] R. Loendersloot, T.H. Ooijevaar, A. de Boer, and R. Akkerman. Development of a damage quantification model for composite skin-stiffener structures. In C. Boller and H. Janocha, editors, New Trends in Smart Technologies, pages 99-108. Fraunhofer Verlag, 2013. 



\section{CHAPter 8}

\section{Conclusions and recommendations}

This thesis focuses on the development of design recommendations and guidelines for the detection, localization and characterization of damage in advanced composite skin-stiffener structures, employing changes in the dynamic behavior. These guidelines contribute to the development of a design tool for research engineers, to assist the implementation of structural health monitoring technology in safety-critical composite structures.

\subsection{Conclusions}

The major conclusions of this work with respect to the objective of this thesis are presented below.

\section{General}

- Vibration based structural health monitoring is a design related problem. The development of a damage identification strategy is made-to-measure work and requires a thorough physical understanding of the potential failure mechanisms, the critical damage locations and their effect on the dynamic behavior.

- A combination of several damage identification techniques, damage features and classifiers is required to identify the wide variety of damage scenarios that can occur in a composite skin-stiffener structure.

\section{Linear dynamic behavior}

- Mode shape curvatures combined with the modal strain energy damage index (MSE-DI) algorithm can be used to detect and localize barely visible impact 
damage (BVID) at the skin-stiffener connection of advanced composite skinstiffener structures. The method can also roughly estimate the geometry of the damaged area.

- Damage at the skin-stiffener connection can be detected and localized with more confidence by employing the MSE-DI algorithm than by considering individual mode shapes or mode shape curvatures, since damage related information of separate mode shape curvatures is combined into a single indicator.

- The effective application of the MSE-DI method is highly dependent on the damage location with respect to the structural design. The most effective results were obtained by considering the 1D MSE-DI formulation underneath and in the direction of the stiffeners for damage at the stiffener mid-section and perpendicular to the stiffeners for damage at the stiffener run-out. Impact damage at the skin in between the stiffeners could not be identified. This limits the effective application of the method to health monitoring of skinstiffener connections.

- Damage at the skin-stiffener interface mainly affects the bending modes. The modes with torsional deformations around the stiffener are hardly affected since the damage is located close to the local rotational axis.

- The number of measurement points and their location with respect to the damage affect the sensitivity to identify damage at the skin-stiffener interface. A reduced number of measurement points or a larger distance between the measurement points and the damage (perpendicular to stiffener) lowers the ratio between the damage index values of the damaged area and the pristine area.

\section{Nonlinear dynamic behavior}

- Damage at the skin-stiffener interface can introduce clear nonlinear effects in the dynamic behavior of the structure. These nonlinear effects are attributed to the interaction between the skin and stiffener that occurs during opening and closing motion of the damage.

- The opening and closing motion of the damage at the skin-stiffener connection is mainly driven by the motion of the skin at both sides of the stiffener.

- A linear system description obtained by modal analysis based damage identification methods is feasible for low excitation amplitudes, but suffers under its linear system assumption for the higher amplitudes. Nonlinear methods are, in that case, required to obtain a more adequate description of the nonlinear dynamic behavior introduced by the skin-stiffener damage.

- Vibro-acoustic modulation based damage identification allows for the detection 
and localization of impact induced damage at the skin-stiffener connection, based on locally increased amplitude modulation effects. The damage hardly modulated the frequency of the carrier response. Analysis of the characteristics of the nonlinear modulations opens the ability to characterize the nonlinear dynamic behavior introduced by the damage at the skin-stiffener interface.

- A time domain analysis of the vibro-acoustic modulation phenomena at multiple spatial locations revealed that the nonlinear modulation phenomena in the dynamic response is highly dependent on the underlying dynamic behavior of the structure around the carrier excitation frequency.

\subsection{Recommendations}

With respect to the work presented in this thesis further research is recommended on the following aspects:

- More research is required on the influence of changes in the operational and environmental conditions.

- A next step towards the practical application of the presented methodologies for vibration based structural health monitoring is to use integrated sensor systems. For this purpose, a numerical model can be utilized to optimally place the sensors.

- A combination of multiple damage identification techniques, damage features and classifiers can be beneficial to the overall damage identification performance. The current approach showed that it was primarily successful in the identification of damage at the skin-stiffer connection. The extension to alternative techniques operating on a complementary sensor set can enable the development of a complete structural health monitoring solution.

- Other types of composite structures, such as sandwich panels and torsion boxes, should be investigated for the development of a design tool. A design tool can assist the implementation of structural health monitoring technology in safety-critical composite structures.

From a broader perspective, the technology gaps, as described in Section 1.3.4, provide a good impression of what direction further research is required to take. 



\section{Dynamics based nondestructive testing techniques}

The present appendix provides a description of the most commonly used nondestructive testing technologies that utilize dynamic principles to identify damage. The structural vibrations (SV) and electro-mechanical impedance (EMI) techniques primarily rely on standing wave patterns, while the acoustic emission (AE), acousto-ultrasonics (AU) and ultrasonic testing (UT) approaches utilize traveling wave characteristics.

\section{Structural vibrations and acoustics (SV)}

This group of techniques utilizes the changes in the structural dynamic behavior (e.g. natural frequencies, damping, modes of vibration) of structures caused by damage, as schematically illustrated in Figure A.1(a). Damage in a structure can significantly alter the structural integrity and therefore the physical properties like stiffness, mass and/or damping. The dynamic behavior of a structure is a function of these physical properties and will therefore directly be affected by damage. The low-frequency vibration based technology provides data that is relatively easy to interpret. More complex structures can be analyzed with these methods and a relatively large area can be explored at once. The frequency range, and hence the resolution, is however limited [1]. As a consequence, only relatively severe damage such as delaminations can be identified.

\section{Electro-mechanical impedance (EMI)}

The electro-mechanical impedance technique is essentially a structural vibration technique, but is usually considered to be a separate technique. This approach uses changes in the mechanical impedance of the structure to identify damage [2]. The mechanical domain and electrical domain are connected by means of a piezoelectric 
(a) Structural vibration and acoustics

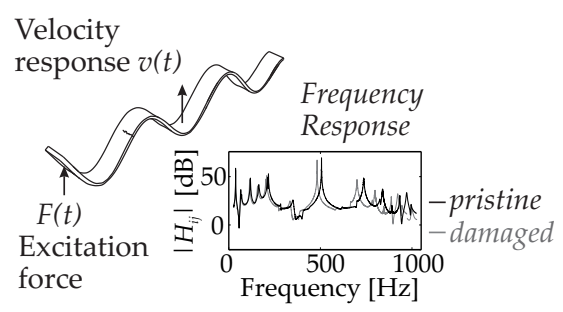

(b) Electro-mechanical impedance
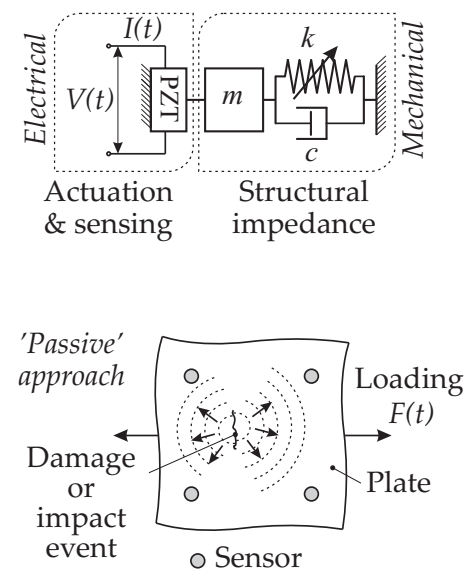

(c) Acoustic emission

(d) Acousto-ultrasonics

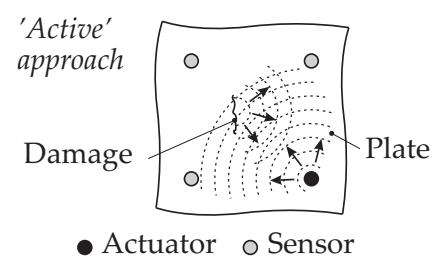

(e) Ultrasonic testing

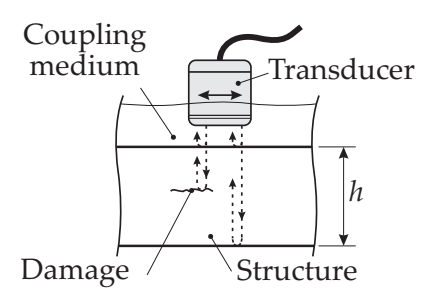

Figure A.1 Schematic representation of the most commonly used nondestructive testing techniques that utilize structural dynamic principles to identify damage. 
element that is attached to the structure (see Figure A.1(b)). An excitation signal is applied to the piezoelectric element. The applied voltage $V(t)$ and the current $I(t)$ that flows through the element are measured simultaneously to determine the mechanical impedance $Z_{\text {st }}$. This approach is low cost and easy to apply, but is generally lacking in the physical interpretation of the measured deviations [3].

\section{Acoustic emission (AE)}

The acoustic emission technique utilizes the transient stress waves generated by a local source [4]. The variety of sources comprises, for example, an actively growing defect in a structure under operational loading, a mechanical impact, but also a fluid or gas leakage. The emitted stress waves propagate through the surface and are recorded by a network of sensors, shown in Figure A.1(c). Once processed, the signals allow the source to be located by using a triangulation algorithm [5]. Unlike most other techniques, Acoustic Emission does not require an active excitation. Other advantages include the fast inspection using a limited number of integrated sensors as well as the ability to discern between developing and stagnant defects. A drawback of Acoustic Emission is that a continuous operation of the system needs to be guaranteed. One of the key difficulties is to discern the signals from other environmental noise while the structure is in operation.

\section{Guided wave acousto-ultrasonics (AU)}

The acoustic-ultrasonic technique essentially combines the acoustic emission technique with an active ultrasonic excitation [6]. Two configurations are possible. In the pitch-catch configuration (see Figure A.1(d)) a narrow bandwidth pulse signal is sent across the specimen, while a sensor at another location receives the signal. The propagating signal will be affected by intermediate disruptions caused by damage. For the pulse-echo configuration, a sensor collocated with the actuator is used to listen to the echoes of the pulse coming from damage induced discontinuities. Despite a high sensitivity and a small number of required sensors, the complex interpretation of the wave forms significantly impedes the application of this technique to complex structures $[6,7]$.

\section{Ultrasonic testing (UT)}

Ultrasonic testing is, in many respects, similar to the acousto-ultrasonics technique. The method also utilizes high frequency ultrasonic waves to characterize a specimen. The main difference lies in the traveling direction of the ultrasonic waves, which is usually normal to the surface of the specimen (see Figure A.1(e)). Consequently, ultrasonic testing is primarily a local scanning method and therefore 
requires access to the structure. Common formats to present the responses are known as A-scan, B-scan and C-scan presentations [4]. Advantages of this approach include the high sensitivity to structural discontinuities and the high accuracy to determine the position, size and shape of subsurface defects. The required accessibility of the surface and the time-consuming scanning process makes this technique less suitable for health monitoring applications.

\section{References}

[1] C.-P. Fritzen and P. Kraemer. Self-diagnosis of smart structures based on dynamical properties. Mechanical Systems and Signal Processing, 23(6):1830-1845, 2009.

[2] C. Liang, F.P. Sun, and C.A. Rogers. An impedance method for dynamic analysis of active material systems. Journal of Intelligent Material Systems and Structures, 116(4):323-334, 1994.

[3] W. Yan and W.Q. Chen. Structural health monitoring using high-frequency electromechanical impedance signatures. Advances in Civil Engineering, 2010:1-11, 2010.

[4] C. Hellier. Handbook of nondestructive evaluation. McGraw-Hill, 2003.

[5] T. Kundu, S. Das, and K.V. Jata. Detection of the point of impact on a stiffened plate by the acoustic emission technique. Smart Materials and Structures, 18(3):035006, 2009.

[6] A. Raghavan and C.E.S. Cesnik. Review of guided-wave structural health monitoring. The Shock and Vibration Digest, 39(2):91-114, 2007.

[7] R.P. Dalton, P. Cawley, and M.J.S. Lowe. The potential of guided waves for monitoring large areas of metallic aircraft fuselage structure. Journal of Nondestructive Evaluation, 20(1), 2001. 


\section{ApPendix B}

\section{Damage features and classifiers}

A structural health monitoring technique typically consists of the selection of an appropriate damage sensitive feature and the subsequent condensation and classification of the information with the help of a damage metric. The following table provides a general overview of the damage features and the (statistical) classifiers that are commonly utilized for vibration based damage identification purposes. Although the overview is far from complete, it gives an impression of the versatility of the damage identification methods that are proposed in the literature.

\section{Time domain}

Time response / waveform

Statistical time series analysis

$\begin{array}{llll}C O R & \text { Correlation functions (non-parametric) } & \text { Fassois } & 2007 \text { [1] } \\ A R & \text { Autoregressive models (parametric) } & \text { Fassois } & 2007 \text { [1] }\end{array}$

Time-frequency analysis

$\begin{array}{llll}\text { WA } & \text { Wavelet transform based methods } & \text { Rucka } & 2006 \text { [2] } \\ \text { HT/HHT } & \text { Hilbert(-Huang) transform based methods } & \mathrm{Hu} & 2010 \text { [3] }\end{array}$

\section{Frequency domain}

Fourier / power spectra

Frequency response function / operational deflection shapes

\begin{tabular}{|c|c|c|c|}
\hline FRFCH & Frequency response function change & Kessler & $2002[4]$ \\
\hline FRFDI & Frequency response function damage index & Banerjee & 2009 [5] \\
\hline FRFSHP & Frequency response function shape method & Liu & 2009 [6] \\
\hline$D R Q$ & $\begin{array}{l}\text { Detection and relative damage quantification } \\
\text { indicator }\end{array}$ & Sampaio & 2009 [7] \\
\hline$F R A$ & Frequency response assurance criterion & Nefske & 1996 \\
\hline$F D A$ & Frequency domain assurance criterion & Pascual & 1997 \\
\hline
\end{tabular}




$\begin{array}{llll}\text { RVAC } & \text { Response vector assurance criterion } & \text { Sampaio } & 2009 \text { [7] } \\ \text { ODSC } & \text { Operational deflection shape change } & \text { Pascual } & 1999 \text { [10] } \\ \text { GSC } & \text { Global shape correlation } & \text { Zang } & 2007 \text { [11] } \\ \text { GAC } & \text { Global amplitude correlation } & \text { Zang } & 2007 \text { [11] }\end{array}$

Frequency response function curvature

FRFC Frequency response curvature

Sampaio 1999 [12]

SFRFDI Strain frequency response damage index

Maia 2003 [13]

Mechanical impedance $(Z)$

RMSD Root mean square deviation

$M A P D \quad$ Mean absolute percentage deviation

Park

$2003[14]$

$C C D \quad$ Correlation coefficient deviation

Giurgiutiu 2005 [15]

Giurgiutiu 2005 [15]

Transmissibility function $(T)$

TDI Transmissibility damage index

Johnson

$2002[16]$

Antiresonances

AFN Antiresonance shift

Dilena

$2004[17]$

Higher harmonics (nonlinear effect)

$\mathrm{HH} \quad$ Higher harmonic imaging

Krohn

$2002[18]$

Modulations (nonlinear effect)

VAM Vibro-acoustic modulations

Donskoy

1998 [19]

\section{Modal domain}

Natural frequencies

$\begin{array}{llll}C A C & \text { Cawley-Adams criteria } & \text { Cawley } & 1979 \text { [20] } \\ \text { DLAC } & \text { Damage location assurance criteria } & \text { Messina } & 1998 \text { [21] } \\ \text { MDLAC } & \text { Multiple damage location assurance criteria } & \text { Messina } & 1998 \text { [21] }\end{array}$

Mode shape

MS Mode shape amplitude change

Ho

2003 [13]

MSS Squared mode shape slope change

Ho

2003 [13]

RMS Relative mode shape change

Khoo

2004 [22]

MAC Modal assurance criteria

IMAC Inverse modal assurance criteria

COMAC Co-ordinate modal assurance criteria

Parloo

2003 [23]

Allemang 2003 [24]

FD Fractal dimension method

GFD Generalized fractal dimension

Parloo 2003 [23]

Hadjileontiadis 2005 [25]

MSRC Mode shape rotation change

Wang

2007 [26]

Abdo

2002 [27]

Mode shape curvature

MSC Mode shape curvature method

MSC Mode shape curvature squared method

Pandey

1991 [28]

$C D F$

Curvature damage factor method

Maia

2003 [13]

Wahab

1999 [29] 


\begin{tabular}{|c|c|c|c|}
\hline GSM & Gapped smoothing method & Ratcliffe & 1997 \\
\hline MSEDI & Modal strain energy damage index method & Stubbs & 1995 \\
\hline MSECR & Modal strain energy change ratio & Shi & 1998 \\
\hline \multicolumn{4}{|c|}{ Modal damping } \\
\hline$S D C$ & Specific damping capacity & Guild & 1981 \\
\hline \multicolumn{4}{|c|}{ Dynamic stiffness (combination of modal parameters) } \\
\hline ESC & Effective stiffness change & Khoo & 2004 \\
\hline \multicolumn{4}{|c|}{ Dynamic flexibility (combination of modal parameters) } \\
\hline$M F L$ & Modal flexibility method & Pandey & 1994 \\
\hline MFLC & Modal flexibility curvature method & $\mathrm{Lu}$ & 2002 \\
\hline ULS & Uniform load surface method & Zhang & 1998 \\
\hline ULSC & Uniform load surface curvature & $\mathrm{Wu}$ & 2004 \\
\hline$M C I$ & Modal compliance index method & Choi & 2005 \\
\hline
\end{tabular}

Updating methods

Other methods

MF $\quad$ Modal filters $\quad$ Deraemaeker 2006 [39]

MD Modal peak density

Chrysochoidis 2004 [40]

\section{References}

[1] S.D. Fassois and J.S. Sakellariou. Time-series methods for fault detection and identification in vibrating structures. Philosophical Transactions of the Royal Society A: Mathematical, Physical and Engineering Sciences, 365(1851):411-48, 2007.

[2] M. Rucka and K. Wilde. Application of continuous wavelet transform in vibration based damage detection method for beams and plates. Journal of Sound and Vibration, 297(3-5):536-550, 2006.

[3] H.F. Hu, W.J. Staszewski, N.Q. Hu, R.B. Jenal, and G.J. Qin. Crack detection using nonlinear acoustics and piezoceramic transducers - Instantaneous amplitude and frequency analysis. Smart Materials and Structures, 19(6):065017, 2010.

[4] S.S. Kessler, S.M. Spearing, M.J. Atalla, C.E.S. Cesnik, and C. Soutis. Damage detection in composite materials using frequency response methods. Composites Part B: Engineering, 33(1):87-95, 2002.

[5] S. Banerjee, F. Ricci, E. Monaco, and A. Mal. A wave propagation and vibration-based approach for damage identification in structural components. Journal of Sound and Vibration, 322(1-2):167-183, 2009.

[6] X. Liu, N.A.J. Lieven, and P.J. Escamilla-Ambrosio. Frequency response function shape-based methods for structural damage localisation. Mechanical Systems and Signal Processing, 23(4):1243-1259, 2009.

[7] R. Sampaio and N. Maia. A Simple Correlation Factor as an Effective Tool for Detecting Damage. In Modeling, Simulation and Control of Nonlinear Engineering Dynamical Systems, pages 233-242. Springer, 2009. 
[8] DJ Nefske and SH Sung. Correlation of a coarse-mesh finite element model using structural system identification and a frequency response assurance criterion. In Proceedings of 13th International Modal Analysis Conference, pages 597-602, 1996.

[9] R. Pascual, J.C. Golinval, and M. Razeto. A frequency domain correlation technique for model correlation and updating. In Proceedings of the 15th International Modal Analysis Conference (IMAC XV), pages 587-592, 1997.

[10] R. Pascual, J.C. Golinval, and M. Razeto. On-line damage assessment using operating deflection shapes. In Proceedings of the 17th International Modal Analysis Conference (IMAC XVII), pages 238-243, 1999.

[11] C. Zang, M.I. Friswell, and M. Imregun. Structural health monitoring and damage assessment using frequency response correlation criteria. Engineering Mechanics, 133(September):981-993, 2007.

[12] R.P.C. Sampaio, N.M.M. Maia, and J.M.M. Silva. Damage detection using the frequency-response-function curvature method. Journal of Sound and Vibration, 226(5):1029-1042, 1999.

[13] N. Maia, J.M.M. Silva, E.A.M. Almas, and R.P.C. Sampaio. Damage detection in structures: from mode shape to frequency response function methods. Mechanical Systems and Signal Processing, 17(3):489-498, 2003.

[14] G. Park, H. Sohn, C.R. Farrar, and D.J. Inman. Overview of piezoelectric impedance-based health monitoring and path forward. The Shock and Vibration Digest, 35(6):451-463, 2003.

[15] V. Giurgiutiu and A. Zagrai. Damage detection in thin plates and aerospace structures with the electro-mechanical impedance method. Structural Health Monitoring, 4(2):99-118, 2005.

[16] T.J. Johnson and D.E. Adams. Transmissibility as a differential indicator of structural damage. Journal of Vibration and Acoustics, 124(4):634, 2002.

[17] M. Dilena and A. Morassi. The use of antiresonances for crack detection in beams. Journal of Sound and Vibration, 276(1-2):195-214, 2004.

[18] N. Krohn, R. Stoessel, and G. Busse. Acoustic non-linearity for defect selective imaging. Ultrasonics, 40(1-8):633-7, 2002.

[19] D.M. Donskoy and A.M. Sutin. Vibro-acoustic modulation nondestructive evaluation technique. Journal of Intelligent Material Systems and Structures, 9(9):765-771, 1998.

[20] P. Cawley and R.D. Adams. The location of defects in structures from measurements of natural frequencies. Journal of Strain Analysis, 14(2):49-57, 1979.

[21] A. Messina, E.J. Williams, and T. Contursi. Structural damage detection by a sensitivity and statistical-based method. Journal of Sound and Vibration, 216(5):791-808, 1998.

[22] L.M. Khoo, P.R. Mantena, and P. Jadhav. Structural damage assessment using vibration modal analysis. Structural Health Monitoring, 3(2):177-194, 2004.

[23] E. Parloo, P. Guillaume, and M. van Overmeire. Damage assessment using mode shape sensitivities. Mechanical Systems and Signal Processing, 17(3):499-518, 2003.

[24] R.J. Allemang. The modal assurance criterion - Twenty years of use and abuse. Journal of Sound and Vibration, 1:14-21, 2003.

[25] L.J. Hadjileontiadis, E. Douka, and A. Trochidis. Fractal dimension analysis for crack identification in beam structures. Mechanical Systems and Signal Processing, 19(3):659-674, 2005.

[26] J. Wang and P. Qiao. Improved damage detection for beam-type structures using a uniform load surface. Structural Health Monitoring, 6(2):99-110, 2007. 
[27] M.A.-B. Abdo and M. Hori. A numerical study of structural damage detection using changes in the rotation of mode shapes. Journal of Sound and vibration, 251(2):227-239, 2002.

[28] A.K. Pandey, M. Biswas, and M.M. Samman. Damage detection from changes in curvature mode shapes. Journal of Sound and Vibration, 145(2):321-332, 1991.

[29] M.M. Abdel Wahab and G. De Roeck. Damage detection in bridges using modal curvatures: application to a real damage scenario. Journal of Sound and Vibration, 226(2):217-235, 1999.

[30] C. Ratcliffe. Damage detection using a modified laplacian operator on mode shape data. Journal of Sound and Vibration, 204(3):505-517, 1997.

[31] N. Stubbs and C.R. Farrar. Field verification of a nondestructive damage localization and severity estimation algorithm. In Proceedings of the 13th International Modal Analysis Conference (IMAC XIII), pages 210-218, 1995.

[32] Z. Shi and S.S. Law. Structural damage localization from modal strain energy change. Journal of Sound and Vibration, 218(5):825-844, 1998.

[33] F.J. Guild and R.D. Adams. The detection of cracks in damaged composite materials. Journal of Physics D: Applied Physics, 12(1):5-42, 1981.

[34] A.K. Pandey and M. Biswas. Damage detection in structures using changes in flexibility. Journal of Sound and Vibration, 169(1):3-17, 1994.

[35] Q. Lu, G. Ren, and Y. Zhao. Multiple damage location with flexibility curvature and relative frequency change for beam structures. Journal of Sound and Vibration, 253(5):1101-1114, 2002.

[36] Z. Zhang and A.E. Aktan. Application of modal flexibility and its derivatives in structural identification. Research in Nondestructive Evaluation, 10(1):43-61, 1998.

[37] D. Wu and S.S. Law. Damage localization in plate structures from uniform load surface curvature. Journal of Sound and Vibration, 276(1-2):227-244, 2004.

[38] S. Choi, S. Park, S. Yoon, and N. Stubbs. Nondestructive damage identification in plate structures using changes in modal compliance. NDT E E International, 38(7):529-540, 2005.

[39] A. Deraemaeker and A. Preumont. Vibration based damage detection using large array sensors and spatial filters. Mechanical Systems and Signal Processing, 20(7):1615-1630, 2006.

[40] N.A. Chrysochoidis and D.A. Saravanos. Assessing the effects of delamination on the damped dynamic response of composite beams with piezoelectric actuators and sensors. Smart Materials and Structures, 13:733-742, 2004. 



\section{Appendix $\mathbf{C}$}

\section{Hilbert transform}

The Hilbert transform $\mathcal{H}[x(t)]$ of a real-valued function $x(t)$ extending from $-\infty<$ $t<\infty$ is a real-valued function $\hat{x}(t)$ defined by [1]:

$$
\mathcal{H}[x(t)]=\hat{x}(t)=\frac{1}{\pi} \int_{-\infty}^{+\infty} \frac{x(\tau)}{t-\tau} \mathrm{d} \tau
$$

The associated analytical signal $z(t)$ yields:

$$
z(t)=x(t)+i \hat{x}(t)=A_{\text {inst }}(t) e^{i \phi(t)},
$$

where $A_{\text {inst }}(t)$ is the envelope signal and $\phi(t)$ the instantaneous phase signal. The envelope $A_{\text {inst }}(t)$ is extracted from the original time signal $x(t)$ and the Hilbert transformed signal $\hat{x}(t)$ by:

$$
A_{\text {inst }}(t)=\sqrt{x^{2}(t)+\hat{x}^{2}(t)} \text {. }
$$

The associated instantaneous phase $\phi(t)$ is described by:

$$
\phi(t)=\arctan \frac{\hat{x}(t)}{x(t)}=\Im \ln z(t),
$$

and can be used to calculate the instantaneous frequency $\omega_{\text {inst }}(t)$ [2]:

$$
\omega_{\text {inst }}(t)=\frac{\mathrm{d} \phi(t)}{\mathrm{d} t}=\Im \frac{\mathrm{d}}{\mathrm{d} t} \ln z(t)=\Im \frac{1}{z} \frac{\mathrm{d} z(t)}{\mathrm{d} t} .
$$

\section{References}

[1] M. Feldman. Hilbert transform in vibration analysis. Mechanical Systems and Signal Processing, 25(3):735-802, 2011.

[2] J.F. Claerbout. Earth soundings analysis: processing versus inversion. Blackwell Scientific Publications, 2004. 



\section{Dankwoord}

De bel heeft geklonken, de laatste ronde is ingegaan en de finishlijn komt in het zicht. Ik kijk naar de laatste rit van de Olympische $5 \mathrm{~km}$ langebaanschaatsen in Sochi, Rusland. Net zoals voor de meeste sporters die in actie komen tijdens de Olympische spelen is dit proefschrift ook het resultaat van een 4-jarige inspanning. In de afgelopen jaren heb ik geleerd dat er meerdere overeenkomsten zijn tussen het nastreven van sportieve ambities en het verrichten van een promotieonderzoek. De weg naar het beoogde resultaat vereist de nodige toewijding en wordt nimmer beschreven door een lineair verband tussen de inspanning en de gewenste progressie. Bovendien kan het gewenste eindresultaat niet bereikt worden zonder de hulp van een goede begeleiding. De totstandkoming van dit proefschrift was daarom niet mogelijk zonder de ondersteuning en het vertrouwen van veel mensen.

Allereerst wil ik graag Remko Akkerman en André de Boer bedanken. Jullie hebben het mogelijk gemaakt dat ik na mijn afstuderen verder heb kunnen werken aan dit onderzoek. De vrijheid die ik heb gekregen om invulling te geven aan het onderzoek heb ik als uitermate plezierig ervaren. Jullie scherpe en pragmatische benadering hebben mij geholpen om dit proefschrift te voltooien. Bovendien wil ik jullie bedanken voor het ondersteunen van de leerzame onderzoekssamenwerking met de Nondestructive Evaluation Sciences Branch van NASA Langley Research Center. Tevens wil ik Tiedo Tinga bedanken. Jouw heldere kijk op het onderwerp en feedback na het lezen van het proefschrift hebben mij geholpen dit boekje te verbeteren. Veel succes met het uitbouwen van de nieuwe leerstoel gericht op 'Dynamics Based Maintenance'.

Mijn dagelijkse begeleiders Richard Loendersloot en Laurent Warnet verdienen eigenlijk meer dan een bijzondere vermelding. Ik heb genoten om ook samen met jullie dit onderzoek vanaf de grond af aan op te bouwen. Ik wil jullie bedanken voor de vele waardevolle discussies over het onderzoek, maar ook over alles wat daar buiten viel. Onze samenwerking heeft geholpen om een eigen visie te ontwikkelen over waar het onderzoek op dit vakgebied naar toe zou moeten. Jullie enthousiasme was een inspiratie om het onderzoek door te zetten.

My research is financially supported by the European research program Clean Sky and was part of the Eco-Design Integrated Technology Demonstrator. Within the framework of this project I would like to thank all industrial partners. In particular, I appreciate the support of Nava Sela from the Israel Aerospace Industries (IAI) by leading the work package. 
In the third year of my PhD research, I received the opportunity to conduct research at the Nondestructive Evaluation and Sciences Branch (NESB) of NASA Langley Research Center in Hampton, Virginia, USA. My special thanks goes to Matthew Rogge, who provided me this opportunity. It was an honor to collaborate with you for a period of approximately 7 months. I have learned a lot from your views and approaches regarding the challenges I have faced during that time. Also the support of Cara Leckey, James Ratcliffe and Wade Jackson was really helpful to make this experience a success.

Het onderzoek dat gepresenteerd is in dit proefschrift was onmogelijk zonder de onvoorwaardelijke steun van Fokker Aerostructures. Alle constructies die in dit proefschrift zijn gebruikt, zijn door jullie geproduceerd en beschikbaar gesteld. In het bijzonder wil ik Jaap Willem van Ingen bedanken. Zelfs als ik proefstukken wilde gebruiken voor experimenten in de Verenigde Staten kon dat op korte termijn gerealiseerd worden. Geweldig!

Frank Grooteman van het Nationaal Lucht- en Ruimtevaartlaboratorium (NLR) wil ik bedanken voor de samenwerking op het gebied van met name optische sensor technologie. De uitdagingen waar we voor gestaan heb ik als uitermate leerzaam ervaren. Helaas is maar een klein deel van het werk in dit boekje terecht gekomen. Hierbij wil ik tevens de onlangs gestarte promovendus Jason Hwang (tevens NLR) veel succes wensen met het vervolgonderzoek.

Ik kan dit proefschrift niet afsluiten zonder alle (oud-)collega's binnen de vakgroepen Toegepaste Mechanica (TM) en Productie Technologie (PT) te bedanken. De talloze discussies hebben bijgedragen aan de realisatie van dit werk. In het bijzonder wil ik mijn kantoorgenoten Arnoud van der Stelt, Emiel Drenth en Shaojie Liu bedanken. Ik heb veel baat gehad bij de inhoudelijke discussies. Ook onze gesprekken over van alles en nog wat waren uitermate plezierig. Arnoud, wanneer gaan we een broodjeszaak openen...?

De experimenten die ik heb verricht zouden waarschijnlijk een mislukking zijn geworden zonder de technische ondersteuning van Bert Wolbert, Bert Vos, GertJan Nevenzel en Laura Vargas Llona. Wouter Grouve wil ik graag bedanken voor het beschikbaar stellen van zijn thesis template. Tevens bedank ik afstudeerder Matthijs Oomen (inmiddels promovendi) voor de prettige samenwerking. Speciale dank gaat uit naar de secretaresses Debbie Zimmerman van Woesik en Belinda Bruinink. Jullie zijn van onschatbare waarde om het reilen en zeilen binnen de vakgroepen op rolletjes te laten verlopen.

Gedurende de eerste jaren van mijn promotieonderzoek heb ik het geluk gehad dat ik mijn sportieve ambities nog redelijk heb kunnen nastreven. De balans tussen het sporten enerzijds en het promoveren anderzijds heeft me in die tijd in veel opzichten geholpen. De diverse hoogtepunten waren niet mogelijk geweest zonder de steun van mijn teamgenoten. Aanvullend daarop wil ik de (schaats)trainingsgroep bedanken voor de opbeurende woorden als ik weer eens een uurtje kwam 'harken' op mijn inline-skates of schaatsen. 
Tot slot bedank ik mijn familie en vrienden. Jullie waren nooit te beroerd om mijn 'geneuzel' aan te horen op de momenten dat het nodig was.

Ted Ooijevaar 



\section{Publications}

\section{Journal articles}

1. T.H. Ooijevaar, R. Loendersloot, L.L. Warnet, A. de Boer, R. Akkerman. Vibration based structural health monitoring of a composite T-beam. Composite Structures, 92(9):2007-2015, 2010 (Chapter 3 of this thesis).

2. T.H. Ooijevaar, L.L. Warnet, R. Loendersloot, R. Akkerman and T. Tinga. Impact damage identification in composite skin-stiffener structures based on modal curvatures. In preparation for: Structural Control and Health Monitoring, 2014 (Chapter 4 of this thesis).

3. T.H. Ooijevaar, M.D. Rogge, R. Loendersloot, L.L. Warnet, R. Akkerman, T. Tinga. Nonlinear dynamic behavior of an impact damaged composite skinstiffener structure. In preparation for: Composite Science and Technology, 2014 (Chapter 5 of this thesis).

4. T.H. Ooijevaar, M.D. Rogge, R. Loendersloot, L.L. Warnet, R. Akkerman, T. Tinga. Vibro-acoustic modulation based damage identification in a composite skin-stiffener structure. In preparation for: Structural Health Monitoring, 2014 (Chapter 6 of this thesis).

\section{Book chapters}

1. R. Loendersloot, T.H. Ooijevaar, A. de Boer, R. Akkerman. Development of a damage quantification model for composite skin-stiffener structures. In: New Trends in Smart Technologies. Fraunhofer Verlag, Stuttgart, pp. 99-108, ISBN 978-38-396-0577-6, 2013.

2. R. Loendersloot, T.H. Ooijevaar, L.L. Warnet, A. de Boer, R. Akkerman. Vibration based structural health monitoring and the modal strain energy damage index algorithm applied to a composite T-beam. In: Vibration and Structural Acoustics Analysis: Current Research and Related Technologies. Springer Netherlands, Chapter 6, pp. 121-150, ISBN 978-94-007-1702-2, 2011. 


\section{Conference proceedings}

1. T.H. Ooijevaar, R. Loendersloot, M.D. Rogge, R. Akkerman and T. Tinga. Vibro-acoustic modulation based damage identification in a composite skinstiffener structure. Submitted to: $7^{\text {th }}$ European Workshop on Structural Health Monitoring (EWSHM 2014), Nantes, France, 2014.

2. T.H. Ooijevaar, M.D. Rogge, R. Loendersloot, L.L. Warnet, R. Akkerman and A. de Boer. Nonlinear dynamic behavior of impact damage in a composite skin-stiffener structure. $9^{\text {th }}$ International Workshop on Structural Health Monitoring (IWSHM 2013), Stanford, CA, USA, 2013.

3. T.H. Ooijevaar, L.L. Warnet, R. Loendersloot, R. Akkerman, A. de Boer. Vibration based damage identification in a composite T-beam utilising low cost integrated actuators and sensors. $6^{\text {th }}$ European Workshop on Structural Health Monitoring (EWSHM 2012), Dresden, Germany, 2012.

4. R. Loendersloot, T.H. Ooijevaar, A. de Boer, R. Akkerman. Development of a damage quantification model for composite skin-stiffener structures. $5^{\text {th }}$ ECCOMAS Thematic Conference on Smart Structures and Materials (SMART'11), Saarbrucken, Germany, 2011.

5. T.H. Ooijevaar, R. Loendersloot, L.L. Warnet, R. Akkerman, A. de Boer. Structural health monitoring of an advanced composite aircraft structure using a modal approach. $8^{\text {th }}$ International Workshop on Structural Health Monitoring (IWSHM 2011), Stanford, CA, USA, 2011.

6. T.H. Ooijevaar, F.P. Grooteman, L.L. Warnet, R. Loendersloot, R. Akkerman, A. de Boer. Dynamic characterisation of a damaged composite structure with stiffeners employing fibre Bragg gratings. $5^{\text {th }}$ International Conference on Composites Testing and Model Simulation (CompTest 2011), Lausanne, Switzerland, 2011.

7. R. Loendersloot, T.H. Ooijevaar, L.L. Warnet, A. de Boer, R. Akkerman. Vibration based structural health monitoring of a composite plate with stiffeners. International Conference on Noise and Vibration Engineering, ISMA2010, Leuven, Belgium, 2010.

8. T.H. Ooijevaar, L.L. Warnet, R. Loendersloot, R. Akkerman, A. de Boer. Vibration based structural health monitoring of a composite plate structure with multiple stiffeners. $5^{\text {th }}$ European Workshop on Structural Health Monitoring (EWSHM 2010), Sorrento, Italy, 2010.

9. R. Loendersloot, T.H. Ooijevaar, L.L. Warnet, R. Akkerman, A. de Boer. Vibration based structural health monitoring in fibre reinforced composites employing the modal strain energy method. $3^{\text {rd }}$ International Conference on Integrity, Reliability and Failure (IRF2009), Porto, Portugal, 2009. 
10. T.H. Ooijevaar, R. Loendersloot, L.L. Warnet, A. de Boer, R. Akkerman. Vibration based structural health monitoring in fibre reinforced composites employing the modal strain energy method. $15^{\text {th }}$ International Conference on Composite Structures (ICCS15), Porto, Portugal, 2009. 




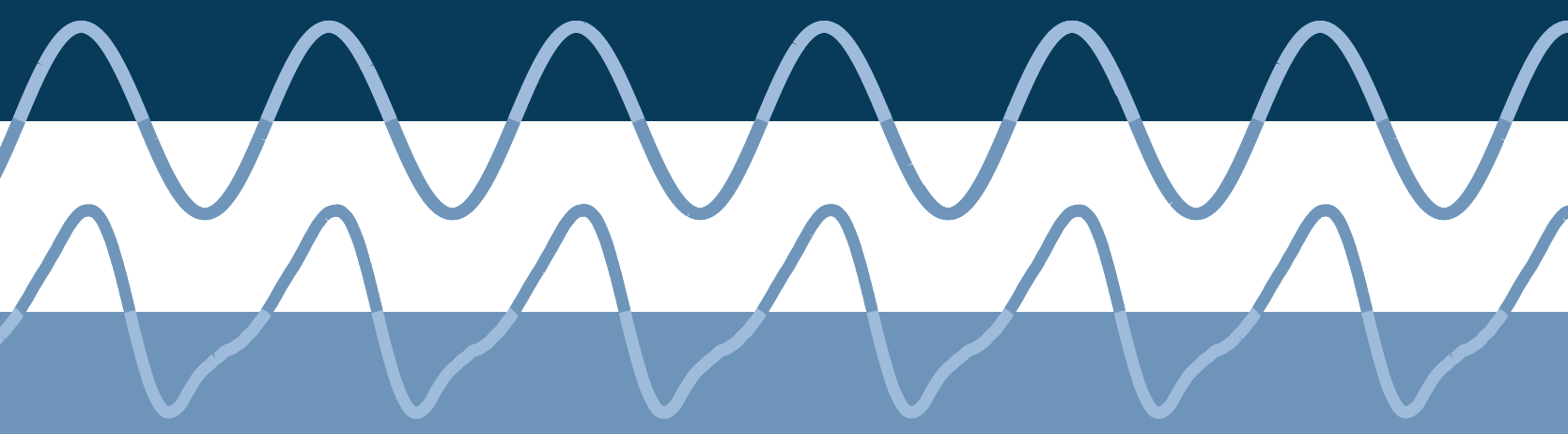

\section{UNIVERSITY OF TWENTE.}

ISBN: 978-90-365-3624-0 